\title{
A Brief History of the Future of Urban Computing and Locative Media
}

by

Anne Galloway, B.A. (Hons.), M.A.

\begin{abstract}
A thesis submitted to
the Faculty of Graduate Studies and Research

in partial fulfillment of

the requirements for the degree of

Doctor of Philosophy

Department of Sociology and Anthropology

Carleton University

Ottawa, Ontario
\end{abstract}

(C) 2008 Anne Galloway 


$\begin{array}{ll}\begin{array}{l}\text { Library and } \\ \text { Archives Canada }\end{array} & \begin{array}{l}\text { Bibliothèque et } \\ \text { Archives Canada }\end{array} \\ \begin{array}{l}\text { Published Heritage } \\ \text { Branch }\end{array} & \begin{array}{l}\text { Direction du } \\ \text { Patrimoine de l'édition }\end{array} \\ \begin{array}{l}\text { 395 Wellington Street } \\ \text { Ottawa ON K1A ON4 } \\ \text { Canada }\end{array} & \begin{array}{l}\text { 395, rue Wellington } \\ \text { Ottawa ON K1A 0N4 } \\ \text { Canada }\end{array}\end{array}$

Your file Votre référence ISBN: 978-0-494-43894-7

Our file Notre référence

ISBN: 978-0-494-43894-7

NOTICE:

The author has granted a nonexclusive license allowing Library and Archives Canada to reproduce, publish, archive, preserve, conserve, communicate to the public by telecommunication or on the Internet, loan, distribute and sell theses worldwide, for commercial or noncommercial purposes, in microform, paper, electronic and/or any other formats.

The author retains copyright ownership and moral rights in this thesis. Neither the thesis nor substantial extracts from it may be printed or otherwise reproduced without the author's permission.
AVIS:

L'auteur a accordé une licence non exclusive permettant à la Bibliothèque et Archives Canada de reproduire, publier, archiver, sauvegarder, conserver, transmettre au public par télécommunication ou par l'Internet, prêter, distribuer et vendre des thèses partout dans le monde, à des fins commerciales ou autres, sur support microforme, papier, électronique et/ou autres formats.

L'auteur conserve la propriété du droit d'auteur et des droits moraux qui protège cette thèse. $\mathrm{Ni}$ la thèse ni des extraits substantiels de celle-ci ne doivent être imprimés ou autrement reproduits sans son autorisation.
In compliance with the Canadian

Privacy Act some supporting forms may have been removed from this thesis.

While these forms may be included in the document page count, their removal does not represent any loss of content from the thesis.
Conformément à la loi canadienne sur la protection de la vie privée, quelques formulaires secondaires ont été enlevés de cette thèse.

Bien que ces formulaires aient inclus dans la pagination, il n'y aura aucun contenu manquant.

\section{Canada}




\section{ABSTRACT}

Since the late 1980 s, researchers have been working on a "post-desktop" paradigm for human-computer interaction, known as "ubiquitous" or "pervasive" computing. Combining any number of mobile, networked and context-aware technologies, pervasive computing involves the embedding of computational capacities in the objects and environments that surround us. When this research began to spread from university and corporate labs to the popular imagination, there was an almost immediate and negative reaction, marked by anxieties around the idea of technologies penetrating into everyday life. In North America and Europe in particular, privacy concerns came to the fore as commentators envisioned a world of absolute surveillance. Conversely, the more recent emerging research agendas in "urban computing" and "locative media" present a strongly utopian vision.

Following urban computing and locative media and their accompanying visions from labs, conferences and classrooms to journal publications and popular media accounts, this dissertation presents four case histories in corporate, academic and artistic design practice. An analysis of the Mobile Bristol, Passing Glances, Sonic City and Urban Tapestries research and design projects draws out the idea that everyday life in the future city is expected to become more expressive, engaging and meaningful. The increased extensibility and transmissibility of the city itself, along with an increased ability to be socially embedded within it, is seen to be a fundamental promise inherent in these projects. The dissertation argues that such spatial and cultural potentialities can be productively understood as involving temporary, selective and mobile publics, where creative and playful interactions emerge as primary means of social innovation.

The dissertation builds on available sociological approaches to understanding everyday life in the networked city to show that emergent technologies reshape our experiences of spatiality, temporality and embodiment. It contributes to methodological innovation through the use of data bricolage and research blogging, which are presented through experimental and recombinant textual strategies; and it contributes to the field of science and technology studies by bringing together actor-network theory with the sociology of expectations in order to empirically evaluate an area of cutting-edge design. 


\section{ACKNOWLEDGEMENTS}

I could not have completed my dissertation without the support of extraordinary faculty, friends and family, and I would like to express my gratitude to the individuals who accompanied me on this adventure.

First, I thank my thesis committee. It was my supervisor, Rob Shields, who originally convinced me to apply to the doctoral programme. While working fulltime, I took his "Virtual Spaces"course and remembered why I wanted to be an academic. Since then, Rob has never ceased to be interested and interesting, two qualities I greatly admire and ones that unfailingly provided support when needed. He set a high standard of research and scholarship for me, and was always willing to help me reach it when I struggled. My knowledge and understanding of space and culture is deeply indebted to what Rob taught me over the years, and it is my great hope that my dissertation offers something worthwhile in return.

In the first year of my doctoral studies I took a reading course in humancomputer interaction with Gitte Lindgaard, and I immediately knew I could not ask for a more supportive addition to my thesis committee. Her unflinching but always kind attention to detail helped me better understand the contexts in which I sought to intervene, and she never failed to be open to new ways of thinking and writing about issues in the field. Gitte has always served as a strong advocate for me and my work, consistently demonstrating the benefits of cross-disciplinary teaching and learning. I am also deeply grateful for her uncanny ability to say exactly what I needed to hear to keep going, and for always reminding me to laugh.

Carlos Novas joined the department, and my committee, while I was writing my thesis. Without hesitation, he met a demanding reading schedule and consistently offered invaluable comments on all matters related to social studies of science and technology. Undoubtedly, my dissertation's focus in these areas was greatly improved by Carlos' thoughtful suggestions, and I very much appreciate his help during the final stages of writing and preparing for the defense.

I am particularly thankful to Mike Michael in the Department of Sociology at Goldsmith's College, University of London, who kindly agreed to join us by telephone as the external examiner for the thesis defense. Professor Michael immediately put me at ease, but never let me off the hook. His challenging questions helped me better understand the strengths and weaknesses of my arguments, and his astute comments were instrumental in guiding the final revisions. I also greatly appreciate his suggestions for further research and publication, and look forward to putting them into action.

My dissertation also directly benefited from the questions and comments of the other examiners. Andrea Doucet introduced me to experimental writing methods 
in sociology, and her questions about the field continue to inspire me. Avi Parush admirably rose to the challenge of evaluating a dissertation-and a rather unusual one at that-outside his field. I attempted to address his concerns in the final revisions and remain grateful for the questions he raised.

I am also grateful to two professors who indirectly helped me get to this point. During my Bachelor of Arts at the University of Alberta, Ruth Gruhn taught me to value the questions raised in social and cultural studies, and the importance of looking far and wide for the best answers. During my Master of Arts at Trent University, John Topic instilled in me the belief that technology, space and culture can never be separated, and that a radical empiricism is required to productively understand them. Without this knowledge and understanding, I would have never believed that my doctoral project was possible.

In addition to such strong scholarly support, my studies could not have been completed without a Doctoral Fellowship from the Social Sciences and Humanities Research Council of Canada, an Ontario Graduate Scholarship, and the financial support of the Department of Sociology and Anthropology at Carleton University.

I would also like to thank the individuals who stood beside me for so many years and played such vital roles in my everyday life. First and foremost, I am grateful to my two great loves: Jason Kiss, who made all this possible and worthwhile, and Enid Coleslaw, my constant companion and world's best listener. Special thanks go to Bob Krukowski for being such a supportive friend, and indulging my love of bad television without complaint. Thanks to Nikki Guerrero for always making me laugh, and never missing a pho date-even if it meant going out in a blizzard. Thanks to John Stevenson for his wisdom and wicked sense of humour. Thanks to Craig Davey for reminding me of what is really important. Thanks to Daphne Guerrero for understanding that the right answer often involves brunch. Thanks also to Linda Campbell and Herb Hartshorne for believing in me for so many years.

Thanks to Jean Burgess, who makes me think hard and laugh harder, and stuck with me in the final stretch. Thanks to Matt Webb for some of the best conversations I have ever had. Thanks to Timo Arnall for his trust and understanding. Thanks to Ehsan Roudiani for giving me a home away from home. Thanks to Rod McLaren for knowing just what to say. Thanks to Molly Steenson for her interminable enthusiasm. Thanks to Jack Schulze for never being afraid to take the piss out of me. And special thanks to everyone who read and commented on what I wrote along the way. I could not have done this without you!

And last but not least, I am grateful to my parents, Betty and Hamish Galloway, for giving me the gift of a curious mind and for always supporting my studies.

I dedicate this dissertation to my Mum, who taught me to never give up. 


\section{TABLE OF CONTENTS}

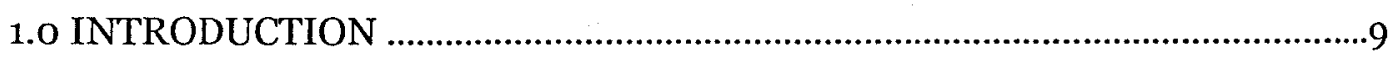

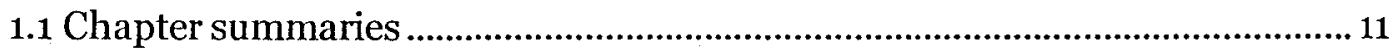

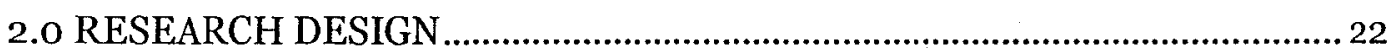

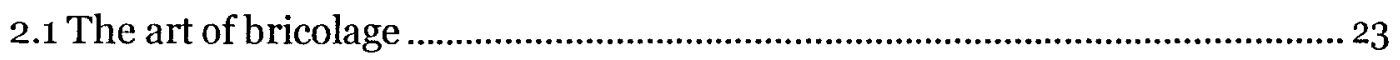

2.1.1 Mobile sociology meets mobile methodology ......................................25

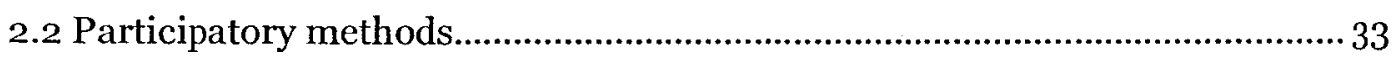

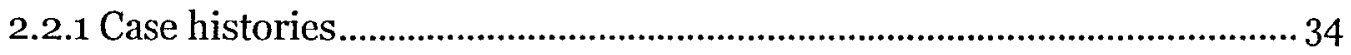

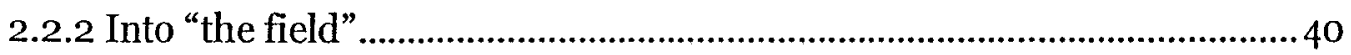

2.3 Writing experimental ethnography........................................................... 48

2.3.1 Different ways of reading and writing ...................................................50

2.3.2 A note on interpretive validity ..............................................................57

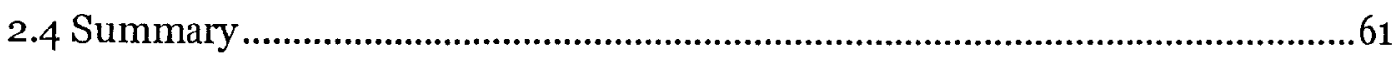

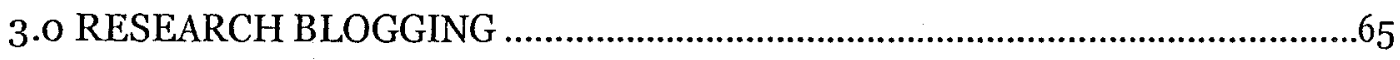

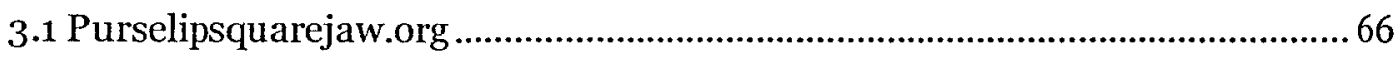

3.2 Authorship, identity and academic authority ….................................... 70

3.2.1 Blogging and affective politics...........................................................76

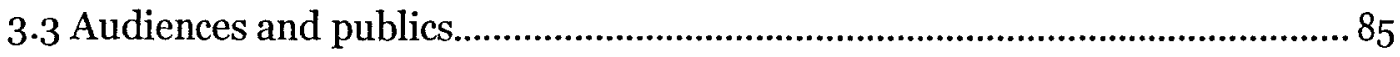

3.3.1 Blogging and voice ......................................................................... 92

3.3.2 Blogging as collective and collaborative work ...................................... 98

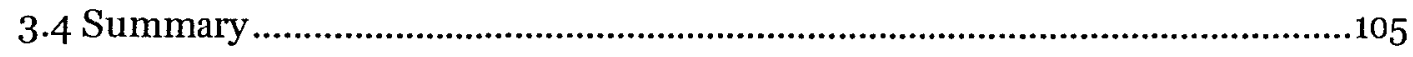


4.1 Introducing ubiquitous or pervasive computing …………………….................109

4.1.1 Computing in the $21^{\text {st }}$ century.......................................................................... 112

4.1.2 Seamless versus seamful computing .......................................................... 116

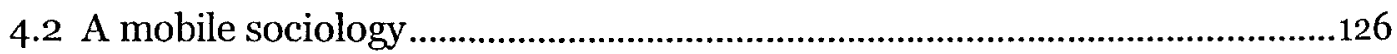

4.2.1 Translations and associations ....................................................................... 127

4.2.2 Transduction and other complexities ........................................................129

4.3 Expectation, affect and the question of temporality.........................................133

4.3.1 Affecting hope............................................................................................139

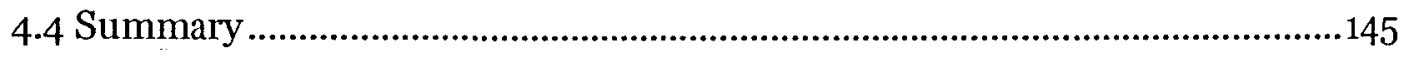

5.o ENACTING URBAN COMPUTING \& LOCATIVE MEDIA ..............................147

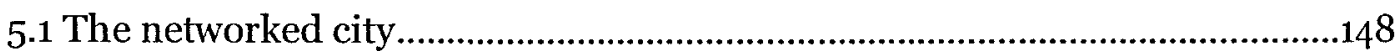

5.1.1 From cyberspace to hybrid space ..............................................................150

5.2 Off the desktop, out of the lab, and into the world ..........................................155

5.2.1 The temporality of expectations and technological determinism ............159

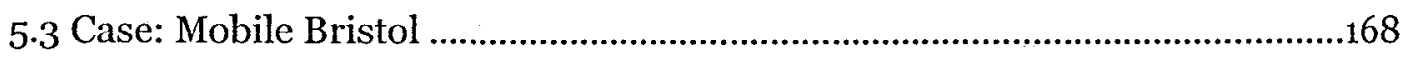

5.4 Spaces and times of urban computing and locative media research ................176

5.4.1 Following actors and contemplating entanglements ................................182

5.5 The politics of locative media and urban computing research ........................192

5.5.1 Reflections on collaborative work ………………………………….............20

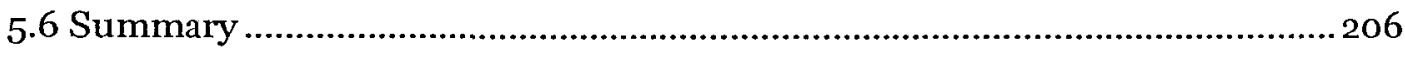


6.o TECHNOLOGY TO MAKE EVERYDAY LIFE MORE MEANINGFUL .........209

6.1 Location, location, location? ........................................................................212

6.1.1 Over, under and around the surface of the city..........................................215

6.2 Case: Passing Glances ......................................................................................

6.2.1 Activating places, activating people.............................................................219

6.3 A brief note on protoypes............................................................................... 222

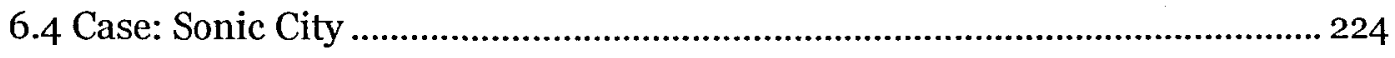

6.4.1 Location, context and scale ....................................................................... 225

6.4.2 Aesthetics and sociability in the (sonic) city ............................................ 229

6.5 Case: Urban Tapestries ................................................................................. 234

6.5.1 Sensing cities and affective spaces.............................................................. 240

6.5.2 Public Authoring ........................................................................................... 244

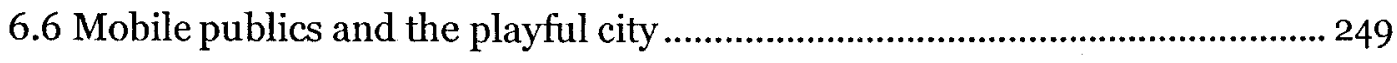

6.6.1 Mobile publics ………………….............................................................. 250

6.6.2 Playful cities, playful lives.........................................................................257

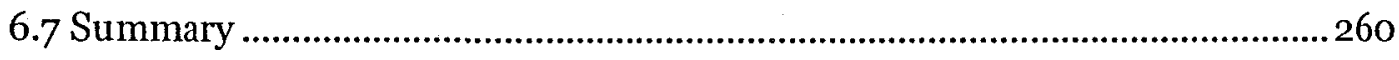

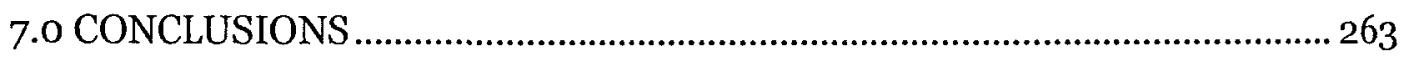

7.1 Ethnographic methods ..................................................................................... 263

7.2 Social studies of technology, space and culture ……………………………..... 266

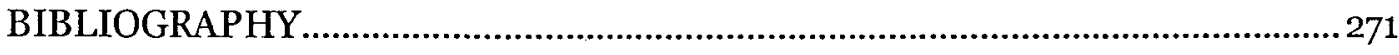

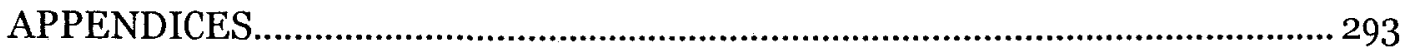




\section{LIST OF APPENDICES}

Appendix 1 - Application to the Research Ethics Committee

Appendix 2 - Questionnaire and Interview Protocol

Appendix 3 - Cultural Probe Protocol 


\subsection{INTRODUCTION}

Since the late 1980 , researchers have been working on a "post-desktop" paradigm for human-computer interaction known as ubiquitous or pervasive computing. Combining any number of mobile, networked and context-aware technologies, this vision hinges on the possibility of embedding computational capacities in the objects and environments that surround us. In order not to be overwhelmed by such a proliferation of new technologies, researchers have most often worked to integrate them in ways that make it difficult to identify when and where we interact with these systems. For example, many of us are aware of, or have used, Global Positioning System (GPS) technologies in our vehicles, or Radio-Frequency Identification (RFID) technologies in public transportation passes like London's Oyster card and Hong Kong's Octopus card. When sensor technologies are added to the mix, these systems can measure and monitor everything from environmental conditions such as air pollution or noise levels, to bodily functions such as heart-rate or temperature, and connect that data to any number of applications or services. While certainly not infallible technologies, interaction with such systems is generally so seamless that it is easy to overlook the significant infrastructure that underpins their management and use.

By the early 1990s, sufficient engineering and computer science advances had been made to bloster the claim that, while the era of pervasive computing might not have yet arrived, it almost certainly would in the future. When research in these areas began to spread from university and corporate research labs to the popular imagination, there was an almost immediate reaction against such a 
totalising vision of technological penetration in everyday life. In North America and Europe in particular, privacy concerns emerged front and centre as commentators envisioned a world of absolute surveillance. Even within the human-computer interaction research community, responses were mixed. In the mid-1990s, strong criticism emerged and researchers debated the pros and cons of developing such "dangerous" technologies. However, technological limitations at the time still allowed researchers to claim these social concerns were theoretical rather than actual, and the matter faded from public consciousness again until the early 2000 .

By the turn of the $21^{\text {st }}$ century, mobile phone penetration was globally on the rise, and a vision of ubiquitous information and communication technologies no longer seemed a fantasy. Technologies that had not existed even five years earlier were becoming commonplace and, firmly embedded within broader consumer desires for convenience and comfort, the pervasive computing vision began to roll out with unprecedented vigour. Industries and governments began heralding the coming "Internet of Things," where the global supply chain would be managed in ways that could create "smart objects" or a web-presence for consumer goods. Again popular media tended to focus on the surveillance possibilities, and ubiquitous or pervasive computing discourse began to take on a distinctly dystopian tone. However, at the same time, new research agendas in urban computing and locative media emerged to present a strongly utopian countervision. 
My thesis focusses on these emergent research agendas in an attempt to better understand how, contrary to the discursive construction of pervasive computing as 'everywhere,' research projects in locative media and urban computing actually locate these technologies 'somewhere.' I draw on actor-network theory and sociological approaches to expectations and affect as a means to understand and account for the complexity of these processes. By focussing on the roles of imagination and desire in shaping technological change, I examine how urban computing and locative media research involves persistent tensions between pasts, presents and futures, and how that makes certain practices and identities possible or probable, and others impossible or improbable. Working on the assumption that recent expectations surrounding locative media and urban computing have more to do with present technosocial concerns than with future predictions, I look for indicators of how research is currently being organised and how relations between people, computers and everyday life are being actively reconfigured in the process.

Drawing on both online and offline participant observation, as well as experimental ways of writing culture, my doctoral project seeks to open new ways of conducting sociological research that firmly position our work within the embodied and situated practices of everyday life. Through recombinant textual strategies that encourage listening over telling, and often description over explanation, my dissertation presents a multivocal and multiperspectival account as a pleated or layered text. Weaving together theoretical and analytical discussion with scholarly quotes, questionnaire and interview excerpts, blog 
posts, news stories and personal reflections, readers are invited to join in their entangled differences as active producers of their own knowledge rather than as 'passive' consumers of academic wisdom. I argue that the validity and value of such an approach may be found precisely in its ability to avoid presenting a single voice or point of view, and to ask more questions than provide answers.

In addition to these methodological contributions, my dissertation seeks to build on sociological approaches to understanding everyday life in the 'networked city,' especially in terms of how emergent technologies stand to reshape our experiences of spatiality, temporality and embodiment. Following these technologies and their accompanying visions from labs, conferences and classrooms to journal publications and popular media accounts, I draw out the idea that hybrid city spaces and social behaviours are increasingly expected to be more expressive and affective. This increased extensibility and transmissibility of the city itself, along with an increased ability to be socially embedded within it, is seen to be the fundamental promise inherent in the four cases presented here. And I suggest that these spatial and cultural potentials can be productively understood as involving temporary and mobile publics, where playful interactions emerge as primary means of social innovation. Despite the positive tone of such visions, I also attempt to draw out some less than positive implications.

Ultimately, I aim to present an account with multiple entrances and exits so that researchers and practitioners with various interests, and from a variety of 
disciplines, can follow-up in different ways. My dissertation raises intriguing questions about individualisation and subjectivity, collective action and collaborative work, and infrastructure and governance, to name just a few-and I hope that readers will conjure even more.

\subsection{CHAPTER SUMMARIES}

The first two chapters following the introduction outline the methodological approach taken in my doctoral project, and the third provides a theoretical foundation. The subsequent two chapters present and analyse the empirical research I conducted, and the final chapter assesses the findings.

\section{Chapter 2}

This chapter argues that methodological bricolage is particularly well suited to tackle the indeterminacy and contingency of social and cultural knowledge in the early years of the $21^{\text {st }}$ century. Beginning with a brief introduction to a shift in sociological focus from society to sociality, I position my dissertation within sociological traditions more concerned with processes and relations, than with objects and structures. This kind of mobile sociology is seen to compel the mapping of connections and associations, always emphasising situated positions and partial truths.

I describe a multi-sited approach to ethnography "designed around chains, paths, threads, conjunctions, or juxtapositions of locations" (Marcus 1995:105) that results in accounts that are choreographed and performed with others. 
Grounding my project in participatory methods, I explain that my approach to ethnographic fieldwork attempts to strike a balance between online and offline participatory observation. Not only does this best reflect my research experiences, but it seeks to open new ways of conducting academic research that position our work within the embodied and situated practices of everyday life. My empirical research, in the form of site visits, questionnaires and interviews, is presented in the form of case histories. In contrast to exhaustive and generalisable case studies, the Freudian and Foucauldian case history stresses partiality and internal intelligibility.

Faced with the challenge of how to re/present such an approach as a written dissertation, I turn to experimental approaches to reading and writing found within anthropology and feminist theory. Following Richardson (1997:303), I write here "the way my life is experienced," full of recombinant strategies that often encourage listening over telling, and description over explanation. Seeking to explore ways of re/inserting affective experience into the rational products of intellectual labour, I choose multivocal and multiperspectival accounts presented as pleated or layered texts.

My dissertation, then, weaves together theoretical and analytical discussion with multiple genres of text: scholarly quotes, survey and interview excerpts, blog posts, news stories, personal reflections, etc. And it is precisely in their entangled differences that the reader is invited to join. By following my zig-zagging paths, and remaining open to understanding things according to their own logic rather 
than imposing a singular or stable logic to control them, the reader is encouraged to become an active producer of her own knowledge rather than a 'passive' consumer of academic wisdom.

Given the situated and partial nature of such an account, I conclude this chapter with a brief discussion of interpretive validity. Stressing a critical approach based on the validity of transgression, and a "strategy of excess and categorical scandal" (Lather 1993:677), my dissertation seeks to evoke further reflection and questioning. In fact, part of the validity and value of my argument may be found precisely in its ability to avoid presenting a single voice or point of view that reinforces the false notion that my subject of study is stable and describable in its entirety. In evaluating its success, we can ask if I succeed in creating such a questioning text. Put a bit differently, we can ask if it demonstrates what is in play, and if it invites us to play with it.

\section{Chapter 3}

In this chapter I introduce my weblog, purse lip square jaw, as an integral part of my dissertation's methodology and my personal experience of 'becoming PhD.' I describe research blogging in terms of its ability to reconfigure, to greater and lesser extents, traditional sociological understandings of authorship, identity and academic authority-although the political power of these emerging practices and relations should be further qualified. By engaging multiple audiences and publics, my blog can also be understood as a form of participant observation that raises 
interesting questions about the differences between collective and collaborative research.

Emphasising how blogging is simultaneously private and public, individual and collective, I raise a variety of questions about authorship, audience and authority in contemporary academic knowledge production. Beginning with a discussion of blogging and affective politics, I use excerpts from my blog and the comments people made there to draw attention to the more physical and emotional, financial and political, aspects of intellectual labour. They may be excluded from our formal work, and often even from the classroom, but they can nonetheless find a place online-where we and others can engage them in new and productive ways.

Finally, I address the question of audiences and publics, and their connection to 'voice' in online academic writing. In my case, the matter of blogging identity has been dominated by what kind of academic I have wanted to become, as well as what kind I have been 'allowed' to become. This is related to the reality that, at least sometimes, I did research near but not with non-academics-which raises interesting, if largely unresolved, questions about what it means to do sociology through blogging. Indeed, I think critical questions arise around what actually constitutes 'research' in these scenarios.

In this chapter, I leave more questions unanswered than answered-but I think this is consistent with the sort of immediate and emergent quality of blogs that I 
attempt to describe. I also want to emphasise that the analysis of research blogging is in its very earliest stages, and much work still needs to be done.

\section{Chapter 4}

In the first part of this chapter, readers are introduced to pervasive or ubiquitous computing as an emergent agenda in human-computer interaction research characterised by tensions between seamless interaction and calming effects on one hand, and more transparent infrastructures and active appropriation or engaged use on the other. I show that from its earliest debates, researchers have been divided on whether such a technosocial future would be profoundly dystopian or utopian.

In order to better engage these tensions and other intangibles of emergent or future-oriented technologies, elements of actor-network theory along with notions of transduction, as well as sociological approaches to expectations and affect, are positioned as the most promising ways for social researchers to understand and account for the complexity of the processes at hand. A sociology of expectations looks to the affective roles of imagination and desire in shaping technological change, and expectations are seen to be performative in the sense that they attract interest from potential allies, define roles, and "build mutually binding obligations and agendas" (Borup et al. 2006:286). Such a perspective requires we ask how pervasive computing involves persistent tensions between pasts, presents and futures-and how that makes certain identities and objectives possible or probable, and others impossible or improbable. 
In this chapter, I outline a position from which I seek to claim that contemporary expectations about urban computing and locative media have more to do with present technosocial concerns than with future predictions. Likewise, expectations about urban computing and locative media can be seen to shape how we approach research in these areas today, along with our very definitions of-and how we understand relations between-people, computers and everyday urban life.

\section{Chapter 5}

I begin this chapter by providing a brief overview of the 'networked city,' with its dynamic combinations of the material and the semiotic, the virtual and the actual. Avoiding the claim that urban computing and locative media are entirely 'new' contributions to this discourse, I instead focus on what is different and what remains the same. Starting with technological changes, I contrast cyberspace and virtual reality, and their ethics and aesthetics of disembodiment and dislocation, with the promise of augmented or mixed reality and hybrid space, and their emphases on embodiment and location.

By introducing the first of my case histories, Mobile Bristol, I begin to move backand-forth between small and large stories, or different scales of research. Conversations with the Hewlett-Packard researchers return us to the role of affect in communicating research visions, successes and failures. In these stories we see processes of translation working to create particular associations and expectations, including an increased emphasis on making research 'public.' 
Further following formal mechanisms of knowledge creation and dissemination such as conferences, classrooms, workshops and journal publications, and juxtaposing these activities with more informal weblog and popular press accounts, allows me to trace how urban computing and locative media are enacted in the present. I draw attention to how the spaces of urban computing and locative media research and development are remarkably heterogeneous, despite sharing a somewhat homogeneous shared vision. And ultimately, I call attention to the value placed on inter-disciplinary research and 'public' involvement in order to discuss the politics of such collaborative work.

\section{Chapter 6}

This chapter shifts focus almost entirely to the smaller stories of individual urban computing and locative media research projects in order to question what, exactly, is expected in some of these future scenarios. Contrary to the discursive construction of pervasive computing as 'everywhere,' these projects can be seen to locate technologies 'somewhere.' Context-aware computing, researchers suggest, enacts particular but dynamic spatialisations, temporalisations and embodiments. In doing so, city spaces and social behaviours are expected to become more affective and expressive, and potentially more 'meaningful.' This technologically-mediated extensibility and transmissibility of the city, along with an increased ability to be socially embedded within in, are shared expectations amongst all the cases presented here.

The Passing Glances project is described in terms of an imagined future where 
images could be embedded in the built environment and triggered by text message, augmenting urban waiting spaces with random and emergent narratives as well as the potential for random and emergent social interactions. Sonic City is positioned as both a listening and composing technology that promises the city itself as media co-creator. Although it is not considered an interpersonal technology, it can nonetheless be seen to expect new relationships between people and places. Urban Tapestries is likewise described as expecting and promising a reinvigorated sense of social and spatial belonging based, in part, on the ability to play with spatial boundaries and social identities.

I argue that the desire to augment reality is not a desire to use technology to replace people, places or activities, but rather one that expects to amplify or extend the most vital qualities of our lives in order to multiply possibilities for future connections. A primary expectation that informs all these research projects is that future technological applications would, and should, facilitate playful or transformative experiences, dense with aesthetical and ethical action. In this way they position themselves against a totalising vision of ubiquitous computing, and situate their applications as temporary or partial interventions into everyday urban life.

At the same time, such visions and expectations tend to reify the ideals of consumer capitalism and fail to acknowledge the implications for people who cannot afford, or do not wish to use, such technologies. Furthermore, they advocate use scenarios that reinforce the value of urban life to the exclusion of 
rural life, thereby excluding half the world's population and maintaining certain socio-spatial divides. Finally, I argue that a critical take on urban computing and locative media requires further research into the infrastructural and governance issues raised by these expectations and promises.

\section{Chapter 7}

In keeping with my dissertation's goal to provide multiple entrances and exits, the final chapter is dedicated to identifying particular issues and concerns that deserve further consideration. Reconfiguring the structure presented in the preceeding chapters, I divide my discussion into two broad categories: ethnographic methods and social studies of technology, space and culture. In each section I summarise what I consider to be the main contributions of my thesis, and end with a set of possible questions for others to pick up. 


\subsection{RESEARCH DESIGN}

This chapter details the research design and unfolding of my doctoral project between 2002 and 2007. The first section is largely theoretical, and stems from the notion of messiness or complexity in social science research, beginning with a discussion of methodological bricolage in qualitative research and moving into a discussion of what might constitute a mobile sociology for the $21^{\text {st }}$ century. Characterised by contingency and indeterminacy, sociality is seen to involve practices that are substantially altered by stable and totalising explanations, compelling more dynamic and contingent approaches to sociological research.

To this end, the second section outlines my multi-sited ethnographic approach to online and offline participant observation. Special attention is given to the selection of research participants, and how my relationships with them evolved over time. Arguing for a situated and embodied case history approach, rather than a distanced and generalisable case study, the complex relations between seeing, doing and writing are further explored. Primarily, this involves a description of my original research plan, and specifically how my trajectories shifted over time.

The third and final section repositions my research project within broader experimental approaches to ethnography, focussing specifically on the guiding role that experimental writing in feminist social theory takes in my dissertation. I then conclude with a brief discussion of the question of interpretive validity in the approaches I present. 


\subsection{THE ART OF BRICOLAGE}

In my PhD project proposal I wrote the following:

The approach to research design taken by this dissertation project is best described as experimental, iterative and participatory. Each phase of research will be used to inform the following stage, and in addition to standard theoretical research, I am interested in exploring and evaluating a small set of interdisciplinary and critical methods [including] what might be considered intimate and playful research methods.

This methodological approach is best described as a kind of bricolage (cf. Lévi-

Strauss 1966; Kincheloe 2001, 2005; Denzin and Lincoln 2005). The French

word bricoleur refers to a handyman, or someone who uses whatever is at her

disposal to get things done. While this kind of ingenuity and creativity may be

highly respected and rewarded in domains such as technology design, Kincheloe

(2001:680) shares a story that may still be indicative of reactions in the social

sciences:

Prepped and ready to answer in detail questions about their methods and research agendas, my students spoke of their theoretical embrace and methodological employment of the bricolage. Much too often for our comfort, search committee members responded quite negatively: "bricolage, oh I know what that is; that's when you really don't know anything about research but have a lot to say about it." Much to our dismay, the use of the concept persuaded such committee members not to employ the students.

\section{[...]}

If hermeneutics came to connote the ambiguity and slipperiness of textual meaning, then bricolage can also imply the fictive and imaginative elements of the presentation of all formal research. Indeed, as cultural studies of science have indicated, all scientific inquiry is jerryrigged to a degree; science, as we all know by now, is not nearly as clean, simple, and procedural as scientists would have us believe. Maybe this is an admission many in our field would wish to keep in the closet. Maybe at a tacit level this is what many search committee members were reacting to when my doctoral students discussed it so openly, enthusiastically, and unabashedly. 
Avoiding uncritical support of bricolage, Kincheloe argues that it requires repeated exploration and evaluation precisely because its implicit interdisciplinarity may now be the only possible kind of research, and academics should be aware of its strengths and limitations.

My argument here is that we must operate in the ruins of the temple, in a postapocalyptic social, cultural, psychological, and educational science where certainty and stability have long departed for parts unknown. In the best sense of Lévi-Strauss's (1966) concept, the research bricoleurs pick up the pieces of what's left and paste them together as best they can. The critics are probably correct, such a daunting task cannot be accomplished in the time span of a doctoral program; but the process can be named and the dimensions of a lifetime scholarly pursuit can be in part delineated (Kincheloe 2001:681).

This dissertation can be seen as my first step in "a lifetime of scholarly pursuit," an adventure in 'becoming sociologist' during the early years of the $21^{\text {st }}$ century.

Reflecting the incredible diversity of contemporary social and cultural experience, bricolage begins and ends as a multi-perspectival and polyvalent activity, a way of asking different questions and allowing different answers:

Bricolage does not simply tolerate difference but cultivates it as a spark to researcher creativity ... Sensitive to complexity, bricoleurs use multiple methods to uncover new insights, expand and modify old principles, and reexamine accepted interpretations in unanticipated contexts (Kincheloe 2001:687).

The work of the bricoleur can also be regarded as important boundary work between disciplines, and even between people of all sorts. Its reach can be seen as more inclusive and with more opportunities for diverse kinds of action. Choosing appropriate tools with which to conduct bricolage research has been part of the 
challenge and the journey of this dissertation. As Lincoln (2001:693-694)

explains in her response to Kincheloe's (2001) article:

Kincheloe's bricoleur is far more skilled than merely a handyman. This bricoleur looks for not yet imagined tools, fashioning them with not yet imagined connections. This handyman is searching for the nodes, the nexuses, the linkages, the interconnections, the fragile bonds between disciplines, between bodies of knowledge, between knowing and understanding themselves.

And while Kincheloe (2001) suggests that this practice relies on the disciplinary rigour associated with Foucault's (1980) geneaology, Lincoln (2001:694) prefers scholars "who are committed to methodological eclecticism, permitting the scene and circumstance and presence or absence of coresearchers to dictate method"as so much feminist critique has also come to do. It is this sense of bricolage to which I turn here, one based on the real complexity of the world and struggles for power in the production of sociological knowledge.

\subsubsection{Mobile sociology meets mobile methodology}

In its hard labors in the domain of complexity, the bricolage views research methods actively rather than passively, meaning that we actively construct our research methods from the tools at hand rather than passively receiving the "correct," universally applicable methodologies. Avoiding modes of reasoning that come from certified processes of logical analysis, bricoleurs also steer clear of preexisting guidelines and checklists developed outside the specific demands of the inquiry at hand. In its embrace of complexity, the bricolage constructs a far more active role for humans both in shaping reality and in creating the research processes and narratives that represent it. Such an active agency rejects deterministic views of social reality that assume the effects of particular social, political, economic, and educational processes. At the same time and in the same conceptual context, this belief in active human agency refuses standardized modes of knowledge production (Kincheloe 2005:324-325).

If this is an awful mess ... then would something less messy make a mess of describing it? [W] hat happens when social science tries to describe things that are complex, diffuse, and messy? (Law 2004:1-2) 
There is a new 'structure of feeling' that complexity approaches both signify and enhance. Such an emergent structure of feeling involves a greater sense of contingent openness to people, corporations and societies, of the unpredictability of outcomes in time-space, of a charity towards objects and nature, of the diverse and non-linear changes in relationships, households and persons, and of the sheer increase in the hyper-complexity of products, technologies and socialities (Urry 2006:111).

In the past half decade, concepts of heterogeneity and complexity have characterised social theory to such an extent that the notion of society has arguably been replaced with concerns around sociality. According to Albertsen and Diken (2000:7-8)

Any heterogeneous social element is defined by its intensity and the affective reactions through which it breaks the laws of homogeneity, as in the cases of excess, delirium, madness and violence. But this is not all; elements that appear to be constitutive of homogeneity can also belong to heterogeneity... [and at the same time heterogeneity] is what escapes, or what flows in and through homogeneity.

Bauman (1998) reiterates the importance of heterogeneity in social theory and also emphasises ambivalence. He locates ethics at the centre of social behaviour, but an organic ethics based on facing ambiguity and making choices, rather than one based on an external rule-set or system. In this way, Bauman (following Levinas) replaces the notion of society with one of sociality, or the interpersonal negotiation of ambivalence and heterogeneity. He is concerned not with what holds us together (society) but with the affective relations that emerge in social interaction.

Bauman (following Simmel) invokes the concept of habitat. Away from society, and towards sociality, habitat is a complex system and the context in which 
agency operates. Habitat is where sociality takes place, a territory characterised by indeterminacy and ambivalence. Simmel's (1971:143) stranger "comes today and stays tomorrow... [and is] an element whose membership within the group involves both being outside and confronting it." Bauman uses the concept of the stranger to demonstrate that sociality consists of belonging to more than one category: always ambivalent, contingent, inconsistent and indeterminate. Neither fixed nor clearly bounded, sociality is seen as hybrid and heterogeneous. Accordingly, for Bauman, the social can only define itself against its strangers.

But the concept of ambivalence is not characterised solely by chaos or complete indeterminacy. Rather, ambivalence suggests a continuum between chaos and order, or contingent mixtures of the two. According to Thrift (1999:33) "the chief impulse behind complexity theory is an anti-reductionist one, representing a shift towards understanding the properties of interaction of systems as more than a sum of their parts." Lessons taken from notions of chaos and complexity include the "primacy of processes over events, of relationships over entities and of development over structure" (Ingold 1990:209).

Along related lines, Deleuze and Guattari (1987) argue that the raw materials of existence-the social, the mental and the physical-are constantly in flux, lacking consistency and making connection difficult. However, by using their concept of the machine we may understand how consistency and order emerge from the chaos, if only in contingent ways. Machines are productive assemblages that connect multiplicities, and machinic relations take place "immanently and 
pragmatically, by contagion rather than by comparison, unsubordinated either to the laws of resemblance or utility" (Massumi 1992:192). Deleuze and Guattari (1987) continue to argue that every social phenomenon faces escapes and inversions. It is in these lines of flight that sociality escapes organisation and centralisation, and so it is to these lines that we must look to find the socially meaningful. This de-territorialisation is characterised in terms of nomadic subjectivity, where nomadism is based on freedom of movement, on choice and becoming. Nomadology itself is a line of flight, a process which constantly resists the sedentary and the fixed (Deleuze and Guattari 1986).

These matters of mobility and becoming were also taken up decades earlier by Sartre (1947), in his eloquent description of Alexander Calder's mobiles:

[Mobiles] have to draw their mobility from some source... They feed on air, they breathe, they borrow life from the vague life of the atmosphere. Thus their mobility is of a particular kind. The 'mobile'...never [has] precision and efficiency...[it] weaves uncertainty, hesitates and at times appears to begin its movement anew, as if it had caught itself in a mistake.

\section{[...]}

[T]hese hesitations, resumptions, gropings, clumsinesses, the sudden decisions and above all that swan-like grace make of certain 'mobiles' very strange creatures indeed, something midway between matter and life. At moments they seem endowed with intention; a moment later they appear to have forgotten what they intended to do, and finish by merely swaying inanely...It is one [mobile], single and whole. Then all of a sudden it goes to pieces and is nothing but a bunch of metal rods shaken by meaningless quiverings.

\section{$[\ldots]$}

[Mobiles] do not seek to imitate anything because they do not 'seek' any end whatever, unless it be to create scales and chords of hitherto unknown movements-they are nevertheless at once lyrical inventions, technical combinations of an almost mathematical quality, and sensitive symbols of Nature...of that inscrutable Nature which refuses to reveal to us whether it is a 
blind succession of causes and effects, or the timid, hesitant, groping development of an idea (Sartre 1947).

Although I was unable to locate any sources that acknowledged Sartre's prescient contributions to this discourse, this kind of philosophical and poetic thinking has found its way into social and cultural theory in a multitude of ways. Notably, Cresswell (2006) argues that mobility and its regulation have always been an integral part of modernity, and Urry (2000:18) seeks to reconfigure sociological practice for the $21^{\text {st }}$ century by “develop[ing] through appropriate metaphors a sociology which focuses upon movement, mobility and contingent ordering, rather than upon stasis, structure and social order"-a mobile sociology.

Of primary interest to this discussion is how these theoretical understandings of sociality manifest methodologically, and I have found both John Law's (2004) work on "mess" in social science research and Bruno Latour's (2005) discussions on "reassembling the social" to be particularly relevant. While both approaches get applied to different concerns throughout this dissertation, it may be useful at this point to establish a basic foundation on which to continue building. Following what can broadly be termed the "practice turn" in theory (see Pickering 1989; Schatzki, Knorr Cetina and von Savigny 2001), the kinds of ethnographic practice described by Law and Latour are based in actor-network theory, and predicated on the understanding that what researchers witness, participate in, and create is always multiple and partial. 
Although best known as actor-network theory, a "sociology of associations" may also be better understood as a methodology where the social must be explained instead of providing the explanation (Latour 2005). As Latour has long advocated "following actors" through the world, John Law focusses on how multiple methods situationally enact multiple subjects, objects and perspectives. Accordingly, to present one's research subject as a singularity can be seen to "hide the practice that enacts it, [and] also conceal the possibility that different constellations of practice and their hinterlands might make it possible to enact realities in different ways" (Law 2004:66).

This perspective builds on other research in social studies of science, as well as decades of work in anthropology and feminist theory. For example, in order to trace people, objects and ideas as they circulate, anthropologists like Hannerz (2003) and Marcus (1986; 1995:105) advocate a multi-site or multilocal ethnography, where research is "designed around chains, paths, threads, conjunctions, or juxtapositions of locations." While sustained engagement with a specific field has historically been the hallmark of anthropological research, Marcus (1985) points out that shifting global relations challenge the feasibility and appropriateness of studying isolated places or cases. Furthermore, he stresses the fact that fieldwork has actually always involved some combination of following people, things, metaphors, plots, stories or allegories, lives or biographies, or conflicts. In other words, it may actually be impossible to do research that is not multi-sited, or perhaps better put, situated in multiple ways. 
Similarly, Donna Haraway (1988) claims that all academic research is highly "situated" or positioned knowledge, that arises from particular combinations of people, places, objects and ideas. For example, laboratory studies (see for example Latour and Woolgar 1986; Knorr-Cetina 1999) have demonstrated that much rational, linear, singular and universal knowledge emerges from situations that are actually quite passionate, non-linear, multiple and local. To acknowledge the situatedness of knowledge production, then, is to deny the positivist scientific 'view from nowhere' and focus instead on relational processes that highlight the possibility of different perspectives. As Strathern (2004a) puts it, anthropology works through the social construction of what can quite often be precarious and “partial connections," and always "partial truths" (cf. Clifford 1986).

Such accounts are necessarily more embodied, possibly more modest, and arguably more convincing and productive because they leave any given matter open insofar as providing readers with multiple entries and exits. Unsurprisingly, they are also not straightforward in either process or product. As Cook et al. (2005:16) point out,

Critics might argue that writing in this area can, itself, be inadequately positioned and/or un-situated. And purists could argue that it's inappropriate to step back and offer an overview of an approach which criticizes those who claim to be able to step back and offer an overview!

All this suggests that perhaps more so than in other fields of academic knowledge production, ethnographic researchers actually do dance with their subjects. 
More specifically, my approach to methodological bricolage can also be seen to share something in common with choreography (cf. Janesick 2003). Both qualitative research and choreography are highly situated, and continually recontextualised, within shared experiences-and "both refuse to separate art from ordinary experience" (Janesick 2003:47). More generally, just as a choreographer combines the prescriptions of the minuet with various improvisations, the bricoleur can be seen to move through various stages of research and writing, some more structured than others:

First is the warm-up, preparation or pre-choreographic stage of design decisions at the beginning of the study; second is the exploration or tryout and total workout stage, when design decisions are made throughout the study; and third is the illumination and formulation or completion stage, when design decisions are made at the end or near the end of the study. At the same time, the qualitative researcher, like the choreographer, follows set routines... as well as improvisational moments (Janesick 2003:52).

In my case, like many doctoral students, the "warm-up" stage was the completion of comprehensive exams and the preparation and presentation of a thesis proposal. During this period I completed literature reviews, articulated research interests and orientations, and formally delineated a programme of study. The following period involved actually doing the research, or rather doing research, as the plan continually changed according to my experiences and interaction-and now, as I write my final account, I re/search again. However, while I found Janesick's (2003) three stages to be appropriately described, it was not my experience that they were either exclusive or sequential. For example, I often felt myself sliding back and forth between the second and third stages, and I might 
even suggest that every improvisation involved returning to the first stage, if only partially and temporarily.

Looking back, I see these fluid methodologies being well suited to an era of mobile sociology, and I think the role of the bricoleur and choreographer resonates with my experiences in ways that a static model, objective account or other form of traditional sociology could not. In fact, taking this position inevitably produces a different kind of sociological knowledge: one that is more processual and relational than structural, one that tells many stories subjectively instead of one objectively, and one that raises more questions than provides answers.

\subsection{PARTICIPATORY METHODS}

[W]riting cannot be the sole heroine of this [account], because I believe that writing and fieldwork are imbricated in productive and unsettling ways (St. Pierre 1997:414).

Although my PhD studies have largely focussed on sociological and theoretical concerns, my background in empirical anthropology has not been abandoned. During my Bachelor and Master's degrees, I conducted one season of fieldwork in Canada, one in the United States, and two field seasons in Peru. This taught me the value of embodied, located and experiential research, as well as the productive-if sometimes tense-relations between seeing things, doing things and writing about them. In keeping with the ideas put forth above, an emphasis on situated practice appears in my doctoral research in several ways. 
Following Callon (1986) and Latour (1999), I see that the social comprises a multitude of chains between diverse humans and non-humans, and so any account of the social must necessarily "follow the actors." This method of tracing requires the kind of multi-sited and heteroglossic approaches I described earlier. In practical terms, this meant I wanted to visit as many places, talk to as many people, and do as many things as I could within the constraints of my personal and professional life between 2002 and 2007-and in the process, write about them. After my PhD coursework was completed, I made the decision to publically document these experiences through a personal weblog, but what I did not know at the time was how much of my research would actually happen online. The role of research blogging in my doctoral project is the topic of the following chapter, but in the remaining sections of this chapter I trace my actions back in time and begin to fold my blog into the narrative.

\subsubsection{Case histories}

During the early years of my doctorate I regularly worked as a technology research and design consultant. (I continue to do so, but not as often.) In that role, I have variously described myself as web designer, information architect, interaction designer, design researcher and ethnographer-and it was through my practice in these areas that I first connected pervasive computing to my academic interests in space and culture. More specifically, it was my participation in related conferences, workshops and online conversations that both catalysed my interest in the general domain and crystallised my decision to conduct 
surveys, interviews and site visits with particular research and design practitioners.

This hybrid identity of mine has expressed itself as conference attendee and hallway conversationalist; conference presenter, moderator and panel organiser; workshop organiser and participant; lurker and agitator; thinker, doer, speakerand ultimately, writer for many different audiences. I have always approached these professional and social activities from the perspective of a participant and an observer, and wanted to continue along that ethnographic line of flight. However, when participant observation occurs within the context of one's own life it begins to take on a distinctly performative and collaborative quality. Through my overlapping online and offline activities-going to conferences, reading blogs, etc. - I became familiar with more and more collaborations between technologists and artists. Posting interesting ones to my weblog inspired online and offline discussion with friends and colleagues around how emerging technologies stood to reconfigure our understandings and experiences of space and culture.

I was particularly taken by mobile technology and new media projects that focussed on everyday life, public spaces and public use-issues that had clear cultural and political resonance but, in the early 200os, remained under-explored in the broader human-computer interaction research and design fields. And finally, as a student-becoming-professional, I remember being interested in what 
I saw as technologists and designers moving into a research area I had learned to be dominated by sociology, anthropology and cultural geography.

EXCERPTS from purse lip square jaw by Anne Galloway

http://www.purselipsquarejaw.org/2003/04/dear-god-is-she-still-going-on-about.php

Wednesday, April 16, 2003

Dear God - is she still going on about digital cities?

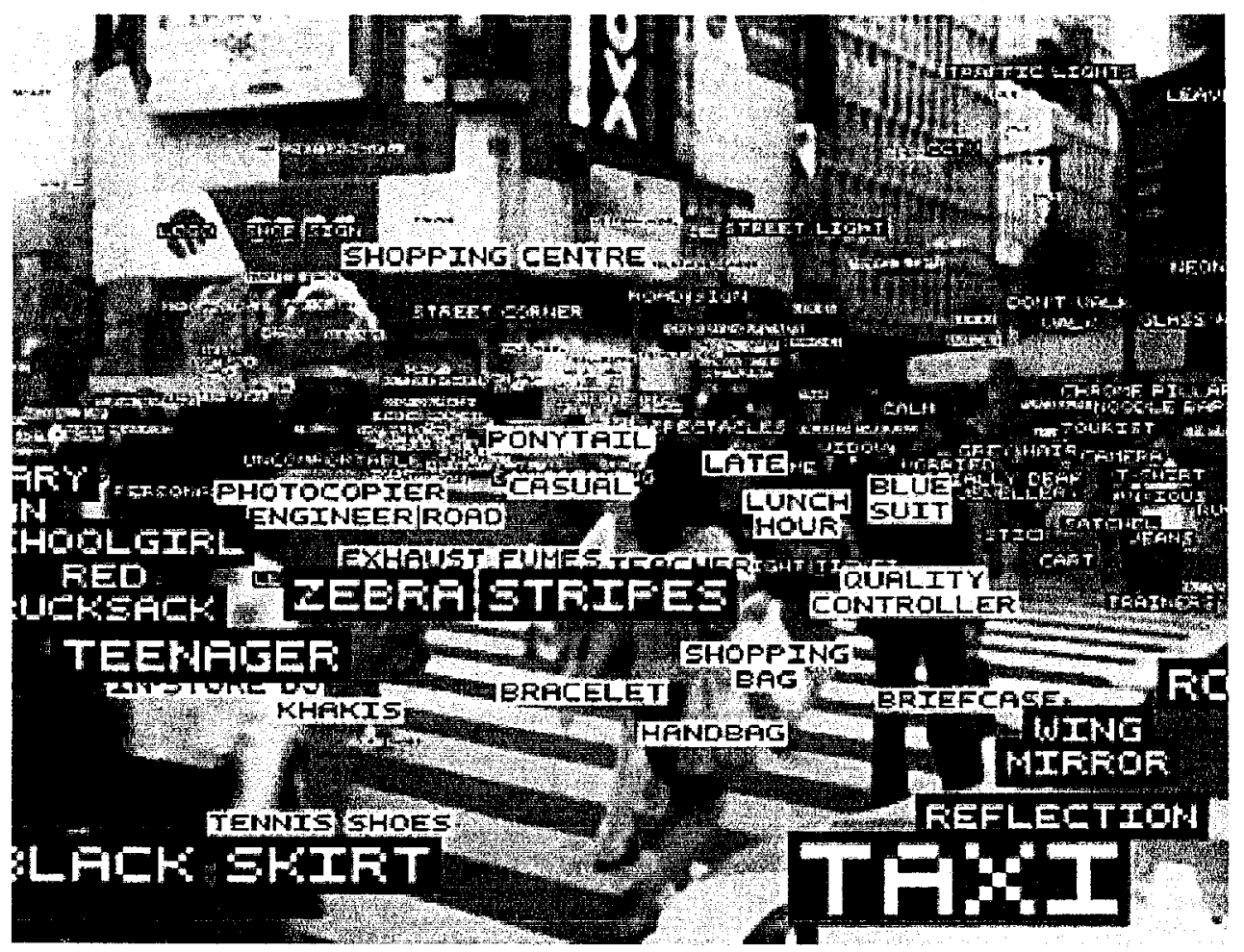

(Photo Fibre Design 2001)

I really like this image. It fits right in with my recent research on digitally annotated cities and the movement of crowds. (I have no idea where I found it - it's been on my hard drive for a few years - so if you know where credit is due, please let me know.)

posted by Anne at 09:23 
http://www.purselipsquarejaw.org/2003/04/ambient-interludes-from-dublin.php

\section{Sunday, April 6, 2003}

\section{Ambient Interludes from the Dublin Cityscape}

A collaborative project of the Media Lab Europe Story Networks group, Texting Glances was designed with the NTRG in Trinity College. 'This ambient 'waiting' game establishes a symbiotic relationship between a transient audience, a waiting place, and a story engine that matches SMS inputs to image output. By incorporating culturally current messaging norms, the audience becomes an active collaborating author in a layered exploration of social familiarity and public space."
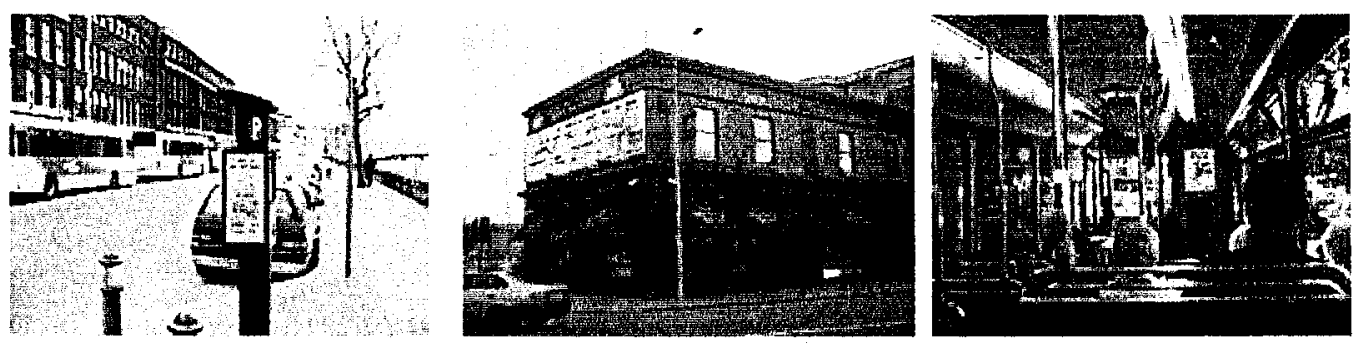

(Photos Vaucelle et al. 2003)

Wow. Between developing a new course and reading Benjamin's Arcades Project, l've become rather smitten lately with the idea of annotated city spaces. This project is very much along the lines of what I envisioned for Amsterdam RealTime, and together with other projects I have recently noted, one of the more appealing shapes of emerging social computing applications.

But the pictures got me thinking that none of these spaces are entirely public. What 1 mean is that the public (masse) are not entirely free to interact with buses or parking meters that belong to municipal government, or buildings that belong to private citizens there are existing restrictions for such social spaces. I'm curious how we might negotiate the actual use of this type of technology, short of as public art projects. I also immediately cringed when I thought about this technology being used for advertising and other propaganda - because even though I imagined being able to talk back, it takes far less effort to delete digital grafitti than it does to whitewash a wall, and I don't imagine a great deal of dissent marking the landscape. Still, the potential is incredible.

posted by Anne at 11:23

I collected highly evocative images from design projects, understanding that entire dissertations could be dedicated to the role of digital imaging in the creation of future computing scenarios. This realisation led me to 'limit' their role in my project to a form of inspiration, where I let myself be moved by these 
images-I enjoyed being moved by these images-but never explicitly theorising or analysing their content.

As time went on, I contacted the research and design leads for six projects across a range of industry, university and non-profit domains that I had encountered by following links online. Besides belonging within the broader mandate to embed computation in everyday life, what all the projects had in common was an interest in exploring new technologies in public spaces (i.e. outside the lab), and collaborating with artists or others outside their immediate fields in order to see how this could be done. None of the projects were producing commercial products, but all were exploring new ways to apply or use emerging technologies. The choice to focus my research on pre-competitive products and the design of future-oriented technologies is a topic to which I return in Chapter 4, but I was first and primarily interested in better understanding how different projects approached matters of space and culture.

In keeping with the perspective drawn out in the previous section, and given my highly subjective and affected perspective as both insider and outsider, I approached all the design projects as potential case histories rather than case studies:

Cases are rarely chosen because they are thought to be representative, but generally because of their illustrative significance. Criticism of case studies should therefore be directed towards their logical consistency and not towards their statistical generality (Mitchell as cited in Jackson 1984:107). 
Cousins and Hussain (1984:3) explain that while a case study "uses evidence governed by the rule of exhaustiveness", a case history, in the tradition of Freud and Foucault, involves "evidence governed by rules of 'intelligibility', denying the natural science project of producing final pronouncements." Furthermore, Freud's interpretations of dreams and Foucault's case histories do not:

accord privilege to the search for origins which function as a point from which a causality and a narrative can be deployed and where elements borrow their identity from their origins. Beginnings are only 'configurations of elements' not origins ... [Case histories] neither 'demonstrate' metaphysical positions, nor do they reconstitute the analysand's past as a [final] 'history'... [Instead they] make a problem intelligible by reconstituting its conditions of existence and its conditions of emergence (Cousins and Hussain 1984:3).

This approach is fully consistent with the kind of situated knowledges, partial connections and partial truths I described above. The question of how to evaluate this kind of qualitative ethnographic research is the subject of Section 2.3.2 below, but it is important now to point out that rather than providing a definitive account of urban computing and locative media that can be evaluated according to its exhaustiveness or generalisability, my dissertation offers a fragmented and incomplete account that invites the reader to assess it in terms of internal intelligibility and illustrative capacity.

Ultimately, four projects accepted the invitation to participate in my research: Mobile Bristol (Hewlett-Packard Labs, Bristol, UK), Passing Glances (Trinity College Dublin and Media Lab Europe, Dublin, Ireland), Sonic City (Future Applications Lab, Viktoria Institute and PLAY Research, Göteborg, Sweden) and Urban Tapestries (Proboscis, London, UK). At the time, most research and 
design in this area seemed to be located in the UK and Europe, and so my case histories came to be located in three countries and four cities overseas. What came to constitute all the materials of these case histories, however, reaches even further. In addition to empirical research, my dissertation collects a variety of related or supporting texts from numerous sources, both traditional academic texts and online publications. How I chose to re/present these texts is the subject of Section 2.3.1 below.

After selecting cases, the next step was to formally articulate a research plan and get ethics approval for my project from the university. I was grateful to have made some connections in other departments, and I was able to learn from their successful applications. When I had a draft, I sought out the advice of the university's Research Ethics Committee coordinator and revised my application as suggested. I officially submitted my application (Appendix 1) and it was approved in the first meeting of the committee, in March 2004. I immediately emailed questionnaires (Appendix 2) to all the project participants and started to make arrangements for follow-up interviews and site visits in May of the same year.

\subsubsection{Into "the field"}

My original plan was to see where the questionnaire responses took me, and to leave "cultural probes" with the participants after the interviews. As I wrote in my project proposal: 
Cultural probes (Gaver et al. 1999) will be used in this project as a playful means for participants to interact with their surroundings and express themselves, and as an experimental and inspirational approach by the researcher. Cultural probes are used by designers to stimulate imagination; the designer takes the role of "provocateur" and the information collected is "inspirational data ... [used to acquire] a more impressionistic account of [people's] beliefs and desires, their aesthetic preferences and cultural concerns" (Gaver et al. 1999:25). Each researcher and designer interviewed will be left with a cultural probe containing one disposable camera and twelve pre-addressed and stamped postcards to return to me within one month of my visit. The camera will be re-packaged to remove it from its commercial context, and to create space on the camera itself for note-taking. Each postcard will ask an evocative, open-ended question concerning mobility, cities, intimacy, play, design and ubiquitous computing.

In retrospect, the probes were the most poorly thought out aspect of my project proposal-however, in my attempt to employ them I effectively entered the second phase of research (cf. Janesick 2003) with my first concrete improvisational move: abandoning this route of inquiry. Upon meeting the participants, all of whom maintained very busy schedules, I decided that asking them to take photographs would constitute a significant imposition that I could not justify and the cameras were never distributed. However, not willing to give up everything at once, I did go ahead with the postcards (Appendix 3). However, after receiving two sets of answers on what kinds of playful things designers did during the day and what parts of the city they preferred, I could not figure out how the information could be used at that stage in my project, and the postcards were also abandoned. Looking back, I think the cultural probes would have been much more useful if I had used them to help select case projects and determine questionnaire and interview questions. I could have learned more about particular research processes at an earlier stage, and used that to guide my direct interactions. Instead, I collected too much disparate information and was later forced to work with far less material than my research generated. 
In the end, by plane and train, I was able to meet with all the UK and Irelandbased participants, but was not able to travel to Sweden as well. I had piggybacked my research on paid-for trips to unrelated workshops in London and Manchester, which were the only means available to me to travel to Europe. With the exception of Giles Lane (Urban Tapestries), whom I had met before, May 2004 marked my first meetings with the project participants and at the time I had no idea how our paths would cross again.

First I visited the Department of Electronic and Electrical Engineering at Trinity College Dublin-I remember thinking it auspicious that there was a large Calder stabile on campus-and met Linda Doyle, who would forever alter my idea of what an engineer could be. I visited the old Guinness Storehouse, which was home to Media Lab Europe at the time and a curious jumble of historical and futuristic elements. I returned to London and cooked risotto with Giles Lane and Alice Angus of Proboscis in their comfortable home, the first of many shared meals to come. I also took the train to Bristol and visited the HP Labs campus, and was overwhelmed the entire time.

EXCERPTS from purse lip square jaw by Anne Galloway

http://www.purselipsquarejaw.org/2004/05/dissertation-dreams.php

Thursday, May 20, 2004

Dissertation dreams

Spent all day yesterday at HP Labs Bristol - interviewing the folks working on Mobile Bristol about things related to technology, space and culture. Quite fascinating really. And quite different from the academics and artists with whom I have spoken for the other case studies. 
With all the interviews now done, I dreamed about a completed dissertation, and it was good.

posted by Anne at 06:00

http://www.purselipsquarejaw.org/2004/05/from-trinity-college-to-media-lab.php

\section{Wednesday, May 5, 2004}

\section{From Trinity College to Media Lab Europe}

Trinity College Dublin is a gorgeous campus. I had tea with Linda Doyle this morning and will be meeting with her post-grad students tomorrow to discuss my research, as well as spending some time interviewing her for my dissertation case study of the Passing Glances project (in collaboration with MLE - Story Networks). I'm off to Media Lab later. Everything is good.

Later: Media Lab Europe is amazing. It is located in the old Guinness building, so it's this lovely combination of old wood floors and rafters, open brick walls and tons of technological devices. It is also full of interesting people doing interesting things. I met with Stefan Agamanolis, who leads the Human Connectedness group, and I'm already looking forward to going back on Friday to talk with some other reseachers.

posted by Anne at 06:22

I have continued to see Giles Lane about twice a year since then, mostly at conferences and workshops. Likewise, I have stayed in touch with Linda Doyle and in early 2007 invited her to participate in a panel discussion I was coorganising for Futuresonic's Social Technologies Summit. However, the only time I had the pleasure of seeing any of the Hewlett-Packard researchers again was at the Pervasive and Locative Arts Network event in January 2005.

Although I never managed a site visit, my relationship with the Sonic City researchers has also been a combination of online and offline interactions, primarily conference and workshop based. I first met engineer and interaction 
designer Lalya Gaye at Ubicomp 2003, where I was introduced to her $\mathrm{PhD}$ research, and knew immediately that we had many shared interests. Lalya and I have regularly stayed in contact, more often as $\mathrm{PhD}$ students sharing our experiences than as researcher and study participant. In August 2004, Lalya joined a panel I organised at Designing Interactive Systems (DIS) 2004 and presented her continuing research on Sonic City. At that conference I also met Ramia Mazé, one of the designers working on the project. I had met Margot Jacobs, the other designer, at an Intel Research Berkeley event the month prior. Neither one was able to participate in my questionnaires or interviews, and both have gone on to do other things, so much of the Sonic City discussion in my dissertation relies on my continued relationship with Lalya Gaye as we both struggle to complete our doctorates this year.

At this point, social scientists may be wondering about the use of names in my narrative. Although my ethics approval depended on ensuring anonymity and confidentiality, the consent forms made provisions for participants to waive these rights, and none of the project participants objected to their real names being used. At the time of the questionnaires and interviews, all the projects had published research online and were well known enough in the 'design community' to arguably make anonymity a moot point. It is beyond the scope of this thesis to draw out all the implications of research anonymity (see for example Wiles et al. 2006) in the era of online communication, but this small example raises issues that deserve to be addressed by social scientists and university ethics committees alike. 
By now it should also be clear that my experience of being in 'the field' included being online and on the ground, and just as in my everyday life, I simply experience these as different but complementary ways of being in the world with others. While anthropologists have thoroughly troubled the place, role and affect of fieldwork (see for example Strathern 1993; Gupta and Ferguson 1997; Marcus 1998; Watson 1999; Anderson et al. 2004), it is worth drawing attention to the fact that more recent online communications further complicate relationships between people and places. While "virtual ethnography" (see Markham 1998; Hine 2000) generally refers to doing ethnography online, references to using collaborative or collective online applications like wikis, blogs and social networking sites to disseminate and discuss research ideas in progress are few and far between.

Being online, for me, was another 'field' for participant observation. In other words, whether posting to my blog, participating in conferences and workshops, or going on site visits and conducting interviews, I was always already engaged in an ethnographic performance with the subjects of my study. I was trying to learn about new cultures, and in doing so I could not avoid shaping them, and being shaped by them in return. These exchanges also shaped and reshaped my research project, right up to and including the act of writing. For example, contrary to what I had anticipated I never got the opportunity to see working prototypes for any of the projects, and that reconfigured my understanding of the objects I would mobilise in my account. Images of the prototypes appear alongside my text but, for example, Proboscis has published enough visual 
material on Urban Tapestries to warrant an entire thesis, and so most images are not addressed in any detail.

My initial interest in intimate and playful technologies became less compelling to me than finding playful and intimate ways to represent my ideas. Not only did that match my experience doing research, but ultimately all I was left with were texts: transcriptions of what the participants said, reports and papers they had written, online exchanges, etc. In fact, the sheer volume of available textual materials on all the projects presented here would have provided sufficient resources for several dissertations without ever doing fieldwork. To further complicate things, it was not until late 2006 that I started to understand that the responses from my questionnaires, and the content of the interviews, was so diverse that I would have to be very selective with them alone just to bring my dissertation topic to a manageable size.

In particular, I needed to separate the content on how designers worked from the content about how designers envisioned urban interaction with technology. After listening to the interview recordings several times and taking notes, I realised that I had too much disparate information for one thesis. I decided that if I was going to be able to focus in any depth on space and culture, then it would be helpful to address only the material I had on Urban Tapestries, Passing Glances and Sonic City. While various Mobile Bristol applications were relevant to these interests, my interviews focussed on Mobile Bristol as a platform for applications rather than on the applications themselves. This made the case qualitatively 
different from the other three examples, and in order to keep my dissertation focussed and manageable, I focus my discussion of Mobile Bristol in terms of broad research agendas.

In keeping with the particular methodologies described earlier in this chapter, I performed selective transcription (cf. Coyle 2002) of interviews with Giles Lane and Alice Angus (Urban Tapestries), Linda Doyle (Passing Glances), and Phil Stenton and Richard Hull (Mobile Bristol). I also selected excerpts from questionnaires completed by Lalya Gaye (Sonic City) and Giles Lane (Proboscis). In addition to these questionnaire and interview selections, excerpts from the projects' websites and published reports, and a variety of web-based publications also appear in my dissertation. Initially intending to explore "a set of relations for resonating with and amplifying chosen patterns" (Law 2004:117), I ultimately found myself with an eclectic collection of information that resisted many attempts at ordering.

In sum, participant observation for this dissertation was seen to informally involve all the conferences and workshops I attended during the past five years, as well as the formal site visits and interviews I conducted with project participants for the case histories. In both cases, I documented my experiences on my weblog, further engaging the participants and others along the way. These short-term visits and the tendency of online publishing to follow the "logic of mash-up culture" (cf. Shiga 2007) presented me with a challenge: How could I 
represent these experiences-these online and offline performances-of mine as a

doctoral dissertation?

\subsection{WRITING EXPERIMENTAL ETHNOGRAPHY}

My intentions then-and now-have never been to dismiss social-scientific writing-but to examine it. My intentions then-and now-have never been to reject social-scientific writing-but to enlarge the field through other representational forms (Richardson 1997:298).

I believe, I see, that the state of things is more like a scattering of islets in archipelagos in the noisy and barely-known disorder of the sea, islets whose peaks and edges, slashed and battered by the surf, are constantly subjected to transformation, wear and tear, being broken, encroached upon; with the sporadic emergence of rationalities whose links with one another are neither easy nor obvious (from Michel Serres' Le Passage du Nord-Ouest, translated in Law 2004:117)

The fragmented narrative can function as political action in many ways: It can resist traditional academic systems, which may acknowledge alternate ways of knowing but nonetheless continue to lock sociological inquiry into normative forms that serve to reify the traditional system itself. It can also open the space for reflexivity for both the author and the reader. A researcher's choices throughout the research process matter, in that they lead to interpretations and subsequent forms of presentation that have persuasive effects. Revealing even a few of the author's choices in the production of social knowledge can open a space for critical and reflexive authorship and reading. Juxtaposition and fragmentation help authors see-through disjuncture-their own habits of interpretation, to reveal, or at least question, taken-for-granted patterns of sense making. Fragments also tend to reveal and, therefore, make available the interstices of reading, so that the reader is not locked into a single line of argument, the form of which is transparent in its smooth familiarity. Multiplicity is made more possible. One must understand that the goals of research may be distinctively different than in traditional research. In fragmented narratives, power is more distributed: The piece can simultaneously make the author's particular set of arguments and allow for alternatives by revealing the practices at work in the interpretive process. In the end, something important about the topic is learned, but the outcome is not completed, controlled, or predicted by the form (Markham 2005:815-816).

Since I was obligated by the university to produce a written dissertation, and my

primary materials were written texts, I knew that I would need to find ways of 
writing sociology and anthropology that would not fundamentally misrepresent my research experience and the worlds I was trying to describe. What I saw was messy, and what I did was messy. My project covers five years, various cities, and an unknown extent of the World Wide Web. It blurred boundaries between work and play, and like much of everyday life, it often manifested itself as glimpses or glances, instead of a protracted gaze (cf. Shields 2004).

Students of cultural studies will be familiar with the use of bricolage in the writing of Walter Benjamin, and his Arcades Project (1999) continues to serve as a wonderful example of what a fragmented narrative might look like. While Bruno Latour (1996) uses a similar approach in Aramis, or the love of technology, where interview excerpts, documents and analysis are interspersed throughout the text in montage style, most work in this area has been done through feminist epistemological critiques of social and cultural knowledge. Accordingly, it is to them that I turned and ultimately found ways that made sense to me-all without altering, or hiding, what I felt and thought about what I had done and seen.

In particular, I wanted to write a dissertation that would be of interest to the university examiners, the study participants and the readers of my blog-and I saw that as possible only if I could engage in more fragmented or experimental writing where trajectories and links were "neither easy nor obvious." As part of the opening quote by Markham (2005:816) explains, 
Fragments...tend to reveal and, therefore, make available the interstices of reading, so that the reader is not locked into a single line of argument, the form of which is transparent in its smooth familiarity. Multiplicity is made more possible. One must understand that the goals of research may be distinctively different than in traditional research. In fragmented narratives, power is more distributed: The piece can simultaneously make the author's particular set of arguments and allow for alternatives by revealing the practices at work in the interpretive process.

\subsubsection{Different ways of reading and writing}

The idea that writing can serve as a form of qualitative inquiry relies on the acknowledgement that all ethnographic accounts involve the crafting of selves (cf. Kondo 1990). As Laurel Richardson (1997:303) so poetically puts it:

I have accepted writing as process of discovery, and writing autobiographically as a feminist-sociological praxis. In the next few years, I plan to write more of these essays, structured rhizomically, the way my life is experienced-lines of flight, whirling whirling skirts of pleated texts. A surprisingly surprising de-disciplined life.

I too want to write "the way my life is experienced" and this dissertation can be seen as a step in that direction. Richardson's (1997) "pleated texts" offer another example of how the structure and content of an academic thesis can be used to make new connections and reach new audiences. Her work can also be seen to stress the politics of location as research is always highly situated in space and time. Furthermore, Richardson (1998) considered writing about one's physical location as a means to relocate the self in research, which takes on new meaning when we consider a mobile or relational sociology. Not only are researchers challenged to identify multiple and shifting contexts, we will inevitably re/position ourselves in the process. By doing so, the experimental writer can also 
be seen to create ruptures in the narrative where others can escape or enter, and surely this is what Kincheloe had in mind when he claimed that bricolage should "uncover new insights, expand and modify old principles, and re-examine accepted interpretations in unanticipated contexts" (2001:687).

In its broadest sense, experimental writing in sociology and anthropology is concerned with "evoking the world without representing it" (Marcus 1986:190), allowing for greater focus on the performativity of research. Recognising that academic definitions of 'culture' always already involve written accounts, since the 1980 s anthropologists and sociologists have increasingly moved towards ways of writing that make explicit, and interrogate, the production of social and cultural knowledge (see for example Clifford and Marcus 1986; James, Hockey and Dawson 1997). Attention to the practices of "writing culture" encourages ethnographers to acknowledge our positions, and pay close attention to the voices we choose to hear, the texts we choose to see, the things we choose to do, and how we choose to re/present all of them. Doing ethnographic research means asking more questions: What are the most appropriate ways to contextualise other voices without speaking 'for' people or 'allowing' them to speak for themselves? How do we best accommodate different perspectives without flattening the field?

Law (2004:117) claims that the "elusive objects" and "fluid results" of a mobile sociology compel "non-conventional forms," and recalling my earlier discussion of bricolage, "perhaps, then, it is useful to think of method assemblage as a radio receiver...a set of relations for resonating with and amplifying chosen patterns 
which then return to the flux." In practical terms this means tuning in to particular frequencies of everyday life, or sampling the spectrum (see Crow, Longford and Sawchuck in press). And, without stretching this sound metaphor too far, I can also evoke 'remix' or 'mash-up' culture in their capacity as recombinant strategies. Both my process (everything up until now) and my product (this text) have sampled materials (sound/image/text/etc.) and I have improvised and attempted to arrange (disorder and reorder) them in harmonious ways. In reading the text, it is my hope that you understand where I am coming from, and find an interesting place to go from there.

In sociology and anthropology, this crafting of relations includes narrative and textual activities, or, in broader and more political terms, matters of voice. In writing this dissertation I want to stay attuned to different contexts and “individuating local intensities" (Gregg 2007). When I took texts as my material I chose to include relatively large selections of other people's words. In terms of voice, I first wanted to see if this could serve as a small act of scholarly modesty. It was, and is, my hope that readers will not get the impression that I have done all this work alone, or that I did it before anyone else did. If not precisely a tribute to these others (people, words, texts) that have accompanied me for years, I certainly want to draw attention to them. If nothing else, I wanted to know if I could find a way to temper the impression of elitism that often accompanies specialised/specialist knowledge? Could I make sociological research appealing to more than sociologists? Part of the answer, I believed, was in often listening rather than telling, and sometimes describing rather than explaining. 
To return to my earlier 'mash-up' metaphor, I would like to underscore that "in the mash-up community, copying [sampling] is inextricably tied to listening" (Shiga 2007:97). More generally, a harmonious song (or text) invites the listener (or reader) to follow progressive chords of movement, or simultaneous pitches, and melodious ones create patterns of changing pitches and durations. The act of listening to both melody and harmony, of feeling the horizontal together with the vertical, is crucial to aural appreciation and aesthetic expression. Here we might recall Sartre's (1947) deceptively simple observation that mobiles-as works of art-"have to draw their mobility from some source," and since their source (the air) is unpredictable, so too are the movements of the mobile and their aesthetic trajectories. Rather than "precision and efficiency," a mobile "weaves uncertainty, hesitates and at times appears to begin its movement anew, as if it had caught itself in a mistake" (Sartre 1947). This is, in part, what makes a mobile pleasing and what makes mobility beautiful.

In a more critical take on listening, Sterne's (2003) notion of the audile technique or "virtuoso listening" asks us to consider that for more than 150 years, practices of listening have encouraged rational and instrumental aesthetics-or what he calls a "a distinctly bourgeois form of listening" (2003:94-95) related to habitus and taste. Without being too cynical, surely we can say the same about reading academic writing? Are we not, especially in the social sciences, expected to produce something rational and instrumental? Are we not, in proving our competence as professionals, expected to present ourselves confidently and effectively? 
Since the 1990 s experimental writing forms have been most thoroughly explored in feminist epistemological inquiry, and can be seen to explore new ways of accounting without losing the rigour of more traditional representations. One impetus behind such experimentation has been to delineate the boundaries of disciplinary knowledge, including the systematic exclusion of affect from rational discourse, and how emotional experience (Ellis 1991) might be re/inserted in the products of intellectual labour. However, implicit in these concerns is a broader interest in questions of authority and who 'gets to speak' in an ethnographic account. If an increasing interest in auto-ethnography (Reed-Danahay 1997; Bochner and Ellis 2002; Ellis 2004) is any indication, then a desire to locate the researcher-self predominates, all the while "eschew[ing] seamless linear stories of coming to 'know' our hidden selves" (Gannon 2006:480).

But there is no reason to limit ourselves just to stories of our selves. Multi-vocal, multi-lingual, and multi-perspectival texts all serve to reconfigure relations between research subjects and objects by including different and divergent voices alongside each other in the text. Related implicit and explicit challenges to authority can also serve to bring this kind of writing into the realm of ethical action. As Denzin (2003:137) suggests, what emerges from-and is demanded by-this scenario are "accountable and vulnerable" writers, as well as "reflexive and active readers." And this returns us to the kind of pleated or layered texts I described above:

The layered account offers an impressionistic sketch, handing readers layers of experience so that they may fill in the spaces and construct an interpretation of 
the writer's narrative. The readers reconstruct the subject, thus projecting more of themselves into it, and taking more away from it...The layered account is a narrative form designed to loosely represent to, as well as produce for, the reader, a continuous dialectic of experience, emerging from the multitude of reflexive voices that simultaneously produce and interpret a text (Ronai 1995:396).

However, Latour (1988:169) argues that explaining how research is conducted and including the researcher in the text does not make a sociological account any more interesting or believable. Instead, he argues for a kind of "infra-reflexivity" that emphasises storytelling, "because instead of writing about how (not) to write, it just writes" (Latour 1988:170). By "replacing methodology with style," infrareflexivity can bring a sort of closure to the 'openness' of a text like this one.

Drawing on these practices and descriptions of experimental writing in sociology and anthropology, my dissertation explores ways of writing and representation that resonate with my experiences as a graduate student actually doing this research. Far from being disorderly, this has resulted in a broadly dialectical re/ordering of text, a playful zig-zig of movement reminiscent of Calder's mobiles that is open to witnessing things according to their own logic. Nonetheless, following Latour (1988) I do not ask that my text be privileged over others, but rather that it be seen to raise questions about authority and explanation. As he so bluntly puts it, "my own text is in your hands and lives or dies through what you will do to it” (Latour 1988:171).

Inevitably this has led me to write with a view to the past, and an active re/construction of that past from the present. As Gannon (2006:483) reminds us, 
"memory writing is not a veridical act that reproduces the original experience as it was lived but is necessarily always constituted from a particular time and place and discursive frame." In other words, while I attempt to tell a story in the present I mobilise things I have written in the past, as well as things others have written. Some of these 'others' are academic, and some are not-but both will be readers. Accordingly, theoretical and analytical discussion can be found here among multiple genres of text-scholarly quotes, survey and interview excerpts, blog posts, news stories, personal reflections, etc.-as well as the occasional image. Some bits are so highly contextualised that a reader can barely tell them apart from my own words. Others are obviously naked, starkly juxtaposed without comment. I have chosen a few stylistic conventions to indicate different kinds of quoted text, but do not mean any one kind (including the academic citations) to be the authoritative account. In other words, it is precisely in their entangled differences that the reader is invited to join.

As I have shown so far, the primary theoretical and analytical text is typeset like any standard academic text. It uses a first-person narrative, and offsets quotes by cited authors and researchers. As mentioned above, many of these quotes are excerpted at length, something I have done for a couple of reasons. Primarily, I see it as a way in which different authors' voices can be heard with only minimal filtering, and their context and relevance can be derived from their placement in the text if not by explicit analysis or explanation. This manoeuvre is related to how this dissertation can be read by, and I hope appeal to, a variety of readers. Furthermore, it is one way in which not insubstantial quantities of academic text 
can be made available to non-academic audiences, in keeping with the implicit commitment of bricolage research to include and explore ways of communicating (including giving access to) academic research outside the university.

But before I get to my discussion of research blogging, and begin to introduce some of the other actors in this performance, it may be useful to offer a few thoughts on the broader ontological and epistemological validity of the approach I take here.

\subsubsection{A note on interpretive validity}

We do not abandon theoretical or critical frames in pursuing evocative provocative effects in the texts we write. Rather, genres and speaking positions proliferate. Texts foreground the dialogic relationship between the self and his or her tenuous and particular social/cultural/historical locations (Gannon 2006:477).

A good ANT account is a narrative or a description or a proposition where all the actors do something and don't just sit there ... As soon as actors are treated not as intermediaries but as mediators, they render the social visible to the reader. Thus, through many textual inventions, the social may become again a circulating entity that is no longer composed of the stale assemblage of what passed earlier as being part of society. A text, in our definition of social science, is thus a test on how many actors the writer is able to treat as mediators and how far he or she is able to achieve the social ... A good text elicits networks of actors when it allows the writer to trace a set of relations defined as so many translations (Latour 2005:128-129).

In order to begin to evaluate an experimentally written dissertation like mine-as well as the broader concerns of a mobile sociology--we may turn to the work of Patricia Lather (1993) and what she calls sociology's "fertile obsession" with validity. She approaches validity not as "epistemological guarantees" but as 
multiple, partial, endlessly deferred [validities that] construct a site of development for a validity of transgression that runs counter to the standard validity of correspondence: a non-referential validity interested in how discourse does its work, where transgression is defined as the game of limits... at the border of disciplines, and across the line of taboo (Lather 1993:675).

This perspective is connected to the feminist epistemological critiques discussed above. Lather challenges academics to listen to different voices and registers, to come to terms with what has long been excluded by making it present. In judging such accounts, she suggests a "nomadic and dispersed validity" that employs

a strategy of excess and categorical scandal in the hope of both imploding ideas of policing social science and working against the inscription of another 'regime of truth' [and] rather than prescriptions for establishing validity in post-positivist empirical work [offers] a forthrightly personal and deliberately ephemeral antithesis to more conventional and prescriptive discourse-practices of validity (Lather 1993:677).

Drawing on Deleuze and Guattari (1987) in ways consistent with the kind of mobile or relational sociology I have presented in this chapter, Lather continues to outline a "rhizomatic validity," where rhizomes are understood to supplement and exceed what order has tried to make stable and permanent. As such, rhizomes (including rhizomatic texts) come to produce paradoxical objects, following growth and not surveying a smooth unfolding. Rhizomatic validity, then, would address what it means "to let contradictions remain in tension, to unsettle from within, to dissolve interpretations by marking them as temporary, partial, invested" (Lather 1993:681). The associated politics of excess, of leakage, of "going too far," bring "ethics and epistemology together in self-conscious partiality, an embodied positionality and a tentativeness which leaves space for others to enter, for the joining of partial voices" (Lather 1993:683). 
Such an approach evokes further reflection and questioning, and suggests that the kind of experimental sociological investigation presented here may be evaluated in terms of its ability to do the same. As Lather would ask, does my dissertation "generate new locally determined norms of understanding"? Does it "work against constraints of authority via replay, multiple openings, networks, complexities of problematics"? Does it "create a questioning text that is bounded and unbounded, closed and open"?

In a later article, Lather continues her exploration of rhizomatic validity:

Adding another layer or fold or pleat...rhizomatic validity asks about proliferations, crossings, and overlaps, all without underlying structures or deeply rooted connections. Here, information is organized like a hypermedia environment, a mapping of potential assemblages, a storing, retrieving, and linking well beyond a mere tracing of descriptive information. Changing the way we organize and communicate knowledge, rhizomatic practices question taxonomies and construct interconnected networks where readers jump from one assemblage to another.

\section{$[\ldots]$}

The textual strategies I have delineated work toward a practice that erases itself at the same time as it produces itself. Such a practice makes space for returns, silence, interruptions, and self-criticism, and it points to its own incapacity, gesturing toward a feminist practice of a double science that works from within a tradition even while exposing what that tradition has ignored or forgotten (Lather 1995:58-62).

This is consistent with the kinds of experimental writing-infra-reflexive layered and pleated texts-I described above, and suggests that part of the validity and value of my argument may be found precisely in its ability to avoid presenting a single voice or point of view that reinforces the false notion that my subject of study is stable and describable in its entirety. 
Following Lather, Richardson (1993) also discusses how to validate the kinds of "transgression" that occur in the multiple genres of writing, personal reflections and critical analyses she assembles in her work. She suggests that her textsperhaps like some of the ones I have assembled here-are "vulnerable to dismissal and to trivialization as commonplace” (Richardon 1993:705) but explains that she "had in mind writing sociologies which displayed how meaning was constructed, and which were helpful to people, and not boring" (Richardson 1993:697) and that she tries "to write sociology that moves people emotionally and intellectually. When successful, the texts violate sociology's unwritten emotional rules. Social science writing is supposedly emotionless, the reader unmoved" (Richardson 1993:706) but I too want readers to be moved.

As an alternative to the exclusion of affective experience, Richardson models what she calls a "feminist-postmodernist practice":

In that practice, one's relationship to one's work is displayed. There is a sense of immediacy, of an author's presence and pleasure in doing the work. Livedexperience is not "talked about," it is demonstrated; science is created as a livedexperience. Dualisms-“mind-body," "intellect-emotion," "self-other," "researcherresearch," "literary writing-science writing"-are collapsed. The researcher is embodied, reflexive, self-consciously partial. A female imaginary, an unremarked gynocentric world, centers and grounds the practice. Space is left for others to speak, for tension and differences to be acknowledged, celebrated, rather than buried alive (Richardson 1993:706).

While the content of my thesis is not woman-centred, it does offer a humble feminist critique of the everyday lives of academics by making our work more transparent and by refusing to claim singular authority or truthfulness. It strives to provide multiple points of entry, evidence concatenations of actors, and 
represent the multiple spatialities, temporalities and embodiments that have characterised my experiences, as well as those of the actors and actions I recount. In this way, my dissertation can also be evaluated in terms of its success as a "map" rather than a "tracing" as defined by Deleuze and Guattari (1983a:25-26):

The map is open, connectable in all its dimensions, and capable of being dismantled; it is reversible, and susceptible to constant modification. It can be torn, reversed, adapted to montages of every kind, taken in hand by an individual, a group or a social formation... Contrary to a tracing, which always returns to the 'same', a map has multiple entrances.

Inherent in this ability to move in and out of my narrative is the possibility that readers can-and indeed probably will-get lost. But rather than assuming this signals the exclusion of the reader or a failure to communicate, it may instead point to the opening-up of new spaces for both readers and writers to try something else.

\subsection{SUMMARY}

This chapter has argued that methodological bricolage is particularly well suited to tackle the indeterminacy and contingency of social and cultural knowledge in the early years of the $21^{\text {st }}$ century through a combination of 'open' and 'closed' accounts. Beginning with a brief introduction to a shift in sociological focus from society to sociality-largely characterised by a proliferation of heterogeneity and ambivalence-my dissertation positions itself within sociological traditions more concerned with processes and relations, than with objects and structures. Put a bit differently, the kind of empiricism I attempt here is not about objects, per se, 
but rather about "active and anthropological projects, full of life...ready to take place in a dramatic story" (Latour 1988:173).

This kind of mobile sociology is seen to compel the mapping of connections and associations, always emphasising situated positions and partial truths. A multisited approach to ethnography was "designed around chains, paths, threads, conjunctions, or juxtapositions of locations" (Marcus 1995:105), and resulted in accounts that were choreographed and performed with others. Grounded in participatory methods, my approach to ethnographic fieldwork attempts to strike a balance between online and offline participatory observation. Not only does this best reflect my research experiences, but it seeks to open new ways of conducting academic research that position our work within the embodied and situated practices of everyday life. My empirical research, in the form of site visits, questionnaires and interviews, is presented in the form of case histories. In contrast to exhaustive and generalisable case studies, the Freudian and Foucauldian case history stresses partiality and internal intelligibility.

Faced with the challenge of how to re/present such an approach as a written dissertation, I turned to experimental approaches to reading and writing found within anthropology and feminist theory. Following Richardson (1997:303), I write here "the way my life is experienced," full of recombinant strategies that encourage listening over telling, and often description over explanation. Seeking to explore ways of re/inserting affective experience into the rational products of intellectual labour, I chose multivocal and multiperspectival accounts presented 
as pleated or layered texts. My dissertation, then, weaves together theoretical and analytical discussion with multiple genres of text: scholarly quotes, survey and interview excerpts, blog posts, news stories, personal reflections, etc. And it is precisely in their entangled differences that the reader is invited to join. By following my zig-zagging paths, and remaining open to understanding things according to their own logic rather than imposing a singular or stable logic to control them, the reader can become an active producer of her own knowledge rather than a 'passive' consumer of academic wisdom.

Given the situated and partial nature of such an account, I concluded this chapter with a brief discussion of interpretive validity. Stressing a critical approach based on the validity of transgression, and a "strategy of excess and categorical scandal" (Lather 1993:677), my dissertation seeks to evoke further reflection and questioning. In fact, part of the validity and value of my argument may be found precisely in its ability to avoid presenting a single voice or point of view that reinforces the false notion that my subject of study is stable and describable in its entirety. In evaluating its success, we can ask if I succeed in creating such a questioning text. Or recalling Latour, is the story rich, interesting and believable?

Continuing along this line of flight, the following chapter takes a closer look at research blogging-and how it can further serve the interests and concerns outlined so far. An integral part of my everyday research practice, my blogging experiences and how I fold those texts into the current narrative provide concrete 
examples of how methodological bricolage and experimental writing in sociology can work together now, and into the future. 


\subsection{RESEARCH BLOGGING}

In this chapter I describe my experience publishing a personal weblog and discuss its role as an integral part of my research process. In the first section I introduce my blog, purse lip square jaw, and provide a brief overview of how it began and what it has become over the past five years. Started in 2002, as an attempt to move my research notebook online, my blog has become a record of my experiences as a PhD student and the most stimulating space I have had for working out ideas. In other words, my blog has been an incredibly strong force in shaping both my research project and what it means to me to be a sociologist today.

Emphasising how blogging is simultaneously private and public, individual and collective, the second section raises a variety of questions about authorship, audience and authority in contemporary academic knowledge production. Beginning with a discussion of blogging and affective politics, I use excerpts from my blog and the comments people made there to draw attention to the more physical and emotional, financial and political, aspects of intellectual labour. They may be excluded from our formal work, and often even from the classroom, but they can nonetheless find a place online-where we and others can engage them in new ways.

The third and final section addresses the question of audiences and publics, and their connection to 'voice' in online academic writing. In my case, the matter of blogging identity has been dominated by what kind of academic I have wanted to 
become, as well as what kind I have been 'allowed' to become. This is related to the reality that, at least sometimes, I did research near but not with nonacademics-which raises interesting, if unresolved, questions about what it means to do sociology through blogging.

Despite these qualifications, I believe it is fair to say that while my blog has proven indispensable as a research method used to forge new connections and try out new ideas, it has been no less successful in cultivating a professional persona and reputation that has likewise benefited me. "Start a blog!" is the first piece of advice I offer to any new graduate student who asks.

\subsection{PURSELIPSQUAREJAW.ORG}

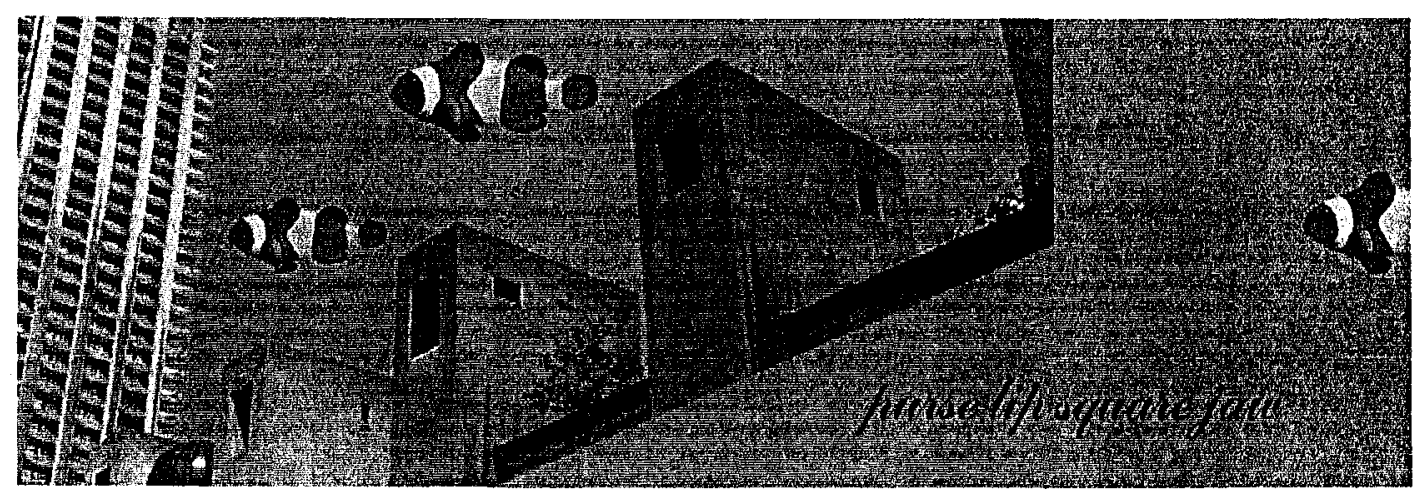

I began blogging in early 2002-five years after the word "weblog" was coined by Jorn Barger, three years after Peter Merholz shortened it to "blog" by suggesting "we blog" (http://en.wikipedia.org/wiki/Blog), one year before the word appeared in the Oxford English Dictionary, two years before it was Merriam 
Webster Online's most searched word, and four years before Time Magazine declared the networked and creative YOU "person of the year."

EXCERPT from jill/txt by Jill Walker

http://jilltxt.net/archives/blog theorising/final version of weblog definition.html

\section{Saturday June 28, 2003}

\section{Final version of weblog definition}

A weblog, or blog, is a frequently updated website consisting of dated entries arranged in reverse chronological order so the most recent post appears first. Typically, weblogs are published by individuals and their style is personal and informal. Weblogs first appeared in the mid-1990s, becoming popular as simple and free publishing tools became available towards the turn of the century. Since anybody with a net connection can publish their own weblog, there is great variety in the quality, content, and ambition of weblogs, and a weblog may have anywhere from a handful to tens of thousands of daily readers.

Examples of the genre exist on a continuum from confessional, online diaries to logs tracking specific topics or activities through links and commentary. Though weblogs are primarily textual, experimentation with sound, images, and videos has resulted in related genres such as photoblogs, videoblogs, and audioblogs.

Most weblogs use links generously, allowing readers to follow conversations between weblogs by following links between entries on related topics. Readers may start at any point of a weblog, seeing the most recent entry first, or arriving at an older post via a search engine or a link from another site, often another weblog. Once at a weblog, readers can read on in various orders: chronologically, thematically, by following links between entries or by searching for keywords. Weblogs also generally include a blogroll, which is a list of links to other weblogs the author recommends. Many weblogs allow readers to enter their own comments to individual posts.

Weblogs are serial and cumulative, and readers tend to read small amounts at a time, returning hours, days, or weeks later to read entries written since their last visit. This serial or episodic structure is similar to that found in epistolary novels or diaries, but unlike these a weblog is open-ended, finishing only when the writer tires of writing.

In retrospect, I suppose I started blogging by updating my personal website-

purse lip square jaw-daily instead of a few times a year. But when I finished the

first year of my PhD programme, and began preparing for my comprehensive 
exams and thesis proposal, I decided to move my research notebook online. I had been reading blogs for a year or so at that point, and noticed that many of them were using an online weblog publishing system called Blogger

(http://www.blogger.com). I knew that if I was going to start publishing my research notes online with anything close to the regularity with which I had always written them by hand, I could not be spending so much time and effort coding HTML and publishing by FTP, and so Blogger seemed like my best option. The decision to use blog software was also an important part of my identification with 'blogging' and I began to see myself as a 'blogger' when blogs I read started to link to mine. Nonetheless, I have always considered myself a writer and researcher more than a blogger, in part because those are identities I have had for much longer than I have kept a blog, and I originally saw blogging as simply another way to do what I was already doing.

In November 2002, purse lip square jaw was acknowledged by Blogger.com as a "Blog of Note" and I became more fully conscious that there was an actual, if mostly unknown, audience for what I was writing. At the end of 2007 my weblog contained almost 2000 individual posts and over 500 reader comments. It has been visited millions of times by thousands of people, and continues to have a regular readership of hundreds. In late 2007, blog search engine Technorati.com ranked the site at \#30 ooo of 112 million tracked blogs, although in the past it was ranked as high as \#19 ooo. Over 500 people currently subscribe to the site's web feed, and online social book-marking site del.icio.us (http://del.icio.us/) lists more than 300 links to the main page, as well as links to over 250 individual 
posts. Everyone from social network analysts to cultural studies scholars could find something interesting to analyse in terms of the actual structure and content of blogs, but in this chapter I restrict my commentary to the role my blog has played in my research.

Like most blogs, purse lip square jaw's content is mostly textual, but images are also posted regularly, video is occasionally embedded, and for a time, audio files (songs) were posted as well. It covers a wide range of personal interests and activities, but primarily I consider it to be a research blog. The first academic blogs I read were Torill Mortensen's thinking with my fingers (http://torillsin.blogspot.com/) and Jill Walker's jill/txt (http://jilltxt.net/). Mortensen is now Associate Professor at Volda University College and Walker is Associate Professor at University of Bergen, both in Norway, but in 2002 they were 'simply' PhD students looking at technoculture from a humanities perspective. Not only did I enjoy reading their blogs because of our shared interests, but after reading their 2002 ground-breaking article on academic blogging I really came to understand my blog as a:

tool for focusing, for exchanging information and being part of a discussion which potentially extends beyond the academic community ... [A] tool with which to think about [my] research, its values, connections and links to other aspects of the world (Mortensen and Walker 2002:250-251).

Most importantly, this sense of blogging emphasised the simultaneously private and public, individual and collective, aspects of blogging-thereby raising interesting questions about authorship, audience and authority in contemporary academic knowledge production. 


\subsection{AUTHORSHIP, IDENTITY AND ACADEMIC AUTHORITY}

Blogs, and other forms of personal home page on the World Wide Web, can be seen to emphasise the presentation of self (Goffman 1959) and performative aspects (Denzin 2003) of writing culture, in particular blurring distinctions between producers and consumers of knowledge, and between public and private as so much personal information becomes publically available online.

For one group of critics, bloggers are narcissists: endlessly remarking, and in luridly public fashion, on what, to this type of critic, is gravely unremarkable: namely, the blogger's own life. And one gets the sense that critics here are reaching to say that bloggers' lives are 'unremarkable' a priori, as if to imply that they've not earned the right to speak so publicly (Cohen 2006:162-163).

Here we might recall that similar criticism has been directed at reflexive qualitative research in general and auto-ethnography in particular. However, far from being entirely new practices, Bolter (2001) reminds us that the Web may simply be "remediating" more traditional autobiographical genres of writing. Chandler (2000) further describes these online performances in terms of bricolage, where an author essentially appropriates or rearranges other materials (images, text, etc.) to continually reconstruct her online identity:

The values of the bricoleur are reflected in the assumptions which underlie specific inclusions, allusions, omissions, adaptations and arrangements ... [This] may seem to suggest that bricolage is a rational, conscious and deliberate practice. But it is seldom like this. Indeed, bricolage lends itself to what may be experienced by the bricoleur as 'discovery' rather than planning ... Especially in a virtual medium one may reselect and rearrange elements until a pattern emerges which seems to satisfy the contraints of the task and the current purposes of the user. Indeed, no version of the resulting text need be regarded as final completion may be endlessly deferred in the medium in which everything is always 'under construction' (Chandler 2000). 
Indeed, I have often understood my blog in archaeological terms, seeing both individual posts, and compiled archives, as stratigraphic profiles. The reversechronological structure imposed by blogging software evokes vertical or accretive processes, but the hyperlinks embedded within each post carve out a seemingly endless horizontal plane. Given this combination of vertical and horizontal ordering, a reader can enter and exit at any point, effectively re-mixing the content at will. In other words, blogs are both linear and non-linear, and 'excavating' them is not unlike the archaeological task of excavation. Rather than being presented with a perfect layer-cake of information, the archaeologist must ask about the natural and cultural processes that have acted to interrupt and disrupt the accretive process over time. So too scholars of weblogs must look backwards and forwards in time, as well as across different time-scales.

To further compound matters, in the case of research blogs, both performance and representation may also be seen to:

straddle the boundaries between publication and process, between writing towards others and writing for oneself. A weblog is always both for oneself and for one's readers. If it were only for oneself, a private diary would be more useful. If it were only for readers, and not a tool for oneself, a more polished and finished form of publication would probably be more appropriate (Mortensen and Walker 2002:256).

In other words, blogs are hybrid genres of performance and representation that are well suited to productively engage equally hybrid research subjects. 
EXCERPT from purse lip square jaw by Anne Galloway

http://www.purselipsquarejaw.org/2003/06/are-scholar-bloggers-public.php

\section{Thursday, June 5, 2003}

\section{Are scholar bloggers public intellectuals? Or do l just write for myself?}

Obviously I see the value of blogging - it helps me keep track of my dissertation research and has allowed me to get brilliant inter-disciplinary feedback. My blog also serves as a type of open field journal, allowing myself, and anyone else who cares to read, access to my broader intellectual and personal interests and influences. This type of activity became hugely appealing to me after reading Malinowski's A Diary in the Strict Sense of the Term - the posthumously published field journals of an anthropological icon. Some anthropologists said that his personal notes should never have been published, not least because they revealed Malinowski to be more than a bit of an asshole, but subsequent scholars have found great merit in these writings for understanding the history of anthropological thought and the production of scholarly knowledge. While I have no desire to either compare myself to Malinowski, or to suggest that my research and personal thoughts are utterly compelling, I do think there is value in exposing myself as I think and work. (As an aside, my research is funded by Canadian taxpayers and I think they should have every opportunity to see what l'm up to. This provides one way, although I remain rather skeptical as to how successful I have been in this regard.)

But blogs are not field journals in the sense of Malinowski's journals; he quite obviously never expected his notes to be published, let alone read by others. They were written as private documents. My blog is not. Many others have noted that one of the primary differences between blogs and earlier forms of personal publishing, like Usenet, is that blogs are inherently moderated by the author, allowing content, tone and general voice to be controlled. In other words, I get to choose which parts of me are made public in my blog. To some extent I can control my image, and those readers who have met me in person are probably better able to judge the "truthfulness" of my self-representation, while others might, after reading my posts over time, decide how much (or how little) they trust me.

The answer to the questions I posed in the post title is "neither and both". Scholar bloggers are not public intellectuals in the same way that French academics, like Pierre Bourdieu, write for national newspapers, or American scholars like Noam Chomsky, make documentary film. A part of me thinks that for a scholar to be a public intellectual, she must be able to offer social and cultural criticism that has the ability to reach the masses and change their minds. But maybe that is too much to ask. Yet, scholar bloggers are public intellectuals in the sense that they may offer access to research that has long been kept from non-academics, in places like journals and closed conference settings. Scholar bloggers are public intellectuals in the sense that they may allow readers to publically comment on their work in progress. And both activities have the potential to change traditional power relations in academic discourse.

But scholar bloggers also write for themselves. Some even claim that their blogs are private (although l've never really understood how that can be so if they are publically available online.) At the same time, they perform particular personas and positions not entirely for private consumption. But, most scholar bloggers do not write detailed 
accounts of their private lives or deepest, and perhaps darkest, thoughts. And, at least in my case, I do write for myself. I chose early on to sacrifice mass readership (as if that were an option!!) in order to write about what interests me and furthers my research goals ... (And honestly, since my position is inherently selfish, I have always been rather amazed that anyone else finds what I write about interesting.)

posted by Anne at 09:16

\section{2 comments}

Biella said...

I have thought a lot of the private vs public dichtomy of blogging and the role of the scholar as blogger too. And there is actually a small relationship between the two for me. On the one hand, I feel like I am creating a very public personacertainly the things I write I via my blog--my blog enteries are not personal in the same way that my private journal is and since blogging I rarely write in the private journal.

But at the same time, one of the things that I like about my blog and those of my friends is that some of the private, usually hidden parts of life are slightly exposed, even if only in a partial, piecemeal, and controlled fashion, the effect of which is that it is hard to reduce a person to "a scholar," "a priest," "a programmer." etc, that is their professional public self.

While those parts (like our professions) of our very public identity are so much part of our identity we can't be reduced to that either or at least we can expose how other parts of lives influence those most public or professional forms of our lives.

So that though I think too that blogs are not personal in the way that my private journal is, I still let bits and pieces of my more closed self whether it is musings about illness or the mundane details of my life out into the world. It is thus a reminder that the private exists, that it is important to our public selves all the while we keep the private primarily not totally hidden.

Anne said...

Biella - nicely put! I hadn't thought to articulate blogs in terms of slippage or flow, but if I understand correctly, that's exactly what you're getting at and I couldn't agree more. Thanks for pushing me in such a nice direction, but now I have more to think about ;)

In my case, the question of blogging identity has been dominated by what kind of academic I wanted to become, and how this has played out in personal and public terms. In terms of authorship, I brought to blogging a pre-existing commitment 
to writing as a method of qualitative inquiry, and so blogging became part of my methodological bricolage. As Richardson (1997:298) asks:

How does the way we are supposed to write up our findings become an unexamined trope in our claims to authoritative knowledge? What might we learn about our 'data' if we stage them in different writing formats? What other audiences might we be able to reach if we step outside the conventions of socialscientific writing?

Blogging very quickly became, for me, a way of being (and not just becoming) a 'good' academic in the sense conjured by Richardson's questions. I blogged, in other words, as a way of exploring how sociology could be done. I saw that the inherently iterative quality of blogging encouraged me to live Foucault's famous challenge:

There are times in life when the question of knowing if one can think differently than one thinks, and perceive differently than one sees, is absolutely necessary if one is to go on looking and reflecting at all ... In what does it consist, if not in the endeavor to know how and to what extent it might be possible to think differently, instead of legitimating what is already known? (1997:113).

I have treated my blog as a place to think out loud, to talk with others and to bring people and objects and ideas together in new ways. Not only did blogging afford a bricolage of my self identity, but also a bricolage of-and for-my research subjects.

As hinted at above, not only can academic blogging be seen as political in its reconfigurations of authorship, authority and accountability, but also in its witnessing of professional development, both of which have been elegantly 
described by Melissa Gregg in her article, Feeling Ordinary: Blogging as

Conversational Scholarship, worth quoting here at length:

It is precisely the 'mid-range' between disciplinary insularism and public intellectual practice that best characterizes blogging ... Blogs reveal the mind of the critic as impressionable and open to persuasion, for the writer is rarely able to sustain the confidence and assurance of a fixed position. Such a function contrasts with conventional modes of academic performance premised on expertise and mastery. It is to admit the hesitancy involved in the difficult task of thinking about the world.

\section{$[\ldots]$}

The participatory nature of writing, response and counter-argument on blogs allows for ongoing debate, critical refinement and thinking-in-process. In this sense, what is rarely acknowledged about blogging is how much it contributes to and mirrors traditional scholarly practice rather than threatening it. One of the main reasons graduate students have taken them up with such fervour is that blogs offer solidarity out of isolation, especially on long projects. They create the conditions for collegiality, brainstorming and frank, fast feedback while also generating and maintaining interest, enthusiasm and motivation. Even the best supervision in the most convivial university department cannot offer this kind of support on a regular basis. The persistence with which established academics condemn blogging as a distraction preventing graduate students from timely completion and participation in their desired career does a disservice to the many instances whereby blogs are utilized as a sophisticated research tool. It also wilfully ignores the wider economic and political circumstances making the potential for a tenured academic career increasingly unlikely for a new generation of graduates.

[...]

Blogs are a modest political tool in that they can help overturn the hierarchies of speech traditionally securing academic privilege ... Blogs allow us to write in conjunction with non-academic 'peers' and 'colleagues' who not only value and improve our ideas but practice their own rigorous forms of assessment, critique and review. Blogs are counter-heroic in that they expose the life of the academic as banal. They help lay bare the fallacy of the ivory tower scholar secluded from the concerns of the 'real world' (Gregg 2006:153-158).

Since this public performance of what has long been private work can be seen as a distinct tactic on the part of academic bloggers, it should come as no surprise that it has been treated as a problem and a threat by critics like the pseudonymous 
Ivan Tribble (2005a and 2005b) in widely-read academic fora like the Chronicle of Higher Education.

Job seekers who are also bloggers may have a tough road ahead, if our committee's experience is any indication. You may think your blog is a harmless outlet. You may use the faulty logic of the blogger, "Oh, no one will see it anyway." Don't count on it. Even if you take your blog offline while job applications are active, Google and other search engines store cached data of their prior contents. So that cranky rant might still turn up. The content of the blog may be less worrisome than the fact of the blog itself. Several committee members expressed concern that a blogger who joined our staff might air departmental dirty laundry (real or imagined) on the cyber clothesline for the world to see. Past good behavior is no guarantee against future lapses of professional decorum (Tribble 2005a).

Popular press and editorial articles like the one above tend to reduce discussion

of academic blogging to career risks and benefits, and connections between

blogging, intellectual labour and collective action have only recently begun to be explored by researchers.

\subsubsection{Blogging and affective politics}

Moving beyond a simple careerist perspective on whether or not to blogarguably of interest only to particular kinds of academics-Gregg (2007) further contextualises early career blogging practices within broader cultural and labour concerns. While some of what she describes may be exactly the kind of "dirty laundry" that Ivan Tribble and his colleagues fear, it also allows for the possibility that the more affective aspects of blogging serve as critique or a 'modest' form of political action: 
For those entering the academy today, the natural order of succession and class reproduction that once applied to their vocation is changing at a macro level. Diminished opportunities for tenure and the casualisation of the academic workforce pose fundamental problems for the model of patronage and initiation that typified the profession earlier.

\section{$[\ldots]$}

That those in tenured positions did little to resist casualisation or the increasingly gruelling requirements for tenure are simmering tensions on many junior faculty blogs. However accurate, this is a genuinely felt generational grievance that spreads beyond the blogosphere. It is directed towards senior scholars who are perceived to have had a less brutal experience of professional advancement and failed to protect this possibility for others.

\section{$[\ldots]$}

Through blogging, early career academics are making this unpalatable condition public. They reveal a fast receding loyalty to the promise that the university life was supposed to offer but does not deliver. Having grown up unable to ignore the realities of economic rationalism on their employment fortunes, these bloggers' experiences of becoming professional differ from their predecessors ... This newly marginalised middle-class professoriat blogs to gain support for work and life choices that they feel have been constrained by wider social pressures; they write to retain a degree of credibility from a sympathetic audience.

\section{[...]}

By virtue of their positions, junior faculty and $\mathrm{PhD}$ bloggers are structurally prevented from influencing many of the decisions immediately affecting their work lives. In this situation, their readership communities offer a form of solace and support as they struggle up the career ladder, while the blogs themselves provide resources for others considering a similar move (Gregg 2007:29-31).

I think that Gregg's account particularly resonates with me because of how deeply I felt my own estrangement and isolation as a PhD student. While I blogged the path my research has taken over the past five years, I also blogged my experience of becoming a professional academic. In treating my blog as a 'room of my own,' I wrote about the difficulties of having to work while studying, about a chronic lack of institutional support, of really not understanding why, after feeling like I had done everything that was asked of me, there were so few rewards in sight. But 
rather than being allowed to wallow in self-pity, these posts encouraged readers to identify to greater and lesser extents, creating a sense of community where none existed before.

EXCERPTS from purse lip square jaw by Anne Galloway

http://www.purselipsquarejaw.org/2006/01/ordinary-madness-of-dissertation.php

\section{Wednesday, January 25, 2006}

\section{The ordinary madness of dissertation writing}

Today it seems to me that this whole business of dissertation-finishing involves no end of completely arbitrary obstacles in utterly farcical contexts. No really. It's like a fucking Beckett play. With bad music.

posted by Anne at 18:34

\section{5 comments}

Finch said...

Perhaps you could convince your committee that you've already finished, because in our age of potentiality the dissertation only fully exists in the moment just before it is realized. Didn't work for me, though.

e-tat said...

Simpatico. Absurd farce it is. Arbitrary too. It may help to read a Zippy cartoon.

Anne said...

Steve - you are so still my hero! And e-tat, it always helps to ready Zippy the Pinhead ;) Cheers

Mathias said...

"...arbitrary obstacles in utterly farcical contexts..." You forgot to mention the humiliation, politics and insecurity of it all. No real words of comfort, unless the fact that you are not alone might help...

Geist said...

It's like fucking Beckett. With bad music. 
http://www.purselipsquarejaw.org/2005/02/on-obstacles-and-small-successes.php

\section{Thursday, February 17, 2005}

\section{On obstacles and small successes}

My dissertation feels further away today than it did a few months ago. My committee is brilliant, but both my supervisor and my primary reader are at different institutions this year, and I've been without my local support network for eight months now and it's really taking its toll on me. Added to that is teaching two classes, which gives me the responsibilities of a full professor and none of the respect or rewards.

I talked with PT yesterday, and he told me I still need to learn to take more joy in my small successes. Like losing fewer than $5 \%$ of the students who originally signed up for my classes. Like teaching courses with no exams that students still bother showing up to every day. Like opening up a new world for just one person. Like finally understanding that one idea. Like being able to apply it to one other idea. Like writing the perfect paragraph. Or sentence. And thanks to some very kind readers, I have also been reminded that what I write here and elsewhere has occasionally been known to inspire.

All of these things are good and true, and I am heartened to know them. Really. But since I feel determined to wallow in self-pity a tiny bit longer, I would like to state for the record that the PhD experience is too often dehumanising and we should be ashamed that we do nothing to deter bright, confident and determined people from feeling utterly alone and defeated.

posted by Anne at 10:34

\section{7 comments}

Pat said...

It reminds me of something that happed a few years back that still makes me laugh when I think about it. I was having an "off" day and came into work, deepin-thought, frowning, etc. One of our homeless residents took one look at me and said, "Cheer up. It can't be that bad." I thought to myself-look-if people who are homeless, on the street are telling you to cheer up, that's pretty bad...

Anne said...

Pat, I'm sure we'd all agree that the self-pity of an over-privileged grad student doesn't compare to the suffering of most people ;)

Susan said...

You inspire the hell out of me!

Christian said...

Take a bit of joy in the fact that people look forward to seeing your thoughts put up here. 
Nui T. said...

I read your page regularly through Bloglines. I hope that the pressure doesn't keep you down for too long. There are these ephemeral distant connections through whom you do matter even if it is not felt directly. Cheers!

Erik said...

I am with you. I find myself more and more identifying with being a grad student as a primary identity, then feeling alone and let down and dumb and hopeless... but it's true that the small successes are rewarding, if you let them be.

Lace Marie said...

l echo Susan's comment above for succinctness, and add my own voice of thanks for the diverse work you do on your blog. The connections you make multiply even when you may not realize it. Rave on!

Granted these posts were written in the dead of Canadian winter, but the highly emotional or affective dimensions of intellectual labour that they evoke should not be dismissed. In social terms, a temporary community emerged that both confirmed and affirmed my experiences. These posts and comments also begin to hint at the reach my 'work' could take online--something that surely could not be supported as easily offline.

EXCERPT from purse lip square jaw by Anne Galloway

http://www.purselipsquarejaw.org/2006/12/heres-rub 05.php

Tuesday, December 5, 2006

\section{Here's the rub}

I'm not usually very tolerant of other people's whining, but damn it, when I've got my own whining to do it's a different story! Feel free to ignore the following, although commiseration is always appropriate in these situations.

Okay. So I really really dislike having to work two jobs so that I can pay for tuition and rent and food, so that I can finish my PhD, and then the two jobs interfere with getting the dissertation writing done, so I end up paying more tuition and still don't finish. I mean, I try not to get upset when people I know tell me how hard it is for them to finish up when 
that's the only bloody thing they've got to do and their entire committee is down the hall.

Try doing it while working two jobs, I want to cry out indignantly. Try doing it after your supervisor and one advisor leave for other universities before you're done! Try doing it alone, with no support! But then I realise that all this makes me sound like a whiny loser, so I keep my mouth shut and fester internally.

posted by Anne at 12:31

\section{8 comments}

MM said...

...those who can afford a position in a virgin or whore dichotomy remain largely unaffected by the consequences, whilst those who cannot are asked to give something up... Don't give up-keep going little salmon!

Collin said...

There are times when I wonder if it wouldn't be better for all dissertators to be in your kind of situation for a semester as they start. My own situation was a little different, but I was a couple thousand miles away from my committee, and teaching 3 writing-intensive courses, as I finished, and because I left my uni before finishing, I had to pony up out-of-state tuition, driving me deeper in debt. I say this not to compare hardships (because I had some really supportive friends and mentors), but in order to say that, later on, when I had chances at summer stipends and a sabbatical, I knew how much of a luxury they were. Struggling through my diss situation made me a much more productive and efficient writer later on. It doesn't make your present situation any better, I know, but I can all but guarantee that the struggle now will pay off in the long run. In the meantime, good luck with your writing...

Michael said...

Forget about there is a reason for everything! I believe from what little i have gathered about you that this is a dream that has been set in motion a long time ago. So stay in motion, keep ur chin up! and know that there are people that love you.:)...And then of course there are people who wonder if there are really people like you who like the way you do with such words:)

e-tat said...

So that's what whiny means, eh? Maybe it seems so to people who are not in the same postion. But from my position, where three part-time jobs don't cover the bills, and the writing veers wildly, unevenly between fine and fucked, voicing such thoughts sounds more like an attempt to gain recognition for the realities of the situation. In your case it's clear that everyone loses if you don't finish, and that whoever makes decisions about deadlines etc. should have special dispensation for people in your position. Do what you can, and let everything else fall by the wayside, including concerns about whether you finish or not. It's much less distracting that way. 
Anonymous said...

Your "whining" - scholarly, reflexive discourse, as I call it - is not lost on many and is entirely justified. Full time job, teaching adjunct at a community college, part-time job every other Saturday, family of four combined with a 37 mile, oneway commute to work all while being $70+$ miles from Univ, advisor etc. If you don't already, read www.phdcomics.com - it helps from time to time ;-)

orange. said...

Dunno--I can well understand reasons to not express material difficulties publicly, but if noone ever did it, how would all the others being in comparable situations know that theres people going fighting through similar oddities? Theres this saying in Germany, geteiltes Leid ist halbes Leid, which won't help you, but which says that you help others-I'm sure. And of course you'll make it.

Anonymous said...

Just take it one day at a time, be forgiving of yourself and stubborn. You can do it!

lilly said...

as a first year grad student, $\mathrm{i}$ love hearing from other people further along. so far, it seems like the $\mathrm{PhD}$ process itself breeds whining from the get go, so i'm sure you're not among the first to do so. ;) i just came across your blog and i really love your writing style. will you presenting any time soon? i would love to hear you present on your research if you will be doing so in the near or not so near future.

http://www.purselipsquarejaw.org/2004/12/student-debt-costs-more-than-money.php

Tuesday, December 14, 2004

Student debt costs more than money

...Right now l'm concerned with how the student loan system disadvantages people as much as it benefits us.

Maybe I shouldn't be surprised that getting a system between governments, universities and corporations to work is easier said than done - but what we have is a mess and I'm not willing to accept that this is the best we can do. Some things are too complicated: we're talking about a system with parts that require paper forms, and other parts that only accept electronic submissions. Other things are too simple: we're dealing with a system that requires face-to-face communication, but prohibits individual people from making decisions and taking action. In any case, we've created a system that places all the responsibility on the borrowers and none of the accountability on the lenders.

It doesn't take a PhD to understand that there is something wrong here and that someone needs to change it. If we truly believe — and our current government says they do - that bureaucratic transparency is crucial in a democracy and that a well-educated population is essential to the future social, political and economic welfare of Canada, 
then we need to seriously and carefully re-evaluate what an education costs, and not just in financial terms. At the end of the day, I'm afraid I will only remember what my government took from me rather than what they gave. And I don't know if l'll be able to live with - and give back to - that country.

Update: I just got news that...this was selected as the CBC Letter of the Day for December 14.

posted by Anne at 10:23

These blog excerpts point to the physical and emotional, financial and political, challenges of being a PhD student and early career academic in North America today. Again, my blog provided sympathetic company and encouragement to continue my course of studies. Being published both on my site and on the national broadcaster's news website, also allowed non-academic readers the opportunity to witness a side to academic life that is sometimes entirely denied, and always hidden in our published work.

But before I overstate the political impact of this kind of affective community, Gregg also recognises the limits of such virtual action and I agree with her blunt assessment:

This collegiality and solidarity that exists in virtual space may yet translate offline to form the basis for real institutional pressure, to create better working conditions for junior faculty. But we would be wise to avoid being too optimistic ... Bloggers who are content to leave their work-related complaints in a virtual realm, disconnected from the agents responsible for their plight, only have themselves to blame for a lack of structural change (2007:31-32).

I should also admit that much of the political manoeuvering that my blog has enabled has been used for personal rather than collective gain. Not quite as bad 
as it sounds, I only mean to point out the kinds of gains that Walker (2006:7)

does in reference to her own blog:

I know that my blogging helped me gain a foothold among researchers in my field, that the regular writing and discussions with readers and other bloggers helped me become a confident writer, and that I had more opportunities to give talks and write in other genres than most of my non-blogging peers. So quite probably, blogging helped me succeed in earning a $\mathrm{PhD}$ and getting my first academic job.

At least in my case, it is fair to say that while my blog has proven indispensable as a research method used to forge new connections, it has been no less successful in cultivating a professional persona and reputation that has likewise benefited me.

EXCERPT from purse lip square jaw by Anne Galloway

http://mww.purselipsquarejaw.org/2005/07/got-blog-no-job.php

Monday, July 11, 2005

Got blog? No job!

I began writing here to keep track of my research and to present some kind of public but personal "field notes" - and it's been an experiment that has paid off in ways I never imagined. If what people have said to me is true, then my weblog has been directly responsible for invitations to present one conference keynote address, moderate and participate in at least half-a-dozen conference panels and workshops, and submit three articles for publication in academic journals and books. It has provided the foundation for a variety of academic discussions and collaborations, and has been instrumental in getting feedback on my doctoral research. l've even seen my blog posts cited in academic publications and as assigned reading for university courses! And if all that isn't enough, my weblog has also provided for an immensely satisfying on and offline engagement with non-academics, interviews for news articles in Wired and The Guardian, and invitations to write for non-academic publications. But all of this feels like bragging, and that's not me. In fact, I think that few of these benefits would have come my way if I didn't reveal some of my non-academic interests and experiences here. After all, I'm a person, not a CV.

posted by Anne at 10:37

The above excerpt was written in response to another academic blogger's call for examples of how blogging had been professionally beneficial rather than

detrimental, as a number of non-blogging academics were publically asserting in 
mid-2005. While the content focussed on what I believed to be 'purely' professional activities, I recall feeling very uncomfortable about posting the equivalent of a résumé for non-academics to read. I felt compelled to remind readers that I was somehow both more and less than those accomplishments, and I was acutely aware that I was both proud and embarrassed to make such a list. Now, I am reminded of how often I have used my blog to discuss precisely those things I was unsure or ambivalent about. Rather than waiting to be certain about what I thought, I have always preferred to treat my blog as a space to think out loud.

\subsection{AUDIENCES AND PUBLICS}

Beyond the affective politics of professional development and identity construction outlined above, blogging's reconfiguration of authorship, authority and accountability does rely on collective interaction, so it seems prudent to ask a few questions. While my blog has afforded me the ability to establish and maintain a sense of camaraderie with people physically absent, what are the temporal dimensions of these connections? Does the immediacy of blogging encourage temporary solidarity, but not long-term relationships? How does that affect what we can, and cannot, do together?

Returning to the claim that my blog serves as a partial record of becoming PhD, and as a method for doing sociology, it is worth exploring in greater depth what kind of scholarship is supported. In terms of sociological research, traditional 
questions about authors and audiences are revitalised by having to account for academic blogging:

Every blogger reckons, sooner or later, with what it means to be 'speaking' to the sometimes anonymous, sometimes chimerical, sometimes homogeneous, sometimes impossibly diverse, sometimes taciturn, sometimes surprisingly large and vocal public that is the Internet. What bloggers do, it seems, is too public (too easily noticed by peevish critics; too easily thought of as pretentious by bloggers themselves), and not public enough (the blogger solipsistically speaking to him or herself; the blogger whose hit count worryingly drops). The difficulty here is due to the fact that blogs sit irregularly between familiar modes of address, never quite addressing a person (dialogue), never quite addressing a crowd (speech, public address), never quite speaking to oneself (diary, monologue, soliloquy)and no one struggles more with this ambiguity, this awkwardness of address, than bloggers themselves ... [B]logs appear to be shifting the balance of personality and impersonality in the operation of publics and in the production of public subjects (Cohen 2006:164-166).

When I write at purse lip square jaw, I never know for sure who is reading. I get some indication of an audience when readers post a comment or send me an email, but I have always understood that the majority of web users-despite the current obsession with online participation-are lurkers. In other words, far more people read my blog than comment on it or email me. But I have also noticed changes in audience over time. Early reader-commenters were mostly in the business of interaction design-mobile and web designers, information architects, etc.-and they shared my interests in technology and social interaction. I have also felt a real sense of online community with other graduate students and junior faculty around research and teaching concerns-and in many ways this virtual cohort has been more influential than my 'real' one. During periods of intense academic writing I have tended to blog less, but more about academic concerns, and as the thesis moved towards completion I had fewer general reader-commenters and more academic reader-commenters. 
EXCERPT from purse lip square jaw by Anne Galloway

http://www.purselipsquarejaw.org/2008/01/plsj-reader-survey.php

Monday, January 2, 2008

\section{PLSJ Reader Survey}

One of the methodological arguments l've made in my dissertation is that over the past five years this blog has provided me unparalleled means by which to engage people in other places, including outside academia.

I found it relatively easy to describe what I think the blog has offered me, and assess what that might mean for social and cultural research, but I'm not comfortable describing or assessing what the blog has been--or done--for others.

I can't speak for anyone else and standard metrics provided by sites like Technorati or del.icio.us act more like citation indices (not always the best way to measure impact) than the kind of anecdotal conversation that is so often central to blogging practice itself.

Analysing the hundreds of comments that have been posted here is one possibility, but I think there's a simpler and more practical option that I hope that you'll be able to help me out with, please.

\section{ALL PLSJ READERS ARE INVITED TO LEAVE A COMMENT HERE DESCRIBING THEIR RELATIONSHIP TOMITH THIS BLOG.}

ANY AND ALL COMMENTS POSTED BY MIDNIGHT 31 JANUARY, 2008 WILL BE INCLUDED IN MY DISSERTATION EXACTLY AS THEY APPEAR HERE.

posted by Anne at 13:56

\section{0 comments}

\section{Darius Kazemi said...}

$\mathrm{Hmm}$. I've been reading your blog for about two years now. I'm not sure what led me here originally--maybe something about psychogeography that caught my eye? Anyway, while I never comment, I've found that I keep reading because I like what you have to say, as banal as it seems. It helps me stay connected to my more academic interests, many of which I don't get to exercise in my day-to-day as a video game developer. Also, I have an emotional attachment to your blog as back in August of ' 06 I showed your Knitting and Politics entry to my girlfriend Dharia, whose reaction in her blog you then quoted in turn in your blog. It felt really cool to have catalyzed a discussion like that!

heyotwell said...

I also can't recall what brought me to PLSJ first, well, it must have been no later than mid-2002? Possibly earlier. I think it was clear even then that you were offering a particular critical and academic voice to a conversation that needed both. Although you weren't able to come to Design Engaged in 2004, you 
suggested including a derive as part of it, which in the end turned out to be the key ingredient. That particular peer group holds you and your work in very high regard, and it was fantastic you could then join us in 2005.

Ms. Jen said...

I have been reading PLSJ for 4 or so years, after I saw Anne either speak at SXSW or Danah Boyd refer to Anne and recommend that folks read her blog. What I like about this blog: Anne's deep thinking but quirky take on life, academia, and her research. This is good. When I was teaching web design and art theory (2000-2005), PLSJ and Danah's Apophenia were a lifeline to me. I also love that PLSJ is striking visually with rich imagery along with the text.

Matt said...

It was odd to stumble, in 2002, upon PLSJ during my first year at Carleton University only to realize that you were not a cyber-person in some far away place, but a student at the very uni I was attending. Since then PLSJ has provided numerous opportunities for me to discover something new, read something provocative, and engage in a live discussion about mobility, tech, theory, etc. Thanks!

\section{Erwin said...}

$\mathrm{Hi}$, I have been reading your blog for some 2.5 years. Probably the main reason why I keep reading it is because it in fact provides a perspective rather perpendicular to my normal one. I find it rather enriching, and thank you for it.

Michael Peterson said...

While your research is quite removed from mine, l've been reading your feed for a long time. I'm interested in space and place, and I have a non-academic interest in technology. As one who teaches and advises graduate students l've also been interested in your comments on grad school and writing process.

Chris said...

Unlike other readers, I *know* how I found your blog: you mentioned Caillois' work in a post, and so few people mention him that it was an instant selling point for me. :) As a game designer, I appreciate input on design issues from outside the industry, where grown ups can occasionally be found... Best wishes!

Darius Kazemi said...

Hmm. Maybe I found your blog through Chris, then!

Peter Merholz said...

I don't know what pointed me to you, but I know when I pointed TO you: http://www.peterme.com/archives/00000317.html

(Christ! It's been over 5 years!) 
After reading this blog and corresponding with you, I had the pleasure of meeting you (and your husband-like person) and enjoying all manner of intellectual discourse. As your studies have evolved, they've moved away from matters I find personally relevant (you used to call yourself an information architect!). Still, I enjoy keeping tabs and seeing how your thoughts are developing, and what French critical theorists' names I can drop to sound smart to Stacy's academic colleagues.

egoodman said...

I have a more ambivalent relationship to this blog than other people, I think. When I started blogging about four years ago, I was in between jobs and travelling around the US. At first it was fun, but then I started feeling really isolated. I missed my friends and colleagues in New York, and didn't really have a life established on the West Coast. I had already started blogging, so reading your blog -- and responding to it - made me feel more connected to a larger community of people thinking and feeling much as I did. On the other hand very ironically - my blogging has fallen by the wayside now that I'm back in school and supposedly doing all this thinking and writing. I'm trying to minimize my time online and have more of a life off-screen. So I don't visit PLSJ as much, because when I read it I end up regretting all the personal (or even schoolrelated) writing I don't seem to find the time to do anymore.

Jamie said...

My notes state that I first bookmarked PLSJ on Dec. 10, 2002. Probably, I checked it out because the research of a close friend of mine had been mentioned therein, or perhaps via a recommendation/link on that person's website. Since then, the site has provided me with a voyeuristic glimpse into certain aspects of life in academia, from the perspective of an observer \& participant whose intellectual preoccupations, cultural preferences and temperament seem consonant with a lot of people I know and like. Moreover, every few months, whenever I Google the search terms of some topic about which I or others whom I read are wondering about, I often discover that PLSJ thought and wrote about it first, better, more informatively and thoughtprovokingly than almost anyone else. Thanks.

\section{Anonymous said...}

I read your blog from around 2003 I think. Never thought of why. Maybe because I like how you make sense in a Brenda Dervin kinda sense. Your blog helps me out to understand who I am and what the world around me is and how to find my way about it. To be more precise, first and foremost is your personality, your attitude, your temperament, judgement. These seem critical for me for information permutations.

Nicolas said...

I think I started reading PLSJ in 2003 when I started a blog (and my PhD). My daily musing on the Internets led me there because of shared interests (mostly locative media/ubicomp at that time) addressed with a different perspective than the one I've been taught (cognitive psychology). I easily remember the moment 
when I stumbled across this blog (and the reading list that spanned from Deleuze to William Gibson or Paul Dourish), which made me realize that I was not lonely in seeing certain connections. PLSJ and Anne's work contributed to making me realize that there are other approaches to dealing with the implications of technologies - mostly, through Anne's perspectives and the references she brought forward.

Sister said...

I think l've been reading your blog for about 3 years. What brought me here? It was probably either someone else's blogroll or a search for sites about technology and culture. What kept me here? I find most of your posts offer challenging ideas and/or interesting thoughts that I don't see elsewhere. The others give a peak into graduate student life. Why didn't I comment until now? I'm a librarian now but once studied sociology, and l'm a soft-touch for anyone trying to get a good sample of survey respondents.

\section{A.S. Galvan said...}

I don't remember how exactly I found PSLJ. One constant in my academic interests was an unwavering devotion to the study of paradigm shifts and if Kuhn's idea could genuinely be applied to social science. I probably found you through some search terms no less than 3 ? 4 ? years ago.

One thing I've loved about your blog is that it's hard. I always find myself chasing down links and learning new concepts when I come to visit.

While you don't write about it very often, l've read an entry or two dealing with a sense of frustration with the process of actually getting a ph.d, but you've continued to push through rather than give up. I've been cheering for you for years, for all of us in spaces like that.

I find something like home here, also, in that I had a hard time finding my niche as an academic. I agree with what's already been written that your work seems to voice something long silent. This space has given me great encouragement and hope: I too can study things that might be "fuzzy" to others and help give them focus.

\section{Lynn V. Marentette said...}

Anne, I just found your blog today through a "google alert" e-mail about ubiquitous or pervasive computing. I posted a link to your blog from my Technology Supported Human-World Interaction blog. I'm a school psychologist who returned to school at mid-life to study computers and technology. Last year, I took a graduate Ubicomp class, which inspired me to consider doing research in this area. I don't know why your website never popped up during all of my internet searches over the years, given our similar interests. I'll take some time to read through your posts!

My other blogs: 
Interactive Multimedia Technology

Tech Psych

(I started blogging because it was a requirement for a class, and I never stopped.)

linda said...

I hesitated slightly before I wrote this. Blogging might be public but reading one is more private.

I first came across this blog in 2003 , when I was doing research on ubicomp for a course essay. Since then it's been a constant source of inspiration in my own work. I'm an anthropologist myself and we seem to share a lot of research interests and play with some of the same thinkers (such as Deleuze and various STS people). In your posts you've often nailed a thought or argument, which l've been wondering about myself.

I think I also immediately felt "at home" because I recognised a certain anthropological tone in your blog posts. I don't know what it is, but there is something about how anthropologists approach the world, which is instantly recognizable no matter what their research topics or analytical preferences are. I study at an institute where few people do research on new technologies. At times, where l've felt alone and isolated in my everyday academic life reading this blog has reaffirmed my belief that this is a valuable area of research to pursue.

Crab Man said...

disgracefully - an occasional scavenger who always finds something wonderful to slip into a mind pocket - this time the many layers of paint on the single paint chip - reminds me of those Parisian artists who first described the democratic art of posters sites, with layer after layer torn and exposed and accidentally juxtaposed

John said...

Anne, Fascinating to follow this project through, occasionally checking in for the past few years, ever since meeting you at the UChicago DGI Conference. Actually, I think of this as a "model" academic blog. With every visit, I find something thought-provoking, touching on common interests, but from a very different perspective. Good job and thanks.

Zach Chandler said...

I used to read PLSJ sporadically, was inspired by your wonderful mix of thoughtprovoking academia and personal bits. Now I visit extremely rarely, am somewhat post-blog, paralyzed by RSS-aggregator overwhelm, watching the number of unreads reach their max in every category. I may have been happier (more curious?) when I knew less. 
Perhaps most intriguing to me is how particular people only commented when I explicitly requested it. With several exceptions, most of the people who responded to the above post were commenting for the first time. In other words, that particular audience was almost completely unknown to me for up to five years-and arguably did not even exist as an audience until my post compelled it. Furthermore, despite their coming together on my blog, it would not be entirely accurate to consider this audience part of the community I described above, and which could be considered my co-authors or subaltern authors (Quiggin 2006:483). Sonia Livingstone (2005) draws out some differences between audiences and publics that are relevant here. Recognising that publics are increasingly mediated technologically and discursively, Livingstone (2005:11) suggests that an audience constitutes a public when it ceases to be an aggregate of individuals and becomes a collectivity that engages with texts beyond the moment of their initial reception. By this definition, my blog has multiple audiences and multiple publics, although the question of participation remains unclear.

\subsubsection{Blogging and voice}

Jill Walker (2006) identifies three kinds of academic blogs: public intellectuals who use their blog for political debate, research blogs (including student blogs) and pseudonymous blogs about academic life. According to this schema, purse lip square jaw would be located between a public intellectual blog and a research blog, or in what Walker (2006:5) refers to as a hybrid genre, "the blog that both discusses the content of research, the ideas themselves, and that also discusses 
the process and experience of researching." Such a description of blogging recalls my discussion in Chapter 2 of participant observation, where blogging emerges first and foremost as a way of doing social and cultural research that combines both online and offline activities.

EXCERPT from jill/txt by Jill Walker

http://jilltxt.net/?p=184

June 6, 2003

Not documenting, doing

Yesterday 1 agreed with Lilia that most researchers' blogs don't document research. Today while reading a post on David Weinberger's blog I realised that that's completely beside the point: research happens in blogs, and in the conversations between blogs. Blogs aren't about documentation, they're about doing, thinking and discussing. And they're about catching fleeting thoughts and making them explicit: if I hadn't blogged my response to Lilia yesterday I probably wouldn't have thought about David's post today as research and wanted to rethink yesterday's ideas as I'm doing now.

Of course blogs can be used as documentation as well, they can be used for almost anything I suspect, but I don't think documentation is the most interesting aspect of blogs in research.

Just as anthropological fieldnotes create culture as well as they describe it, blogging can be seen as a kind of performative assemblage involving multiple subjects and objects: multiple researchers, multiple audiences and multiple publics.

EXCERPT from purse lip square jaw by Anne Galloway http://www.purselipsquarejaw.org/2003/06/weblogs-as-liminal-spaces.php

Monday, June 30, 2003

Weblogs as liminal spaces 
Below is the abstract I submitted for the Into the Blogosphere CFP I mentioned last week.

\section{PERFORMING THE PLACES IN-BETWEEN: WEBLOGS AS LIMINAL SPACES}

We can view weblogs as enabling revolutionary possibilities for communication, or as merely the latest iteration of more than a decade of online self-publishing. However, following post-structural approaches, and especially those of Deleuze and Guattari, we may shift analysis away from such totalising explanations or representations, and towards notions of decentralised performativity and relationality. This shift forces us to examine the spaces in-between which have traditionally been glossed over as void. Historically, anthropologists have referred to the spaces in-between as liminal spaces, thresholds or transitions from one state or space to another. Accordingly, liminality has been understood to perform boundaries, as well as beginnings, becomings, and similar forms of cultural transition or mobility.

This paper applies notions of performativity and relationality to articulate weblogs as liminal spaces, or spaces of flow. In this way, weblogs may be understood as sociotechnical assemblages that negotiate relations between virtuality, actuality, distance, proximity, past, present and future. In other words, weblogs create particular spaces and times in which social activity may, and does, occur. Taking an auto-ethnographic approach, this paper examines the author's own weblog as a social and technological space between online academic and design communities, where boundaries between subjects are blurred, and both individual and collective meaning and identity struggle to emerge. In particular, this paper addresses the role of comments and archives in delineating specific spaces and times of interaction while also creating what might be described as the never-ending weblog.

posted by Anne at $12: 57$

I never ended up writing that paper, but I had wanted to write about how my blog was a space between my Master's and my $\mathrm{PhD}$, between sociology, anthropology and design, between private and public, individual and collective. I saw, and still see, my blog as a space of becoming. What I did not appreciate until recently is the extent to which blogs can serve to bring particular publics into being-and how that impacts not just who the researcher can be but also who can join the audience, or form a public, what the researcher writes.

When people complain, as many do, that intellectuals are not writing clearly enough, their yardstick of good style often turns out to be not just grammatical or 
aesthetic but political. After all, they do not want elegance of just any variety ... They want language that will bring a certain public into being, and they have an idea of what style will work. The question of style, at any rate, entails a worry about the nature and duties of the intellectual (Warner 2002:129).

EXCERPT from purse lip square jaw by Anne Galloway

http://www.purselipsquarejaw.org/2006/04/i-changed-my-mind-autoethnographic.php

Tuesday, April 11, 2006

I changed my mind: an autoethnographic moment

... Online/offline conversations about my research interests with so many non-academics had forced me to try new ways of communicating, and the role l'd most often felt compelled to play is what I call the "good academic". You know, against the Ivory Tower, for the People. I believed that anti-intellectualism didn't exist among intelligent people of any class. I believed that we could - and should - forge common ground. But over the past several years l'd become particularly sensitive to accusations of elitism or arrogance, which are never pleasant but have particular effects if you're a woman. (What passes as confidence in men is still too often perceived as arrogance in women. And even when men are considered to be arrogant, strategies of dealing with the 'problem' are significantly different than dealing with arrogant women. Add to this more individual or idiosyncratic masculine and feminine reactions to intelligent and powerful women, and the situation can get quite messy.) In any case, I believed that accusations of elitism or arrogance indicated my failure to be a "good academic" and undermined my status as a "good woman"....

posted by Anne at 11:26

Returning to matters of voice returns me to the politics of academic blogging, and to what kind of academic I find myself becoming. The most rewarding, and the most painful, blogging experiences have been the reactions of non-academics. Mostly, I have had the pleasure of an audience so supportive that a word like community better describes my relationship with them. But I have also been insulted, and expressly dismissed or excluded. Often readers miss my point, or I fail to make my point, and we talk past each other. More positively, I have been taken to task by intelligent people and I have been forced to 'get over myself.' I 
have been compelled, and perhaps even expected, to find a particular voice on my

blog. Not the voice of authority, but nonetheless a voice of expertise. A critical,

but not too critical, voice. Not an entirely casual tone, but still a friendly or

convivial one. And never, ever, a voice that falls prey to 'academic-speak.'

EXCERPT from Adaptive Path Blog by Dan Saffer

http://www.adaptivepath.com/blog/2006/10/16/saving-situated-technologies-andubicompl

Monday, October 16th, 2006

\section{Saving Situated Technologies and Ubicomp}

I have an interest in ubiquitous and situated computing, thus I was pleased recently to lurk on an email list about the topic, which as I quickly found out was almost entirely populated by academics. And...wow. Not only did most of the talk go way over my head, most of it was nearly a parody of academic speak. A sample:

You mention the "current status of the material object [and] forms of embodied interaction" and l've often thought about this 'return' to the body and the physical after the (failed?) promises of cyberspace disembodiment. In other words, I see a kind of re-embodiment ethos at work right now in research, art and design practice, and a re-newed commitment to the material. In some ways, then, it seems that the pendulum of technological desire has merely swung to the other side.

Me: Unsübscribe.

Now, it's of course entirely unfair of me to pull a random quote out of context like that (No offense to the author, whose work and writing l like and follow.), but there's a lot of discussion on this topic that is like that. Looking over the speakers of this week's Situated Technologies Conference and the recent Ubicomp conference, one couldn't help notice the number of high-level talks by academics with titles like Exurban Noir and Deconstructing Networked Infrastructures and Experience.

This is probably to be expected, I suppose. Most of this stuff is fairly theoretical right now, so it should be no surprise that the talk about it is also theoretical. But still. The discussions around ubicomp and situated technologies remind me of the academic papers from the late-1980s/early 1990s in which computer scientists and $\mathrm{HCl}$ folks (i.e. the $\underline{\mathrm{CHI}}$ crowd) were discussing and creating their own (fantasy) world of what a global, hypertext system might be like. There were all these fantastical systems of what a hyperlink might look like and such. And of course, the internet came along (and, to an extent, hypercard before that) and utterly ruined their theories and went in totally 
unplanned directions because, for the most part, it wasn't built by academics. So it will also likely be for the world of ubicomp.

What l'd like to see is practitioners take ownership of ubicomp and situated technologies. We can't have the voices speaking for them only be coming from the ivory towers.

Those are my words Saffer refers to and, to be honest, I was quite annoyed when I first read his post. But this example is illustrative because a designer took an excerpt from an email I sent to an academic discussion list and posted it 'out of context' on a design blog. This blurring or crossing of domains is so prevalent in online discussion that, arguably, all contexts are 'in' and tensions are inevitable. As someone trying to become a 'good' and 'responsible' academic, I wondered if I could not get away with using specialised language with an 'academic' audience, then when and where I would ever be able to use specialised language? I had also noticed that sociological or anthropological language was considered more egregiously exclusive than other kinds of technical jargon that regularly appear in blog posts-or at least amongst authors that defined themselves in opposition to, or in competition with, academics-and I was unsure how to proceed. This matter of using 'proper' voice further confuses audiences and publics, and the rest of this chapter will try to unravel some of these connections. After all, online interactions like the one above seem to indicate that, at least sometimes, I did research near but certainly not with non-academics. And this needs to qualify any claims of collective or collaborative work I attempt to make here. 


\subsubsection{Blogging as collective and collaborative work}

Warner (2002) describes a public as a self-organised relation amongst strangers, constituted through attention, including the social space created by the reflexive circulation of their discourse, and as Cohen (2006) notes, this is exactly why blogs can seem so personal and impersonal. Again, by this definition, purse lip square jaw's spaces of interaction and audience are indeed public. In fact, I would suggest that over time multiple publics and counter-publics (cf. Fraser 1992; Warner 2002) have congealed and dissolved around particular issues, demanding different modes of discourse and shifting worldviews. For example, when I upheld a sense of public more interested in the fate of all people, I was met by a counter-public that sought to be heard in the particular, demanded to be addressed as such, and never spoken for. Conversely, when I spoke in particulars that would associate me with $a$ counter-public position, I was challenged to make it generalisable for the public. One of the implications is that when it comes to interaction between academics and non-academics, there is actually no such thing as 'proper' or always appropriate voice either online or offline. It is always already a negotiation.

I have been taught to be aware of academic privilege, but nowhere in my education have I felt as accountable as I do when I blog. Recalling Gregg's (2007) comments on the politics of academic voice, and the examples above, perhaps it would be more accurate to claim that I am held accountable in different ways by different publics. Academic readers expect something different than nonacademics, and my dissertation readers may not read my blog at all and simply 
expect me to exclude it. For example, I remember one of my committee members reading parts of my thesis and advising against the inclusion of online writing that contained "inappropriate" language. Although these concerns are reasonable and were voiced with the best intentions, I maintain that self-censoring is not a better solution. I believe that it reinforces boundaries around 'proper' (i.e. rational) academic speech by excluding affective experience and vulgar (i.e. common) communication. In other words, whatever political force my blog may have would be significantly diluted if its content were denied a place amidst the 'real' work of dissertation research and writing.

EXCERPT from purse lip square jaw by Anne Galloway

http://www.purselipsquarejaw.org/2005/02/rant.php

Wednesday, February 23, 2005

\section{RANT}

No sadness today. No self-pity either. Just sheer anger.

(Mum and Dad, please stop reading now because I know the language will be unacceptable.)

Due to circumstances beyond my control, l'll not be able to defend my dissertation by the end of the term. This means l'Il need to register for the spring/summer term (and, of course, tuition increases in May) and then defend by the end of August. But my teaching contracts and SSHRC funding run out at the end of April. And even though I have guaranteed university funding for September - when I had hoped to no longer be a student - they won't pay it out over the summer when I will be a full-time student. So not only am I about to lose all my income, but I will have new bills to pay and full-time unpaid work to do.

What the fuck am I supposed to be learning from this experience?! I've been taught how to develop and use the most precise ideas and language to explain and critique these sorts of situations, but every step of the way they remind me that there's little I can actually do. It's like being forced to take it up the ass and then sweetly say "Please Sir, can I have some more?" Fuck them. I fucking hate this shit.

posted by Anne at 16:11 


\section{4 comments}

Chris said...

I'm so sorry. It is absolutely unfair and unjust. From my experience, the first impulse is to give up and move on. But you have too much to contribute, too much real work to do, to think about alternative careers. We who read your blog know and see your passion for the work. That ought not be taken from you.

molly said...

damn it, anne. i'm sorry to hear this. you are so ready to be done, you deserve to defend it and start the next phase of your life. you really do.

Steff said...

Very sorry to hear of these unfair complications. The administrative and bureaucratic elements of a university are, of course, adverse to learning \& critical discourses. If it wasn't for the students universities would run smoothly, is their unconscious thinking, I assume. Hope you can find some funding for the interregnum months, and finish your diss. in spite of these Kafka-type obstacles. Prolly best not to want to complete out of spite, but for a more pure sense of selfgratification? It's only fair to fucking hate that shit, though.

Daniel said...

Suck. I second Molly's comment. I'm immediately trying to think of solutions...my nature. They'll only fund you in the spring/fall?!? Obviously taking a break is not doable. How can we get you $\$ \$$ over the summer? I don't have enough info to process further. If you want to soundboard though, feel free.

Rex said...

YES. I am right there with you - we are even defending in similar time frame. This sort of thing is utterly ridiculous and yet also totally common. Funk them. Sympathies.

Janice said...

Leave of absence- take one! Then re-register in the fall- take the funding- defendand drop out of contractual obligations. See- you too can stick it to the man!

Lalya said...

$F^{\star *}$ king hell! Why does the administration have to be so bloody stupid? I'm so sorry, Anne. Don't give up though, you'll find a way. Is there anything we can do, like sign a petition or anything? 
Laura said...

I like to read your blog very much!! And I agree with what $u$ said about academe: anyone can mess with anybody at any time, and the messee has no or little recourse. I saw that happening, when I was in graduate school. I got my MA in economics after doing literature and various languages as an undergrad. I saw the messing, and I decided NOT to go into academe. I was considered very promising Ph D material, both in comp lit and in econ, but, no thank u! I work for a finance firm and am left alone to do my job! I do it very well. (I'm also married, have one daughter and another one on the way. My job doesn't own me, as it does in academe.)

Linda said...

My sympathies that totally sucks ! l've had a day of disillusion concerning administrative academic stuff as well. Grrr!

tV said...

You know Anne, I always wondered if behind the clean and cool presentation of your work there was something boiling -- and now I know. Good to hear you write the word FUCK. I hate bureaucracies. You are always welcome to become mired in the sheer insanity of McGill, if you'd like, which is byzantine to the end. Time to pull out the barista apron. Good luck. I didn't get paid from a certain large government grant for_6 months_. I became very angry, broke and depressed and was STILL expected to be doing the work as demanded-and often insisted with a complete lack of tact or understanding--by certain academic upholders of the bureaucracy. This was recently. Luckily there were also a few sweet souls who understood. So I am right there with you.

Anne said...

Thank you. I'm sure everything will be fine in the end.

Irina said...

I'm so sorry to hear this. I second (almost) everyone's comments. Strength from the other side of the Atlantic!

Tom said...

Yes, indeed, that sucks big time. I'm sorry that's happening to you. It is unfair and undeserved. For what it's worth, when I was in grad school, there was a particular class they made me take that I knew I didn't need (I was already teaching the same subject at another school). I protested, but of course that didn't work. So I took the class, and at the first class meeting I met the woman that I went on to marry. So it worked out OK. Here's hoping something good comes out of this for you. Please keep blogging. 
Steve said...

Barl. I'm sorry to hear that, Anne - I hope you can bang some sense into them.

My mother was the first person to post a comment on my blog. I had just installed a separate commenting system to work with Blogger, which at the time did not support comments. Within half an hour of getting the system working, my Mum had posted a note telling me she loved me and was proud of me. I had no idea that she knew I had a blog, let alone read it, and from then on I have written assuming-sometimes even hoping-that my parents are reading. To this day they occasionally leave comments on things they find interesting, although Mum tells me in person that she has a hard time understanding what I write. For some reason, this bothers me far more than do purposely anti-intellectual insults.

But this business of thinking and writing together-with others-still seems tricky to me. It may be collective, but it also strikes me as an iterative kind of collaboration where relations of reciprocity are complex.

EXCERPT from purse lip square jaw by Anne Galloway

http://www.purselipsquarejaw.org/2006/04/at-what-point-does-collaboration-cease.php

Friday, April 28, 2006

At what point does collaboration cease to be reciprocal and simply become appropriation?

When I started blogging my research four years ago, I remember running into other academics both online and offline who thought it wasn't a good idea to share my findings so freely. I remember thinking how sad it was that they were so attached to the idea of intellectual property and their own career advancement. I've since abandoned such selfrighteousness, but stand behind my desire to be the kind of academic who shared 
everything - what I read, what I thought, what I wrote.

I wanted other academics to borrow and build on my work. I trusted them to give credit where credit was due, to return the favour by sharing their own research. And you know what? They did. They do. I haven't lost control of my research and I've had the absolute pleasure of getting to work with, and learn from, some really incredible scholars. But I didn't start blogging just for other academics. I had lofty - if terribly naive - dreams of becoming some sort of public intellectual. I wanted to exceed the fortifications of the Ivory Tower with every post, damn it! I wanted to give back as much as I could to the people who had funded my research. I wanted to be held accountable.

I especially wanted to learn from non-academics, and share with them what I had learned from my own encounters. I was attracted to the cultures of collaboration and sharing I witnessed online. I found kindred spirits and made friends who have been instrumental in shaping my thinking and writing. It's been good, for sure, but I've also learned an important lesson: not everyone understands or values reciprocity in the same ways. In other words, not all sharing is created equal. At first I thought it was simply a case of some people taking more than they give. But now I think it's more than that: I think it's a cultural difference.

I've written many times, here and elsewhere, that I question the kind of reciprocity at work when a small group of people profit from the work of many others. (And don't even get me started on individuals who profit from the not-for-profit work conducted by academics and others, and that includes accumulating and leveraging social capital from recommendations and the like.)

In the past I would have considered these things amongst the ill effects of capitalism, but now I think it's a bit more complicated than that. After all, some of this labour is actually being done for free. Out of love even, like with Flickr or any number of mod communities. The DIY ethic, in fact, is based on the power of creative re-use and re-appropriation. But these terms are now being tossed around in software and hardware development like organisations and companies only care about democratic participation, and not profitability.

Jean Burgess knows much more about mass amateurisation and vernacular creativity than I do, so I hope she can help me out here: At what point are labour and love exploited? When does collaboration become appropriation?

posted by Anne at 07:37

\section{8 comments}

Rob said...

New Term "Venture Academic", as in venture capitalist: So I go to a meeting about generating a collaboration, a "collaboratory" - we have to talk about this term - concerning interactivity and the arts last night and rather than talk about collaboration we were confronted by very enthusiastic proponents of individual projects - what one astute participant outside called "a set of business plans". These were all products in the making - with all the pros and cons to that. So being invited to make a "pitch" for inclusion I reflected on what this might mean 
for the process of academic or arts grant applications which have become a feature of arts faculty life in so many countries and also what it meant in terms of the doing of "research" - and whether research was even possible. In Anne's terms, there was a good sense of "play" in the room, but play between individuals and code, not amongst a group other than the sort of play that gets going between authors and audiences or entrepreneurs and bankers.

Chris said...

Personally, I find you to embody the model of where I wish all academics could be - open, honest, community-integrated. Hell, you even wet your toe in the ongoing nonsense of my blog. Now that's dedication to community! :) If more academics were like you, I wouldn't have left academia after my Masters degree. But, sadly...

Mathias said...

While direct collaboration may not spring from this blog (l dont know) dont forget to take into account the impact on a larger group. Your writing forms part of a larger voice of online writers. By promoting openness you help and form others to do the same. So while this is not direct reciprocal benefit it is, indirectly, creating a better place (wow, that sounds very naive). My real blog is Wrote. Keep writing!

mary said...

In a very coincidental (or maybe synthetic, or maybe numinous) way you've said what l've been thinking for the last few days. You've described it much better, though. "The point" is "when a small group of people profit from the work of many others," whether or not that is social or material profit. And how and where this occurs--academia, profit, not-for-profit--is *beside* the point. There is so much in this. Collaboration is a system, yes? Like capitalism. But social status is the cash. Great, great post. Too bad you already have a PhD thesis.

jean said...

There's a whole thing about researchers or designers collaborating with their constituencies and/or with Big Business on behalf of their constituencies, usually in the name of participatory something-or-other. I work in a research culture where such collaborations are highly valued, which is both a welcome challenge and fraught with ethical issues, and I guess I have the same concerns.

When doing the digital storytelling stuff, l've started concentrating more than anything on understanding why participants are there, and what they want to get out of the process; and a lot less on what they will produce and what that will be useful or valuable for. Then again, if I wanted to make money designing a platform for 'participatory media', that would be kind of essential - the participants would be my customers.

Finally (and now I am hopefully actually responding to your point): 
"But these terms are now being tossed around in software and hardware development like organisations and companies only care about democratic participation, and not profitability."

Exactly. Collectively, with our desire to participate, our labour-as-love and our whimsical half-understood urges to create things and share them, we are grist to the Big (new) Media mill. What l've become interested in lately is the question of whether such participation actually add up to anything at all beyond that and/or beyond the accumulation of new media cultural capital for the early adopters of each new development (blogging, flickring, videoblogging, whatever's next).

None of which should surprise me. Software can only ever replicate the social contexts in which it was created, right? The most active citizens of, say, flickr are uncannily similar, not as the result of some conspiracy, but simply as an effect of just who the early adopters are always going to be.

Jean-Louis Trudel said...

Looking forward to a possible collaboration, how proficient are you in French?

Ultimately, I think the question of whether or not blogging can be considered collaborative academic research remains unresolved. Nonetheless I am convinced that the 'work' I did online involved all sorts of known and unknown people who helped me become a particular kind of PhD student, or academic, or person. And if I take the comments included in this chapter at face value, then I believe I can say that I have positively influenced others as well.

\subsection{SUMMARY}

In this chapter I introduced my weblog, purse lip square jaw, as an integral part of my dissertation's methodology and my personal experience of 'becoming PhD.' Research blogging was described in terms of its ability to reconfigure, to greater and lesser extents, traditional sociological understandings of authorship, identity and academic authority-although the political power of these emerging practices 
and relations should be further qualified. By engaging multiple audiences and publics, my blog can also be understood as a form of participant observation that also raises interesting questions about the differences between collective and collaborative research. More generally, and perhaps most importantly, research blogging requires a rethinking of what constitutes sociological 'research' today.

In attempting to summarise this chapter, I know I have left more questions unanswered than answered-but perhaps that is the very sort of immediate and emergent quality of blogging that I have attempted to describe. I also want to emphasise that the analysis of research blogs is in its very earliest stages, and much work still needs to be done.

One way of looking at weblogs and emerging forms of scholarly discussion and work is that they are the popularisation of research, or a new form of dissemination. If they allow ideas to be worked through it is in the same way as informal conversations in the breaks of a scholarly conference do, or perhaps at best they can replace or augment the debates that ideally (though usually not really) take place in the question sessions after traditional scholarly papers are presented.

$[\ldots]$

Weblogs in their current form can't fully replace traditional publication. They're superficial, quotidian, they're not rigorous enough, one might argue, they are too completely in the moment and encourage fast writing and thought rather than deep consideration and reflection. And yet it is obvious that bloggers tend to revisit the same issues again and again. Many bloggers are adept at linking back to related entries written months or even years earlier, both by themselves and by others. The link itself has become something of an ethics of blogging: link to your sources. If you're not sure of a fact or of the source of your ideas, search the web until you find out more about that and link to it. These foundations are, perhaps, the seeds of a genre that may grow to be as strong as the traditional academic essay (Walker 2006:10).

I agree with what Walker says above-blogs should not be considered replacements for peer-reviewed research-but I also recall what Gregg (2007) 
described as the similarities between blogging and more traditional scholarly activities. In many ways, purse lip square jaw comprises fragmented conversations between me and diverse others that have lead to this moment of writing my dissertation this way.

Looking back I recognise the many conversations that shaped me and my readers into multiple and contingent publics arranged around particular concerns. I can see-always did see-how my blog has provided a space in which I explore different ideas and identities, negotiate relationships with others (including my personal and professional reputations) and expand and strengthen my, dare I say, cross-cultural communication skills. Blogging was how I found my dissertation cases, and where I connected them to others. In many ways my blog has been my playground, but I can also recall days and weeks when blogging was boring or tedious, when I doubted its relevance for my project, or when I could not care less if I ever posted another word. Yet here I am, blogger-bricoleuse, writing my dissertation around and between my blog posts, performing what Zalis (2003) calls a "theatre of recollections" in order to hold it all together.

The following chapter takes up the question of temporality in different but related ways. In Chapter 4 , I continue with my experimental text, sliding between blog posts and analysis, in order to begin my discussion of how to understand other emergent technologies. 


\subsection{UNDERSTANDING EMERGENT TECHNOLOGIES}

Moving on from methodological concerns, this chapter introduces the broadest subject of my dissertation and presents a set of theoretical perspectives that inform my subsequent analysis. In the first section I begin by providing a necessarily selective overview of pervasive or ubiquitous computing as a humancomputer interaction research agenda that has spanned the past 20 or so years. Most often characterised as a "post-desktop" computing paradigm that seeks to seamlessly integrate computation into the very fabric of everyday life, early proponents claimed that its effects would be calming rather than overwhelming and frustrating. However, skepticism and criticism almost immediately arose both within and outside the immediate research community. Understood as having the potential to become totalising and oppressive, critiques have generally centred on systemic risks to privacy and other Western civil liberties. However, a small but persistent segment of researchers has more recently advocated a focus on 'seamful' rather than 'seamless' computing, where infrastructure is rendered transparent and interaction is based on user appropriation, as well as a shift from 'calm' to 'engaged' computing, where users are seen as active rather than passive.

Before moving on to the specifics of urban computing and locative media as subsets of pervasive computing-the subject of Chapter 5 -the remainder of this chapter addresses how sociology might productively engage with such emergent technologies. The second section presents an overview of research in the areas of emergent technologies and actor-network theory, and how they relate to notions of social and spatial complexity. Here I advocate using a combination of 
theoretical approaches based on processes of translation, association and transduction, and on metaphors of flow.

The third section builds on this foundation to include a discussion of the role of expectations and affect, as well as the question of temporality, in a research agenda that is primarily oriented towards a proximate or near future. Rather than treating contemporary rhetoric as predictions for the future, ubiquitous computing visions are seen to be most active in ordering present relations. In this final section, emphasis is placed on the actual complexity of the issues and the cacophony of voices that arise around shared concerns. Ultimately, urban computing and locative media are positioned as emergent practices and processes that hinge on tensions between hope and despair over particular technological futures.

\subsection{INTRODUCING UBIQUITOUS OR PERVASIVE COMPUTING}

\section{Excerpt from Ubiquitous Computing Wikipedia entry}

http://en.wikipedia.org/wiki/Ubiquitous computing (Redirected from Pervasive computing)

Ubiquitous computing (or "ubicomp") is a post-desktop model of human-computer interaction in which information processing has been thoroughly integrated into everyday objects and activities. As opposed to the desktop paradigm, in which a single user consciously engages a single device for a specialized purpose, someone "using" ubiquitous computing engages many computational devices and systems simultaneously, in the course of ordinary activities, and may not necessarily even be aware that they are doing so.

In the opening keynote presentation at Ubicomp 2006, science fiction writer Bruce Sterling (2006) explained that ubiquitous computing appealed to him 
because of "the majesty of the ideas and the lyricism of the language." I take this as an aesthetic judgment-but surely a writer also chooses his words carefully, and a list of related technologies, applications, services, and theory objects does seem to suggest impressive scale and imagination:

Ubiquitous Computing, Pervasive Computing, Mobile Computing, Smart Phones, Wearable Computing, Calm Technology, Spimes, Internet Protocol v6, Invisible Computing, Seamless Computing, $\mathrm{Wi}-\mathrm{Fi}$, Ambient Intelligence, Augmented Reality, Mixed Reality, Radio-Frequency Identification, Intelligent Environments, Internet-Of-Things, Physical Computing, Networked Objects, Smart Dust, Things That Think, Global Positioning System, Tangible Media, Mixed-Reality Games, Thinglinks, Body Area Networks, Blogjects, Context-Aware Computing, Cell ID, Spychips, Everyware, Participatory Panopticon, Smart Homes, Ambient Findability, Geospatial Web, Sensing Technologies, Physical Metaverse, Locative Media, Pervasive Play...

But more so, and especially in its inevitable partiality, this list demonstrates the complexity I found when I attempted to describe this particular domain of research practice at the end of 2007. As Sam Kinsley (2007) so aptly put it in his geography research blog, "How does one summarise the background to a research project when it makes up an entire research agenda in a different discipline?"

But the people behind the words in the list above include scientists and engineers, governments and policy makers, entrepreneurs and corporations, designers and artists, citizens and activists. If the myth of new technologies being developed solely by experts in laboratories still holds any sway-and there is plenty of evidence to suggest this has never actually been the case-then ubiquitous or pervasive computing may bring about its final demise. Still, for the purpose of this introduction I will concentrate on ubiquitous or pervasive computing as it has been defined by human-computer interaction (HCI) 
researchers-although it should also quickly become clear that this research community is neither homogenous nor stable.

In a 2001 column written for the HCI research community, Gregory Abowd attempted to reign in some of the complexity hinted at above:

Do these different names really represent different research agendas? No! We have this proliferation of names because of our individual desires to have an identity as researchers, not because we are looking at very different phenomena. The names we use do not matter. What matters is the overall goal of our separate research endeavors. Rather than argue about the appropriate name for this movement, I want to focus attention on what the research agenda should be about (Abowd 2001:3).

The pursuit of scientific knowledge over individual interests has long been considered one of the ways by which 'good' science is distinguished, although ethnographic studies of laboratories have demonstrated persistent tensions between collective ideals and individual actions in actual practice (see Latour and Woolgar 1986; Traweek 1988; Knorr-Cetina 1999). Abowd's desire to create a shared agenda may be seen as simply pragmatic, but it is also normative and prescriptive. He writes that researchers should abandon their search for the "killer application" and start looking for the "killer existence," or "a suite of applications in service of a population of users" (Abowd 2001:8). In delineating a common research goal, Abowd encourages technologists to create entire ways of life rather than singular applications.

This sort of all-encompassing vision is not new to technological roll-out-for example, large technical systems like the railroad profoundly restructured people's understandings of everyday space and time (Schivelbusch 1986)-but its 
impact on prevailing models of human-computer interaction may evidence a kind of "paradigm shift" (cf. Kuhn 1970) that is of substantial social and cultural relevance. Most notably, by claiming everyday life as its purview, things that had formerly been considered the exclusive domain of HCI research became matters of concern for a much broader public and vice versa, a point to which I will return again in the following chapters.

\subsubsection{Computing in the $21^{\text {st }}$ century}

Mark Weiser's seminal article, “The Computer for the $21^{\text {st }}$ Century," argued that "the most profound technologies are those that disappear. They weave themselves into the fabric of everyday life until they are indistinguishable from it" (Weiser 1991:1). He called this vision "ubiquitous computing" and claimed that not only would it liberate people from the constraints of personal desktop computing but, by privileging the social and physical worlds in which we already live, it would free us from equally isolating immersive and simulated virtual reality environments (Galloway 2004a). Weiser envisioned a world in which people no longer interacted with one big desktop computer, but with hundreds of smaller computers embedded in surrounding objects. The aesthetics and ethics of this vision were reiterated in Weiser's "The World is not a Desktop":

The clock, and the clockwork machine, are the metaphors of the past several hundred years of technology. Invisible technology needs a metaphor that reminds us of the value of invisibility, but does not make it visible. I propose childhood: playful, a building of foundations, constant learning, a bit mysterious and quickly forgotten by adults. Our computers should be like our childhood: an invisible foundation that is quickly forgotten but always with us, and effortlessly used throughout our lives (Weiser 1994:8). 
And again in Weiser and Seely Brown's (1997:75) prediction of "the coming age of calm technology":

Information technology is more often the enemy of calm. Pagers, cellphones, news-services, the World-Wide-Web, email, TV, and radio bombard us frenetically. Can we really look to technology itself for a solution? But some technology does lead to true calm and comfort. There is no less technology involved in a comfortable pair of shoes, in a fine writing pen, or in delivering the New York Times on a Sunday morning, than in a home PC. Why is one often enraging, the others frequently encalming? We believe the difference is in how they engage our attention. Calm technology engages both the center and the periphery of our attention, and in fact moves back and forth between the two.

In Weiser's view, by the late 1980 s information technologies had already encroached enough on the quality of people's everyday lives that something needed to be done. This opinion was not uncommon at the time, and many had begun to call for respite from 'information overload' (cf. Toffler 1970; Klapp 1986). But contrary to the kind of 'common sense' that would call for less information, Weiser and Seely Brown suggested that people be provided with access to more information and, crucially, the ability to have that information at the periphery rather than the centre of our attention.

The result of calm technology is to put us at home, in a familiar place. When our periphery is functioning well we are tuned into what is happening around us, and so also to what is going to happen, and what has just happened. We are connected effortlessly to a myriad of familiar details. This connection to the world around [us] we called 'locatedness,' and it is the fundamental gift that the periphery gives us (Weiser and Seely Brown 1997:77).

The desire to have computing so seamlessly and efficiently embedded in our daily lives is grounded in a profoundly utopian vision connected to cultural and historical notions of technological 'progress' (see Rescher 1980; Lightman, Sarewitz and Desser 2003). It follows a long tradition of technological 'solutions' to social 'problems' or cultural 'needs,' and is allied with the promise of techno- 
science to improve our quality of life-despite the tendency of technology to reinforce prevailing power relations (Wajeman 1991; Silverstone and Hirsch 1994; Oldenziel 2004).

But it can also be seen as a reaction to failed technologies and actual lived dystopias. The rhetoric favoured by Weiser and Seely Brown is highly evocative and emotive-if feeling overwhelmed or abused by technology, who would not prefer something familiar and calming? This early vision of ubiquitous computing seemed to care for people and it is not difficult to imagine why researchers would want to pursue such a goal. Of particular interest is their emphasis on the value of feeling located. Given the particulars of post-911 surveillance (Lyon 2003) and the wide-spread consumer availability of Global Positioning System (GPS) devices today, it is easy to imagine that being located means being tracked. But the repeated insistence on the calming effects of this 'new' kind of computing suggests that Weiser and Seely Brown likely meant feeling grounded. Quite distinct from artificial intelligence research into machine ability to recognise and process human emotion (cf. Picard 1997), this is affective computing in two interconnected senses. First, it is 'becoming' technology and, second, it seeks to move us.

EXCERPT from purse lip square jaw by Anne Galloway http://www.purselipsquarejaw.org/2004/09/questions-about-ubicomp-and-other.php Friday, September 10, 2004 Questions about ubicomp and other tales of ordinary madness 
Emily Zak is currently researching ubiquitous computing and invisible interfaces at the University of London, and she recently asked me to answer some very complex questions. I've posted some thoughts below:

Emily: With a lack of consensus about what ubiquitous technology is - pervasive, ambient, tangible interfaces, 'Calm Computing,' 'Transparent Technologies' - in your view what is ubiquitous or pervasive computing, where is it located or how is it mediated?

Anne: I'm partial to the terms ubiquitous and pervasive because they get at, what is to me, the core of the mythology: a design and engineering paradigm based on the assumption that computing can, and will, be distributed everywhere (i.e. not just on the desktop). Currently it is, by-and-large, located in laboratories and universities in the developed world. What I mean is that ubicomp isn't out-there-in-the-world-with-people yet, and likely won't be for decades to come, if it ever manifests itself as projected.

But this question of ubiquity is complicated and should be unpacked a bit. Unfortunately, Weiser's choice of the word "invisible" seems to be responsible for so much confusion; I don't think it was ever meant to be taken literally. The legacy is that ubicomp still tends to be discussed in terms of "seamless" interfaces, despite Weiser's clarification that "seamfulness" would be rather important. Researchers like Matthew Chalmers have tried to revive this concept, but it's a bit unclear to me what that might actually involve. It also seems to conflict with massive funding programmes like the EU's Disappearing Computing initiative.

Recently l've also noticed a shift away from describing ubicomp as allowing "anywhere, anytime" information, and towards getting people "the right information at the right time." A subtle difference but, I think, evidence that we are starting to understand that total ubiquity - or "always-on" computing - is not only technologically difficult, if not impossible, but also socially undesirable. Nonetheless, I think the obsession with "information" still misses Weiser's point about the importance of people.

Emily: Mark Weiser and others describe the drive toward ubiquitous computing as humane - with computers "getting out of the way." Are there assumptions being made about what is innately human and not-human activity and what is the everyday?

Anne: Weiser said that computers needed to move from the centre to the periphery of our attention, and this is, I think, the type of invisibility he imagined. The problem, as he understood it, was that desktop computers are somehow dehumanising, that they isolate us and take too much away from our quality of life. Of course there are assumptions being made in these scenarios about what computers, people and everyday life are that's one of the things about ubicomp that interests me the most - and these assumptions rarely, if ever, get questioned.

The types of socio-cultural theory and method most often used within the humancomputer interaction community include ecological or systems approaches, ethnomethodology and phenomenology. It is not coincidental that all these ways of thinking are ontologically and epistemologically compatible with the general principles of cybernetics - among other things, it makes translation between (and enrollment among) the necessary players much easier. 
On the other hand, studies in science, technology and society, as well as cultural studies, critical theory and continental philosophy, including feminist theory, have challenged these ways of understanding human (and human-computer) interaction. Researchers like Donna Haraway, Manuel de Landa, Bruno Latour, and Lucy Suchman have been instrumental in these critiques of technoscience - but the body of relevant literature is huge and I won't get into it here.

Emily: How do concepts of intelligent technology, or discourses increasingly mediated by such technologies, challenge the assumption and primacy of human agency and pose ethical and philosophical questions about the nature of agency and intelligence? Further, how do embodied or situated practices, and networks of agency maintained at the sites of innovation, laboratories and research centres, influence the development and application of new media socio-technologies?

Anne: My own research draws a great deal from the work of people like Latour (especially for his notions about collectives of humans and non-humans), Adrian Mackenzie (for ideas about transduction, space and culture), and Deleuze \& Guattari (for notions of mobility and becoming). One thing they all have in common is a blurring of the traditional boundaries between subjects and objects, which automatically reframes the issue of social agency.

Lucy Suchman has written about situated accountability, which suggests some sort of contextual (perhaps bottom-up) ethics will be necessary, but I do tend to agree with Latour that we are far from having a political and ethical position that is adequate for the interconnectedness conjured by his collectives, and technologies like ubicomp. In a world where we still argue about whether it is guns or people that kill people, I'm not quite sure what it will mean - in practice - when we say that neither guns nor people kill, but rather it is an assemblage that can be described as a person/gun that kills.

Connect this to the matter of spatial practice and things get even harder to pin down. I draw mostly on notions of flow - from Deleuze, to Rob Shields, to John Law - in my research. In this way we must also deal with the question of time, and it becomes difficult to say that innovation is maintained at any particular site as, in practice, it flows through many sites.

posted by Anne at 15:14

\subsubsection{Seamless versus seamful computing}

[T]he social impact of embedded computers may be analogous to two other technologies that have become ubiquitous. The first is writing, which is found everywhere from clothes labels to billboards. The second is electricity, which surges invisibly through the walls of every home, office, and car. Writing and electricity become so commonplace, so unremarkable, that we forget their huge impact on everyday life. So it will be with [ubiquitous computing]" (Weiser and Seely Brown 1997:36). 
While heroes and father-figures like Mark Weiser are still prevalent in technoscientific cultures, it is also generally acknowledged amongst practitioners that 'breakthroughs' and 'innovations' are not the product of a single person in a single place and time, but the effect of what has been called distributed or collective intelligence (Johnson 2002; Hight and Perry 2006). A vision of "invisible" (cf. Norman 1998) computers has been remarkably influential in the past decade or so of computing research and design, and has not been limited to the kind of "ubiquitous computing" that Weiser and Xerox Palo Alto Research Center (PARC) researchers advocated. Since the late 1980 s and early 1990s, researchers at places like IBM have been working on "pervasive computing" and academics like MIT's Hiroshi Ishii have been working on "seamless interfaces between people, bits and atoms" or what are sometimes called "tangible media" (Ishii and Ullmer 1997). The reinterpretation of Heidegger's (1996) "ready-tohand" technology can also be seen in "ambient intelligence" (Aarts and Marzano 2003) research and any number of consumer-friendly "smart home" projects. Additionally, since 1998 "The Disappearing Computer Initiative"-part of the European Union's Future and Emerging Technologies Research Programme-has generated almost two dozen, well-funded exploratory research projects with the initial objective:

To explore how everyday life can be supported and enhanced through the use of collections of interacting artefacts. Together, these artefacts will form new people-friendly environments in which the computer-as-we-know-it has no role. The aim is to arrive at new concepts and techniques out of which future applications can be developed (http://www.disappearing-computer.net/). 
This focus on networked and context-aware objects is central to "seamless" computing, both in terms of making it possible in the first place and then offering a necessary corrective. As Weiser and Seely Brown (1997:35) so bluntly put it, "if computers are everywhere they better stay out of the way and that means designing them so that the people being shared by the computers remain serene and in control."

In order for computers to 'do the right thing' in this kind of interaction model, they must be able to sense their surroundings and they need to communicate with other computational objects. This kind of computational reach has made "seamless" or "invisible" computing a primary target for privacy advocates-at least in the North American and European cultural settings I have described so far.

Excerpt from Intel Research Blogs by Roy Want

http://blogs.intel.com/research/2007/10/youre not paranoid they really.php

\section{October 17, 2007}

\section{You're Not Paranoid; They Really Are Watching You!}

The work I am best known for from the '90s is the Active Badge project, which set out to find a way to automatically route telephone calls to the correct place in a building. To a new generation of researchers, this probably seems like a no-brainer; just buy everybody a cell phone!

However, at the time, there were no cell phones, and business phones were almost exclusively based on a Private Branch eXchange service (which many organizations still use). I wanted to automate the process of call-forwarding from an employee's default extension to the extension closest to the person's location. The solution I came up with was to have everybody wear an electronic badge that periodically beaconed a unique infrared signal. A network of low-cost infrared receivers distributed throughout the 
building would then record the signal, and a central server could collect all the data. A simple network service would let clients enter a name and look up the corresponding badge ID to determine the station where it was last sighted, along with the corresponding room and nearest extension.

As soon as we had built the system, we realized it was part of a far bigger pervasive computing story-thus the notion of context-aware computing was born. As you might expect, when shown publicly, the privacy issue was the main discussion point, inspiring a host of press articles with sensational titles such as "The Boss That Never Blinks" (San Jose Mercury News, West Magazine, 8. Mar. 1992) and "Orwellian Dream Come True: A Badge That Pinpoints You" (The New York Times, 12 Sept. 1992). Furthermore, all reporters inevitably asked if we had sensors in the bathrooms and almost seemed disappointed when we told them we didn't. Despite the external jibes at this location capability, the majority of my colleagues weren't deterred from wanting-and proudly wearing - the badges. On the whole, they viewed the project as breaking new ground and embracing the ubicomp vision. Displaying a badge meant you were "in" because ubicomp was "in." The system was certainly useful, but l'm not sure it would have been as successful without the implication that you were also helping to build the ubicomp vision. After all, it contributed to a loss of personal privacy in the office, and individuals might not have considered the value-to-cost trade-off to be worth it. It's hard to know without a control experiment.

The lesson I leamed is that our interpretation of right-to-privacy in the context of a new technology is very variable. What makes technology a good or bad thing is dramatically affected by the social setting in which it is used. In other words, there's no absolute standard for privacy that we can record in a rule book and follow when designing something new.

posted by Roy Want

While Want, in the excerpt above, makes it sound as though it was only journalists who had privacy concerns, and computer scientists were only eager to be part of such popular research activities, Stephen Doheny-Farina (1994) and David Porush (1995) wrote cautionary columns about ubiquitous computing for Computer-Mediated Communication Magazine. Doheny-Farina (1994:18) worried about the "Orwellian nightmares" that could accompany such intrusive technologies and named four principles to guide future development: 
1. The normal state of anyone's computers is OFF.

2. The normal state of anyone's relationship to computer networks is UNCONNECTED.

3. The normal state of knowledge about the location of anyone is UNKNOWN-whether connected or unconnected.

4. Connectivity and location is private information that must be protected by both technological and social policy mechanisms.

Porush (1995:46) was concerned that people would not be able to 'opt-out' of such a world:

None of Weiser's reassurances that the technology will be implemented only with willing participation reassure me. I know how culture and technology conspire to make non-participation virtually impossible.

But he also disagreed with Doheny-Farina's assumptions:

If we imagine-shudderingly-some future state where ubicomp is a reality and the rule, then these propositions effectively mean that the normal state of citizenship is ANONYMITY and INVISIBILITY. I would argue that such assumptions do more harm than good. Perhaps this is the dark end state of our American obsession with privacy, universal paranoia, but I think it is aberrant and threatens the more valuable and enduring notions of community. The normal state of our self in the community, I would suggest, is ON, KNOWN and CONNECTED ... Frankly, I think trying to protect a theoretical freedom to be lost by suggesting it is the normal state of relationship to the society at large is a form of capitulation to the totalizing and dehumanizing aspects of communications technology ... I'll take my chances with Big Brother rather than face a society whose assumption is that its citizens are monads, atoms, or hermits. Beyond that, there is a lesson to learn about projecting our local and history-bound values onto other cultures, even our own culture of the future (Porush 1995:46).

We will return to concerns about citizenship and publics in subsequent chapters, but for now what is of interest is Weiser's (1995) response. Ultimately, he sidestepped either of their concerns by suggesting two "principles of inventing socially dangerous technology": 
1. Build it as safe as you can, and build into it all the safeguards to personal values that you can imagine.

2. Tell the world at large that you are doing something dangerous.

While both assume the inevitability of technology, Weiser recognised that the first principle cannot offer any guarantees and chose to focus more on the second. As part of the aesthetics and ethics of ubiquitous computing, he advocated active engagement with the issues, a "pulling, pushing, and throwing one's weight into composing the life and culture we lead and will lead in the future" (1995:17)another matter to which we will return later, as it relates to the multiple publics mobilised around and through pervasive computing.

The same year, at the 1995 ACM Conference on Computer Science, Augustin Araya weighed in on the debate by pointing out that if the "real potential" of information technology could be found in a more socially-aware ubiquitous computing, as Weiser and his colleagues argued, then this potential might be best understood as:

the power of a technology for expanding itself beyond the limits within which it is currently confined and for unfolding itself to its highest possible degree... [I]n opposition to many other technologies, Ubiquitous Computing is not seen as penetrating circumscribed areas of activities but aims at revolutionizing everyday life itself. In so doing, Ubiquitous Computing is attributing to the unfolding of technology the right to drive by itself the way in which certain aspects of everyday life are lived ... [Accordingly] we characterize the thinking underlying Ubiquitous Computing as an emerging form of technological absolutism [and] an attempt at a violent technological penetration of everyday life (Araya 1995:236-237 emphasis in original).

Araya (1995:234) further associated ubiquitous computing with an "obliteration" of otherness: 
When a book, a person, or any other 'thing' has attached to it a visible or invisible tag which, in conjunction with a ubiquitous surveillance mechanism constitutes what we may figuratively call an 'electronic leash,' the thing has lost some of its otherness. Although in many senses it remains an other, it has lost a fundamental property, namely, the possibility of becoming lost. If due to a malfunctioning of the surveillance mechanism the thing eventually becomes lost, this would only have the character of an anomaly. Normally, the thing is always under surveillance. But things would partially lose their otherness in a more fundamental way. When the surveillance mechanism fades into the background and we are no longer able to experience it, things in general - not just this manual or that tool or those employees - would have been transformed becoming for us surveillable things, whether we effectively subject them to surveillance or not. A fundamental category that governs our dealings with the world would have been deeply altered.

Additionally, because everything that is to be disseminated through ubiquitous computing networks “must be mapped into analog or digital signals," Araya (1995:235) suggested that "electronic surrogates" would come to stand-in so successfully for the things that cannot be disseminated electronically, that people would forget there is an 'other' world at all.

This question of 'otherness' is particularly important to those interested in social and cultural relations. Just over a decade after Araya first voiced these concerns, the everyday use of mobile technologies has become characterised by a sense of perpetual connection to people, places and things that are already familiar to us. In an early 2008 Economist.com special report on "digital nomads" (http://www.economist.com/specialreports/displayStory.cfm?STORY ID =1095 0394) sociologist Manuel Castells explains that "permanent connectivity, not motion, is the critical thing" and numerous studies (see for example Katz and Aakhus 2002; Ling 2004; Ito and Matsuda 2005; Ling and Pedersen 2005; Kavoori and Arceneaux 2006) have demonstrated that mobile phones have 
become instrumental in maintaining "strong ties" but far less successful in supporting “weak ties" (cf. Granovetter 1973). I will return in depth to the question of how urban computing and locative media stand to reshape our experiences with 'others,' as well as related matters of cosmopolitan and cultural citizenship, in Chapters 5 and 6.

Returning to Araya's comments we can see that they share much in common with established phenomenological critiques of technology by the likes of Heidegger (1996), Gadamer (1981) and Idhe (1990), as well as contemporary surveillance studies inspired by both Foucault's disciplinary society (1977) and Deleuze's control society (1997). However, Araya's bold-if a bit reactionary-critique of ubiquitous computing seems to have passed largely unnoticed (or unheeded) by the human-computer interaction research field. One could even make the case that the social and cultural implications of ubiquitous or pervasive computing did not again emerge in HCI discourse with any force until five years later, and it took almost another five years after that before anything like Weiser's "pulling, pushing, and throwing one's weight into composing the life and culture we lead and will lead in the future" became part-and-parcel of ubiquitous and pervasive computing discourse.

EXCERPT from fredshouse.net by Gene Becker

http://www.fredshouse.net/archive/000307.html

October 14, 2004

Is Dog Walking Better With Ubicomp? 
I'm trying to figure out places in my life where ubicomp would be good to have, and I keep drawing a blank. This may be a failure of imagination on my part, of course. But still, I'm trying. Tonight for example, I was walking my dog Snoopy in the neighborhood, and trying to dream up ways that pervasive tech could make it a better experience.

Well here's the reject list:

1. A leash that displays a real-time news crawl along its length.

2. Wi-Fido self-organizing wireless mesh network deployed on local dogs.

3. An historical guide to my street, annotated by my neighbors, with contextual sponsor ads for dog food, dog sweaters, and local dog walkers.

4. Sensor- and actuator-enabled trees that pee back.

5. A wearable eyepiece that shows textual and visual information about the moon and stars and houses and bushes, overlaid on my normal field of vision.

6. Sensate sidewalks that tell my doctor how much I weighed tonight after dinner, and how far I walked.

Here are some that could maybe have a tiny little shred of merit, or at least would be kinda cool:

a. Trees and buildings that glow in phosphorescent shades and patterns and then fade as we walk past them. Maybe a little sound as well, if it makes the experience more beautiful.

b. A wearable eyepiece that allows me to see in new modalities, for example a timelapse view of which animals passed by here and left the apparently maddening scent trails my dog is obsessing over. Or maybe a view that simulates the visual equipment of the dog, so I can see what he sees.

c. Something like Anne's forgetting machine, so I'm not reminded of all the urgent and important stuff on my various to do lists and can thus have hope for a good day tomorrow.

Now here's a test: which ones do you think we're more likely to get?

posted by Gene at 11:40 PM

Explicit attempts to deal with critiques of "seamless" computing came when researchers began recalling Weiser's brief mention of "seamful" interaction, with "beautiful seams" (see for example McColl et al. 2002) and suggesting more visibility for ubiquitous infrastructures and interfaces. For example, after observing users that took advantage of technological glitches like spotty wi-fi coverage and GPS shadows, researchers concentrated on how technological 'failures' could become interaction 'successes': 
Seamfulness is about taking account of these reminders of the finite and physical nature of digital media. Seamful design involves deliberately revealing seams to users, and taking advantage of features usually considered as negative or problematic (Chalmers 2003:1).

Arguing that designers have often accommodated their designs to the available working technology, Chalmers (2003:3) favours design that ensures users can appropriate the technology for their own ends: "Rather than supporting seamless connection and access of devices and services, [one] approach is to enable users to discover and manipulate devices, services and their interconnections." Consistently, he and his colleagues have promoted "designing for appropriation" as a means to empower users of pervasive computing (see also Galloway et al. 2004).

Along related lines, fifteen years after Weiser's seminal article on computing in the $21^{\text {st }}$ century, Yvonne Rogers (2006) claimed that it was time for researchers to "move on" from his vision of "calm" computing. She argued that by focussing almost exclusively on the kind of context-awareness (see Moran and Dourish 2001; Dey 2001; Chalmers 2004; Dourish 2004) necessary for such a vision of computing to succeed, researchers have become overwhelmed by problems that may not have solutions, and all at the expense of other areas of research. She presents a future world where "coziness, comfort and effortlessness" may reign, but suggests that living would only ever be at a distance:

It is as if she glides through life, where everything is done or laid out for her and whenever there is potential for frustration, such as a traffic jam or parking problem, the invisible computers come to her rescue and gently inform her of 
what to do and where to go. It is worth drawing an analogy here with the world of the landed aristocracy in Victorian England whose day-to-day life was supported by a raft of servants that were deemed to be invisible to them (Rogers 2006:4).

Instead of embedding computation in the environments and objects around us in order to reduce the amount of interaction we have with them, Rogers advocates an approach where

technologies can be designed to augment the human intellect so that people can perform ever greater feats, extending their ability to learn, make decisions, reason, create, solve complex problems and generate innovative ideas... [as well as] causing us to reflect upon and think about our interactions with them ... Such toolkits should not need an army of computer scientists to set up and maintain, rather the inhabitants of ubiquitous worlds should be able to take an active part in controlling their set up, evolution and destruction (2006:8-9).

This focus on socially engaging, and engaged, technology also appears in Adam

Greenfield's second and fifth principles of ethical pervasive computing

development, where systems should be self-disclosing: "Ubiquitous systems must contain provisions for immediate and transparent querying of their ownership, use, and capabilities" and deniable: "Ubiquitous systems must offer users the ability to opt out, always and at any point" (Greenfield 2006). Interestingly, all these recent critiques share much in common with the ones from the mid $1990 \mathrm{~s}$ described above, but cite none of them as precedents.

\subsection{A MOBILE SOCIOLOGY}

What I have presented so far in this chapter is a partial account of the values, and critiques, of a vision of ubiquitous computing that has been more or less active over the past 20 years. But before I get into the specifics of urban computing and locative media, I want to step back and take a closer look at how we might 
approach the question of such emergent technologies from a sociological perspective. Given that social studies of science and technology are both wellestablished and diverse (see Hackett et al. 2007 for a current overview), I will limit my discussion here to research in the areas of emergent technologies and actor-network theory, and how they relate to what has been called the "complexity turn" (Urry 2005) in sociology-as described in Chapter 2, Section

2.1. The rest of this chapter, then, focusses on how sociologists might productively engage with, and understand, technosocial assemblages as they take shape in space and time.

\subsubsection{Translations and associations}

Beginning with actor-network theory, or what started as a "sociology of translation," Michel Callon (1986) outlines four moments of translation in scientific research that can help us understand how technologies emerge: 1) problematisation, or how ideas and things become indispensable; 2) interessement, or how allies are locked into place; 3) enrollment, or how roles are defined and coordinated; and 4) mobilisation, or how issues are represented to others. The first 'moment' is a double-movement in which a research problem is identified and, more importantly, associated with particular sets of actors. Rather than being reductive, these problematisations comfortably combine humans and non-humans in complex ways (cf. Latour 1999). However, problematisation involves claiming it is in the interests of all the actors for the research to proceed, and the identities of the actors are defined in ways that make the researchers 
indispensable. Callon calls these material and semiotic associations "obligatory passage points" and notes that problematisation depends on "movements and detours that must be accepted as well as alliances that must be forged" (Callon 1986:220). The second 'moment' involves submissions to the original plan and refusals to accept the proposed transaction. During periods of interessement, actors form and reform identities, orientations and objectives, and their actions attempt to define and stabilise relationships between actors. These actions and devices can be forceful, seductive, practical, and so on, depending on the situation.

Not all problematisations result in enrollment, but if the interessement is successful then the actors move to define, coordinate and enroll themselves and each other into particular roles. "To describe enrollment is thus to describe the group of multilateral negotiations, trials of strength, and tricks that accompany the interessement and enable them to succeed" (Callon 1986:222). As one might imagine, these devices and actions are of particular interest as this is how relations or associations change and remain the same. And of course, at stake in these scenarios are relations of power; assemblages of identities and objectives are often competing and contradictory.

Negotiations that take place during problematisation, interessement and enrollment invariably involve more individuals than a given assemblage claims to, and indeed is able to, represent. This question of representation, or who speaks on behalf of whom, is of clear social, political and ethical concern, and 
Callon (1986:223) reminds us that this situation also raises the crucial question, "Will the masses follow their representatives?" If 'spokesmen' (i.e. people, things and ideas) are designated by putting "intermediaries and equivalences" into place, then looking at these things also allows us to see who and what are silenced or denied a place on the playing field.

To reiterate, participating humans and non-humans are displaced and transformed in these processes of representation. Continuing negotiations between the representatives seek to mobilise and commit absent or silent actors, and if the mobilisation is successful then these relations will be accepted as 'real' and sometimes even 'normal.' This mobilised reality-otherwise known as an actor-network-is

... a result of the generalized negotiation about the representativity of the spokesmen. If consensus is achieved, the margins of the maneuver of each entity will then be tightly delimited ... But this consensus and the alliances which it implies can be contested at any moment. Translation becomes treason (Callon 1986:225).

If translation is a process always already involving instability, displacement and contingent ordering, a sociology of translation might also productively be referred to as a sociology of association (Latour 2005), a point to which I will return shortly.

\subsubsection{Transduction and other complexities}

Despite this knowledge, many theories of technological innovation-and visions of ubiquitous computing-seem to maintain an almost contradictory sense of 
consistency and coherency. Part of this stems from the tendency to discuss new technologies as representational objects or artefacts, rather than as performative “practices, arrangements and ensembles...which permit certain objects to materialize or solidify and not others" (Mackenzie 2003:3). As information technologies become more pervasive in everyday life, the analytical usefulness of more relational concepts becomes evident, and the concept of transduction provides a further means to refocus our investigations towards performative understandings of technological practice:

Transduction provides a way of thinking about technologies processually, that is, as events rather than objects, as contingent the whole way down, rather than covering over or reducing contingency ... It proposes that both normalizing and generative capacities of technologies can be understood as a process of individuation, as an ontogenetic process which results in individuated things and which involves both ordinary and singular events. Much of what is represented as 'new' is in fact the capture and containment of the processual mode of existence in technology (Mackenzie 2003:4-5).

Applied to ubiquitous or pervasive computing, the concept of transduction allows us to shift our focus from networked objects or artefacts to diverse procedures or performances in which socio-technical assemblages or associations take shape. The primary benefit of this sort of approach is the ability to identify precise moments and locations in which we can intervene and alter the course of events, thereby revitalising the role of social and cultural agency-and the potential for critiques of everyday life-in the development and use of new computing technologies (Galloway 2004a).

Drawing out some of these connections between mobility and stability, Mackenzie (2002) further suggests that technicity (following Simondon) is a 
transductive way of understanding technology in terms of flow and movements between abstraction and concreteness, or virtuality and actuality. These and related ontological categories-the virtual, concrete, abstract and probable-have also been explored in terms of intensities and flows by Shields (2003), and the notion of technicity focusses our attention on these fluid relations and a sense of becoming.

Beyond technical objects, technicity inheres with the relationality of the ensembles or assemblages composed of bodies, institutions, conventions, representations, methods and practices. Read transductively, technical objects evolve over time by articulating diverse realities with each other. Technicity is a transcontextual linkage which can be objectified in context-limited ways, but also exceeds its objectification, stabilization or immutabilization (Mackenzie 2003:18).

Put differently, any given application of ubiquitous technology may be understood to comprise its contexts of research, development, manufacture, sale, implementation, use and eventual disposal. Shifting socio-technical arrangements are negotiated in particular space-times, and it becomes impossible to reduce pervasive computing to discrete (or stable) objects of computation-or to singular representations. And so, in order to begin to understand urban computing and locative media transductively, we must seek out their intimations, or what Van Loon (2002) calls "shadows and resonances," and begin to trace their flows.

Latour (2005:108) argues that actor-network theory is unique in science and technology studies in part because of its methodological stance that the social is "to be explained rather than providing the explanation." Put another way, 
Latour's actor-network theory-a sociology of associations-is more properly a methodology:

[The] 'social' is not some glue that could fix everything including what the other glues cannot fix; it is what is glued together by many other types of connectors ... [However] it is possible to remain faithful to the original intuitions of the social sciences by redefining sociology not as the 'science of the social,' but as the tracing of associations (Latour 2005:5).

Integral to these associations are non-linear movements and changes in trajectory, as well as path-dependencies and obduracies, all of which are particularly difficult to trace during the early stages of a technology's development without also turning to research on global spaces of complexity (Thrift 1999; Urry 2003).

In what Urry (2005:1) calls the "complexity turn" in sociology, "there is a shift from reductionist analyses to those that involve the study of complex adaptive ('vital') matter that shows ordering but which remains on 'the edge of chaos"'-a position which recalls Deleuze and Guattari's (1987) de-territorialisations and reterritorialisations, Law's (2004) perspectives on messes and Latour's enthusiasm for a radical uncertainty that "tackles active, warm and extreme situations" where "controversies unfold all the way" (2005:25). A multi-scale approach-in which the global confronts the local (Ingold 1993) and the macro-micro distinction is replaced with a focus on connections (Urry 2003:122-23)-becomes necessary if I hope to trace particular associations and ultimately represent them here as the infra-reflexive, pleated texts born of "nomadic writing practices" (St. Pierre 2002:59) that I described in Chapter 2. 


\subsection{EXPECTATION, AFFECT AND THE QUESTION OF TEMPORALITY}

Compounding the challenges laid out above, to study urban computing and locative media at this point in time is still largely a future-oriented activity. That does not mean that they do not yet exist, but rather that they act in the present primarily as imaginings or visions of a "proximate future" (Bell and Dourish 2007). For my purposes then, a sociology of translation or association must also become a sociology of expectations.

Just as actor-network theory (Law and Hassard 1999; Latour 2005) has, during the past decade or so, grown in influence both within and beyond science and technology studies, the constitutive, performative and generative qualities of social expectations have increasingly been recognised as playing important and intriguing roles in technological innovation (Brown et al. 200o; Hedgecoe and Martin 2003; Brown and Michael 2003; Borup et al. 2006;). Technosocial expectations are considered to be highly situated in the sense that they occupy particular spatial geographies and demonstrate particular temporal patternings. And yet, as Borup et al. (2006:293) explain, "expectations play a central role in science and technology not least because they mediate across boundaries between different scales, levels, times and communities."

EXCERPT from fredshouse.net by Gene Becker http://www.fredshouse.net/archive/000227.html

\section{August 19, 2004}

Why Isn't Ubicomp Sexy? 
It's a well-documented phenomenon that new media technologies are fertile ground for sex-related applications; consider the VCR, personal video cameras, cable TV, CDROM, MUDs, Usenet, the web, streaming video, mobile phones, and so forth. So if ubicomp is the next great revolution in computing, architecture, media, life, the universe, and everything, how come there's no ubisex?

This is a family show, so I don't want this to seem gratuitously prurient. Nor am I advocating for an expansion of the smut industry into this new territory, given the questionable ethical and moral dimensions of the skin trade. However, I am actually curious if this is a salient question about the state of ubiquitous computing. Does the lack of an erotic underground tell us anything significant about the characteristics of today's ubicomp visions, architectures and designs? The sex industry is creative, entrepreneurial, and quick to recognize new ways to reach into people's lives and wallets. Frequently it is an early if unacknowledged pioneer for mainstream media technology practices and business models. If there aren't any sexual applications for ubicomp now, will there be compelling mainstream applications later?

Maybe ubicomp isn't the right kind of medium. Storage and networks are distribution media, so they have obvious applicability for carrying content of any variety; pron just happens to be the early adopter flavor. But ubicomp isn't simply a carrier of bits, it is an embedding of computing and communications into the fabric of life. Nobody expected cars, toasters and alarm clocks to become erotic when digital electronics were designed into them, and maybe ubicomp is more like that - a layer of functionality more mundane than amative.

Maybe it's too early. There are almost no commercial ubi-products, and thus no real channel exists yet for delivering the goods and taking money in return. Ubicomp is still the domain of researchers, and the corporate, government, and university funding sources that support most such research aren't going to be leading the charge in this direction. Museum guides, elder care, memory prosthetics and ornithology, for sure. But how about teledildonics? I'm sure there's scope for some very stimulating work in networked wearables and tangible media, but not under ${ }^{*} m{ }^{*}$ NSF grant, thank you.

Then again, maybe we haven't reached the right level of sophistication in our thinking about ubicomp's potential imprint on the sensual fabric of society. I like to think that one of the great applications of ubiquitous computing will be immersive, social storytelling, where communities of people will build persistent, multisensory story environments that combine audiovisual tapestries of media, many to many communication, and physical talismans and places, into deeply engaging experiences. It would be a true new medium, with potential for great expressive power.

Within such a medium, I suspect we would find strong new modes of erotic expression. Ubicomp could be more than just another vehicle for the repetitive, exploitive and profane depictions of sex that are so common today; ubicomp could become sexy, in the best and most powerful sense of the word.

posted by Gene at 11:48 PM 
A sociology of expectations looks to the affective roles of imagination and desire (i.e. the capacity to be moved) in shaping technological change. Like the complex relations hinted at earlier, expectations are generative in the sense they:

...guide activities, provide structure and legitimation, attract interest and foster investment. They give definition to roles, clarify duties, offer some shared shape of what to expect and how to prepare for opportunities and risks. Visions drive technical and scientific activity, warranting the production of measurements, calculations, material tests, pilot projects and models ... They play a central role in mobilizing resources both at the macro level, for example in national policy through regulation and research patronage, and at the meso-level of sectors and innovation networks, and at the micro-level within engineering and research groups and in the work of the single scientist or engineer (Borup et al. 2006:286).

And expectations are performative in the sense that they attract interest from potential allies, define roles, and "build mutually binding obligations and agendas." As a sociology of translation would also have it, expectations are "central in brokering relationships between different actors and groups" (Borup et al. 2006:289), and this scenario raises interesting questions about relations between imagination, materiality and embodiment in technological innovation. It also explicitly ties expectations to affect, as affective contagion (or lack thereof) increasingly plays a central role in processes of translation.

EXCERPTS from Gumption by Joe McCarthy

http://gumption .typepad.com/blog/2006/09/ubicomp 2006 da 1. html

September 21, 2006

\section{UbiComp 2006: Day 2}

Yvonne Rogers, soon-to-be formerly-associated-with Indiana University, gave the most provocative presentation of the day, on "Moving on From Weiser's Vision of Calm Computing: Engaging UbiComp Experiences", in which she revisited the original vision of Mark Weiser for calm computing, reviewed some of the ways ubicomp has attempted 
to achieve that vision, and raised serious questions about the capability -- and desirability - of computers to act on our behalf. I was reminded of the distinction between "strong Al", which seeks (sought?) to imbue computers with intelligence so that they could replace humans, vs. "weak Al" which seeks to enable computers to augment humans.

Adam Greenfield was invoked, yet again, in observing that much ubicomp can be characterized as "daring to intervene, clumsily, in situations that already work reasonably well". Yvonne issued a call for a Kuhnian-level shift from calm technology to engaging technology, requiring a broader scope and new agendas, themes, questions, frameworks ... and adjectives. Ubicomp should be exciting, provocative, stimulating, visible, engaging, playful and even uncomfortable, enabling people to be active creative and reflective in their work, learning and living. Amen.

posted by Joe McCarthy at 08:29 AM

http://gumption.typepad.com/blog/2006/09/ubicomp 2006 da $2 . \mathrm{html}$

\section{September 21, 2006}

\section{Ubicomp 2006: Day 3}

The field seems to be moving beyond "technology in search of a problem" (an early rant, or concern, of mine) and appears to be reaching a consensus on some problem areas: location, location and location ... and so I might recast my earlier concern as "technology in search of an application" within a problem domain. I am glad to see so much progress being made on location sensing and tracking technologies, and I do share the underlying intuition that these technologies will support useful applications. I am even happier to see a few (more) examples of ubiquitous computing applications in the service of instigating and supporting engaging interactions among people, and I hope that we will see even more examples of technosocial engagement in the future ... so that rather than -- or in addition to -- having presentations being motivated by speculative "imagine, if you will" scenarios, future UbiComp conference(s) will offer more opportunities to "experience, if you will..."

posted by Joe McCarthy at 10:53 PM

While pervasive or ubiquitous computing, like all computing, can be seen to be historically embedded within complex global assemblages of military, industry, government and public interests-including a fundamental belief in technological progress-it also currently occupies spaces that hinge on a future yet to happen, or futures that may not ever happen. Borup et al. (2006:285) claim that "novel 
technologies and fundamental changes in scientific principle do not substantively pre-exist themselves, except and only in terms of the imaginings, expectations and visions that have shaped their potential." Or as Latour rather elegantly explains,

To say something is constructed means that it's not a mystery that has popped out of nowhere, or that it has a more humble but also more visible and more interesting origin. Usually, the great advantage of visiting construction sites is that they offer an ideal vantage point to witness the connections between humans and non-humans. Once visitors have their feet deep in the mud, they are easily struck by the spectacle of all the participants working hard at the time of their most radical metamorphosis ... Even more important, when you are guided to any construction site you are experiencing the troubling and exhilarating feeling that things could be different, or at least they could still fail-a feeling never so deep when faced with the final product, no matter how beautiful or impressive it may be (2005:88-89).

All of this reinforces the idea that pervasive computing involves persistent tensions between pasts, presents and futures that make certain identities and objectives possible or probable, and others impossible or improbable. Expectations can be positive or negative, and especially in the case of technoscience, are often put in terms of utopian or dystopian futures. Expectations in such cases are also associated with the belief that technoscientific progress is both a requirement and a promise, where practitioners, advocates and adversaries of pervasive computing assume a certain technological inevitability and feel obligated to deliver the best possible product, service or alternative solution in response. 
EXCERPTS from fredshouse.net by Gene Becker

http://www. fredshouse.net/archive/000122.html

February 23, 2004

\section{Yet Another Vision of the Ubi-Future}

Not sure how old this is, but Vodafone has put together a very slick, high production value Flash site showing their R\&D lab's vision of the mobile, ubiquitous computing future. It's definitely worth a look, although you'll need some patience to get through it; there's a lot of moving parts and the designers are overly enamored with animated transitions.

So far I've gone through the entertainment scenario, and I haven't seen anything truly novel. It appears to be yet another variation on the theme of context-aware/situationaware computing, spontaneously federated devices, new //O peripherals, ubiquitous connectivity, and social media. Maybe I'm a bit jaded, but it's all starting to sound suspiciously like received wisdom. Is the pervasive computing/ubicomp vision held by so many researchers our modern version of the "personal jetpack" from the '50s?

So there's a good challenge to consider, for which Vodafone's vision is simply a convenient stalking horse: Given what we know about the tremendous advancements in the underlying technologies of computation, communication, $\mathrm{VO}$, etc, combined with our collective understanding (ahem) of human culture and society, can we create more imaginative, more insightful, more believable scenarios of the future? Can we articulate a world where ubiquitous golly-gee-whiz technologies become dull and commonplace, and the resulting long-term patterns of change in people's lives become evident? Can we take a step beyond shiny happy corporate sales tools, to consider the complex and ambivalent nature of ubicomp's impact on our lives, as these new technologies become truly pervasive and embedded in the fabric of the world?

I think it's time to re-evaluate assumptions and goals.

posted by Gene at 09:55 AM

http://www.fredshouse.net/archive/000159.html

April 05, 2004

\section{Prada Epicenter Revisited}

...Ubicomp is hard, understanding people, context, and the world is hard, getting computers to handle everyday situations is hard, and expectations are set way too high. I used to say ubicomp was a ten-year problem; now I'm starting to think that it's really a hundred-year problem.

posted by Gene at 10:22 AM 
To question ubiquitous computing today is to visit a few ruins and a host of construction sites, as well as to follow "future abstractions [and] expectant projections that alter the now" in ways that involve "the future working back on the present" (Borup et al. 2006:289). As these "wishful enactments of a desired future" are made real-or actualised-through a range of embodied interactions and material objects, "promissory commitments become part of a shared agenda and thus require action" (Borup et al. 2006:289). In these ways, future-oriented visions of pervasive computing can be seen to primarily work in the present to shape current relationships and provide particular orientations towards the past, present, and future.

\subsubsection{Affecting hope}

Put another way, technoscientific uncertainty is often countered by certain values and desires. Somewhat ironically, the failure or modification of a technological vision over time is not only common but also commonly expected. Technoscientific and techno-social expectations increasingly involve tensions between what Foucault (1980) calls "regimes of truth" and what Moreira and Palladino (2005) call "regimes of hope."

'Truth' is to be understood as a system of ordered procedures for the production, regulation, distribution, circulation and operation of statements. 'Truth' is linked in a circular relation with systems of power which produce and sustain it, and to effects of power which it induces and which extend it. A 'regime' of truth (Foucault 1980:133).

A regime of hope, on the other hand, involves similar processes that evoke, and invoke, hope. This metaphor is most often associated with, and indeed very well- 
suited to, emerging biotechnologies that stand to redefine life and death. As

Moreira and Palladino (2005:67) summarise,

the 'regime of hope' is characterized by the view that new and better treatments are always about to come, being tested, 'in the pipeline'... The 'regime of truth', on the other hand, entails an investment in what is positively known, rather than what can be.

Brown (2006) more explicitly draws out the political and ethical dimensions of this parasitic (cf. Serres 1982) relationship between regimes of truth and hope. He claims that biotechnologies are not currently debated in terms of evidence or truth, but instead involve discussions about "abstract future-oriented values representing a shift towards more aesthetic and symbolic references ... [and] from authority to authenticity" (Brown 2006; Brown and Michael 2002). This suggests that new biotechnologies are increasingly positioned not as evidential problems but as affective ones, where many different actors are assembled to negotiate affective roles. While urban computing and locative media are obviously different kinds of technoscience, the metaphor of hope plays an important role in managing expectations in those domains as well.

As Brown (2006:9-10) continues,

There is an emerging moral space developing here where failure to invest now may result in moral recrimination later. Futures and expectations are, by and large, shared attributes that in some circumstances can become embedded in what we might call 'communities of promise' ... Communities of promise are highly complex and multi-authored enterprises. It is rarely ever possible to ascribe responsibility for expectations to one actor rather than another ... [D]ifferent participants in a community of promise 'conspire' or 'collaborate' in the authorship of a future ... Agency is also complex across time as well as across present communities of promise. There are no 'first causes' but rather a long and complex prefiguring of expectations through events, practices, statements and promises stretching through time. 
And as discussed earlier, these prefigurings refer to particular interests invested in the present, or in present potentials: "To enable hope requires the coordination and management of the conduct of individuals and groups so that a particular future may come into being" (Novas 2006:291). If a particular translation has been successful, certain identities and associations become irreversible, or pathdependent. If truth can be loosely tied to materiality, and hope to imagination, then expectations can be seen as relational objects that act as 'bids' or tenders on the future (Berkhout 2006). These bids and expectations are understood to be conditional and flexible, and are integral to the complex material and symbolic transformations that occur in processes of translation and bring about particular associations.

EXCERPT from Boxes and Arrows by Adam Greenfield

http://www.boxesandarrows.com/view/all watched over by machines of loving grace some ethical guidelines for user experience in ubiquitous computing settings 1

December 1, 2004

All watched over by machines of loving grace: Some ethical guidelines for user experience in ubiquitous-computing settings

Ubiquitous computing is coming. It is coming because there are too many too powerful institutions vested in its coming; it is coming because it is a "technically sweet" challenge; it is coming because it represents the eventual convergence of devices, tools and services that became inevitable the moment they each began to be expressed in ones and zeroes.

$[\ldots]$

It should be clear that ubicomp represents a substantial raising of stakes over the Web case, the PDA case, the mobile-phone case, or other scenarios we're accustomed to; that its field of operation is by definition total; and that its potential for harm if poorly implemented is such that the user experience is too important to leave to chance, or the discretion of developers. 


\section{$[\ldots]$}

This is not an indictment of engineers. They are given a narrow technical brief, and within the envelope available to them they return solutions. It is not in their mandate to consider the social and environmental impact of their work. From our vantage point as user-experience professionals, however, it is clear that there have always been emergent properties of systems that are designed with a given end in mind - and that sometimes, those properties and effects are of much greater consequence than the intended result.

If ubicomp applications are rushed to market and allowed to appear as have so many technological artifacts in the last thirty years-i.e., without compassionate attention to the needs and abilities of all sorts of human users, without many painstaking rounds of iterative testing and improvement in realistic settings - then they will present those users with a truly unprecedented level of badness.

Imagine the feeling of being stuck in voice-mail limbo, or fighting unwanted autoformatting in a word processing program, or trying to quickly silence an unexpectedly ringing phone by touch, amid the hissing of fellow moviegoers-except all the time, and everywhere, and in the most intimate circumstances of our lives. Levels of discomfort we accept as routine (even, despite everything we know, inevitable!) in the reasonably delimited scenarios presented by our other artifacts will have redoubled impact in a ubicomp world.

Even if for this reason alone, we must ensure that this class of products and services is designed better, with more sensitivity and compassion, than others in the past.

\section{$[\ldots]$}

It is my sense that the time is apt for us to begin articulating some baseline standards for the ethical and responsible development of user-facing provisions in ubicomp applications, before our lives are blanketed with the poorly-imagined interfaces, infuriating loops of illogic, and insults to our autonomy that have characterized entirely too much human-machine interaction to date.

posted by Adam Greenfield

The situatedness of associations should also compel our attention to the situatedness of expectations. As Hayles (2005:132 \& 148) points out in regard to artificial intelligence research paradigms,

Whether or not the predicted future occurs as it has been envisioned, the effect is to shape how 'human being' is understood in the present ... [T] The relation between humans and intelligent machines thus acts as a strange attractor, defining the phase space within which narrative pathways may be traced. What 
becomes difficult to imagine is a description of the human that does not take the intelligent machine as a reference point.

\section{$[\ldots]$}

The future echoes through our present so persistently that it is not merely a metaphor to say the future has arrived before it has begun. When we compute the human, the conclusion that the human being cannot be adequately understood without ranging it alongside the intelligent machine has already been built into the very language we use.

Returning to the case of pervasive computing, such a perspective suggests that contemporary expectations about urban computing and locative media have more to do with present technosocial concerns-especially social networking and security-than serving as future predictions. Likewise, expectations about urban computing and locative media shape how we approach research in these areas today, along with our very definitions of - and how we understand relations between-humans, computers and everyday urban life.

Since this suggests that tomorrow's expectations and today's associations are bound up in rather complex (i.e. non-linear, unpredictable) ways, it may help to recall Gibbons et al. (1994) concept of "Mode 2" knowledge regimes that depend on a surplus of producers, distributors and audiences that create more and more heterogeneous and heterarchical knowledge claims. Along with the kind of interdisciplinarity that historically underpins much research in ubiquitous computing, networked technologies like the internet, and new media formats like blogs, enable associations that rely on complex inscription devices (cf. Latour and Woolgar 1986) and other attempts at material and semiotic translation across traditional boundaries. This slippage between professional and other concerns is 
further complicated by the multiple roles that researchers and others take in everyday life.

For example, at the time of writing, both Gene Becker and Joe McCarthy-whose blog posts I included above-work in ubiquitous computing research and development for Hewlett-Packard and Nokia, respectively. However, both researchers distinguish their personal opinions, posted on their personal blogs, from the opinions of their employers-and sometimes even from the work they do for them. It appears that in pervasive computing research today, not only does laboratory work open up to include more public spaces of investigation and experimentation, but so too the private lives and thoughts of scientists and engineers are folded into public discourse through weblogs and other publically accessible documentation. In these ways, technoscientific knowledge is emerging in both 'top-down' and 'bottom-up' ways.

This returns me to my earlier claim that a primary means by which all this complexity is managed is through affective relations-or the capacity to affect and be affected by others. Accordingly, affect must be approached from two interconnected perspectives: one of technological 'becoming' and one of 'hope' for particular technological futures. In the first sense, affect refers less to emotion than to what Massumi (2002) describes as the potential, indeterminant and emergent-and as Clough (2000:4) explains, "it is its participation in the virtual that gives affect its autonomy-its escape from the particular thing that embodies it." On a related note, we might also see affect as one of the means by which 
different scales or situations are bridged.

Anderson (2006) also explains that hope emerges from particular encounters, and in the case of urban computing and locative media, I am most interested in the hope that emerges from people's fearful encounters with pervasive computing's capacity to produce a profoundly dystopian future in which three models of power-Foucault's panopticon (1977), Deleuze's control society (1987) and Agamben's bare life (1998)-come together under the mandate of machinic protocols to improve everyday life. Like Lyotard before him, Jameson (1991:67) refers to the postmodern sublime as the "simultaneous apprehension of ecstasy and dread," and what becomes particularly interesting, I think, is how urban computing and locative media both emerge from, and enact, particular combinations of hope and despair.

\subsection{SUMMARY}

In the first part of this chapter, readers were introduced to pervasive or ubiquitous computing as an emergent agenda in human-computer interaction research characterised by tensions between seamless interaction and calming effects on one hand, and more transparent infrastructures and active appropriation or engaged use on the other. I showed that from its earliest debates, researchers have been divided on whether such a technosocial future would be profoundly dystopian or utopian. 
In order to better engage these tensions and other intangibles of emergent or future-oriented technologies, elements of actor-network theory along with notions of transduction, as well as sociological approaches to expectations and affect, were positioned as the most promising ways for social researchers to understand and account for the complexity of the processes at hand. A sociology of expectations looks to the affective roles of imagination and desire in shaping technological change, and expectations are seen to be performative in the sense that they attract interest from potential allies, define roles, and "build mutually binding obligations and agendas" (Borup et al. 2006:286). Such a perspective requires we ask how pervasive computing involves persistent tensions between pasts, presents and futures-and how that makes certain identities and objectives possible or probable, and others impossible or improbable.

In this chapter, I set a position from which I seek to claim that contemporary expectations about urban computing and locative media have more to do with present technosocial concerns than with future predictions. Likewise, expectations about urban computing and locative media can be seen to shape how we approach research in these areas today, along with our very definitions of-and how we understand relations between-humans, computers and everyday urban life. The following chapters draw out the implications of these claims, as I examine how research in these areas shapes understandings of new technologies, urban spaces and social relations. 


\subsection{ENACTING URBAN COMPUTING \& LOCATIVE MEDIA}

I begin this chapter by providing a necessarily brief overview of the 'networked city,' with its dynamic combinations of the material and the semiotic, the virtual and the actual. Avoiding the claim that urban computing and locative media are entirely 'new' contributions to this discourse, I instead focus on what is different and what remains the same. Starting with technological changes, I contrast cyberspace and virtual reality, and their ethics and aesthetics of disembodiment and dislocation, with the promise of augmented or mixed reality and hybrid space, and their emphases on embodiment and location.

In the second section I situate this shift within broader research agendas that move computing off the desktop, out of the lab and into the world-a move which reveals a desire to imbue physical locations and objects with networked data. Locative media and urban computing can also be seen to enact a familiar technosocial vision based on access and connectivity, but one also predicated on significant infrastructural change. Following that, related expectations and inevitabilities are raised again in order to further draw out the multiple spatialisations, temporalisations and embodied interactions that comprise these emergent technologies-and to trouble the question of technological determinism within such future visions.

By introducing the first of my case histories, Mobile Bristol, in the third section I begin to move back-and-forth between small and large stories, or different scales of research. Conversations with the Hewlett-Packard researchers return us to the 
role of affect in communicating research visions, successes and failures. In these stories we can also see processes of translation working to create particular associations and expectations, including an increased emphasis on making research 'public.'

The fourth and fifth sections reposition these concerns within broader research trajectories. Emphasis is placed on following formal mechanisms of knowledge creation and dissemination such as conferences, classrooms, workshops and journal publications, and simultaneously juxtaposing these activities with more informal weblog and popular press accounts. In this way, I draw attention to how the spaces of urban computing and locative media research and development are remarkably heterogeneous, despite sharing a somewhat homogeneous shared vision. And ultimately, I call attention to the value placed on inter-disciplinary research and 'public' involvement in order to discuss the politics of such collaborative work.

\subsection{THE NETWORKED CITY}

Once we have both a "real" three-dimensional world, and computerconstructed "virtual" ones, the distinctions between these worlds can get fuzzed or lost (Mitchell 1995:20).

If a transformation from the machine to the computer has taken place, even if it affects only the imaginary, then we need to question what has been transformed and what these changes rearrange with respect to architecture in the city, for the imaginary and the artistic are closely aligned (Boyer 1996:15). 
Arguably all cities throughout history, but specifically modern Western cities (see for example Tarr and Dupuy 1988; Goodman and Chant 1999; Roberts and Steadman 1999; Graham and Marvin 2001) have been shaped by technologies that involve dynamic combinations of the material and the semiotic, the virtual and the actual. In this sense the emergence of the 'networked city' or 'cybercities' is not exceptional. Furthermore, to claim that digital information now shapes urban experience more than the physical environment does is to deny the always already complex relations between the two. As Graham (2003:139) puts it, the "hard material basis for the 'digital revolution' is neglected but crucial ... [T]he 'information age', or the 'network society', is not some immaterial or antigeographical stampede online."

Paul Virilio has long argued that the 'real' space of the city has been colonised by information and communications technologies, along with a logic of speed (1986) that helps bring about a state of permanent overexposure (1987) where everything comes to us without us having to move. In City of Bits, William J. Mitchell (1995:107) argues that "computer networks become as fundamental to urban life as street systems" and social life necessarily comes to revolve around telepresence. Similarly, Manuel Castells (1996) claims that urban space has been transformed into a global "space of flows" characterised by people interacting in real-time without being spatially or physically co-present. However, Nigel Thrift (1997) suggests that such accounts evidence a kind of technological determinism that overstates the impact of new technologies and underestimates the social and cultural contexts in which they operate. Or as Graham (2004:18-19) explains, 
[I]t is now startlingly clear that global urbanization trends, and the intensifying use of computers, internet, telephones and digital media in social, economic and cultural life, are actually closely interrelated processes of change ... We are not experiencing some wholesale, discrete, break with the urban past that has been ushered in by the 'impacts' of new technology. Rather, we are experiencing a complex and infinitely diverse range of transformations where new and old practices and media technologies become mutually linked and fused in an ongoing blizzard of change.

In order to situate urban computing and locative media within this "ongoing

blizzard of change" it may be helpful to first look more closely at some of the changing technologies.

\subsubsection{From cyberspace to hybrid space}

The transphysical city will be suffused with intelligence. Sensors and effectors will be ubiquitous and will be linked everywhere with information utilities as common as running water. How can we begin to envision such a city? ... [T] he transphysical city will not be the postphysical city. As the prefix trans-implies, it will be at once a transmutation and a transgression of the known, but it will also stand alongside and be interwoven into that very matrix ... There is no question that urbanism as we know it will be altered, that our cities will become our interfaces to the net, that we will really be able to "reach out and touch someone" across the planet and as far as our transmissions will allow (Novak 1996).

If cyberspace is dematerialized space, the cyburg is spatially embodied computing, or an environment saturated with computing capability. It is the imminent stage of digital media that places computation in all things around us, from our own skin and bodies (biotechnology and nanotech medication), to our clothing, to our cars, our streets, our homes, and our wildernesses...The cyburg...may indeed functionally sidestep all the dystopian visions of disembodied, disengaged, socially remote cyberlife ... New capabilities of pervasive computing systems will expedite the restructuring of everyday life because they permit what we considered the context to become a bonafide agent in the public arena (Cuff 2003:44).

Science fiction writer William Gibson may be best known to academics for introducing the word 'cyberspace' into the English language, and describing this 
futuristic global computer network as a "consensual hallucination" (1984:51). But

if cyberspace is somewhere people $g o$, then hybrid space is increasingly where

people are.

Excerpt from William Gibson: The Rolling Stone 40th Anniversary Interview by Andrew Leonard

http://www.rollingstone.com/politics/story/17227831/william gibson the rolling stone 40th anniv ersary interview

Nov 07,2007

You made your name as a science-fiction writer, but in your last two novels you've moved squarely into the present. Have you lost interest in the future?

It has to do with the nature of the present. If one had gone to talk to a publisher in 1977 with a scenario for a science-fiction novel that was in effect the scenario for the year 2007, nobody would buy anything like it. It's too complex, with too many huge sci-fi tropes: global warming; the lethal, sexually transmitted immune-system disease; the United States, attacked by crazy terrorists, invading the wrong country. Any one of these would have been more than adequate for a science-fiction novel. But if you suggested doing them all and presenting that as an imaginary future, they'd not only show you the door, they'd probably call security.

\section{What are the major challenges we face?}

Let's go for global warming, peak oil and ubiquitous computing.

\section{Ubiquitous computing?}

Totally ubiquitous computing. One of the things our grandchildren will find quaintest about us is that we distinguish the digital from the real, the virtual from the real. In the future, that will become literally impossible. The distinction between cyberspace and that which isn't cyberspace is going to be unimaginable. When I wrote Neuromancer in 1984, cyberspace already existed for some people, but they didn't spend all their time there. So cyberspace was there, and we were here. Now cyberspace is here for a lot of us, and there has become any state of relative nonconnectivity. There is where they don't have Wi-Fi.

In a world of superubiquitous computing, you're not gonna know when you're on or when you're off. You're always going to be on, in some sort of blended-reality state. You only think about it when something goes wrong and it goes off. And then it's a drag.

\section{Is there a downside to that blended reality? Or could it represent a change for the better?}

People worry about the loss of individual privacy, but that comes with a new kind of unavoidable transparency. Eventually we're going to know everything that every twenty-first-century politician has ever done. It will be very hard for politicians and governments to keep secrets. The whole thing is porous. We just haven't really figured out quite how porous it is.

How would you define the current moment? In your most recent novel, "Spook Country," the pervasive sensation is that the times are fraught. 
Fraught? [Laughs] Fraught is very good. I was going to quote Fredric Jameson about living in the simultaneous apprehension of dread and ecstasy, but l've already done that today. Yep. Fraught. Period.

The types of ubiquitous or pervasive computing of primary interest in my thesis are those that openly seek to create unique forms of inhabitable space and means of habitation-thereby raising issues of spatialisation, temporalisation, embodiment and affect. So-called mixed reality technologies are explicitly concerned with such questions, and mixed reality environments refer to spaces that combine elements of the physical and virtual worlds. According to Milgram et al. (1994:1), "rather than regarding the two concepts simply as antitheses, however, it is more convenient to view them as lying at opposite ends of a continuum, which we refer to as the Reality-Virtuality (RV) continuum." At one end of the continuum are seen to be "real" objects that can be observed directly or "sampled and then resynthesized via some display device," while at the other end are "virtual" objects that are "simulated" through "some sort of a description, or model, of the object" (Milgram and Kishino 1994:1).

Mixed reality comprises anything between the two extremes of the spectrum, and combines aspects of both to create a hybrid environment. The two most common types of mixed reality technologies are "augmented reality" and "augmented virtuality." Augmented reality seeks to enhance physical spaces and objects with virtual reality; augmented virtuality seeks to enhance virtual reality with realworld data and objects. Of interest here is augmented reality, which attempts to overlay physical objects with virtual objects in real-time and allows people to 
experience the virtual as if it were real (Azuma 1997). In some ways, augmented reality has the same ultimate goal as virtual reality: to create new interactive spaces through computation. Where they differ is in how they see this best accomplished, which, in part, involves their assumptions about space, time and the body.

While augmented reality is much closer to Weiser's vision for ubiquitous computing than is augmented virtuality, the term 'amplified reality' may be most relevant to my interest in affect, aesthetics and ethics:

While augmented reality is about enhancing our impressions of everyday objects in our surroundings, amplified reality is about enhancing the expressions of objects and people in the world ... An amplified object is self-contained in regards to its properties. In practice, this means that the properties are embedded parts of the object. In contrast, augmented reality superimposes virtual properties on an object, which in effect does not change the actual object, but rather how we perceive or experience it. Augmented properties are not persistent outside the augmented reality. The important difference between these two approaches lies in the proprietary rights to the information. An amplified object controls the flow of information, while in an augmented reality system the perceiver is in control of the information ... In other words, an augmented reality systems alters the impressions of its user, without there being any corresponding properties in the expression of the object she is perceiving. This is quite different from ordinary life (Falk et al. 1999:3).

Perhaps most notable in this description is the introduction of computation as a material for designing not only the digital realm but also the physical world (see also Orth 2001, Redström 2001), and a shift from concerns with the functional use of computers to the presence, expressions and aesthetics of computational artefacts in everyday life (Hallnäs \& Redström 2001). 


\section{Excerpt from City of Sound by Dan Hill \\ http://www.cityofsound.com/blog/2008/02/the-street-as-p.html}

\section{February 11,2008}

\section{The street as platform}

The way the street feels may soon be defined by what cannot be seen with the naked eye.

Imagine film of a normal street right now, a relatively busy crossroads at 9AM taken from a vantage point high above the street, looking down at an angle as if from a CCTV camera. We can see several buildings, a dozen cars, and quite a few people, pavements dotted with street furniture.

Freeze the frame, and scrub the film backwards and forwards a little, observing the physical activity on the street. But what can't we see?

We can't see how the street is immersed in a twitching, pulsing cloud of data. This is over and above the well-established electromagnetic radiation, crackles of static, radio waves conveying radio and television broadcasts in digital and analogue forms, police voice traffic. This is a new kind of data, collective and individual, aggregated and discrete, open and closed, constantly logging impossibly detailed patterns of behaviour. The behaviour of the street.

\section{$[\ldots]$}

So the patterns of data in the streets, the systems that enable and carry them, the quality of those connections, their various levels of openness or privacy, will all affect the way the street feels rather more than street furniture or road signs. Holes in data, public and private, may become more relevant than the pothole in the pavement - until you trip over it, at least.

\section{$[\ldots]$}

In many of these instances there are decisions to be made about openness, responsibility, privacy, security, interaction, experience. Some of these will be directly under the aegis of government, some through public-private partnerships, some though architects of the built environment, some through architects of this informational environment, some through commercial enterprises, some through NGOs, some through municipal institutions, some through education, some through individuals or community groups, and so on. There are decisions to be made about raw infrastructure - the equivalent of transport networks and power supply ... Without this infrastructure, the street only half-exists, becoming a residual dead-zone in the city. And yet should areas on the street deliberately be dead-zones, shielded from connectivity in order to provide respite, reflection, quietude? How is that to be managed and conveyed?

Posted by Dan Hill

Since ubiquitous computing is considered to involve a "post desktop" interaction paradigm, and much of 'everyday life' takes place at the interpersonal scale in urban settings, it should come as no surprise that the city itself has emerged as a primary interaction design space for a variety of practitioners. By the early 
2000s, wireless technologies had become more affordable and widespread, making exploration in this area more widely accessible to a range of interested parties. Since 2000 there has been notably increased academic and corporate research interest in what has become known as "urban computing" (Greenfield and Shepard 2007; Kindberg, Chalmers and Paulos 2007) or "urban informatics" (Ellison, Burrows and Parker 2007). At the same time, "locative media" artists and activists have also been working with Global Positioning System (GPS), Geographic Information Systems (GIS) and various mobile technologies to 'annotate' places or physically overlay physical spaces with digital information. Following Amin and Thrift (2002), as well as Dodge and Kitchin (2005), Crang and Graham call these emerging urban spaces "sentient cities," where "the city becomes a haze of software as much as a constellation of bricks and mortar" (2007:790) and ask "what happens when the processing and not just the data is embedded in the everyday environment?" (2007:792). In order to answer that question, we can begin by asking more questions about technosocial expectations surrounding pervasive computing.

\subsection{OFF THE DESKTOP, OUT OF THE LAB, AND INTO THE WORLD}

Since the late 1990s, researchers in places like the industry-sponsored and university-based Auto-ID Labs (http://www.autoidlabs.org/) have been working exclusively on "automated identification technologies and applications" such as Radio Frequency Identification (RFID) and Near Field Communication (NFC). If the previous chapter sought to draw out the social reach of future computing, a 
fragment of the Auto-ID Labs' vision clearly identifies the infrastructural

magnitude of pervasive computing, networked objects and hybrid spaces, and

recalls Araya's (1995:234) predictions that the world would be seen in terms of

"surveillable things":

The Auto-ID Center envisions a world in which all electronic devices are networked and every object, whether it is physical or electronic, is electronically tagged with information pertinent to that object. We envision the use of physical tags that allow remote, contactless interrogation of their contents; thus, enabling all physical objects to act as nodes in a networked physical world ... A networked physical world requires a system that includes all traded objects in the world. Such a system must scale to unprecedented proportions, quickly becoming the largest man-made system ever ... Metcalfe's Law explains that the value of a network is the square of the number of users it has. When we apply the law to a network of physical objects of the scale required in our vision, it is clear that a single, open architecture for networking physical objects is much more valuable than smaller scale alternatives ... The critical design feature for our open architecture system is the separation of the information about an object from the object ... We propose assigning a wholly unique, searchable identification number to each physical object. We call this number an EPC, or Electronic Product Code. This number is analogous to the IP (Internet Protocol) address given to compute nodes on the Internet. It is also somewhat similar to the UPC/EAN (universal product code/international article number) system, although where UPC/EAN identifies types of object, the EPC uniquely identifies each individual object (Sarma, Brock and Ashton 2000:5-7).

At the same time, Hewlett-Packard researchers put a similar vision into more consumer-friendly language:

The convergence of Web technology, wireless networks and portable client devices provide new opportunities for computer communications systems designs. At HP Labs we have been exploring these opportunities through an infrastructure to support "web presence" for people, places and things. Our goal is a bridge between the World Wide Web and the physical world we inhabit. It also includes the ability to provide people, places and things - electronic or otherwise - with a web resource that is used to store information about them and which is automatically correlated with their physical presence. We aim to provide users, particularly mobile users, with support for their everyday activities, which mostly concern physical objects other than PC's (Kindberg et al. 2001:1). 


\title{
Excerpt from Internet of Things by Sean Dodson
}

\author{
http://www.guardian.co.uk/technology/2003/oct/09/shopping.newmedia
}

\section{Thursday October 9, 2003}

The tiny microchip measures less than a third of a millimetre wide, little bigger than a grain of sand. It can contain information on anything from retail prices to washing instructions to your medical records. It might look innocuous, but invisible to the naked eye is a microscopic antenna that allows it to be read by a scanning device with a maximum range of $100 \mathrm{~m}$. The tiny chip is called a radio frequency identification tag and last month, in Chicago, it was heralded as the global successor to the barcode.

First deployed by the Royal Air Force during the second world war, radio frequency identification (RFid) is a technology that has been rapidly shrinking in size and cost. Secreted into the swipe cards we use to get into work, injected into our pets if we migrate abroad, even attached to the wrists of POWs during the war in Iraq, the eversmaller tags have become an integral part of our lives without many of us noticing.

That is, until now. Last month, a controversial network to connect many of the millions of tags that are already in the world (and the billions more on their way) was launched at the McCormick Place conference centre on the banks of Lake Michigan. Roughly 1,000 delegates from across the worlds of retail, technology and academia gathered for the launch of the electronic product code (EPC) network. Their aim was to replace the global barcode with a universal system that can provide a unique number for every object in the world. Some have already started calling this network "the internet of things".

The launch of the EPC came just weeks after Wal-Mart - the biggest retailer in the world - demanded that its main 100 suppliers place RFid tags on all its pallets and cases by 2005. But just as the tags begin to be placed on retail items, a small but determined opposition is stirring up a storm of protest.

Chris McDermott is 34 . He is married with children and works as a PR manager for a diet firm. In his striped rugby shirt, he looks nothing like your archetypal activist. As he sips a coffee in downtown Swindon, he says he has never protested before. He has a new baby, a new job and is in the middle of moving house. And yet about once a month, McDermott steals an afternoon to stand outside the Sandhurst branch of Tesco to protest about RFid.

"This could be the ultimate surveillance tool," he says. "The idea that everything that is made could soon have a tiny chip in it that can be readable. That's what scares me the most." McDermott, who last month launched an anti-RFid website -NoTags.co.uk - says he has no problem with companies using RFid in its supply chain management. But he fears we will lose our privacy unless the tags are kept off individual goods.

McDermott counts himself as one of the first of a dedicated band of activists. This global opposition revolves around a small, but influential, pressure group called Caspian (consumers against supermarket privacy invasion and numbering) run by Katharine Albrecht. What makes this new generation of privacy advocates picket supermarkets and 
lobby politicians is the desire to create a greater public awareness of RFids and the EPC network before both become commonplace.

The EPC network is run by an organisation called the Auto ID Centre: a global consortium of retailers and academics based at the Massachusetts Institute of Technology (MIT) in Boston. Founded in 1999 by Gillette, Proctor \& Gamble and Unilever, the consortium now boasts 100 global companies and five of the world's leading research centres, including the University of Cambridge and MIT.

The centre came up with the concept of the internet of things. This poetic description can be expressed as the building of a global infrastructure for RFid tags. You could think of it as a wireless layer on top of the internet where millions of things from razor blades to euro banknotes to car tyres are constantly being tracked and accounted for. A network where, to use the rhetoric of the Auto ID Centre, it is possible for computers to identify "any object anywhere in the world instantly".

"It is a simple concept with enormous implications," reads its website. "Put a tag - a microchip with an antenna - on a can of Coke or a car axle, and suddenly a computer can 'see' it. Put tags on every can of Coke and every car axle, and suddenly the world changes. No more inventory counts. No more lost or misdirected shipments. No more guessing how much material is in the supply chain - or how much product is on the store shelves." In a sense, it is a future where pretty much everything is online...

By 2002, Forbes Magazine was reporting on Auto-ID Labs' work and what Kevin Ashton, executive director of the Auto-ID Center at MIT, called "The Internet of Things." Early mass media reports like the one in Forbes described scenarios where consumer products embedded with RFID tags "which bear a unique number known as an electronic product code, will let businesses track what customers are buying"

(http://www.forbes.com/technology/forbes/2002/0318/155.html). Returning to Hewlett-Packard's vision, rather than the RFID-centric vision evoked by the Auto-ID Labs and their partners, the broader desire to "enhance physical entities with virtual services" (Kindberg and Barton 2000:1) is of primary interest here, as it comes closest to the promise and the peril associated with ubiquitous computing by HCI researchers in the early 1990 s (see Chapter 4, Section 4.1). 
Understanding that the Internet contains enormous amounts of information on

particular places, but remains physically distanced from them, HP researchers

believe that:

[T]he physical world and the virtual world would both be richer if they were more closely linked. More and more of the physical world is becoming "smart", and users need a convenient framework in which they can benefit from the smart artifacts around them ... Our goal is a seamless marriage of the World Wide Web with the physical world we inhabit ... People are, of course, the users of things and the occupants or visitors in places. Places have a special role as the venue or container for people and things. Our goal is to expand our access to people, places, and things by bridging them to the virtual world of web content. We want to make people, places, and things web-present (Kindberg et al. 2000:1-2).

The ability, then, to imbue physical locations and objects with networked data emerged not only as a social vision based on consumer capitalism, access and connectivity, but also one predicated on substantial infrastructural (i.e. physical, political and economic) change. Again, the totalising quality of this vision may well distinguish pervasive computing from any of its predecessors, all while evoking profound (and historically familiar) senses of both hope and despair for our shared technological future.

\subsubsection{The temporality of expectations and technological determinism}

Now, for most people 'computing' is what happens inside the ugly boxes that sit on our desks. But those desk-top boxes are old news. They are the steam engines of computing. Today's computing is everywhere-but nowhere to be seen. The world is already filled with 30 computer chips for every man, woman, and child on the planet. In 1998 some 4.8 billion microprocessors were sold; only 2.5 percent of those were for personal computers. The other nearly 4.7 billion chips went-where? They went everywhere. They're like cockroaches. Only smarter ... But do all these chips make for better products? Or a better life? Let me tell you a strange thing. Hardly anyone is asking that question ... We are designing a world in which every object, every building - and nearly every human bodybecomes part of a network service. We may not have set out to design such an outcome, but that's what we're going to get. Unless things change, we'll achieve 
pervasive computing and ubiquitous networking without having forethought the effects this will have or the quality of life we are bequeathing our children (Thackara 2001:48)

So far I have presented a world of ubiquitous computing that exists primarily in discursive terms. In other words, these are some of the things expected from pervasive computing in the near future. In early 2006, I was thinking about the connections between technosocial expectations and the kind of 'soft' technological determinism embodied in people's assumptions that technological 'progress' in these areas is inevitable.

\section{EXCERPT from purse lip square jaw by Anne Galloway}

http://wmw.purselipsquarejaw.org/2006/02/technological-inevitability-and.php

Monday, February 13, 2006

\section{Technological inevitability and intervention}

In my interviews, we discussed the "whys" of locative media and among the answers were: "we're doing it because we can' and 'we're doing it because they're doing it, whether we want them to or not'. In both cases, and in articles like this too, technological development and implementation is considered absolutely inevitable, and by extension, natural or normal.

This same belief in inevitability has also figured prominently in my informal discussions with designers over the past few years. Comments typically go something like this: 'ubiquitous computing isn't just coming, it's already here, and our efforts should go towards doing it right'.

In fact, it has been very rare for a discussion to engage the possibility of no technological intervention at all. And trying to discuss how someone's career is heavily invested in maintaining this sense of inevitability around technology is rife with social dangers. (Let me just say it's amazing how quickly a conversation amongst friends can deteriorate into accusations of academic arrogance or irrelevance!)

But where I'm struggling the most...is around the matter of intervention. In other words, if pervasive computing is inevitable, what's the best we can do? What are the limits on our agency? If ubicomp is going to be different or better than what we've made so far, why are we still resorting to utopian/dystopian discourses just like we did in the early days of the internet?

posted by Anne at 08:12 
This post-in which I linked a news story to my research concerns-generated twenty comments totalling seven single-spaced pages of text. The almost exclusively male commenters included a new media policy researcher and $\mathrm{PhD}$ student (UK), a ubicomp researcher at Hewlett-Packard (US), an independent scholar (CA), a research and communications consultant (US), a writer and consultant (US), a photographer (US), an anonymous author and me. Four of the comments were my replies to other comments, and seven comprise a direct backand-forth dialogue between two people. Under half of the comments refer directly to my post, and the rest focus on the content of other comments. These conversations-it is not right to call it $a$ conversation-took place over a period of four or five consecutive days.

Together, they can be seen as typical of the kind of discourses afforded by blogs in general, and by my blog in particular. Blog conversations are usually rapid and short-lived, with occasional bursts of emotional intensity relative to the topic at hand. They are highly performative in the sense that authors know they are being read by more people than are writing, and they know that their words are being archived. Yet they also have a temporary or ephemeral quality, as readers also know that they will be replaced by new posts, eventually pushing the entire matter off the front page of the blog. Put a bit differently, these conversations tend to be read only when they are happening. To read them here, then, is to profoundly alter their sense of online presence and immediacy. 
In terms of relations between the commenters, I had met several of the authors in person, and all but one or two had commented on my blog before. Some of them also knew some of the others, either online or offline, and the rest of us were effectively strangers. The register of our conversations could be described as passionate-about pervasive technology, about the role of technology and technologists in society, about asking questions, about taking positions and staking claims. Indeed, the content of this particular set of conversations was very interesting.

One author brought up the matter of complexity, and tied it to the logic of capitalism and the culture of speed:

What I always find missed in these discussions is the issue of "complexity" -- not complexity in the "complicated or tangled" sense of the word, but in the "powerful, productive" sense. Complex systems produce, and not knowing what they produce (or are capable of producing) does not slow them down. Likewise, they are not constrained by anyone's good intentions. About all that's assured is that the more complex a system, the more it is capable of doing and the more it will eventually do if allowed to.

The real complexity in computers is not in the individual devices but in the connections between devices. The resulting system is "greater than the sum of its parts." The most complex "devices" on earth are people. When computers enable or facilitate connections between people the level of complexity in the whole System jumps up. Way up. Some guy named Tim devises a way for computers to help scientists share and cross-reference documents and, viola!, out pops porn sites and Amazon.com and ...

This is what technologists never want to talk about (or think about). If they crank up the complexity they may get the result they are after, but they will also get a lot of things they never intended. It is very difficult to evaluate and adjust for this unintended complexity. More difficult is getting an employer or investor to fund such evaluations. 'We've got the product you've paid for done but now we'd like a few more years to study what else the complexity it creates is capable of ..." 
The other factor to consider when looking at these issues is that in today's world technology advances in a market driven "vehicle" and, as everyone knows, the market drives way over the speed of reason. Market capitalism's great strength is its complete blindness. It just goes wherever, running over whatever. And the market's greatest trick is that no one's to blame - no one is responsible for the complete lack of moral or ethical behavior of the market. More precisely, everyone's to blame and therefore no one is responsible.

My feeling, Anne, is that the sense of inevitability is justified not so much because technologists just love making new stuff, but because there is that blind, reckless, "full speed ahead and damn the consequences" market system pushing them on, grabbing anything and everything they come up with just to see if it will help the profit margins.

While this comment clearly sides with the belief that pervasive computing is inevitable, it may not be correct to characterise it as technologically deterministic. More specifically, understanding expectations and how particular assemblages shape them requires a more nuanced understanding of temporality. In fact, another commenter asked specifically about the timescale of pervasive computing development to which I was referring:

Which bits of pervasive computing do you see as inevitable, and on what timescales? There are lots of moving parts to this ubicomp thing; some pieces are here today (phones, mp3, GPS and similar gadgets, mostly isolated islands and closed networks), some are 10 years away (arphids in widespread consumer uses), some are probably 50+ years out (animated ice cream carton displays that show the life stories of the cows that gave the milk, the migrant workers that picked the cacao beans, etc). Some ubicomp predictions are simply naive or boldly incompetent ideas that will never survive practical implementation or market forces. I would not be too quick to paint a broad brushstroke of inevitability. And where intervention is called for, good news, I think we have some time to respond.

And yet another commenter suggested that I:

Begin with intervention and then ask how the sense of inevitability shapes the possibilities and types of intervention. The sense of the inevitable sometimes leads to action designed to limit negative affects. Very often the sense of a big thing coming leads to a rush and the adoption of a series of quick guerilla-like interventions. The sense of the inevitable shortens the time span imagined for interventions. 
A less monolithic view where there is a bit of a crack in the monument of inevitability may also lead to an appreciation of multiple temporalities for various interventions.

I thought these were very important questions and suggestions, but was unsure

how to proceed until later the same year. In the October 2006 European

Association for the Study of Science and Technology (EASST) Review, Lars

Risan tackled the question of technological determinism, temporality and the

differences between 'small' and 'large' stories in science and technology studies-

all of which directly bear on the subject of my dissertation. He tells a story worth

repeating here at length, and ultimately issues a call for scholars:

I left EASST 2006 to go to Geneva airport by train, and started doing this speculation. The train was scheduled to leave Lausanne at 16:17 and to arrive Geneva Airport 43 minutes later. I had reasons to believe it would be fairly on time in Lausanne and actually use about 43 minutes (being in Switzerland ...). The train was on time and it used 43 minutes.

Was I being a "technological determinist" in believing in the inevitable and technologically determined unfolding of a future, a future "determined" by the Swiss railway system? No, I think I was not. This is not what we mean by that term. So, then, how do we analytically separate the possible or impossible inevitability of the future from a case such as the stability of the Swiss railway system? I suggest we do it by separating the (alleged) inevitability of the future from the inevitability of the present. There is such a thing as the inevitability of the present. The present is inevitably here. Thus, when travelling with a train in Switzerland, the whole trip is part of a present. The event or duration, the "chunk of time", that is the present in relation to such a trip includes the whole trip. This present is not a given. It is an achievement, an achievement of the Swiss railway system (In Britain it is not the same kind of achievement, and the present is a different thing when travelling with trains in the UK). Doing the trip from Lausanne to Geneva was an unfolding of a present. And the present has to unfold, as it is not a moment, but a duration.

\section{[...]}

If, then, we want to criticise technological determinism, we should not criticise descriptions when they describe an unfolding of a present, even when that present consists of a long chunk of time, like, say, 20 years ("cars and roads will still be the dominant machinery of transportation in 20 years time").

If, however, we want to argue that a particular unfolding of events is an unfolding of a present time, we have to argue the case empirically. It cannot be assumed. 
And the arguing may be difficult and uncertain. There are epistemic uncertainties: often we may not now - because we have not figured it out - if some event belongs to the present or the future. And there are ontological uncertainties, notably in accidents when the future interrupts the present... (Risan 2006).

I immediately began to think about whether urban computing and locative media were happening at different times or scales than pervasive computing, as well as when and where, exactly, any of the activities associated with any of these domains was happening. At the time of writing, the only research paper on ubiquitous computing to specifically question its temporal dimensions is Bell and Dourish's (2006) “Yesterdays' tomorrows: notes on ubiquitous computing's dominant vision" In it, they explain that

the dominant tense of ubiquitous computing writing is what we might call the "proximate future." That is, motivations and frames are often written not merely in the future tense, describing events and settings to come, but describe a proximate future, one "just around the corner." The proximate future is invoked in observations that "Internet penetration will shortly reach..." or "We are entering a period when..." or "New technological opportunities are emerging that..." or "Mobile phones are becoming the dominant form of..." A brief perusal of proceedings of recent conferences confirms the pervasive sense of the proximate future; of the 108 papers comprising the Ubicomp conference proceedings between 2001 and 2004 , fully $47 \%$ of the papers are oriented towards a proximate (and inevitable) technological future (e.g., from only Ubicomp 2004, and more.) Indeed, Weiser's foundational article originally published at the start of the last decade of the twentieth century and entitled "The computer for the twenty-first century" is, similarly, built around a vision of the proximate future, the future just around the corner or over the horizon (Bell and Dourish 2006:134).

Is this near or "proximate" future best understood as part of the future, or part of the "unfolding” present described by Risan above? Certainly, by claiming an immanent future, researchers are able to align themselves with existing, and present-focussed, commercial markets, research agendas and funding opportunities. While Bell and Dourish point out that future-oriented visions tend 
to tell us more about the present than they do the future, their biggest concern seems to be that the 'wrong' future is being mobilised today. Such a position may be seen as critical, but it also maintains their investment in a particular present and proximate future. The mangle of pasts, presents and futures can also be seen as an example of "long and complex prefiguring of expectations through events, practices, statements and promises stretching through time" (Brown 2006:10).

Returning to the blog post above, and a very present perspective, one author wrote:

As to your question what is the best we can do? I'm not quite sure what you mean, but my humble opinion is 1) Fight constantly and unwaveringly for designs, architectures and technical standards that admit openness, access, transparency, and individual freedom to create. Resist walled gardens, closed architectures, and centralized control of the new ubimedia. 2) Quest for and demonstrate the potential for beauty, inspiration, creative expression, to elevate our sense of humanity. There will be plenty enough dystopian thinking to go around in a pervasive world; try to fill the world with light and insight. It sounds really loony but I mean this seriously -- this is one of the central design challenges we (should) face as we go about filling our world with the technoclutter of convenience.

Although I tended to agree in principle, and still do, I added:

In my mind, as it stands right now, we have terribly inadequate forums for negotiating what we want and what we don't want, let alone infrastructure in place to deal with unintended consequences as they manifest themselves in the coming years.

And, again, the response was quite thought-provoking:

So today the "forums for negotiating what we want and what we don't want" are primarily 1 . open markets; 2 . institutional regulation (courts, government agencies, NGOs); 3 . special interest groups (NRA, Sierra Club, Christian Coalition in the US...); 4. grassroots activism (CASPIAN/SpyChips, antiglobalization movement, etc). And yes these do seem rather inadequate, but like 
it or not they are the systems that have evolved as the way we have society-wide "discourse" about what we do and do not want.

As [another commenter] pointed out earlier, I don't know how we make mainstream researchers and designers accountable for challenging marketdriven inevitability, as they tend to be embedded in the commercial system and driven by its goals. For all the talk about "user-centered design", most design work is actually "profit-centric" at its core. Resisting the status quo has historically been the province of artists, activists, and visionary individuals, and these people frequently operate at the fringes, marginalized in their influence by better funded, more powerful and entrenched interests.

Maybe this is a useful angle - could/should researchers and designers align with (or become) artists and activists and visionaries working from a perspective outside the commercial system? Fewer Nielsen/Normans, IDEOs and frogs, and more PAIRs, SRLs and Jeremijenkos? And would such non-commercial motivation result in interventions that are objectively "better" at identifying and coping with the consequences of tech or non-tech choices?

In fact, my very interest in urban computing and locative media arose directly from such collaborations. Unlike more technologically driven examples of ubiquitous or pervasive computing, my initial attraction (see Galloway 2003) to the field was in large part motivated by the explicit desire of artists and activists to intervene-as producers of technology and knowledge-in what has long been the exclusive domain of scientists and engineers.

In order to grasp urban computing and locative media, I have found it most productive to move back-and-forth between large-scale accounts of pervasive computing (like what $I$ have presented so far) and small-scale accounts of urban computing and locative media (like what I will present next as case histories). As Risan (2006) suggests, telling the difference between something happening in the present and happening in the future is difficult. But by focussing on technosocial expectations, we can see how particular relations are being enacted in the 
present, and how they recall particular pasts in order to position particular futures-and not others.

\subsection{CASE: MOBILE BRISTOL}

A research and development programme run by Hewlett-Packard Laboratories in Bristol, UK between 2002 and 2005, Mobile Bristol sought to

provide an experimental test-bed for technology and user value research in pervasive mobile media [by] investigating how mobile devices and pervasive information technology can be used to enhance the ways in which residents and visitors experience and interact with their physical environment and with each other in urban and public spaces (http://www.mobilebristol.com/).

As discussed in Chapter 2, Section 2.2.1, in $2004 \mathrm{I}$ interviewed four members of the Mobile Bristol team but for the purposes of this thesis, I will only include my conversations with Phil Stenton, the project lead, and Richard Hull, one of the primary investigators-both of whom focussed on the programme as a whole, rather than on its individual applications.

Sitting on a comfy couch in a lab that reminded me of a rec room, I asked Richard Hull how the Mobile Bristol project started: Who were the partners? How was the project funded? He politely answered both questions in less than thirty seconds, and then took time to tell me what might better be described as a genesis story or creation myth:

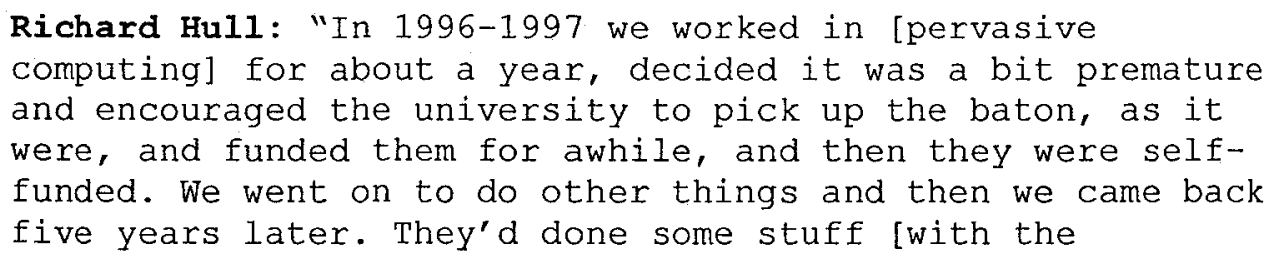


technology] in the meantime so it was a really good time to
get together again. As ever, these things are a combination
of the perspective you've gained through your past work, and
the position you find yourself in, and chance. Some of it is
opportunistic. Phil just happened to be working on a
proposal to get money to fund this kind of work, we'd worked
together in the past, we know each other, we like each
other, it all comes together, there was a moment where it
made sense to do it, so that's what we did. [We] worked
together, and also with a university person, to put together
the programme, a proposal, to shape it to go to [the
Department of Trade \& Industry], to go through endless
rounds of reshaping to meet their criteria. That took about
eight or nine months. In the meantime, we just started doing
the stuff on the assumption that we would get the money. It
was a very small team to begin with and we just started
building exemplars of the kinds of experiential applications
we had in mind."

Although Mobile Bristol officially started in November 2002, everyone I spoke with was quick to point out that work had begun well before then. A lengthy leadup time was attributed to writing and submitting the funding proposal itself, but the conditions that made the proposal possible, as well as a viable option to pursue, were seen to extend much further into the past. In the excerpt above, Richard mobilised HP research conducted five years earlier, as well as his entire career experience, as elements necessary to the project. He also clearly acknowledged challenges along the way: the technologies that needed to be created, the need to find researchers outside HP to get certain work done, the proposals that needed multiple revisions, etc. At the same time, he also stressed the role of chance and serendipity in finally creating "a moment where it made sense to do it."

Richard's story evidences a certain amount of technological inevitability or determinism, insofar as HP imagined a technological future and set up research 
years ago that could eventually make this future happen. However, reaching that point and being able to act on it were not the kind of smooth processes or sharp breakthroughs we might associate with technological innovation. And even as sufficient technology became available in the present, their focus was driven by the past and yet still future-oriented:

Imagine a digital landscape overlaying the physical world. As we walk around this landscape, we can tap into the digital sounds, sights and interactions that are positioned in the landscape and activated by our presence and actions.

The digital landscape is formed from a dynamic and overlapping set of mediascapes which are context-sensitive combinations of digital media and interactions created and deployed by various authors.

The project has created a toolkit, which provides a digital canvas over the physical landscape onto which digital experiences can be painted and new commercial opportunities can be explored.

As people walk through the physical environment, a diverse range of digital media experiences augment the ambiance and bring these spaces alive (http://www.mobilebristol.com/).

The project or programme was also inevitable or deterministic in the sense that the researchers started developing things before all the formal sanctions were in place. Although they were technically subject to institutional constraints, there were sufficient resources-notably a shared vision and HP support-to begin work. In other words, the Hewlett-Packard researchers were moved by their vision of, and support for, a "digital landscape" that could unfold right outside their windows-and they hoped that everything would just work out in the end. 
In my conversation with Phil Stenton we can see a similar bid on the future, but

one that focusses more explicitly on what and who 'belongs' in the present

\section{landscape:}

Phil stenton: "It occurred to me that in all these [other] labs, whether university or corporate research, particularly in the area of pervasive computing and wearables, people would build something like a cyber-jacket. They'd wear it around the building, they'd collect the data, write the paper and then push the technology on a bit more. Because that's what their job is, to push the technology forward, leaving a trail of wisdom in the form of published papers. But what about the rest of the folks out there who would determine whether the technology was going to stick, whether the types of applications you put it to would be the things that people welcome into their everyday lives? What emergent things would happen if you give this technology to people? Sometimes, the use you think it's going to be put to doesn't happen and something else comes out of it. You only get that, 1) by giving it to the eventual users, your target users, and 2) by getting people who aren't computer scientists or getting an eclectic bunch of people together to come at this from different perspectives, who have different ideas about what's valuable and what isn't, and getting them into the design process.

What I wanted to do was something that makes the technology and the ability to do experiments more accessible to more people. The aim of Mobile Bristol was to lower the bar for people to try ideas and increase the scope of the number of people who could experience those ideas ... I put the idea to the DTI that we would create a test bed in Bristol of a wired and wireless infrastructure that would network devices together, that people could carry around with them, that would deliver media and basic experiences. Mobile Bristol is a test bed. The applications are aimed at being exemplars, like look there is this technology and these are some things you can do with it in education, in leisure,' and let people come in and say, 'oh, we've got an idea'."

Me: "But why the city at large?"

Phil: "Because we're here, at the edge of Bristol and Bristol has a good media industry. And because the city provides a rich arena in which to try these things out. From people using the city as a working environment, to tourism, 
to councils trying to provide services to the many people who live here or come through Bristol. There's a rich set of potential applications."

In his story, Phil conjures a sense of responsibility that goes beyond 'knowledge for knowledge's sake' and opens up research and design practice to include those who have traditionally been excluded. But perhaps what makes this part of his story so intriguing is that it tempers the kind of social and political utopianism that so often accompanies more 'public' engagement with technoscientific innovation. For example, while Phil emphasises the importance of involving "more people" it is always, in part, to improve research practice and create more 'meaningful' products. Getting a glimpse of unintended, or unanticipated, effects (a positive event) is considered to be much more likely if different people are directly involved, and the more people making stuff, the better. Put another way, while external 'users'-both individuals and communities-stand to benefit from such an approach, their success is also the research success:

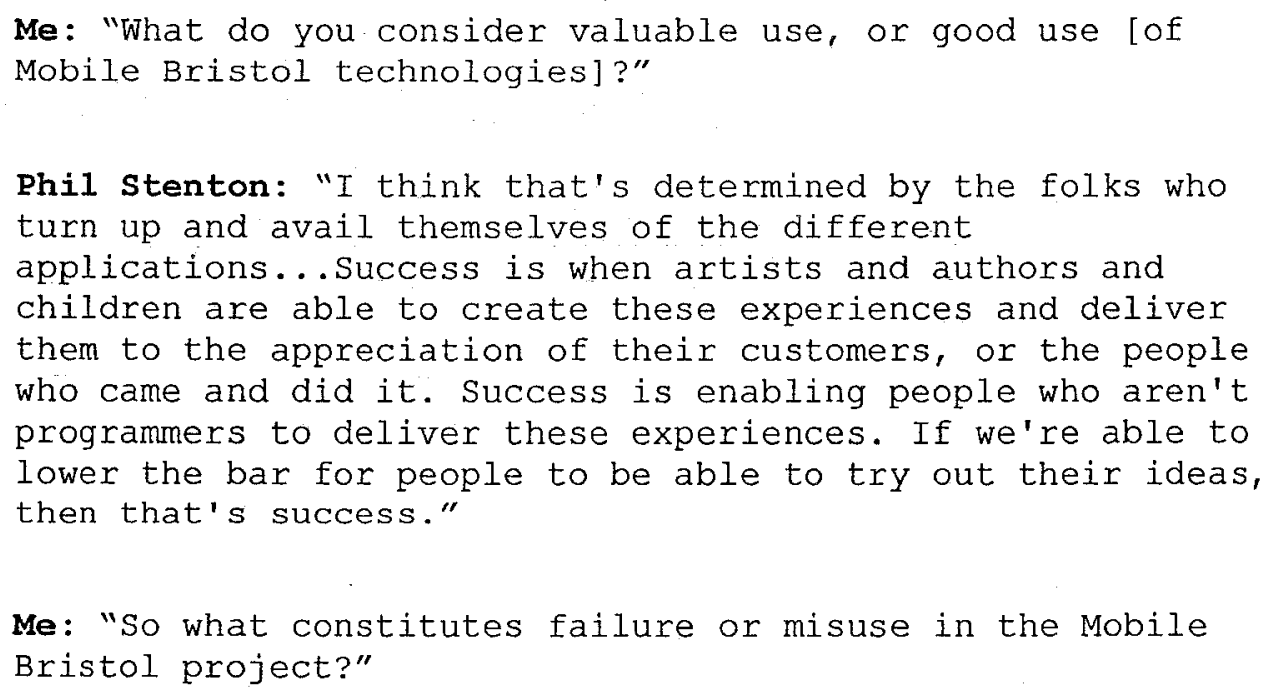


Phil: "Failure would be that we don't inspire anyone to create content in this space. This is a new medium, we're creating a canvas over the city, we're giving people a palette of technology with which they can display and deliver their content, and if we don't inspire anybody to do more than tourist trails, I would think that's a failure. Whether that's because they can't use the tools, we don't get the message across, or the exemplars we put out aren't very interesting, that'll be failure. Misuse would be spam, a bunch of retail stuff, invasion of privacy. That would be misuse."

With expectations like these, Mobile Bristol emerges as a research agenda that relies quite heavily on public involvement, but also one that configures the public, and public spaces, in particular ways. In addition to a public of artists, or authors, or children-aligning corporate (dystopian?) research with non-corporate (utopian?) values-there is a public with the capacity to see and do what it has not been able to see and do before:

Me: "If we think of the augmented city, what value is added to a place through technologies and practices like these?"

Phil stenton: "The space in a city is a mixture of its present and its past. The city is shaped by people adding buildings to it, having a vision of what it ought to look like and how it will progress, and it's a mixture of different years and such. But things happen in the city. Either they are going on now inside buildings, so on the Harbourside tour, while you go by the Industrial Museum, you get a video of Andy King, who is a curator there, saying, this is what happens inside this building, here are some of the exhibits we've got, blah blah blah, and by passing by the bricks and mortar outside you get a glimpse inside. So the technology can take you inside the building. You can get to know something of the social buzz of a city, and not just the architecture.

Historically, things happen. There are historically interesting parts of the city, there are events that might happen in the future, so what this technology can do is give another dimension to the city. An accessible, visible, 
audible dimension to the city. Once you can get to know the inside of buildings then you get to know the social side of the city. And I think this technology can help do that. For people visiting, you can get much more of a feel for what goes on beyond the architecture. Then there are all those tourist things, like you can go experience history in that recreated way. But essentially, I think it adds another dimension and makes the city more accessible, even to the people who live there. It gives depth of field.

Currently you get a very small depth of field in the snapshot you get of a city. It's usually down to the architecture, but it may be down to the fly-posting so that I know what's going on, what's happened, who's been there. I think the technology will increase the depth of field. You'll be able to come to Bristol and have more of an experience of more of Bristol in terms of time and social depth. As cities move and shift in terms of their centres of social existence, parts of the city that were really important one hundred or two hundred years ago start become places you just pass through. I think you'll be able to keep more of that, more of the city as it moves and shifts. The technology will enable you to remember."

By focussing on the technological ability to create "depth of field," Phil conjures a public that effectively sees through walls, thereby rendering private space public. He also evokes a sense of the city that involves greater temporal depth or extension, and claims that history or memory for the public as well.

In talking with him, I actually got the sense that his expectations of the public, and his belief in people, were so positive that I would not be able to dismiss the following comments as an attempt to avoid accountability-even if that turned out to be an unintended outcome:

Me: "Do you see risks in these areas?"

Phil stenton: "It comes down to social mediation. A lot of these things you can try to design to death, try to figure 


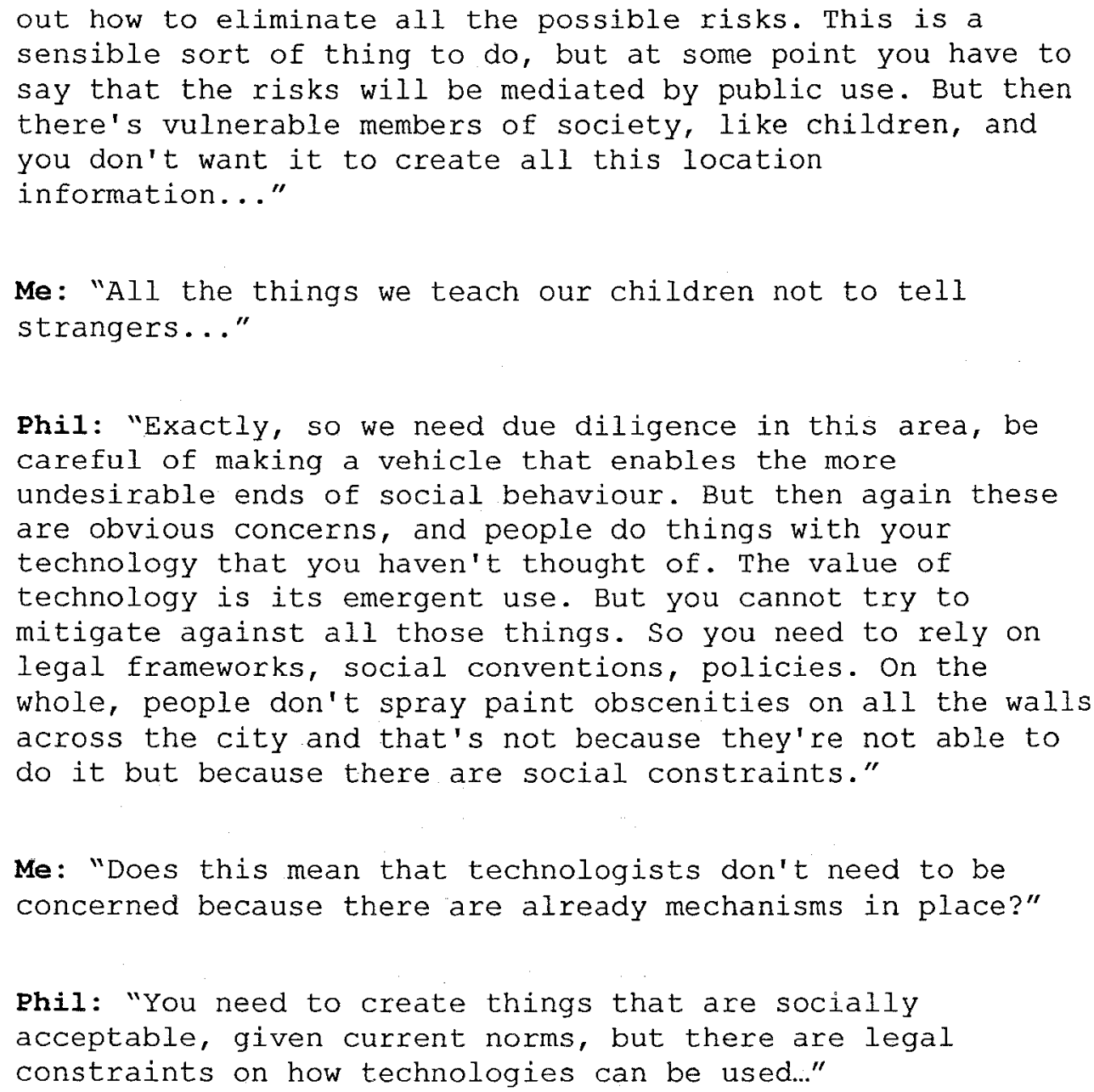

Phil's ideas about the relationships between researchers and publics can be seen as connected to broader cultural attitudes and expectations around democratic politics and policies surrounding new technologies, as well as situated within overarching research agendas. In this way, the corporate/non-corporate and dystopian/utopian divides are also blurred a bit. In order to further explore these connections through other cases, I would like to move from this small-scale account and back to the large-scale story, to re-contextualise these ideas within broader concerns and other research in the field. 


\subsection{SPACES AND TIMES OF URBAN COMPUTING AND LOCATIVE MEDIA RESEARCH}

The first issue of the IEEE journal Pervasive Computing was published in 2002

with a clear historical legacy and future mission:

Mark Weiser described a tantalizing destination just over a decade ago. In a seminal article, 'The Computer for the 21st Century,' he described a hypothetical world in which humans and computers were seamlessly united. The article's opening words are memorable: 'The most profound technologies are those that disappear. They weave themselves into the fabric of everyday life until they are indistinguishable from it.' He called this vision ubiquitous computing. Its essence was the creation of environments saturated with computing and communication yet gracefully integrated with human users. When articulated, this was a vision far ahead of its time-the hardware technology needed to achieve it simply did not exist. Not surprisingly, the implementation attempted by Weiser and his colleagues at Xerox Parc [sic] fell short. After a decade of hardware progress, many critical elements that were exotic in 1991 are now viable commercial products: handheld and wearable computers, wireless LANs, and devices to sense and control appliances. We are now better positioned to begin the quest for Weiser's vision. IEEE Pervasive Computing's mission is to be a catalyst for progress toward this vision (Satyanarayanan, 2002:2).

While firmly embedded in the modern ideal of scientific and technological progress, this story also happens in non-linear time as it is part origin myth in which a 'hero' (the scientist) emerges from a 'sacred place' (the laboratory); part future vision with new potential actors (journals, projects, research, authors); and it acts in the present as a means to organise people, things and ideas today.

Five and a half years after that first issue, "urban computing" was defined by guest editors of a special issue on the topic as "the integration of computing, sensing, and actuation technologies into everyday urban settings and lifestyles" (Kindberg, Chalmers and Paulos 2007:18). This rather technical description is 
positioned within a broader "carry small and live large" cultural ethos proposed by the journal Editor-In-Chief in the same issue:

['Carry small'] embodies the idea that for mobility, small computers are attractive; they fit in a pocket and can be carried without encumbering their owner. 'Live large' speaks to the idea that we have high expectations for our interactions with computers, and we expect them to positively impact our lives (Want 2007:2).

This worldview also acknowledges obstacles and barriers that threaten the 'technological' component of the vision at hand. Apparently, there are currently not enough commercial products with sufficient computational resources to run complex applications, and there is insufficient infrastructure in place.

Nonetheless, it is still assumed that “Once it's available for the consumer electronics market, this technology, driven by the associated reduction in pricing, stands a good chance of becoming ubiquitous" (Want 2007:3).

In sum, the state of urban computing today-as problematised or defined by the editor-in-chief of a prominent scientific journal-is seen to be:

...mainly associated with direct interaction using the devices we carry and with the data that service-provider networks deliver. In the future, this could be a far richer experience, involving close coupling of the computation you carry with the displays and keyboards that you find around you. Technology trends that will further support this use model are high-bandwidth short range radio ... At some point in the near future, we'll cross a processing threshold, and our smart phones will be capable of running most of the high-end applications we're interested in using. Furthermore, the short-range wireless bandwidth will be high enough for us to effectively connect to large wireless displays. At that point, urban computing will take on a whole new experience, and we'll move closer to the pervasive computing vision (Want 2007:4). 
Faith in progress, or at least in the inevitability of technological development, as well as a strong belief in consumer capitalism figure prominently in future computing visions. As a research agenda, "urban computing" has a place at this table, so to speak, by virtue of being a subset of pervasive or ubiquitous computing. How processes of translation in pervasive computing have and have not been successful over the past 15-20 years could be the subject of an entire dissertation and cannot be addressed here, but it is clear that urban computing relies on attaching itself to existing 'regimes of truth' (cf. Foucault 1980) in engineering and computer science research cultures.

In addition to finding urban computing worthy of a special journal issue, for example, the guest editors claim the articles within "confirm that urban computing is a practical reality but that research is still at an early stage, with much of the subject still to be mapped out systematically" (Kindberg, Chalmers and Paulos 2007:19). The fundamental problematisation of urban computing here involves delineating urban computing research as a historically-inspired but currently viable and valuable endeavour that, while still in its early stages, is expected to be systematically mapped in the future. And the editors go on to make a broad analogy that we will see repeated again: "Like cities themselves, urban computing includes a broad range of opportunities and issues" (Kindberg, Chalmers and Paulos 2007:19). This position effectively becomes an obligatory passage point (Callon 1986; Latour 1987) for present and future research in the field, where urban computing is expected to both embody and transform the complexity of "cities themselves" (see also Greenfield and Shepard 2007). 
But, as some argue, urban computing already exists.

Despite the complexities, urban computing is, in a limited sense, already a mass phenomenon. Roughly half the world's population lives in urban environments. In addition to PDAs and laptops, most people have mobile phones, and most mobile phones have capabilities beyond simple voice calls. Connectivity is extensive. Mobile phones are increasingly equipped with Bluetooth for shortrange communication, in addition to long-range cellular data connections. Wi-Fi networks are also commonplace. And the technology is put to more interesting uses than you might at first think. Users have appropriated some technologies in ways that their designers didn't necessarily envisage, just as they appropriated the short-message service for text messaging (Kindberg, Chalmers and Paulos 2007:19-20).

In that one paragraph, the journal editors displace urban computing as a potential professional research agenda, and transform it into particular technological devices and capabilities already enjoying wide-spread public use. It is difficult to know what they mean by vague phrases like "most people" and "extensive" but they do conjure an image of existing computational ubiquity that has global cultural resonance. Furthermore, they introduce important new actors: unpredictable users and actions that may be approached as interesting opportunities rather than as obstacles to be overcome. Here we might recall the discussion of "seamless" versus "seamful" computing in Chapter 4, Section 1.2, as well as Phil Stenton's interest in recruiting different perspectives to Mobile Bristol's research and design process.

But as discussed in Chapter 4, Section 3, and pointed out above by Risan (2006), emerging technologies are particularly difficult to describe because of the competing temporalities and spatialities in which they take shape, and urban computing is no exception. As soon as I claim that pervasive computing and 
urban computing are emergent rather than existent, I must immediately qualify that with the notion that they do not currently exist as they have been envisioned in the past-and that they are not yet done. Bell and Dourish (2007) point out that pervasive computing has been characterised by its future-orientation from the moment of Weiser's original vision, but go on to suggest that we now live in the future imagined then. The problem, they say, is that the future has changed. And it will continue to change.

Social studies of science have long recognised the importance of "inscription devices" (see for example Latour and Woolgar 1986) in stabilising scientific knowledge, and of academic citation practices in establishing intellectual legacies and social bonds. To formally cite Mark Weiser's published works is to enter into an existing research trajectory-future-oriented or otherwise-but as Bell and Dourish suggest, researchers more often ally themselves with Weiser's vision rather than pointing out that his vision may not be entirely applicable to today's technological and cultural realities. In fact, they suggest that "the future that ubicomp has been attempting to build is not our own future, but 1989 s futureyesterday's tomorrows" (Bell and Dourish 2007:135). They also claim that "postulating a seamless infrastructure is a strategy whereby the messy present can be ignored, although infrastructure is always unevenly distributed, always messy. An indefinitely postponed ubicomp future is one that need never take account of this complexity"(Bell and Dourish 2007:140). 
Encouraging the pervasive computing research community to see ubiquitous computing in a different light, they turn to cases in Singapore and Korea rather than American or European examples like those I have discussed so far.

Ultimately, their claim is that ubiquitous computing already exists but it does not involve the same technologies or people that Weiser envisioned. Perhaps most notably, Bell and Dourish (2007) suggest that other places and people "imaging [sic] ubiquitous computing as a collective practice, rather than a set of discrete individual actions, is an important reframing of that technological vision" (137138, emphasis mine). Similar expectations and processes can be traced for urban computing and locative media, with interested collaborators attaching and allying themselves with both technological issues and urban and cultural research concerns. As elaborated upon in Chapter 4 , these spatially and temporally located expectations are continually displaced and transformed, as well as stabilised and protected (Borup et al. 2006; Brown and Michael 2003; Brown et al. 2000), to reshape urban computing and locative media in complex ways.

Actually, the emphasis on complex social and spatial interaction had already been taken up in IEEE Computer magazine a year earlier, where urban computing was specifically positioned in terms of navigating space and context. The challenge for designers, the guest editors argue, is that public (i.e. urban) spaces

...are complex spaces, as they are navigated both through physical movement and interpretations of social context. As computing blunders into our personal worlds-annoying, interrupting, or distracting us-it is potentially even more disruptive in public spaces, where friends and strangers alike navigate the complex social context of coexistence ... As much as public space brings with it a sense of egalitarianism where civic life is played out and embraced, it also can be fraught with adversity and conflict. Both these contingencies must be taken into 
account when considering the design of computing for public spaces (Shklovski and Chang 2006:36-37).

More specifically, they lay out a path for successful future research:

We are not calling for technology designers to become urban planners and social scientists, but we do suggest that there is a wealth of research in these areas that needs to be taken into account when designing new technologies. Collaborations are crucial to understanding social life and creating technologies that can augment it in positive ways. We believe that research in urban computing can be useful for augmenting and extending existing theories in relevant fields and for greater blending of these fields to develop a coherent understanding of public social life (Shklovski and Chang 2006:37).

Inter-disciplinary research collaborations are enrolled here as necessary for relevant research to occur in urban computing-something Weiser also called for in his vision of ubiquitous computing (Galloway 2004a). However, considerably less attention has been given to how to locate accountability (Doruff 2007; Galloway 2007; Strathern 2004b; Suchman 2006) in this kind of collaborative work-a point I raised in the Mobile Bristol interviews and to which I will return in Chapter 6.

\subsubsection{Following actors and contemplating entanglements}

So far, urban computing has been positioned as a subset of pervasive computing-a professional research agenda attached to existing regimes of truth in engineering and computer science practice. In addition to researchers and 'users,' the concatenations of actors (see Chapter 2.1 and 4.2) at hand now include publics and public spaces, corporate research laboratories, universities, conferences, workshops, academic journals, articles, weblogs, etc. In 1999, before the launch of the IEEE Pervasive Computing journal discussed above, the First 
International Symposium on Handheld and Ubiquitous Computing took place in Karlsruhe, Germany. The second symposium was held in Bristol, UK. In 2001, the First International Conference of Ubiquitous Computing (UbiComp) replaced this series with the mandate to "bring together research practitioners in all disciplines developing the new paradigm of computing off-the-desktop that moves towards the notion of a disappearing or invisible computer" (http://www.ubicomp.org/ubicomp/). At UbiComp 2003 in Seattle, USA architecture professor William J. Mitchell gave the opening keynote presentation on his latest book, Me++: The Cyborg Self and the Networked City (Mitchell 2003), and the urban dimensions of ubiquitous computing emerged front and center.

Meanwhile, in the early 200os, while American and European academics were at conferences rallying around urban computing, artists and activists were holding locative media and mapping workshops. Initially coined by Karlis Kalnins as a "test-category" for processes and products coming from the Locative Media Lab (http://www.locative.net/), an international network of artists and activists working with GPS and mobile technologies, locative media practitioners were quick to distinguish their work as being enabled by technology, rather than enabling technology-which was seen to be an academic, industry and military activity. However, just as urban computing research is an elusive category, so too is locative media; both challenge traditional boundaries between science and art, 
academia and activism, etc.

Andrea Zeffiro (2006:1) names the (2003, not 2002 as she states) RIXC Locative Media Workshop (http://locative.x-i.net/) as the event where "conceptual frameworks" for locative media were "inaugurated," but my first exposure to these ideas was a year earlier when I read Ben Russell's (1999/2007) extraordinary Headmap Manifesto. Written in 1999, and subtitled "Know Your Place," the original document comprised 34 pages of fragmented text and poetic ideas about location-aware devices; the version online at the end of 2007 is subtitled headmap 3 redux and comes in at an impressive 115 pages of the same:

location aware, networked, mobile devices make possible invisible notes attached to spaces, places, people and things.

the headmap manifesto articulates the social implications of location aware devices.

it manifests a world in which computer games move outside and get subversive. sex and even love are easier to find.

real space can be marked and demarcated invisibly.

what was once the sole preserve of builders, architects and engineers falls into the hands of everyone: the ability to shape and organise the real world and the real space.

real borders, boundaries and space become plastic and malleable, statehood becomes fragmented and global.

geography gets interesting.

cell phones become internet enabled and location aware, everything in the real world gets tracked, tagged, barcoded and mapped.

overlaying everything is a whole new invisible layer of annotation. textual, visual and audible information is available as you get close, as context dictates, or when you ask. 
In retrospect, if there is any single document or event which inspired my dissertation it would have to be the Headmap Manifesto-and it deserves far greater acknowledgement and attention than I can give it here. Russell (2004) works the manifesto's ephemeral and fragmented ideas into the introduction to the Locative Media Lab's Transcultural Media Online Reader, providing a definition of locative media practice I continue to find helpful:

Locative media is a term that ties together a set of questions, critical perspectives and practices. Its catalytic premise was civilian awareness and engagement with a particular 'operational construct' with military origins. A combination of GPS, mobile data communications and mobile computing would allow the annotation of space. This catalytic premise is not locative media; it is not the goal or the point. Locative media is many things: A new site for old discussions about the relationship of consciousness to place and other people. A framework within which to actively engage with, critique, and shape a rapid set of technological developments. A context within which to explore new and old models of communication, community and exchange. A name for the ambiguous shape of a rapidly deploying surveillance and control infrastructure.

Albert (2004) more concretely defines locative media as "artwork that utilizes media that can express an index of spatial relationships" and claims that locative media practitioners "are keeping the technologies close to the ground, available for hacking, re-wiring and re-deploying in non-authoritarian ways." But before I get any deeper into the politics at hand, it is worth pointing out that these expectations are not exclusive to artistic and locative media practice. Or rather, much work in urban computing can claim the same, even if it does tend to be top down' in the sense of originating in universities and corporate research labs. 
In July 2004, the Urban Atmospheres Research Project (www.urban-

atmospheres.net/) at Intel Research Berkeley held a one-day event called "Street

Talk: An Urban Computing Happening.” The event announcement explained:

Urban Computing captures a unique, synergistic moment - expanding urban populations, rapid adoption of Bluetooth mobile devices, and widespread influence of wireless technologies across our urban landscapes ... We are gathering for an event to expose, deconstruct, and understand the challenges of this newly emerging moment in urban history and its dramatic influence on technology usage and adoption (http://www.urbanatmospheres.net/StreetTalk/).

The inter-disciplinarity and complex interests of urban computing were reinforced by international (North American, European) participants from industry (Intel, Microsoft), academics (anthropology, architecture, art and design, computer science, performance studies, sociology, urban studies), as well as independent artists and activists (including the Billboard Liberation Front) working in and around public spaces. Also present in the audience for these presentations were representatives from the likes of NASA, France Telecom, Ricoh, IDEO, Nortel and the Institute for the Future (an American non-profit technology foresight group).

Excerpt from Weekly INCITE by Katrina Jungnickel

http://weeklyincite.blogspot.com/2004/07/my-experience-at-recent-street-talk.htm/

\section{Sunday, July 18, 2004}

My experience at the recent Street Talk: An urban computer happening at Berkeley supports a supposition of taxonomic perplexity. Architects talked like social scientists, developers sounded like artists, designers like researchers and I could even understand what computer scientists were on about. The group of 70 participants and presenters shared a passion and at most times a language for experimental location based applications whilst still being able to provide critiques and challenges from specific 
perspectives. It felt like it moved beyond interdisciplinary or even transdisciplinary collaboration to something far more individually integrated. As if you cannot work in this area without opening yourself to the relevancy of wider disciplinary consideration. There was a call for even more blurring between the urban, social and computer sciences particularly in this area of research. Why? To actually try to improve everyday life rather than just focus on the coolest and newest applications designed for a select tech advanced audience.

posted by Kat at 04:19:00 PM

Excerpt from geekitude by Jeffrey Heer

http://jheer.org/blog/archives/000321.html

July 21, 2004

\section{Talkin' bout the street}

This past Friday I had the pleasure of attending StreetTalk, a one-day workshop on urban-centered computing organized by Eric Paulos of Intel Research Berkeley. Though the basic premise is to find new and compelling ways of using digital technology to enhance/enrich/change urban life, a wide array of viewpoints were presented, including largely non-computational ones.

I stashed my notes in meta's bag at the end of the day, and have waited too long now to retrieve them, so I'm going to try to do this from memory for now... Here were some of the highlights.

- Dennis Crowley showed off his system dodgeball, which allows you to broadcast your location so your friends can find you. I've since signed up for the service, and it's interesting receiving location messages about your friends. As my friends seem to be using the system judiciously, no resulting awkward social situations have surfaced... yet.

- Cassidy Curtis spoke about his excellent graffiti archaelogy project. I spoke with him briefly at the end of the day, and got to learn more about his process of documenting various actual and potential graffiti sites as well as his encounters with graffiti artists and cultures.

- Jack Napier taught us how to improve the urban landscape through billboard liberation. Already an Adbusters fan, needless to say I was enthralled.

- Anne Galloway took the stage to dispel any digital utopianism left amongst attendees. While techno-utopianism is an undercurrent of much of the humancomputer interaction field, the ubiquitous computing literature is particularly full of unexamined (and, imho, in many (most?) cases unwarranted) optimism. Hopefully Anne's polemic helped kill that good and dead for those in attendance, promoting a balanced, critical perspective.

- Paul Dourish speaks eloquently, insightfully, and quickly. His lesson (among others) - don't forget that cities are living things subject to continual interpretation and negotiation. Beware of succumbing to the temptations of positivist modeling in your urban computing endeavors. 
- Peter Lunenfeld pointed us all towards the work of Jane Jacobs as a foundation for further urban-centered work. He argued that her work should be as pivotal to these endeavors as Christopher Alexander's work on design patterns has been to the software engineering community.

Afterwards we went to Rx Gallery in San Francisco to socialize. Some of us got more social than others.

posted by jheer at 07:19 PM

Excerpt from purse lip square jaw by Anne Galloway

http://www.purselipsquarejaw.org/2004/07/street-talk-urban-computing-part-i.php

\section{Monday, July 19, 2004}

\section{Street Talk: Urban Computing - Part I}

Although each presentation at Street Talk was interesting, Ben Hooker was one of the speakers who most caught my attention and imagination.

With Shona Kitchen, Ben worked on the Altavistas project - which includes Edge Town:

"After an intensive phase of location-scouting, we decided to specifically design for places we had identified at the edges of the city: places where open countryside starts to rub up against suburbia, and the regulated 'nature' of landscaped motorway embankments, reservoir complexes and allotments coexists with airports, business parks and residential blocks. Transitional landscapes like these feel half-finished, as if waiting for some kind of built intervention which accentuates their unique qualities. We used computer-based illustrations to communicate a series of architectural proposals based on developing 'electronic ecologies' to integrate into these spaces to the effect that the immaterial information flows that run through our cities can be experienced alongside more natural phenomenon."

Edge Town reminds me of spectacular carchitecture and the more mundane Motorway House. An exploration perhaps more of non-places than of third-spaces, the project still focusses on contested space - or those spaces (and identities) that do not easily easily fit into either/or categories. Hybrid spaces. Voluptuous spaces. A non-place is an ambiguous site: the very type of space that would appear in a pattern language (like a place to wait) but that would also challenge or resist the entire premise of stable structure that underlies patterns. Very interesting.

On a related note, Ben's DATACLIMATES design practice partner is Pedro Sepúlveda Sandoval - who did an amazing PhD project for the RCA:

Digital Shelters: "A new landscape is emerging in the urban space, a 'Scanscape' that transgresses the boundaries and protocols of public and private space due to the extensive use of electronic, electromagnetic, surveillance and telecommunication technologies in the urban realm. How can we define these 'Scanscapes'? How can we create 'Digital Shelters' that will protect us, isolate us or allow us to live with in these 'Scanscapes'?" 
I really appreciate the focus on resisting surveillance by means other than sousveillance. After all, humans have always sought shelter from oppressive climates and dangerous cultures. In caves, Jews found sanctuary from the Nazis, and while fallout shelters may not have saved people from nuclear devastation, they arguably provided comfort from fear and uncertainty. It should come as no surprise, then, that we will also need safe and quiet reprieves in - and from - our digital landscapes.

posted by Anne at 19:47

Not only, then, were locative media and urban computing being practiced in some places and discussed in others, but they continued to circulate, and get connected to other people and practices, within blog conversations-especially amongst doctoral students-online.

At a one-day workshop called "Ubicomp in the Urban Frontier" at Ubicomp 2004 (in Nottingham, UK) the range of participants continued along the same lines, further underscoring the expectation of moving beyond (every)one's everyday practice. In 2005 and 2006, the Intel researchers again collaborated with academics working in architecture and computer science to lead two more UbiComp workshops: "Metapolis and Urban Life" (in Tokyo, Japan) and "Exurban Noir" (in Orange County, California, USA). Again, all the workshop proceedings were published online and continued to circulate after the events themselves.

However, if the informal (but still invite-only) event at the corporate lab opens urban computing to 'non-researchers,' then the professional conference workshop closes ranks around university or corporate-based research. The 
research domains of these spaces are also contained-temporarily stabilised-by published proceedings that continue to circulate online and off. Both serve important functions as spaces for socialising and career networking, although the conference workshop and its proceedings are understood to be where more speculative kinds of scientific research take place. Between exploratory workshops and completed projects presented in conference panels are technological demonstrations and poster sessions that focus more on research-inprogress or proofs-of-concept. All act as spaces of techno-scientific problematisation and interessement-as described in Chapter 4, Section 4.2-and the actors create chains of material and embodied practices.

Urban computing also takes place, pedagogically, in the university classroom. For example, in late 2006, the University of California Berkeley ran an undergraduate class in architecture and new media-"Metapolis"-co-taught by academic (architecture) and industry (Intel, IDEO) partners, and building on the "Metapolis and Urban Life" workshop at UbiComp 2005. At New York University's Tisch School for the Arts' Interactive Telecommunications Program in early 2007, writer Adam Greenfield and Kevin Slavin, designer of "large-scale, multiplayer games that include some form of real-world interaction," taught a course called “Urban Computing." Far more courses in art and design schools could be added to this list, although none may self-identify as part of an urban computing research agenda. However, perhaps the most important thing to note here is the increasingly non-technological focus of these classes. In these 
overlapping scenarios, "urban computing" gets displaced once more and becomes a set of concerns for others: academics, architects, artists, designers, citizens, etc.

In promoting urban computing or locative media as research agendas, particular techno-scientific devices and protocols (such as 'smart phones,' GPS, Bluetooth, RFID) must be present in order to provide materials with which to work, but absent in the precise configurations that are required for the proposed vision to be realised. Put more bluntly, without this gap, there is no space for new research. Likewise, particular associations between actors must be in place in order to facilitate further connections. Material and embodied practices like laboratory work, conference presentations, workshops, journal articles, teaching and blogging all serve to stabilise knowledge long enough that it can be exchanged and act as 'obligatory passage points' through which subsequent research must pass.

Of course, while the "actors" I have followed so far appear at several different scales, most are found at the structural level of institutionally supported research and development. It is beyond the scope of this dissertation to attend to specific applications or projects beyond my specific case histories, but the journals, conferences proceedings and classes listed above would provide ample resources and inspiration for future sociological analysis. 


\subsection{THE POLITICS OF LOCATIVE MEDIA AND URBAN COMPUTING RESEARCH}

An emphasis on inter-disciplinarity continues on the periphery of computing and engineering in numerous ways (see McCullough 2005, 2006; Rheingold 2002), and the matter of computation in urban spaces has also increasingly been the research domain of critical sociology, anthropology, and cultural geography (see Kopomaa 2000; Graham and Marvin 2001; Graham 2003; Galloway 2004a \& 2004b; Galloway and Ward 2006; Goggin 2006; Seijdel 2006). In this sense, urban computing and locative media also involve the practices of sometimes oppositional actors. While each 'side' invariably comes into contact, either directly or indirectly, with others, all professional practitioners define themselves as distinct, and attempt to enroll others to their singular and collective visions of urban computing. The roles of intermediaries and 'spokesmen' (people, papers, etc.) become integral here, as they are primary actors in the continuing negotiations and exchanges between communities of practice. For example, in a study of "how electronic art is made," Nigten (2007:127) suggests that art functions as a "boundary object" (cf. Star and Griesemer 1989) or "shared method" between researchers working in "zone[s] or conceptual space[s] between existing disciplines or knowledge domains"-a point to which I will return in Section $5 \cdot 5$ below.

As technoscientific practice is currently expected to involve research interests and engagements outside of a practitioner's traditional domains of expertise and experience, urban computing cannot be a 'pure' engineering or computer science, 
any more than locative media can be a 'pure' art. While urban computing definitely comprises distinct, and hetereogeneous, computing and engineering research cultures that work to advance the state of scientific knowledge within their own disciplines, they never act separately from broader practices involving a wide range of competing knowledge claims within a relatively homogenous shared vision. As Tuters and Varnelis (2007:362) explain,

[L]ocative media offers a conceptual framework by which to examine certain technological assemblages and their potential social impacts. Unlike net art, produced by a priestly technological class for an elite arts audience, locative media strives, at least rhetorically, to reach a mass audience by attempting to engage consumer technologies and redirect their power.

However, they also point out that the politics are a bit more complex than the previous passage suggests:

Raised on a steady diet of institutional critique, this generation sees art's purview as transdisciplinary and eagerly pursues projects that could be classified as research ... In the case of locative media, this means that artists adopt the model of research and development wholesale, looking for corporate sponsorship or even venture capital ... The reluctance of many locative-media practitioners to position their work as political has led some theorists, such as Andreas Broeckmann (director of the Transmediale Festival), to accuse locative media of being the "avant-garde of the "society of control", referring to Gilles Deleuze's description of the contemporary regime of power (Tuters and Varnelis 2007:360).

This matter of power and control had been eloquently tackled by academic and artist Drew Hemment in an early 2004 essay on locative media and surveillance, posted to nettime.org and worth quoting at length:

Locative media uses portable, networked, location aware computing devices for user-led mapping and artistic interventions in which geographical space becomes its canvas. The rhetoric of locative media gestures to a utopian near-future in which the digital domain and geographical space converge, and the course it plots towards this future demands not only that data be made geographically specific but also that the user - if not defined by their location - at least offers up their 
location as a condition of entering the game. In this respect, not to mention its choice of tools, locative media operates upon the same plane as military tracking, State and commercial surveillance, its concern for pinpointing and positioning shared with coercive forms of social control, forcing a consideration of how locative media might challenge, or be complicit with such forms of social control, and of the point at which the locative utopia rubs up against the dystopian fantasy of total control...

To the extent that locative media simply celebrates the ability to locate all things at all times, it could almost be described as little more than a marketing wing for this branch of the control society, locatives style leaders as much as early adopters. Equally, in competing with the corporates in the race to produce a locative operating system, a location-aware internet or geo-repository, it risks being just another player in the Location-Based Services market. And yet where the focus is placed upon the social before the spatial, either in the creation of open tools or in user-end applications, it becomes something fundamentally different. Like surveillance, locative media is a social project, but the grass-roots, social networks it advocates offer a critical distance to the system of domination of the control society. Locative media exults in the pleasure of locating and being located, and finds in this the basis for an emergent sociality - driven not by marketing but by networks of reciprocity and trust - as well as new ways of representing, relating to and moving in the world. Just as it contests the top down approach of conventional cartography to open up a manifold of different ways in which geographical space can be encountered and drawn, so in appropriating and refunctioning positioning or tracking technologies, locative media indicates how they may be used not for pinning down but for opening up...

[But] perhaps another term is needed, that speaks neither of utopia or dystopia, and which holds this paradox open. One possibility might be _embedded media which comes close to ambient technologies or augmented reality, without the Californian gloss. The term highlights the way media technologies pervade every aspect of the social domain, while its origin, referring to the placing of journalists in military columns during the war in Iraq, serves to highlight an inherent complicity in the operation of power. As a descriptive term it would highlight the way in which locative media is embedded not only in geographical space but political and cultural space as well. And as a metaphor it might be reclaimed as a rhetorical strategy for inhabiting this ambiguous and conflictual space, for intervening in the membranes of the multifarious datastreams (of military surveillance, criminal databases, immigration authorities, financial transactions, etc) that constitute the invisible threads of an emerging social fabric. To stretch the metaphor yet further, we might ask where the pockets-of-resistance to this form of embedded media might lie, the moments of disturbance or sites of interruption not of the telos of technological war, but of social control (Hemment 2004a).

Leaving aside whether the better term is "locative" or “embedded," Hemment's

post-and our conversations at the 2004 Futuresonic conference he organised-

helped solidify my interest in the social and political aspects of locative media. 
Excerpt from purse lip square jaw by Anne Galloway

http://www.purselipsquarejaw.org/2004/04/mobile-connections-day-1.php

Friday, April 30, 2004

\section{[Futuresonic] Mobile Connections - Day 1}

Good stuff at Urbis today! The morning kicked off with Sadie Plant on the social and cultural aspects of mobile phones. I'm particularly interested in some of the tensions she described: a sense of social security (always connected, always supported), a sense of social insecurity (extreme spontaneity, uncertainty of plans), a reinvigorated sense of place ("where are you?"), reduced chances of serendipity (never "who are you?"), and the increasing importance of questions like "where are you coming from?" and "where are you going?"

The first panel was on the network commons, where topics of discussion included public wireless access by free2air and TAKE2030, and wireless jamming by WiFi Hog.

The second panel was on locative media - including projects like teletaxi, murmur, biomapping and shrinking cities. Then Ben [Russell] and I discussed intimate assemblages, locating accountability, problems with black-boxing and technological determinism, amongst other things. I know we lost some people, but others seemed to really enjoy it.

The third and final panel of the day was on the Creative Crossings workshop I posted on a few days ago, and I'm looking forward to tomorrow's panels and checking out more of the interactive city experiences and exhibitions.

posted by Anne at 15:23

http://www.purselipsquarejaw.org/2004/05/mobile-connections-day-2.php

\section{Saturday, May 1, 2004}

\section{[Futuresonic] Mobile Connections- Day 2}

The day kicked off with Matt Adams of Blast Theory discussing hybrid performances and audience participation in their mobile mixed reality games. Riffing on Hakim Bey, Matt introduced the idea of TPZs: Temporary Performative Zones.

Their Uncle Roy All Around You game has been running in Manchester, taking a strangely intimate look at matters of absence and presence. It requires you to get close with people far away, and to enter into social contracts with complete strangers. Given our increasingly interconnected worlds, this raises the particularly interesting issue of what responsibility we may have to distant people.

A few audience members accused him of selling out because they have collaborated with industry. And frankly, it surprised me to see several panel discussions get hung up 
on utopian vs. distopian discourses, where art was almost expected to comprise some sort of "pure" practice, completely divorced from capitalism. It seems a shame to me that when people were trying to work with existing social practices and institutions they were attacked; acceptable critical practices seemed to be limited to only working outside of everyday life. As if that were possible.

This tension resurfaced later on when Tom Melamed was asked what was the end point or ultimate objective of the Mobile Bristol project. He said he hoped it would never be finished, and I wondered why an end point would be preferable. There was also much talk of (to use Marko Peljhan's phrase) freedom in the electromagnetic sphere. He claimed that the battle over a publically owned telecommunications infrastructure has already been lost and that artists and designers should be focussing on technologies for people that don't have lots of leisure time and money. While I certainly agree on one level, this focus on efficiency to the exclusion of pleasure seems oddly mechanistic and restrictive. The wireless spectrum is still up for grabs, and I wonder how artists, designers and researchers can change telco policies if they do not engage the people who make them.

posted by Anne at 15:08

That trip was the first time I was directly exposed to the locative media perspective on pervasive computing, and I took these interests with me to the Intel StreetTalk urban computing event later that summer. In fact, between 2002 and 2007-the time of this study-I found myself continually traversing such cultural and spatial boundaries. I visited labs and studios in America and Europe; a scientist amongst artists, an artist amongst scientists, but never self-identifying as either. But maybe that was precisely because I was interested in-and found myself within-the in-between spaces. My experience of 'becoming sociologist' has been profoundly shaped by packing a theoretical and methodological toolkit that I could bring with me along my journeys through spaces that may as well have been marked on the map as "Here Be Dragons." But I find it helpful to think about these spaces-including my own-as ambiguous. As Hemment (2004b) explains, 
Locative Media's political moment might not be despite its complicity in mechanisms of domination but because of it, residing in the acceptance of the paradox and occupying the ambiguous space it creates, creating a site of resistance by working from the inside. But at the same time as the creative and transformative potential of new logics is celebrated, there needs to be a corresponding engagement in the economic and political forces that work to reterritorialise this space according to familiar axiomatics of exploitation and control.

Furthermore, Tuters and Varnelis (2007:362) "suggest applying the strategies of locative media to create what Rousseau called for, an awareness of the genealogy of an object as it is embedded in the matrix of its production." And Pope (2005) similarly argues that

the novelty of these projects seems to be in the way they extend the human community to include an array of agents, arranged in space which includes antennae, rooftops, trees, buildings, masts and the like ... With the technologies of locative media, we are made precisely aware of the scale of built things and their relationship to each other. It's the built environment that now appears as our preferred 'knowable community'.

However, returning to the distinction made between, on one hand, pervasive and ubiquitous computing as an elite engineering, computer science and humancomputer interaction research activity, and on the other, locative media as critical and sometimes public art practice, Townsend (2007:346-347) claims that:

[A]rtists are playing an unprecedented role in interpreting context-aware technologies and identifying and investigating the potential conflicts. At the core of this process is the idea that bottom-up approaches to creating contextual sensing and sense-making systems are superior on a variety of levelsideologically, socially and economically. In a sense, one of the main tenets of the locative media movement seems to be that location-aware computing should illustrate the complexity and richness of culturally constructed space. This is in stark contrast to the top-down forms, which largely seek to circumvent such "obstacles." Whereas top-down visions of contextual computing often seek to guide the user, bottom-up versions seek to enable creativity, allow transparency and help new groups to form.

$[\ldots]$ 
However, it needs to be understood that the current excitement over locative media is but the first round of a series of creative bursts that will probably last for half of this century or even longer. For the questions being raised by contextaware systems are about more than just location, how we experience space and the meaning of place. Underlying these investigations are serious challenges to our currently held beliefs about the fundamental nature of how we experience the world. The artists of today are grappling with location awareness in the way that much of 2oth-century art did with our visual perception of the world. The artists of tomorrow will have to explore the meaning of perception in a world in which we will have outsourced many of our perceptive tasks to machines, to extend and augment our abilities.

If net art is the art of the Internet, then locative art is the art of mobile and wireless systems. The emergence of locative media signals a convergence of geographical and data space that comes about as soon as computing becomes mobile or ambient, reversing the trend toward the view of digital content as placeless, only encountered in the amorphous and other space of the Internet. The exploratory movements of locative art are located between the art of communications and networking and the arts of landscape, walking and the environment. Artists are responding to the technical possibilities of electronic mapping and positioning technologies and location-aware, networked media by asking what can be experienced now that could not be experienced before, in some cases creating more or less conventional screen-based visualizations using location data, in others mapping new horizons for creative content and the art object and a new understanding of the relation between physical and digital.

While Townsend gives credit to artists and activists more than most commentators do, I would not want to overestimate the political potential of (artcentric) locative media and underestimate the political potential of (academic and industry-centric) urban computing. By delineating a shared playing field-the city as interaction design space and publics as co-creators-the boundaries between the two become so blurred that maintaining strict distinctions becomes difficult. It is this reality that has compelled me to use the phrases "urban computing" and "locative media" not interchangeably, but always in consort.

I do not think it is reasonable to reduce computer technologies to uncreative business applications, or to maintain an understanding of technology that 
excludes beauty and joy, any more than it makes sense to claim that artists working with computer technologies are completely disinterested in accuracy, reliability and efficiency. In other words, if locative media arts wish to position themselves as more creative or critical than academic and corporate research, it also falls to them to demonstrate how academic and corporate research fails to meet their expectations. For example, Zeffiro (2006) points out that

Locative media practitioners maintain that one of the field's defining characteristics is its separation from Location-Based Services (LBS), those corporate to corporate, business-to-business and business-to-user services such as fleet tracking and in-car navigation.

But I would argue that urban computing, in its capacity as academic and industry research, does this as well.

For example, my initial interest in playful and intimate technologies led me to exclude strictly business-oriented applications like the kinds Zeffiro mentions, but that still left a wide variety of corporate takes on entertaining or engaging technologies. More to the point, in the computer science and engineering journal special issues presented earlier in this chapter, none of the applications could be characterised as business-oriented, and a focus on more playful technologies was also evidenced in my conversations with Hewlett-Packard researchers:

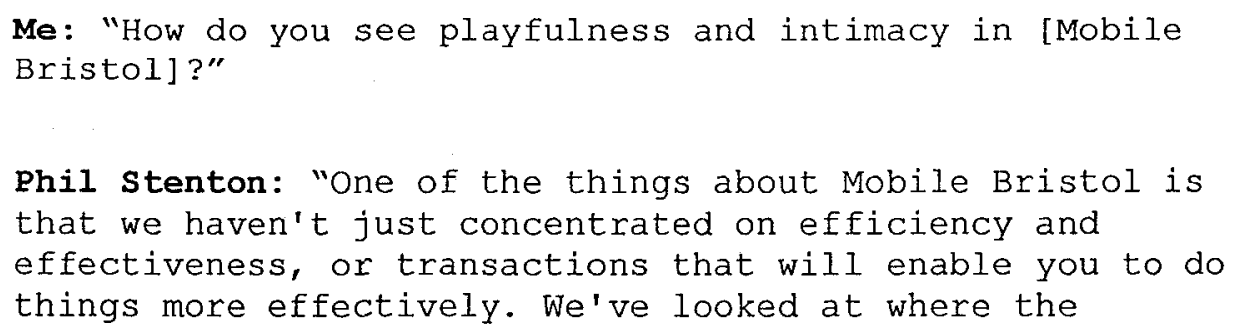




\begin{abstract}
experience is the goal in itself. Whether that's a playful thing, a thoughtful and immersive thing, we don't care, but people come up with playful things and our centre of gravity is more to that end than productivity and efficiency. And intimacy with the city can be personalised, since personalisation gives you an increased level of intimacy. Urban Tapestries, as a way of taking some of Mobile Bristol's ideas to London, looks at people putting intimate recollections onto spaces in the city and then sharing them with people.
\end{abstract}

\footnotetext{
What we have is a good vehicle for doing that and I think that the technology allows you to do that. Rather than putting physical graffiti on the walls, which is actually a kind of intimacy with people, you can do it in an invisible way, or a virtual way, accessible through your PDA. We are, in a sense, targeting a level of intimacy with the technology. Person to person intimacy needs to ask what we are doing beyond the phone. SMS is great and with this technology we're adding another dimension whether it's intimacy between two people or a street community. If we have our space, a street that we can publish to and read from, then it gives us a level of intimacy with our particular street and our neighbours. It comes down to the value of narrow-casting, and location-based services allow you to do that, focussing on a specific or narrow space, unlike the Internet."
}

Furthermore, I think that the highly collaborative nature of both urban computing and locative media research and development makes it very difficult to speak of anything resembling either 'pure' science or 'pure' art, and the political implications of such entanglements or collaborations deserve to be examined a bit more closely.

\title{
5.5.2 Reflections on collaborative work
}

Between 2005 and 2007, the Pervasive and Locative Arts Network (PLAN) was

"an international and interdisciplinary research network in pervasive media and locative media funded as part of the Engineering and Physical Sciences Research 
Council (EPSRC) Culture \& Creativity programme.” Although I was one of the initial partners, my involvement was limited to participating in the first (in 2005) of three events, where I presented the preliminary work of my doctoral project (and later commented on my blog). It was also the first time I had been exposed to such a large research collaboration between academic science, industry and art, and I fully realised both the benefits and challenges of working in-between all of these domains.

Excerpt from purse lip square jaw by Anne Galloway

http://www.purselipsquarejaw.org/2005/02/london-ottawa.php

Friday, February 4, 2005

London > Ottawa

Back from a brilliant trip to London - and a rather blissful five days without once checking my email or going online - jetlagged, but really happy.

PLAN was good fun - tons of interesting people, but not near enough time to talk with everyone who inspired me. If you were there and I didn't get to chat for more than a minute, and subsequently didn't come even close to answering your questions or comments, please email me and we'll pick it up again.

For those who couldn't be there, I'm sure there must be lots of notes around but I'm too tired to look for them, and so for now here are just a few from Molly Steenson, Nicolas Nova and Tom Carden.

There were too many interesting presentations to mention now, but I was very impressed by Eyal Weizman's talk - Molly's notes are here - and I'll write about that later. All the speakers are also supposed to submit their presentations, so check the PLAN site in the coming days.

posted by Anne at 16:47 
http://www.purselipsquarejaw.org/2005/02/many-voices.php

Monday, February 14, 2005

\section{Many voices}

PLAN: On Locative Media's European Reception by Marc Tuters

This commentary on the recent PLAN event in London - and on locative media in general - focusses on its characterisation by the broader European electronic arts community as a (somehow unified and homogenous) practice that avoids positioning itself as politically avant-garde. In other words, seeming "relatively content to directly collaborate with industry and government" is apparently not compatible with a critical position.

As an academic, I lurk at the very edge of the new media arts world. In other words, I keep up on my reading but I am not an artist. In fact, it was only at last year's Mobile Connections conference at Futuresonic that I got my first direct exposure to the arts community.

At the time, I was quite confused and disappointed by the overt hostility towards any sort of politics or practice that diverged from the norm. In the social sciences, politics and political practice are just as highly contested as anything else, and to think that there can be absolutely 'acceptable' or 'unacceptable' politics makes no sense to me. Personally, and not a little ironically, I found it rather oppressive to be discouraged from engaging different or more nuanced understandings of politics, ethics and production. After all, 1 had always been taught that critical theory began - not ended - with the Frankfurt School.

Plenty of artists and researchers (both academic and corporate) have dismissed my work as being dull, irrelevant, or insufficiently revolutionary, and in the end I can only assume we have divergent interests, desires and agendas - despite my, I think, genuine appreciation of their work. Nonetheless, PLAN is an EPSRC-funded initiative to investigate what sorts of collaboration are possible between the sciences, arts and industry. And while I heard scientists express overt interest in more critical approaches, and I listened to industry researchers hoping the audience wouldn't throw things at them, I wondered how the arts community would extend the proverbial olive branch.

But in the end, I don't think that it's productive to talk about "artists" any more than it makes sense to treat all academics, corporate or government researchers as if they were the same. Clearly, we all share an equal ability and responsibility in keeping potential collaborations open and just, and this is no time to crush the diversity of cultures at hand.

\section{Update}

For critiques of locative media, see:

Drifting Through the Grid: Psychogeography and Imperial Infrastructure by Brian Holmes 
Questioning the Frame: Thoughts about maps and spatial logic in the global present by Coco Fusco

posted by Anne at 14:21

While Nigten (2007:127) suggests that art can serve as a boundary object between researchers working in "zone[s] or conceptual space[s] between existing disciplines or knowledge domains," the scenarios I have described here seem to suggest that urban computing and locative media might serve as boundary objects between academia, industry and art. In other words, not only do their practices enact particular technosocial visions for the future, but they also help broker relations between (pervasive computing) practitioners today.

If earlier I described urban computing as the domain of academia and industry, and locative media as the domain of artists and activists, then I hope that I have also done something to muddle those categories. In fact, I might even go so far as to suggest that there is no research and development in either of these areas that is not collaborative. If artists work with commercial technologies (like GPS, mobile phones, etc.) then they are automatically implicated in both technological (i.e. military-industrial) and consumer cultures-even when their work challenges distinctions between production and consumption, powerful and powerless. But in the case of pre-competitive technologies, like all the examples in my case histories, relations are even more complex. The actual hardware and software is originally supplied by academia or industry, as a test or experiment in 
collaboration with artists, in order to encourage and enable the development of new technologies and applications that might otherwise be overlooked or underestimated. In other words, collaboration is-in both simple and complex ways-how 'innovation' gets done.

Excerpt from purse lip square jaw by Anne Galloway

http://www.purselipsquarejaw.org/2006/09/on-collaboration.php

\title{
Tuesday, September 12, 2006
}

\section{On collaboration}

\begin{abstract}
MAINTANN A CONSTRUCTIVE CLIMATE FOR THE RECOGNITION OF THE NEW TECINOLOGY AND THE ARTS B Y A CIVILIZED COLLABORATION BETWEEN GROUPS UNREALISTTCALLY DEVELOPING IN ISOLATTON ELTMINATE THE SBPARATION OF THE INDIVIDUAL FROM TECHNOLOGICAL CHANGE AND EXPAND AND ENRICH TECHNO OGY TO GIVE THE INDIVIDUAL VARIETY, PLEASURE A ND AVENUES FOR EXPLORATION A ND INVOLVEMENT IN CONTEM PORARY LIFE. ENCOURAGE INDUSTRIAL INITIATTVE IN GENERATING ORIGINAL FORETHOUGHT, WNSTEAD OF A COMPROMISE IN AFTER MATE, AND PRECIPITATE A MUTUAL AGREEMENT TN ORDER TO AVOID THE WASTE OF A CULTURAL RE VOLUTION.
\end{abstract}

Experiments in Art and Technology (E.A.T.) Statement of Purpose, 1967

John Cage: "If the artist can become aware of the technology, and if the technologist can become aware of the fact that the show must go on, then I think we can expect not only interesting art, but we may just very well expect an interesting change in social order. The most important aspect of this is the position of the engineer as a possible revolutionary figure. And it may very well come as a result of the artists and engineers collaborating, because the artists, for years now, have been the repository of revolutionary thought, whereas the engineers, in their recent history, have been the employees of the economic life. But in relating to the artist, they become related to a revolutionary factor..."

Billy Klüver: "Together the artist and the engineer went one stop beyond what either of 
them could have done separately. But perhaps more importantly, the artist-engineer collaboration was the training ground for larger-scale involvement in social issues for both the artist and the engineer."

I've never quite understood what Cage means whenever he talks about the "revolutionary" ethos and actions of artists, especially if this relies on art being extraeconomic, and I hear it regurgitated (like academics with Deleuze) by too many artists today, but I do believe that both he and Klüver are onto something valuable when they narrow in on the potential of collaborating as a force for social change.

I especially like the implication of political collaboration. Rather than the hippie-utopian dream of everyone holding hands and working/playing together productively, their call for a re-ordering of things conjures images in my head of shaven-head French women after the war. So many boundaries crossed that the powers-that-be snap to attention, fiercely defending the borders-that-be. (Submit, you seditious whore!) We still fear miscegenation. We want to protect the human, and the machine. We want to maintain certain borders around certain practices and values in art, technology, design, sociology and anthropology too. But we want--we need--to collaborate. To "go beyond" what we can achieve separately. To not merely survive the siege, but come out the other side, like emerging from a crowd, unscathed but nevertheless transformed.

posted by Anne at 06:30

It is beyond the scope of this dissertation to take up the topic of innovation and collaboration in any more depth (see Dodgson, Gann and Salter 2005; Broers 2005) but I would suggest that the importance of collaborative research in urban computing and locative media cannot be overstated. Furthermore, collaboration in these domains-as in many other emergent disciplines and practices-is not always positive, and can involve bitter struggles over authority and expertise. Here we might recall Chapter 4 , with all the steps of translation that are required before an actor-network is formed, and how these complex new territories are always already under threat of being deterritorialised and reterritorialised by others. However, rather than assuming that these are negative processes, it may be useful to acknowledge their productive or generative capacities. Put 
differently, this is how urban computing and locative media get made, for better and worse.

\subsection{SUMMARY}

In the previous chapter I discussed "regimes of truth" and "regimes of hope" in the context of biotechnologies research:

The 'regime of hope' is characterized by the view that new and better treatments are always about to come, being tested, 'in the pipeline'... The 'regime of truth', on the other hand, entails an investment in what is positively known, rather than what can be" (Moreira and Palladino, 2005:67).

And in this chapter I positioned urban computing and locative media within both of these technosocial regimes. While perhaps not saving lives like biotechnology promises to do, locative media and urban computing research consistently promises-or at least expects-to enhance or improve people's social and spatial experiences. I contrasted cyberspace and virtual reality, and their ethics and aesthetics of disembodiment and dislocation, with the promise of augmented or mixed reality and hybrid space, and their emphases on embodiment and location.

Then I explained that in order for this vision to succeed in the future, things must be done today - a process which involves all the utterances and objects that are exchanged between actors as they broker and bid on particular futures. For example, we can see this in conferences, publications, classes and media accounts. If expectations of the future "build mutually binding obligations and agendas"(Borup et al. 2006:289) in the present, then tracing how particular expectations and promises circulate helped describe some of the ways in which 
urban computing and locative media enacts or generates different socialities, spatialities and temporalities.

By introducing the first of my case histories, Mobile Bristol, I began to move back-and-forth between small and large stories, or different scales of research. Conversations with the Hewlett-Packard researchers returned us to the role of affect in communicating research visions, successes and failures. In these stories we saw processes of translation working to create particular associations and expectations, including an increased emphasis on making research 'public.' Further following formal mechanisms of knowledge creation and dissemination such as conferences, classrooms, workshops and journal publications, and simultaneously juxtaposing these activities with more informal weblog and popular press accounts allowed me to trace how urban computing and locative media are enacted in the present. I drew attention to how the spaces of urban computing and locative media research and development are remarkably heterogeneous, despite sharing a somewhat homogeneous shared vision. And ultimately, I called attention to the value placed on inter-disciplinary research and 'public' involvement in order to discuss the politics of such collaborative work.

In the next chapter I will introduce three more cases, and focus on what such small-scale stories can tell us about larger-scale social and cultural processes. In particular, I will further discuss the implications of treating cities as interaction 
design spaces and publics as co-creators or producers of new technologies and media. 


\subsection{TECHNOLOGY TO MAKE EVERYDAY LIFE MORE MEANINGFUL}

This chapter builds on the previous two chapters by shifting focus to the smaller stories of individual urban computing and locative media research projects, and asking what expectations and promises emerge in their future-oriented visions. Beginning with a discussion of the differences between location and context, it becomes clear that researchers in these areas seek to understand the more performative aspects of technology use in everyday life. Contrary to the discursive construction of pervasive computing as 'everywhere,' urban computing and locative media projects expect to locate these technologies 'somewhere.' Contextaware computing, researchers suggest, enacts particular but dynamic spatialisations, temporalisations and embodiments. In doing so, city spaces and social behaviours are expected to become more affective and expressive, and

potentially more meaningful. Similarly, knowledge becomes a matter of knowing interiority, or what is going on inside of or under the surface of things. In this vision of the city as an interaction design space, computation also extends over the built environment, enacting or transducting another layer of exteriority to be experienced. This extensibility and transmissibility of the city, along with an increased ability to be embedded within in, is a core expectation and promise shared amongst all the cases presented here.

The first project I discuss is Passing Glances, whose interaction model involved using text messages to trigger images embedded in the built environment and 
create random and temporary narratives for urban waiting spaces. Waiting in the city was described by researchers as uninteresting and uneventful situations, and it was expected that this activity could be (re)vitalised through the creative use of mundane technologies like the mobile phone. The research can be seen to be distinguished by its call to charge these in-between spaces with potential, to augment them with new ways of thinking, and to pleasantly surprise people. But this scenario also appears to expect a time when everyday life is no longer exempt from technological intervention, and so promise to make these interventions more playful.

Sonic City, which consists of a wearable computer that senses people's physical contexts and actions and maps them to an algorithm that generates music in realtime, is the second project I present. Distinguished as both a composing and listening technology, the Sonic City project really begins to draw out the transformative possibilities of urban computing and locative media. Positioned as a tactical and creative intervention in urban spaces, the application's users may not be able to 'get closer' to other people, but they can get closer to the city. While this suggests that interpersonal relations may continue to be restricted by technological hardware, sociality and sociability are clearly extended to include a variety of non-humans (sound, light, buildings, etc.).

The implications of these kinds of individualised user agency and creativity are examined at length in the final case history. The Urban Tapestries application was designed to allow people to "annotate" physical space with text, image and 
sound in order to foster a greater sense of belonging. As with Sonic City, users reported experiencing changes in how they viewed the urban environment and others within it. Most notably, workshop and field trial participants used the application to personalise and aestheticise the city in ways that enabled boundary-making and identity formation. Urban Tapestries is further distinguished as an example of the tendency to use urban computing and locative media as aesthetical tactics that open up the possibility of becoming ethical tactics of everyday life as well.

In the final section of this chapter, I introduce notions of mobile publics and playful cities as productive ways to engage the spatial and cultural potentials enacted in my dissertation's case histories. Focussing on transformative activities, as well as individual and collective uncertainty, compels an approach to mobility and play that is more fluid than traditional network models allow. The playful city, then, emerges as one characterised by social and spatial disorderings, "where transitional identities may be sought, sensual and imaginative experimentation indulged" (Edensor 1998:219). Ultimately, I argue that augmented reality research does not expect or promise that technology will replace people, places or activities, but rather seeks to amplify or extend the most vital qualities of our lives in order to multiply possibilities for future connections. A primary expectation that informs all these research projects is that future technological applications would, and should, facilitate playful or transformative experiences, dense with aesthetical and ethical action. 
At the same time, such visions and expectations tend to reify the ideals of consumer capitalism and fail to acknowledge the implications for people who cannot afford, or do not wish to use, such technologies. Furthermore, they advocate use scenarios that reinforce the value of urban life to the exclusion of rural life, thereby excluding half the world's population and maintaining rigid socio-spatial divides. Finally, I argue that a critical take on urban computing and locative media requires further research into the infrastructural and governance issues raised by these expectations and promises.

\subsection{LOCATION, LOCATION, LOCATION?}

A 2006 special issue of MIT Press' Leonardo Electronic Almanac was dedicated to locative media, and the contributors-computer scientists, engineers, social scientists, architects, designers, artists-further demonstrate the various and overlapping perspectives that come to bear on making computing urban and media locative. In both situations, and distinct from prevailing accounts of cyberspace, the where and when of interaction emerge as paramount. Yet as Dourish (2006:304) argues, these technologies

do not create new spaces, but rather allow people to encounter and appropriate existing spaces in different ways. These new practices, then, transform existing spaces as sites of everyday action. Far from creating a space apart, technology is fundamentally a part of how one encounters urban space.

The locative case appears in Old Latin and Sanskrit grammar, as well as in modern Balto-Slavic languages (such as Latvian, the host language of the first locative media workshop in Karosta) to indicate the 'where' of a particular noun 
phrase, but it is more-or-less replaced by prepositional phrases (in, over, beside, during, etc.) in English. More generally, as a descriptive adjective, the word 'locative' simply serves to locate or fix something in position for a certain amount of time. Put back in technological terms, locative media always rely on some form of location or context-aware computing.

Accordingly, much early work in locative media made use of Global Positioning System (GPS) technologies and Geographical Information Systems (GIS) data in order to support both 'collaborative mapping' and 'personal cartography,' which often but not necessarily (see 2004's Mobile Outskirts workshop held on Lofoten Island, Norway) occurred in city environments. For example, in the early to mid200os, Amsterdam Real Time (http://www.waag.org/realtime/) and The Daily Practice of Map Making (http://www.planbperformance.net/dan/mapping.htm) recorded the movements of individuals and groups of people through urban areas and rendered them as static (if sometimes sequential) maps. While such data visualisations are often quite lovely renderings or representations of urban mobility,

by abstracting and stabilising our movements in space-time, GPS tracings can become de-contextualizing practices, and ultimately shift focus away from our (constantly changing) 'on the ground' potential. Furthermore, by reducing our spatial experiences to latitude and longitude coordinates, social/spatial interaction can take on a totality, precision and predictability that it [actually] lacks. While the city may indeed emerge as the collective movement of her people, these maps and curatorial projects are not particularly amenable to such (re)interpretation, and risk only ever being intelligible to, and actionable by, the people who created them (Galloway and Ward 2006). 
If these early mapping projects represented urban mobilities after-the-fact, then subsequent urban computing and locative media projects tended to reposition the city as a real-time platform or stage for performance, where process trumps product.

For example, Chang and Goodman (2006) claim that "locative media move beyond pinpointing location to enacting place as a medium for expression" in their project Asphalt Games, where players "conquer turf on an online map by performing and documenting game moves on real-world streets." Indeed, since 2000, collaborations between researchers at the Mixed Reality Lab, Nottingham University, and Blast Theory, a London-based artist group, have created several well-known exemplars in the highly performative area of "pervasive games" (see McGonigal 2006), including Can You See Me Now?

(http://www.blasttheory.co.uk/bt/work cysmn.html) and Uncle Roy All Around You (http://www.blasttheory.co.uk/bt/work uncleroy.html). Both games involve people online and on the streets, where play is both expectedly and unexpectedly shaped by movements through space and communications along the way, as well as by technological "glitches" (see Benford et al. 2006). Such projects take advantage of pervasive computing's potential to enact 'hybrid worlds,' where 'online' and 'offline' become explicitly interdependent, and slippage between the virtual and the actual is ever-present. 
Nonetheless, it is important to remember that this sort of spatial overcoding

(Dodge and Kitchin 2005, 2007) or haunting (Hetherington 2001) is not entirely new, nor exclusively a technological issue:

[Since] the overlaying of different spaces is a conceptual problem that is not connected to any particular technology, we may start to think about which architects and artists have already been working on this problem. To put it another way, the layering of dynamic and contextual data over physical space is a particular case of a general aesthetic paradigm: how to combine different spaces together. Of course, electronically augmented space is unique - since the information is personalized for every user, it can change dynamically over time, and it is delivered through an interactive multimedia interface, etc. Yet it is crucial to see this as a conceptual rather than just a technological issue (Manovich 2006: 225-226).

\subsubsection{Over, under and around the surface of the city}

One of the most intriguing aspects of urban computing and locative media research projects is how they play on tensions between what a city is, and what it could be. In contrast to, and perhaps even in reaction to, expectations of a total surveillance culture enabled by pervasive computing (see Chapter 4 , Section 4.1 and Chapter 5 , Section 5.2), these researchers actively pursue what they consider to be more socially and culturally positive applications for the future. Here we might recall the case of Mobile Bristol presented in Chapter 5:

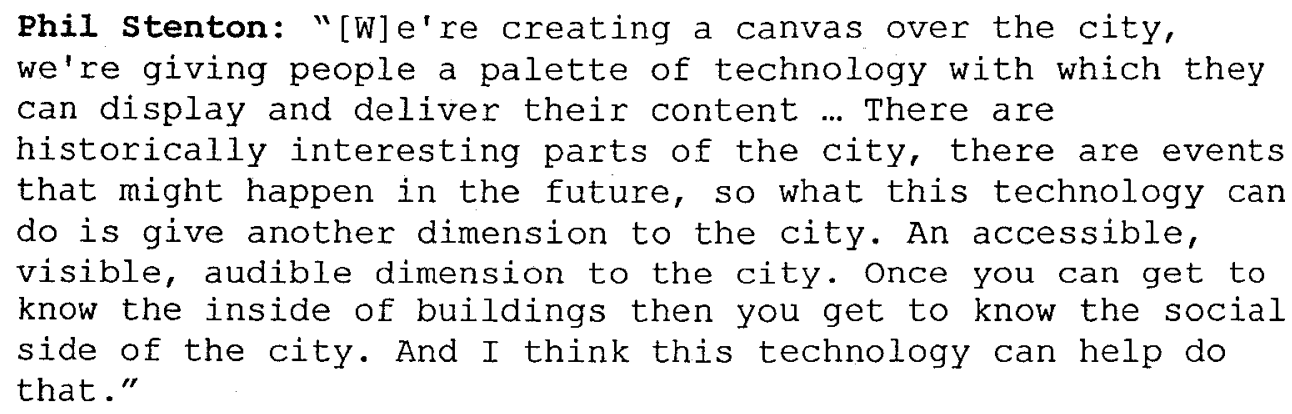


In Mobile Bristol, the city emerges as a place seething with activity, where people thrive-but all this is beyond the threshold of what we can see as detached observers of architectural monuments. As the microscope is expected to compensate for the limitations of the naked eye, context-aware computing is expected, at least in part, to overcome the constraints of the physical world, or space-time. Rather than being detached from the world around us, we become more deeply embedded in it. Similarly, knowledge becomes a matter of knowing interiority, or what is going on inside of or under the surface of things. In this vision of the city as an interaction design space, pervasive computing also extends over the entire built environment, enacting or transducting another layer of exteriority to be experienced. This extensibility of the city, and an increased ability to be embedded within in, is a shared expectation amongst all the cases presented here.

Indeed, by positioning the city as a sort of platform for digital media, possible situations and potentialities are seen to multiply. However, in this scenario the real (i.e. lived, vital) city becomes the augmented city. People with the proper technological capacities are able to live each time and space of the city to which they have access; past and future events are made present; they can move, and be moved, in many directions.

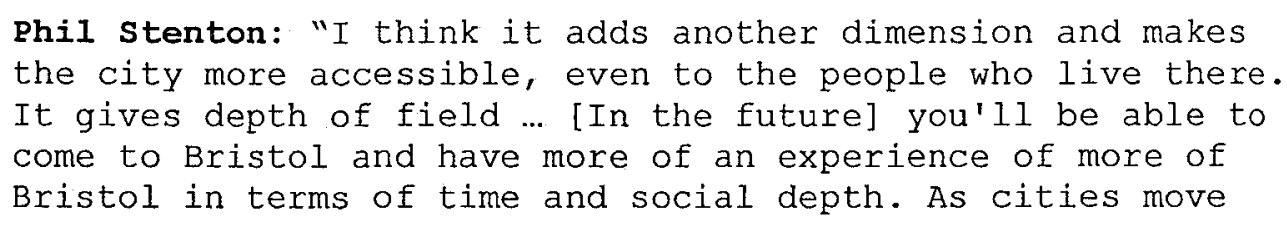




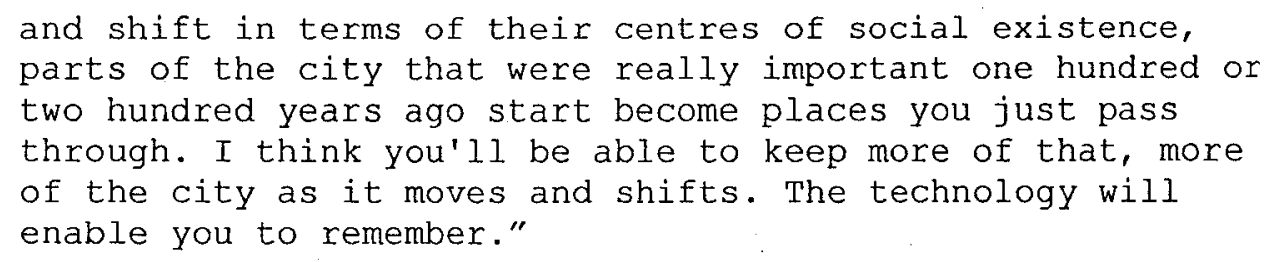

However, this story, and the future it expects, also brackets out the possibility of what happens, for example, if these technologies are unequally distributed. People without the proper technological capacities get stuck in an incomplete present, without the sense of potential afforded by memories and dreams, never quite able to experience or live a fully augmented life. These exceptations and promises also preclude technological failure (Will we all be doomed to a less than full life? Will our very lives break down?), as well as any unintended consequences (What if we drown in these depths of field? What if we want to forget? Or someone else chooses for us?)

In order to better understand what it might mean to technologically 'activate' urban experience, and by extension 'meaningful' lives, the remainder of this chapter will use three case histories to investigate researcher expectations and promises around emerging technological and social agencies.

\subsection{CASE: PASSING GLANCES}

Passing Glances, also known as Texting Glances, was a short-lived project (2002-2004) collaboratively designed by artists and engineers in the Story Networks research group at Media Lab Europe (MLE) and the Networks \& 
Telecommunications Research Group (NTRG) at Trinity College, Dublin. Passing

Glances researchers and designers proposed:

a system in which transient audience participants co-create emergent narratives that are revealed in public space. Passing Glances enables users to create these ambient urban interludes through the use of SMS text messages. The Passing Glances system contains a wealth of keyword-associated imagery that is stored 'in the city'. Images are revealed to the transient audiences when SMS message keywords trigger the system. The mobile phone therefore acts as an expressive device revealing hidden layers of the city to construct short-lived stories (Vaucelle et al. 2004:1534).

While undoubtedly within the purview of urban computing and locative media, this case history differs from the others in one significant way. Although their vision employed widely available technologies (mobile phones), the application never made it out of the lab. Nonetheless, the project vision did manage to travel overseas-and through cyberspace-in the form of image and text for conference presentations and posters (see Vaucelle et al. 2003, 2004). While it is notable, then, to see the project function almost entirely as an imagined future, it is precisely this vision in which I am interested.

Originally, I was attracted to the Passing Glances project for two related reasons. First, I was impressed by its appreciation of the mundane spaces and activities of everyday life, and intrigued by the desire to intervene in people's experience of urban waiting spaces. Second, I was drawn to the sense of ambiguity and ephemerality in its desire to generate random and temporary stories for these waiting spaces. Marc Augé (1995) identifies such in-between or "non-places" as increasingly central to our experience of everyday urban life, but perhaps at the expense of places for organic (i.e. 'authentic') social interaction. However, he also 
suggests that more historically and creatively vital places still exist, and even manage to reconstitute themselves within non-places. While not cited as inspiration, the vision behind Passing Glances can be seen to share something in common with Augé's views insofar as they are both concerned with making nonplaces into more meaningful places. At the same time, the vision denies that possibility that waiting is already rich with meaning, or that boredom can be positive.

\subsubsection{Activating places, activating people}

Take, for example, this excerpt from a conversation between me and engineer

Linda Doyle, the NTRG's principle investigator:

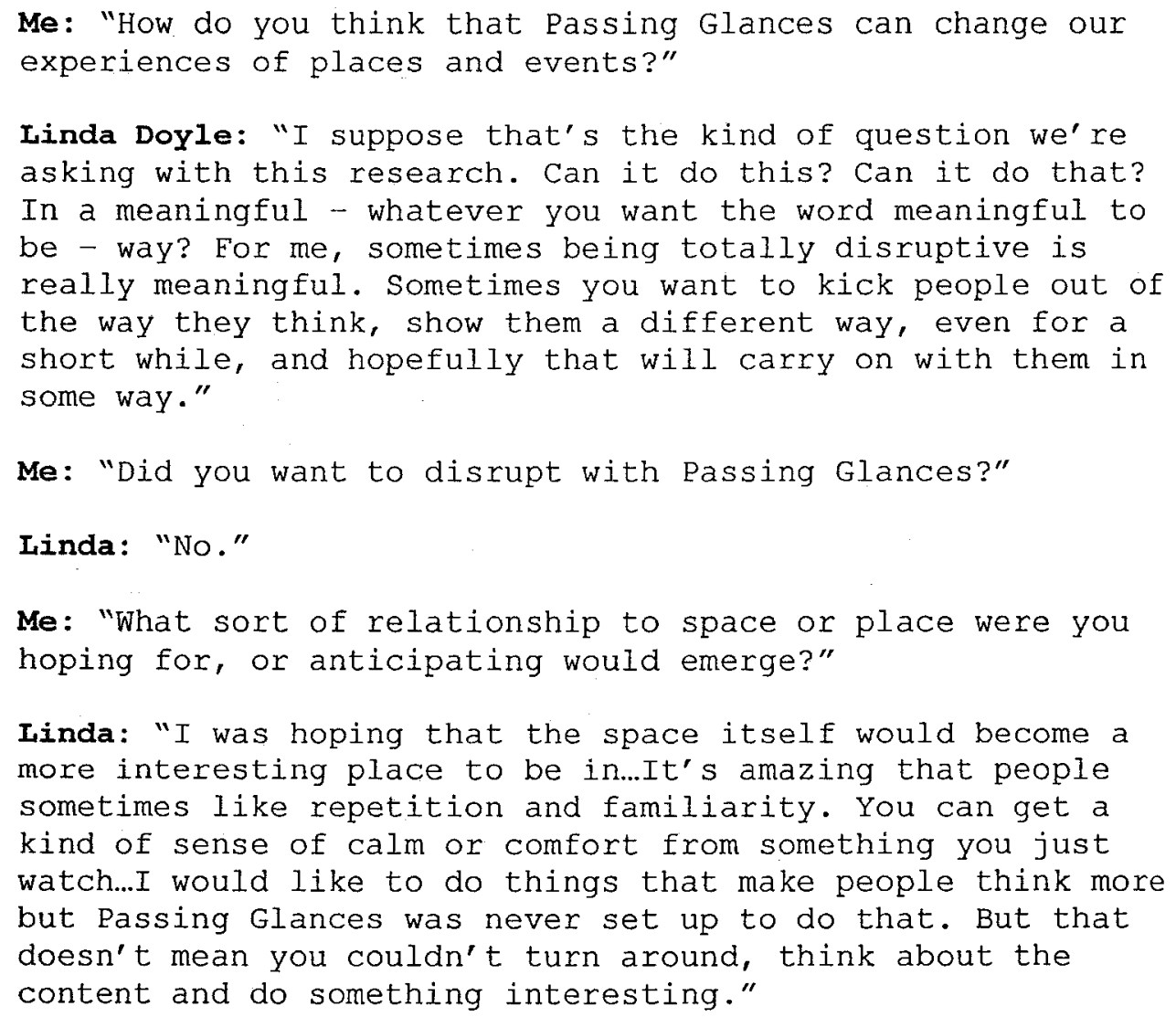


Me: "Did you not have the intention of changing the way we experience waiting in the city?"

Iinda: "Yes, that's true. It's disruptive in that sense."

Me: "You describe the city centre as moving, mobile, but you chose to focus on when we have to stand still..."

Linda: "Yes, in that sense it tries to change the way people experience things...The bit I like the most is that you put down the technology and think about something else. In Passing Glances you make stories out of images, or you might talk to the person standing next to you. You never know."

Me: "You seem to be touching on the importance of ambiguity..."

Iinda: "Yes, it was important to me that the system be random."

Me: "If I can get back to this bit about waiting, you've mentioned that if you're waiting alone you can be totally engaged with Passing Glances, or talk to someone else..."

Linda: "We wanted to encourage that yes..."

Me: "So both individual and collective action..."

Linda: "Yes. One of the things about waiting spaces that I like is - you know when people go to wait for the train, and some people always stand in the same place on the platform? - what I originally wanted to do is have a huge image in a train station but it's totally out of focus, and only comes into focus slowly over say four months, but only focussed in the spaces where people stood. As people notice the photo is coming in based on where they stand, they might decide to stand somewhere else on the platform. I love this idea that you're doing something slowly, repeatedly, something ordinary... It takes you ages to realise that something's happening, and it takes you ages to realise that you can change it...

Waiting time in the city definitely fascinates me, and your behaviour in that space, the repeated behaviours...tife has gotten so busy. So fast. In the last ten years Ireland has changed. We went from being poor to wealthy. You can see it in the aggression and pace of the city, it's different than it used to be. So I think that something that makes someone stop for a moment [is good]. You're giving people access to interesting content, or you're making it interesting because you're giving people access in places they don't expect it." 
Linda's enthusiasm for her work is infectious and, as we sat in her noisy office at the university, she vividly evoked a picture where everyday life in Dublin was increasingly speedy and hectic, where people inevitably found themselves stuck somewhere trying to get somewhere else, often alone despite being in close physical proximity to other people. She described waiting as uninteresting and uneventful situations that could be revitalised through the creative use of mundane technologies like the mobile phone. So while I tend to prefer the idea that such places might still provide temporary shelter or refuge from pervasive communication technologies, I could not help but be moved by Linda's call to charge these in-between spaces with potential, to augment them with new ways of thinking, to surprise people.

As suggested in the previous section, such urban computing and locative media projects are distinguished by their desire to activate urban spaces-to make present multiple potentials-through the production and consumption of text, image and/or sound. Following Amin and Thift (2002) and Urry (2003), Michael (2006:113-115) describes this complex enactment of urban spatiality as a matter of disclosure, where new technologies work to open up, rather than enclose places, thereby enacting or transducting what Crang (2000) calls the "transmissible city." In the case of Passing Glances, multiple relations could potentially emerge: textual ones (messages sent to the system), image-based ones (triggered photos), and verbal ones (talking with bystanders about the texts and/or images) to name just a few. The rich potential of these experiences also recalls a 'deepening' (cf. Latour 2004) of meaning in terms of increased 
connections, or an augmenting of what Michael (2006:117) also calls the "density of spaces."

Nonetheless, Passing Glances also positions the city and everyday social interaction as somewhat lacking, or in need of improvement. In terms of expectations it also becomes clear that the researchers believe that everyday life has already been irrevocably colonised by information and communication technologies, and so their promise is to improve the quality of our interactions with them in the future by enabling us to play with other people and places.

\subsection{A BRIEF NOTE ON PROTOYPES}

Before I introduce the remaining two cases, and continue my discussion of how urban computing and locative media stand to change everyday experiences of spatialisation, temporalisation and embodiment, I would like to take a brief look at the role of technology prototypes in expecting and transducting future scenarios.

Both the Sonic City and Urban Tapestries research projects involved the documented making, testing and refining of prototypes. Defined in the OED as "a first full-size working version of a new vehicle, machine, etc., of which further improvements may be made" or "a preliminary version made in small numbers for evaluation, or from which improved or modified versions may be developed," prototypes are instrumental in trying out, or playing with, new technologies (Schachtner 2002). First, they are crucial in determining and demonstrating 
technological feasibility, and second, they can be seen as material instantiations of ideas or theories. In effect, they set research in motion, or grind it to a halt.

Social studies of science and technology have clearly identified the importance of visually-based material objects such as sketches, drawings and diagrams in research and design practice (see for example Lynch 1985; Latour and Woolgar 1986; Latour 1986; Turnbull 1993; Henderson 1998). Ideally they serve as easily understandable and reproducible models, but they also act to recruit allies and to create "obligatory passage points" (Callon 1986) through which other researchers must move. In technology design work, the object prototype is especially important as it makes tangible what has previously only existed as ideas, words or images. It is seen as an attempt to translate the 'merely' imagined into the real. It is also explicitly made to be changed, as most commercial products go through multiple prototyping phases, and pre-competitive research projects-like the cases presented here-only ever reach the prototype or investigatory phase.

For the purposes of my dissertation, then, prototypes are interesting precisely because they enable me "to draw out [some of] the normative claims and assumptions embedded within them" (Garrety and Badman 2004:199) and, by extension, within particular expectations and promises surrounding the role of urban computing and locative media in everyday life. 


\subsection{CASE: SONIC CITY}

Part of Lalya Gaye's doctoral research at the Future Applications Lab, Viktoria Institute, in Göteborg, Sweden, Sonic City was a collaborative research project (2002-2004) with Ramia Mazé and Margot Jacobs. Like the previous cases, research and design was highly collaborative and multi-disciplinary, and it was a project made to explore ubiquitous computing technologies and what roles they might play in "enabling future everyday aesthetic practices" (Gaye 2005).

Although devoted to mobile music-making, Sonic City's first experimental prototype caught my attention as a piece of clothing:

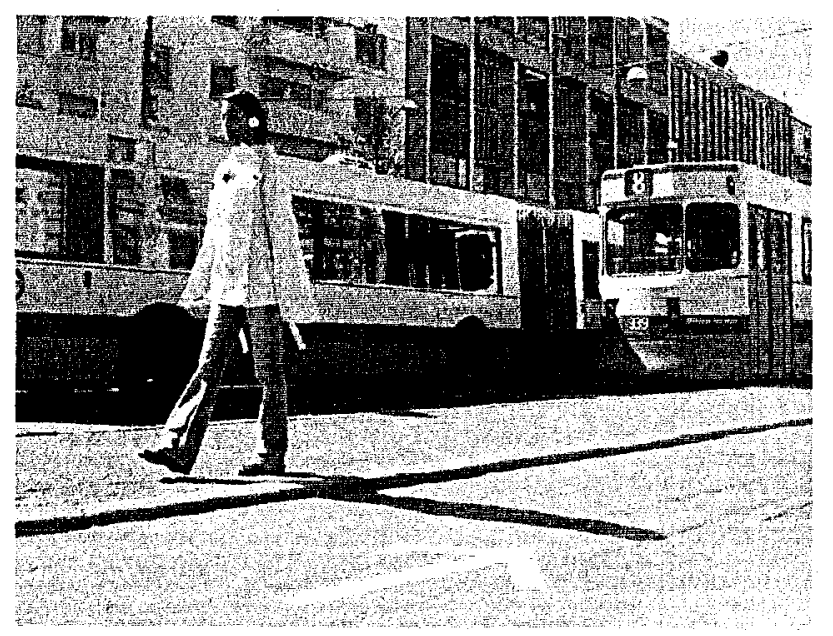

(Photo: Ramia Mazé and Margo Jacobs, 2003)

I had never seen a computer that looked like a beautiful straightjacket, and I wanted to learn more:

The prototype senses the user's context and actions when walking through the city, maps this information to the audio processing of live urban sounds in real time, and outputs the resulting music through headphones. It is an open-ended platform for iterative prototyping of sound content and musical interaction that enables testing in real-world settings ... Current sensors used in this 
implementation are a metal detector, an IR-sensor measuring proximity to walls and objects, a light intensity sensor, a microphone measuring sound level, and an accelerometer sensing stops, starts, and the starting user pace that determines the music tempo of a whole session. We have also experimented with sensing pollution and temperature and plan on adding a heart-rate sensor. Low-level sensor input such as light intensity or presence of metal are continuously measured and mapped to the music, whereas the context recognition of highlevel parameters such as "standing still at night" are updated every other beat. (http://www.viktoria.se/fal/projects/soniccity/prototype.html).

I had originally planned to focus my doctoral research on wearable computing,

but the more I read about Sonic City, the more I was drawn to the implications of interaction design for urban environments. I was intrigued by the emphasis on the generative capacities of cities, and by extension, urban computing and locative media.

\subsubsection{Location, context and scale}

Following De Certeau's (1984:91-110) well-known discourse on the spatially, temporally and socially productive capacities of walking in the city, Sonic City is positioned as a tactical intervention in urban space:

Everyday urban experience involves active interpretation and impels creative response - consider the meaning of a screeching noise, the smell of burning rubber and a car headed your way! As a 'physical interface', the city provides a built infrastructure and established ways of using it creatively. Even the mundane act of taking a walk involves the complex coproduction of bodily movement in relation to obstacles. Along the way, there are always elements of serendipity: an unexpected view, surprising encounters or fleeting ambiances. Built and transient conditions require continual tactical choices and inspire possibilities along the way. Whether a pleasant stroll or a mundane commute, being in the city involves dynamic creative improvisation ... In this project, we take the simple act of walking to explore the city as an interface and opportunity for personal creativity. Everyday behaviours, personal (mis)uses, and aesthetic practices suggest the inventive ways in which people already use the physical city. As a new platform for personal expression and urban experience, Sonic City explores public space as a site for private performances and emerging behaviours, and the city as an interface for personal musical expression (Gaye, Mazé and Holmquist 2003:1-2). 
Sonic City further highlights how people's everyday movements "generate particular everyday spatializations that incorporate the 'local' and the 'global"'

(Michael 2006:121).

The user only interacts with her local context, not with the city as a whole. This brings a dimension of immediacy to the interaction and makes the musical experience situated. Because the system is wearable, the space of enabled interactions is also user-centric and non site-specific. This interaction space is however scaled to the dimensions of a city: the musical time-line is matched to the user's path and the time it takes to travel certain distances. This implies a certain scale of musical gesture (Gaye and Holmquist 2006).

Interested in how designers were approaching new interaction spaces, I asked how the researchers thought the Sonic City application could reshape people's experiences of space and place:

\footnotetext{
Lalya Gaye: "The notion of place is central to the project. The music is situated; it is produced and experienced in context. However, because it is centred around the user's perspective of the city, the system does not rely on GPS or other types of location information. Sensor data is not stored; only the resulting music is recorded...but even that is not necessary. As the music is a result of the user's interaction with her urban space, the music could be seen as a representation of contextual data. The location cannot be derived from listening to the music, unless you hear some recognisable sound in the background, so the data is more contextual than locational. And speaking of data, users only have access to the music, both while using the system and afterwards when listening to the recording. They cannot directly access raw sensor data."
}

The distinction between location and context is particularly important amongst locative media and urban computing researchers. Location is considered to be a matter of longitude and latitude, a precise measurement afforded by mapping technologies. Context, on the other hand, is considered to be much broader and more fluid, as it relies more on dynamic input from sensor technologies. In terms 
of interaction design, the 'real' value of a place is people's experience of it (see for example Dourish 2001). Location, as defined above, is considered irrelevant here-but context and experience are considered paramount. By shifting focus from location to context, researchers can focus on the transformative aspects of technologically-mediated spatiality, temporality and embodiment:

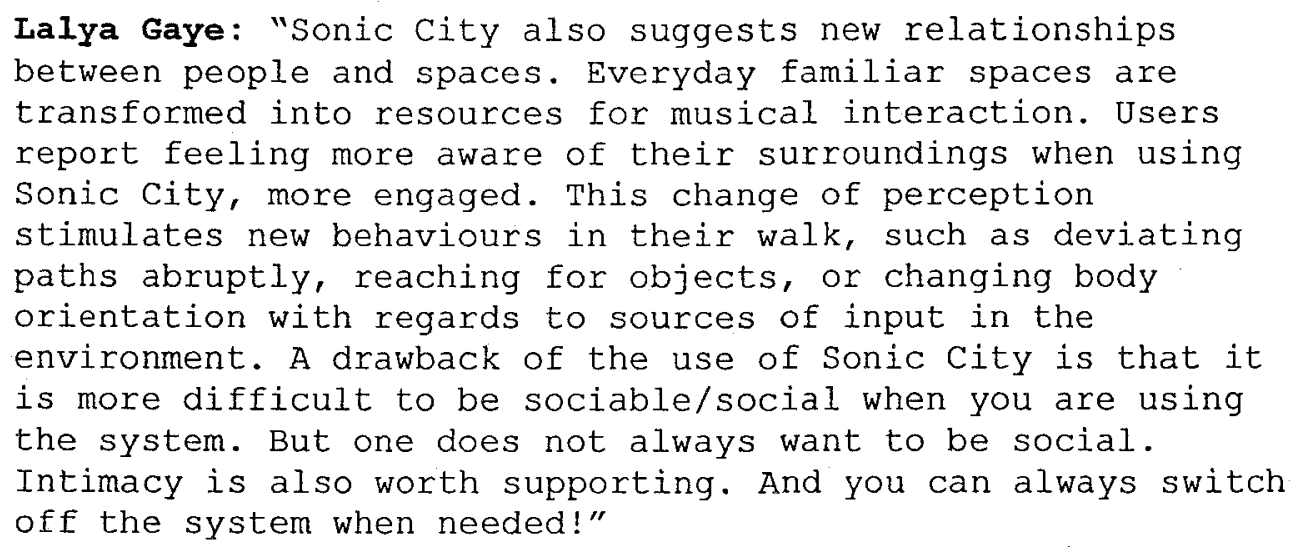

While the wearable technology envisioned in Sonic City may allow new relations

of scale between people and the city, the researchers also acknowledge that it may

be at the expense of interpersonal relations.

However, the greatest transformative potential of Sonic City may be that it promises to turn the city into a musical instrument and the city walker into a musician.

Me: "In several conference papers you (and the other authors) describe the city as an interface and mobility as a musical gesture. Can you please expand on each phrase and explain how they relate to each other?"

Lalya Gaye: "The way we conceive the city as an interface is double. Eirst, we look at it from the perspective that it is an interface between physical urban space (including the 
user's embodied experience of the city) and the digital layer of music being created. Familiar interactions with urban space are augmented with musical interactions that add a layer of meaning to urban interactions that the city dweller takes part in. Second, we look at it from the perspective of it being a user interface for playing music. There is a long tradition of musical interfaces where physical interaction creates music in real time. The design of these user interfaces are sometimes based on traditional instruments - the synthesizer keyboard is based on that of the piano - or completely different objects that the user might or might not use for other purposes (e.g. new interfaces with original design vs. augmented everyday objects).

In Sonic City, we build on this tradition by augmenting something that users are familiar with, but not in terms of making music with it. Urban space - which we are all familiar with and have learned to live in - becomes the user interface, from both local and global perspectives. At the larger scale, one navigates non-linear musical scores through one's movement in space, the paths one takes in the city, and the changes in urban context that one encounters. On a local level, one's immediate surroundings become a variety of 'knobs' and 'dials' to play with when passing by.

As walking through the city is an inherently mobile activity, the surroundings and interaction possibilities at hand change continuously. For example, the letter-box on your right will only be in your vicinity for so many seconds. Your path takes you through different urban contexts with different qualities and corresponding interaction opportunities that shape the score you are making. The idea of physical motion as musical gesture produces musical sounds projected on a physical path. "Playing the city" means playing with an interface that unfolds at each step, an interface that you are used to dealing with but that now has extra meaning and invites you to use it in a new way."

While Passing Glances envisions the city as a place where new media can be creatively produced and consumed, expecting and promising new media ecologies, Sonic City stretches this idea even further. Not only can the application's user generate her own music (instead of listening to pre-recorded 
sounds) but by sampling the urban environment, the music is dynamically cocreated with the city itself.

Explicitly positioning the city as an interface between a person and a technological device, Sonic City fully draws out the implications of expecting cities to become interaction design spaces. The city of urban computing and locative media emphasises how specific contexts (relations, situations, etc.) actively reconfigure the social, the spatial and the technological. Perhaps more interesting, the prototypes also point to how researchers envision new technologies reshaping our relations with the spaces, and people, around us.

\subsubsection{Aes thetics and sociability in the (sonic) city}

Cities, after all, insist on the senses at the level of sound. It is easier and more effective to shut your eyes than it is to cover your ears. Ears cannot discriminate in the way eyes can - as with smell, hearing puts us in a submissive, sensuous relation with the city. And yes still we glance at sounds in the city, we don't gaze. Individuals' relation to sound in the everyday spaces of the city tends to be one of distraction rather than attention (Tonkiss 2003:304).

Idhe (2003) explains that auditory polyphony profoundly shapes how we perceptually and imaginatively experience different modes of co-presence. Put another way, everything we hear, and do not hear, affects how we engage with the urban environment and with other people. While the Sonic City application shares much in common with the personal stereo (it is highly mobile and requires the use of personal headphones), it differs in its ability to change the user's role from media consumer to media producer. 
Michael Bull has written extensively on the role of personal stereos, urban experience and the management of everyday life. In his view, Walkmans and iPods have profoundly reshaped urban aural experience-and aural desirethrough a consumer-driven mass individualisation of the soundscape, and of social relations. Describing the personal stereo as "the icon of personal taste" (2002), Bull primarily characterises these technologies as ones that detach their users from the space and people around them, as people tend to use them to escape sounds and other people they find objectionable, and to replace or overlay this less desirable reality with a more desirable one (2000, 2007).

However, Beer (2007) suggests that rather than treating sound as an intrusion into the spaces of everyday life, "we listen more closely to the ambient architecture of the streetscape [so that] we become sensitized to music and sounds that [already] affect how we live" (Atkinson 2005 as cited in Beer 2007:851). In this way, he argues, personal stereos can instead be seen to “operate a self-regulated information overlay that transforms [people's] experience of the city (without allowing them to 'get away' from it in any substantive sense)" (Beer 2007:858). This notion of layering is particularly apt when we consider the expectation that urban computing and locative media will augment or overlay the urban environment. Arguably, Sonic City goes one step further and takes the publically sensible aspects of the city and changes them into personal soundtracks. 
Interestingly, the application's users may not be able to 'get closer' to other people, but they can get closer to the city. While this suggests that individualisation continues to underpin such visions and interpersonal relations may continue to be restricted by technological hardware, sociality and sociability are both enabled by these relations and clearly extended to include a variety of non-humans (sound, light, buildings, etc.).

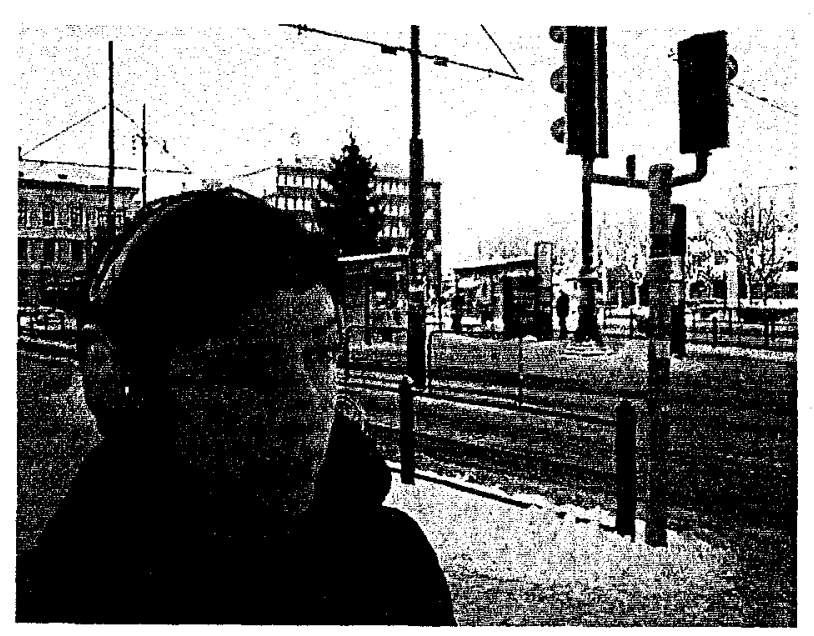

(Photo: Sonic City 2004)

But Bull (2000, 2007) also stresses that listening to one's own music while walking through the city is a powerful tactic to reclaim a sense of control over situations that might otherwise diminish the quality of people's urban experiences, and this notion takes on new meaning when applied to Sonic City. As Tonkiss (2003:305) explains, while

walking the city, people invent their own urban idioms, a local language written in the streets and read as if out loud ... Walking, we compose spatial sentences that begin to make sense, come to master the intricate grammar of the streets; slowly, we learn to make the spaces of the city speak. 
In these ways cities become something "to grasp and make sing" (Barthes 1997:172), and indeed Lalya and her colleagues explain how the Sonic City application reconfigures people's experience of control in everyday urban life:

Using Sonic City enhanced the users' perception of and engagement with their everyday settings. They felt more aware of details highlighted by the system, of things that they had stopped paying attention to or never even noticed. However, they also perceived that the city was more in control of the music than they were, due to unpredictable and uncontrollable factors encountered in urban environments that had more effect on the music than their own actions. This pushed the users to actively regain control over the music, which they would do through various ad hoc tactics, both on a path level and on a local immediate level. The users modified their planned paths in order to search for unusual urban contexts (electrical chamber, etc), and engaged in local interactions with shifting resources at hand, directing sensors with their body towards sources of input (such as metal) or modulated the city's input by shadowing sensors from noise or light with their body posture. Paths could be seen as scores articulated by ad hoc local bodily interactions ...

The experience alternated between being active and passive, going back and forth from an immersive experience to background music listening, to active interventions in the music. During active phases, users looked for sources of input and interacted with them. The experience would become passive when the activity of dealing with the city had higher priority or when the users wanted to simply hear what the city did musically, at which point the experience would become more introspective and intimate. Navigation through space alternated as well between being motivated by intentional musical actions (such as suddenly getting closer to a wall) and by normal everyday mobile behaviours (crossing a street, avoiding a dog...) Sometimes, users even made musical actions pass as everyday activity, pretending for example to be looking at a shop window when actually aiming to hide the microphone from loud traffic noises (Gaye and Holmquist 2006).

More poetically, one user even recognised that a person "would have to do a lot of exploring to...develop an ability to play" the city as an instrument, and noticed that quiet environments were experienced as "one very long song" (Gaye and Holmquist 2004:3-4). The city, in other words, can go a long way and take a long time. 
As an embodied and mobile experience, however, Sonic City may not be substantially different from current personal stereos. Thibaud (2003:338-339) explains that walking through the city listening to music enacts six related things: the route, the stride, the gait, the style, the detour and the short cut. The routegetting from one place to another-is distinguished by the choice of sound accompaniment; the stride encourages continual movement or continuity and "gives priority to musical rhythms;" the gait modulates walking speed in accordance to the music; through bodily gesture and improvisational choreography, the style makes movement aesthetically pleasing; and, finally, the detour extends and the short cut reduces the listener's experience of time. While the precise terms might differ, it is clear that Sonic City, as both a composing and listening technology, enacts a variety of active and passive activities that similarly reshape people's experience of space, time and bodies.

In sum, the Sonic City prototype and the values embedded in it, point to novel forms of technologically-mediated urbanism based on the desire to take advantage of, through technological modulation, the vital qualities of everyday life. Recalling Dourish's (2006) claim that these are not new spaces as much as new means of experiencing existing spaces, I would add that projects like Sonic City (and the others presented here) also point to the expectation that the 'real' world could, or should, be amplified or augmented in positive ways. What constitutes 'positive' ways will be explored in depth in the final case history, but Sonic City already hints at the fundamental value: increased user agency and creativity. 


\subsection{CASE: URBAN TAPESTRIES}

The context Urban Tapestries aims for is one in which a community organically records layers of histories, experiences and events that are linked to familiar locations and accessible to everyone. As the name suggests, it aims to knit together many layers of narrative and discourse over the topography of the city. Urban Tapestries seeks to provide a forum for ordinary people to write and remember their stories and share them with others, enabling an alternative to the single authored storytelling in our museums, history books and media. By collecting these stories a community's memory may grow on many levels with a hierarchy defined only by a user accessing what is of interest to them (Jungnickel 2004:3).

The final case history presented in my dissertation is Urban Tapestries, a project developed by the London-based research and design collective Proboscis, in collaboration with partners in government, industry and academia, between 2002 and 2004. The Urban Tapestries prototypes were designed to combine mobile and internet technologies with geographic information systems to facilitate an activity Proboscis refers to as "public authoring," or "a kind of Mass Observation for the 21st Century."

Like the founders of Mass Observation in the 1930s, we were interested in creating opportunities for an "anthropology of ourselves" - adopting and adapting new and emerging technologies for creating and sharing everyday knowledge and experience; building up organic, collective memories that trace and embellish different kinds of relationships across places, time and communities (http://urbantapestries.net/).

The Urban Tapestries interaction model uses mobile devices to "annotate" particular places with images, sounds, text, etc., and the map-based interface also allows users to find and access other people's annotations. This is, in a very real sense, what Phil Stenton, in the Mobile Bristol case (Chapter 5, Section 5.3), called "depth of field" and what other Hewlett-Packard researchers allude to when they say "We think the physical world and the virtual world would both be 
richer if they were more closely linked" (Kindberg and Barton 2000:365). It also involves what I described above as the extensibility of the city, and the "endlessly disclosable" (Michael 2006:114) or dense quality of technologised space.

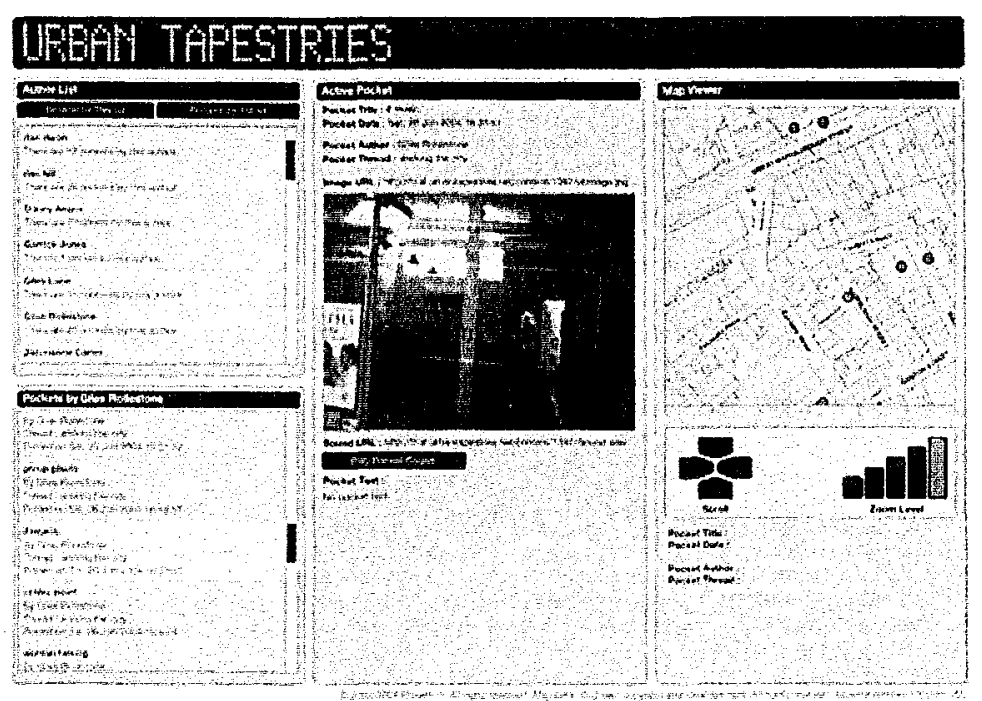

(Photo: Proboscis 2004)
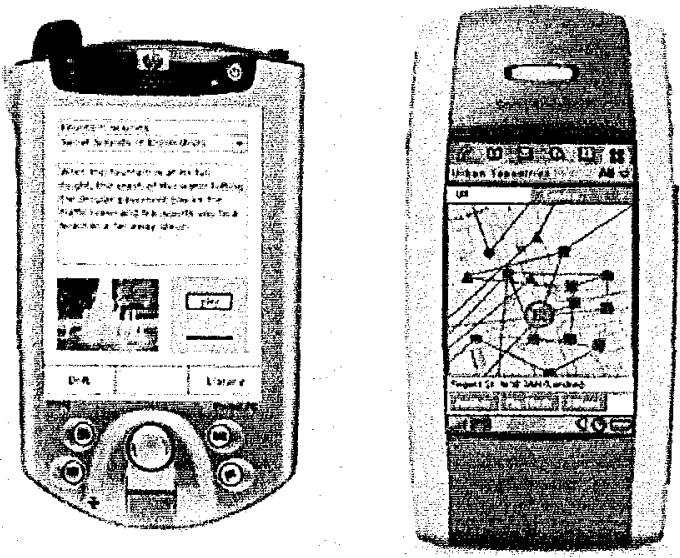

(Photo: Proboscis 2004)

But Urban Tapestries began, one of the principal investigators Giles Lane explained, because he believed that too many technology research proposals were being put forth without any interest in "real people" or any social or cultural 
issues in mind. When they were interested in people, the projects Giles had witnessed were "all about consumption" and he thought that this was a "very narrow" view to take. He gave the example of an application that would provide housing prices in situ, and explained that while he had no desire to eliminate such projects, he felt compelled to investigate other options and additional possibilities:

Giles Lane: "We' ve been able to, through our particular set of perspectives, point out the deficiencies of some of more situated tools and technologies. We've pointed out that we actually need quite broad technologies that are flexible enough to be reconfigured to suit micro-contexts. One of the problems with situated technologies is that they are too determined and our research has shown that they speak to too few people, ordinary people. So our solution is to make the superstructure configurable, very configurable, and instead of designers designing the context stuff, allow ordinary people to design the context stuff. But to help them do that, you have to give people examples because these are new technologies. They involve paradigm shifts and you have to give people hooks."

Alice Angus: "I think what is important is that we're not just designing a tool and parachuting it in so that people can use it whatever way they want. What we're doing is looking very carefully at how people might use a tool, developing scenarios and ideas around that tool, and continuing to develop the tool with that kind of feedback."

Giles: "In parallel to what Alice has described, we also look at what people cannot do. We look at [if] this technology [can] offer something in addition to what already exists? So it's an augmentation of daily life, so that yes we can still stop someone on the street and ask directions. Urban Tapestries won't stop that, it's not intended to in any way. But if we had stuff to share, without necessarily having to be stopped on the street, is there a way we can overlay that in the places where that context-aware information is available, and for it to be there to access if and when they want, and for people to respond to it? That is new. Broadcast models may not the best avenue to explore that. Mobile, location-based technologies might be the best way to explore that..." 
Me: "Can you please describe how you think Urban Tapestries
can impact our experience of events, spaces and place?"
Giles Lane: "Urban Tapestries does not collect data as such.
It is a set of protocols for building relationships between
locations and places that are linked thematically to content
(text, audio, visual). It is about using place and the hinge
in new relationships between people, and the things they
wish to share and communicate with each other. People
annotate and upload data in the form of sounds, words and
pictures that are associated to places. In future, the
client software should be able to take advantage of
functionality on the server which will enable users to
define 'places' rather than just a set of coordinates. This
would make possible the association of ideas/information
with an area, not just a single long/lat location. All data
is accessible to the people who have contributed it via a
web interface - allowing participants in the trial to
continue to add and edit information in their own time, as
well as explore the system for things embedded by others..."

As in the other cases, Giles emphasised that location-based services were valuable only in so far as they tied 'meaning' to a place. He stressed that he did not see applications like Urban Tapestries "replacing" everyday life and social interaction, but simply "augmenting" it for anyone who was interested. The emphasis on public participation, and ground-up media creation and sharing, is also crucial to the Urban Tapestries vision and I will return to it in depth below.

At the project level, Urban Tapestries was again primarily self-described as a research endeavour, not technological product development. While the technology prototyping was participatory, iterative and well-documented online, it always seemed clear that Proboscis was using technology as a social research tool as much as they were researching technology in society:

Giles Iane: "I think the whole project, as a research project, is about how we make relationships and how we 
inhabit urban space. The [technological] tool is just a mode of describing these things and looking at the possibilities. It's not about mobile phones. That's why there's the whole conceptual design part of the project, the whole catalog of ideas. It's not just about making a viable product for mobile phones. It's about the whole gamut of relationships we develop to places, and the different kinds we might want to develop with different tools. Urban Tapestries operates on several levels. It operates on the level of relationships to place. It's also a way of describing and building a database that can reflect the complexity of these relationships. And on another level it's about how we can begin to map and share the information that enables us to construct those relationships."

Here again we return to the layered city, where not only is information embedded in space-put in place-but people are too:

Me: "What's the difference between owning a space and belonging to it? Are they oppositional?"

Giles Lane: "I think that taking ownership implies a sense of belonging. I think that if you take ownership of a space...I don't think they're oppositional at all. Part of that feeling of not belonging, of dispossession, it's interesting that it's all about owning. If something belongs to you, you therefore own it. It represents something you feel you have an investment in."

Me: "So we can belong to others as well? Like a slave belongs to his master? He's owned."

Giles: "Well I think that's an interesting side to take. But I see this as being more about the construction of identity. I don't think of it as owning in terms of objects, in that sense. It's not so much that you own that bench, or that tree, or even the house that you live in...It's not about owning capital, it's about owning experience. Urban Tapestries isn't a location-based technology, it's a technology based on relationships. It's about how do you construct relationships between people that are all based around places and notions of belonging to a place, and taking ownership of it implies that you belong there. I think that if you feel like you don't belong somewhere it's maybe because you don't have enough investment in a place. And it strikes me that if you can inject some aspect of your personality into a place then it provides a vicarious sense of ownership, and therefore a sense of belonging..." 
I asked who these people were, and what they wanted to belong to:

\begin{abstract}
Giles: "There is a huge range of individuals to design for, but if you start to look for the universal things, the stuff that cuts across economic barriers, social divides, those are the things that everyone has to engage with, no matter how rich or poor you are. You need to know about things like nappies. Where do you get them? How do you get them? If you've never been a mother before, this is all stuff you have to learn. There's a lot of information out there, but it's not situated information. You have to know how to find it, where to go to get it in the first place.
\end{abstract}

\begin{abstract}
So what if in our application there's a thread, you can see it really easily in a mobile phone, or someone tells you that someone has created a whole thread for your neighbourhood with all the clinics, all the shops you need to buy this or that, what things cost, comparisons... what if that was all just there? Situated so that it could take you to the place where you actually needed to get? One of the things we found, and we're educated, relatively well-off, we know where to find this information but it's still a pain to actually go round and gather it all. And actually, interacting with institutions is not pleasurable, no matter how well educated or not you are. They're unpleasant environments. Hospitals, clinics. They're not nice. People are put off. If you can identify the universal or generic scenarios, then you can get at a 'real' person, doing 'real' things."
\end{abstract}

By this point, it should be getting clearer that in the case of Urban Tapestries, as well as the other examples presented here, the 'real' is effectively the mundane but somehow meaningful part of everyday life. Augmenting reality, then, is not about using technology to replace people, places or activities, but rather seeking (and expecting) to amplify or extend the most vital qualities of our lives in order to multiply possibilities for future connections. However, just as with Sonic City, the expectation or promise is that individuals will be able to 'tune' the city in more meaningful ways, and that normative desire deserves to be questioned further. 


\subsubsection{Sensing cities and affective spaces}

Looking at the actual use of the Urban Tapestries prototypes adds another layer to this story. Proboscis, from the outset of the project, collaborated with sociologists at the London School of Economics, and substantive user studies and socio-cultural analyses further distinguish Urban Tapestries as a collaborative research project interested less in technology than in people and places. For example, approximately six months before the first field trial a small group of participants was invited to give feedback on mock-ups of what the Urban Tapestries system might look like, and the findings of these early bodystorming activities were used in consort with further exercises to help Proboscis shape and design the actual UT prototypes.

Silverstone and Zujon's (2005) report on one of these workshops asked whether or not people could "use UT in meaningful and interesting ways," and concluded that indeed they could. However, as they point out, the more important question is what constitutes "meaningful and interesting" engagement, and in this case it was how people used the Urban Tapestries mock-ups to negotiate social and spatial boundaries. Claiming that participants used Urban Tapestries "in order to negotiate boundaries and mark their territories, stake claims and identify their personal preferences," Silverstone and Zujon (2005:33) focus their analysis on individual knowledge production and aesthetics.

First, participants are reported as having an interest in delineating the spatial boundaries of the field trial, and differed in their boundary-making based on 
familiarity with the neighbourhood, and whether or not they marked boundaries based on geographical space or social activities. "The point here is that the pathways and places respondents are drawn to reflect not only their knowledge of Bloomsbury, but also allows for the customization of place, by facilitating a kind of geographic aestheticization" (Silverstone and Zujon 2005:35). This recalls Bull's (2000) discussions of how people use personal stereos to claim territory, or manage urban space. It is also consistent with Giles Lane's explanation above of what it means to belong to a place.

But a different kind of aestheticisation also occurred, and it was similar to something also described by Bull (2007). He explains that iPod users often treated, or experienced, the city as if it were a film with a soundtrack, as these examples indicate:

Karen: "I sort of feel like I'm in my own music video."

Berklee: "It feels as if I'm in a movie at times. Like my life has a soundtrack now." Jason: "My world looks better. I get more emotional about things, including the people I see and my thoughts in general. Sometimes I project the lyrical content of songs on to the people I see while I'm listening" (Bull 2007:41-43).

Urban Tapestries trial participants also reported (Jungnickel 2004:9) feeling the desire to 'make up' things about the city and its people, again suggesting that both perceptual and imaginative (playful) spaces were being enacted through people's uses of the mobile technologies:

My mind started drifting and I was eager to start writing a fictional story about the people entering the cafe, to be picked up as a thread by someone else on 
another day, a rambly fictional story of a real place. But I couldn't post a thread and the creative moment was lost. Shame.

Posted by Lawrence at December 11, 2003 07:40 PM

I'd like to go out on different days in different moods and sometimes write biographical stuff, sometimes complete fantasy.

Posted by Jemima at December 14, 2003 07:39 PM

This sort of customising or aestheticising approach to cities indeed conjures urban environments that are made richer or more meaningful through the use of mobile, networked and context-aware technologies. While personal stereos and applications like Sonic City are not sharing, and therefore explicitly social, technologies, Urban Tapestries was designed to be. Participants in the early bodystorming activities repeatedly mentioned that part of what they enjoyed about using Urban Tapestries was how it facilitated a feeling of presence, both in terms of using the application with other people and connecting with absent others (Silverstone and Sujon 2005). But the question remains if this sort of “deepening” of connections (Latour 2004) or "disclosability" (Amin and Thrift 2002) of space actually enriches social and cultural interaction in more than highly individualised ways.

If the Urban Tapestries' field trails are any indication, then it may be fair to suggest that such future computing applications would actually encourage the individual use of technologies for social or collective purposes. For example, Katrina Jungnickel (2004) analysed the 2003 London-based field trial from the perspective of how users "imagined multi-sensory annotations of the urban landscape." She begins by explaining that pervasive computing stands to 
affect our sensory experience of the city by augmenting how we look, listen, talk and connect, search and find objects, places, people and information. In turn our language is being adapted to our device's reactions to ubiquitous computing environments as they sniff, see and read things we ourselves cannot ... [W] don't know what the long-term effects of ubiquitous computing and location based wireless networks will have on society. What we do know is that rapidly emerging adoption has created a field for inquiry not only about what they are, how they are created, but what they are intended for versus how they are used and what reactions they catalyse (Jungnickel 2004:2).

Similar to what the Sonic City researchers described, the primary reaction of the first set of Urban Tapestries users was that the application served as

a catalyst to re-experience the city and connect with other users. They describe their heightened sensory awareness of the city and rather than just a visual experience, Urban Tapestries stimulated them to sense other elements of city life (Jungnickel 2004:5).

As Jungnickel (2004:5-9) notes, trial participants reported feeling differently about their surroundings during, and after, using the application:

I love the idea of creating or reading individual stories or information about a city. It is like a bunch of short stories threaded together in a common area. It is almost like walking around in a book of short stories, except you can feel, hear, smell, and see the same things that the other authors of the pockets and threads did.

Posted by Jennifer at December 11, 2003 07:47 PM

...the conceptual experience of walking in a content rich environment was interesting - as it was possible to speculate further about where this will go. ...I feel like I wanted more detail and more personal experiences, rather than information I wanted a sense of presence from a previous passer by.

\section{Posted by gomes at December 11, 2003 03:38 PM}

Knowing that there was content around me made me think and behave differently in otherwise familiar streets and squares. I looked around more, and thought more about information I could usefully offer to others.

\section{Posted by david at December 13, 2003 04:09 PM}

Enjoyed reading content created by other people. Made me think about what's happened throughout history... and behind the various walls. Would like to have 
read about discourse between people that had passed through the same spaces, and experienced similar things.

Posted by Noam at December 14, 2003 07:54 PM

.... it will be fascinating to see what virtual geographies might emerge, overlaid on our cities, and whether, like the geographies we have in our heads and trace in our journeys, they gradually eclipse the physical ones from which they spring.

Posted by Ant at December 13, 2003 06:18 PM

I'd like to go out on different days in different moods and sometimes write biographical stuff, sometimes complete fantasy.

Posted by Jemima at December 14, 2003 07:39 PM

The affective draw of Urban Tapestries should not be underestimated, although

it is impossible to say whether people were reacting to novelty and, if so, how long people could be affectively mobilised by such applications. It also remains unclear how, or if, such applications would actually create the types of socially meaningful experiences the artists and designers envisioned.

\subsubsection{Public Authoring}

Situated knowledges are about communities, not about isolated individuals. The only way to find a larger vision is to be somewhere in particular.... Its images are not the products of escape and transcendence of limits (the view from above) but the joining of partial views and halting voices into a collective subject position that promises a vision of the means of ongoing finite embodiment, of living within limits and contradictions - of views from somewhere (Haraway 1996: 259).

As Giles Lane hinted at in the conversations excerpted above, and does again below, the greatest potential of-and expectation for-Urban Tapestries was to support place-based knowledge sharing: 
Me: "Can you please describe what you think the social and cultural implications of this and related technologies might be, including advantages and disadvantages."

Giles Lane: "Urban Tapestries is designed to create asynchronous interactions that are essentially anonymous centred on places. It is easy to imagine future users deciding to create 'buddy lists' of friends/neighbours (even unknown familiar strangers) and using such additional layers of inter-relation to band together to address specific issues -- perhaps over local housing or public space issues. In a sense, Urban Tapestries could be described as a system designed to support anonymous collection communication offering opportunities for people to animate their environment through shared knowledge building. Outcomes of this might well have other manifestations such as demonstrations, community parties, etc.

There is an extensive literature on how people mark boundaries between different communities through visible (as well as more subtle) signs and signals in the physical geography. This helps give structure to local identities and can be inclusive as well as exclusive. It is also clear that the concept of people being part of specific immutable and stable communities is shifting (especially in urban contexts) to an appreciation of the multiplicity of communities that overlap each other, and that people may simultaneously belong to many different communities. Urban Tapestries is designed to support such markings of territories, borders and boundaries, as well as mapping the overlaps and the interrelations that this implies. We believe that this could have a major impact on people's understanding of the diversity of the cultural landscape they inhabit. We'd hope that this leads to more tolerance and acceptance of difference and diversity through greater and more effective communication, but may of course have far different outcomes in practice."

\section{The process of personalising urban spaces with anecdotal stories or commercial}

recommendations-as Urban Tapestries users most often did-can be seen to express the ability of such applications to foster a kind of "social currency" exchange (Silverstone and Zujon 2005:41) that indeed bolsters a sense of collective meaning and identity. In other words, this kind of small-talk or gossip can be a powerful social binder, as people regularly use it as a way of including or 
excluding others, and negotiating shared values (see for example Fine 1985;

Coupland 1991). However, as Silverstone and Sujon (2005:42) suggest, more extensive use of such technologies, and research in these areas, would also help social scientists better understand if such recommendation activities "indicate that [people] are 'stuck' in consumer patterns of behaviour and struggle to imagine social interactions or public behaviour outside of consuming something or making exchanges."

Concerns stemming from the actual content people chose to 'embed in the city' return us to Urban Tapestries' notion of "public authoring" and its potential as a form of "Mass Observation for the $21^{\text {st }}$ century." It is immediately clear that Urban Tapestries shares a common interest in capturing the everyday in much the same way as the early Mass-Observation movement did (see Highmore 2002; Hubble 2006), including the implications for citizenship and civil society. For example, Giles Lane's (2004:4-5) explanation of how he understands agency and authorship is worth quoting at length:

I believe that the future for our society lies in broadening the capabilities of its members to be actors, agents and authors, not merely consumers of a culture created by others employed in the 'culture industry'. The control of information and communications has long been understood to shape how societies develop and behave; using network technologies to gather, create and share knowledge at grassroots - no matter how informal - offers the possibility of profound changes to the way in which we engage with our environment and the people who inhabit it.

By making available simple tools of authorship and communication (which are also asynchronous and anonymous) to people going about their everyday lives, it is possible to imagine a rich and vibrant culture of exchanging stories and local knowledge, where our sense of how we value our neighbours is derived from the richness of the knowledge we all share. Urban Tapestries is built on the notion that these network technologies should enable communication between people at 
all levels, and not be forced into the straitjacket of consumption and consumerism - repurposing the print and broadcast media created and designed for a different age to sell as 'high-value' location-based content.

If, as is so often claimed, content is king, then surely the most valuable and relevant content about local places for local people is not going to come from media companies, but directly from their peers and neighbours? And if this is the case, then surely the point of sharing such information is not to sell media content but to communicate?

A key issue for developing this sense of personal agency will be our changing perception of citizenship and its role in how we construct our identity. Is it an attribute bestowed upon us by the State and government according to our place of birth or sworn allegiance? Or will it become something we assert through practice and inhabitation, through participation in community life? The impact of the revolution in communications has been to shift our perceptions of space and territory so that we are no longer defined or our horizons limited by the (particularly nineteenth century) concept of nationhood. Our sense of where, to whom and what we belong to alters too. In an age of conflicting loyalties and populations that are less and less ethnically or religiously homogenous, this presents a major problem to the traditional apparatus of power, yet offers extraordinary possibilities for individuals and communities.

By explicitly tying "public authoring" to matters of civil society and citizenship, expectations and hopes for future technologies, at least as enacted in Urban Tapestries, begin to take on a more explicitly political tone. Put otherwise, the tendency to use urban computing and locative media as aesthetical tactics opens up the possibility of them becoming ethical tactics as well.

Rather than having to do with morals, ethics also refers to ethos, or the characteristic spirit and sentiment of a people. Following Maffesoli (1991) ethical action and aesthetic experience are always already productively combined in everyday life. As Shields (2002:205) further explains, "Ethics alone is insufficient to make changes or guide actions. It is a content that requires a form - an aesthetics ... Aesthetics alone is equally insufficient, for it leads to an 
aestheticized politics of manipulation and of form alone without content." In the case of Urban Tapestries, the emergence of a bottom-up ethics depends greatly on participating publics. However, given the exploratory nature of technological prototypes, and the lack of commercial availability of any of the applications discussed in this dissertation, it is very difficult to figure out who-if anyonewould actually use such technologies in the future.

Some of the potential barriers to the use of Urban Tapestries discussed by Silverstone and Sujon include cost, interest and social context, and for some of their study participants,

the threat of losing control over who would interact with you, how much and what kind of information you would be exposed to and the risk of being flooded with [device] beeps and irrelevant stories overshadowed any appeal UT might have held (2005:46).

However, it is also clear that other workshop participants were quite excited about emergent (and less socially demanding) relations they could have with the city and with the technology. As we saw with Sonic City, while sociability and connection with non-human actors may be seen to increase, the matter of interpersonal relations remains far less clear.

One possibility - hinted at earlier and in the other case histories-is that relations between people, places and objects could become more playful. As one Urban Tapestries bodystorming participant put it, "It seems like a recreational thing. It's kind of an adult toy isn't it?" and Silverstone and Sujon (2005:48) replied, 
UT is in some ways a toy. A toy that helps users make sense out their own locations, test their boundaries, solidify their connections to place and play with memories, fantasies in and through their spatial practices.

In sum, Urban Tapestries can be seen to have a very well articulated desire for present and near-future relations to technology and media that are based on increased public agency and creativity-both of which, it is hoped, will lead to positive changes in citizenship and civil society. The final section of this chapter will look more closely at what such playful cities and politics might look like-and how that relates to expectations around future technologically-mediated forms of spatialisation, temporalisation and embodiment.

\subsection{MOBILE PUBLICS AND THE PLAYFUL CITY}

[T] he development of cities ... favors the confrontation of different cultural traditions, which tends to expose their arbitrariness practically, through firsthand experience, in the very heart of the routine of the everyday order, of the possibility of doing the same things differently, or, no less important, of doing something different at the same time (Bourdieu 1977:233).

[A]s a place of encounters, focus of communication and information, the urban becomes what it always was: place of desire, permanent disequalibirum, seat of the dissolution of normalities and constraints, the moment of play and of the unpredictable (Lefebvre 1996:129).

I began this chapter with a brief discussion of the performative qualities of urban computing and locative media projects, including a notable research interest in pervasive games or pervasive play. First, what I wanted to do was reiterate the idea that the most general expectation underpinning all the projects presented here is that pervasive computing will be centred on embodied interaction rather than cognitive abstraction. As McGonigal (2006:5) puts it, "It is not the mimetic 
references or cognitive concepts that ubicomp wants to proliferate; it is rather interactive experiences and phenomenal affordances that will be made pervasive.” This also suggests that urban computing and locative media researchers believe that such a focus is currently lacking, and their promise is to try to enable it in the future. Second, I wanted to begin to draw out the spatial and cultural implications of the active and creative publics enacted in these alternative technosocial scenarios.

\subsubsection{Mobile publics}

The idea of 'public' as both actor and audience has long been connected to technological development, especially as related to media production and consumption in urban spaces. For example, in the mid-180os Kierkegaard implicated mass media and communication technologies when he blamed 'the press' for turning 'the public' into a "monstrous abstraction, an all-encompassing something that is nothing" (1978:79). Kierkegaard's 'public' was indifferent, and people were left with an inability to act, which has serious consequences for matters of collective aesthetics and ethics. At the turn of the century, Georg Simmel (2004:13) conjured a similar kind of political impotence in his descriptions of the "blasé attitude" and faster, increasingly technologised, urban life where "punctuality, calculability and exactness" are considered to encourage "the exclusion of those irrational, instinctive, sovereign human traits and impulses" that would otherwise construct a vital, internally-generated life. 
However, drawing on Walter Lippmann's (1925) notion of publics, Noortje

Marres (2005:214) argues that a public-in much the same ways as the potential future users of applications like these-is "precisely not a social community." Or more specifically, the 'community' is not pre-existing; it is created by particular people implicated by particular issues, or people brought together around shared interests and concerns. However, rather than falling prey to impotent abstraction these publics rally force in their inconsistency and contingency:

[T] he agency of the public derives in part from the fact that this entity is not fully traceable. That is, the force of the public has to do with the impossibility of knowing its exact potential [...] The fact that the public cannot be definitively traced back to a limited number of identifiable sources is thus crucial to the effectiveness of the public: this is what endows publics with a dangerous kind of agency (Marres 2006:80).

The "phantom public," then, has power precisely because its potential is both unknown and, in many ways, infinite. Its ethics are situational but actionable, and it will continue to congeal and dissolve new publics, aesthetics and ethics as needed-or at least as possible.

Elements of individual and collective uncertainty, potential and transition also appear in the work of Mikhail Bakhtin. Of particular interest here is how Bakhtin positions action at the level of the practical everyday, and how reasoned ethics are seen to emerge from particular places and situations. These kinds of bottom-up ethics and micro-politics elicit something far more unstable and unruly than Habermas' (1989) ideal public sphere, and perhaps more in line with the complex situations and issues conjured by Lippman and Marres above. 
As Gardiner (2004:38) points out, where Habermas saw "sober and virtuous debate" using "ideal speech" in a "public sphere," Bakhtin witnessed in the carnival a "tumultuous intermingling of diverse social groups and widely divergent styles and idioms of language...including the use of parodic and satirical language, grotesque humour, and symbolic degradations and inversions." Public gatherings like the carnival privileged radical difference and multiple voices in many of the same ways as Lippman's publics, but also made clear that these kinds of coming-together can be transformatively transgressive:

[A]1l were considered equal during carnival. Here, in the town square, a special form of free and familiar contact reigned among people who were usually divided by the barriers of caste, property, profession, and age (Bakhtin 1984:10).

"Feast crowds" were also described by Elias Canetti (1998:62) as ones in which “everyone near can partake." Canetti's feasts, like Bakhtin's carnivals, are situations of difference, excess and potential:

There is more of everything than everyone together can consume and, in order to consume it, more and more people come streaming in. As long as there is anything there they partake of it, it looks as though there would be no end to it... Nothing and no-one threatens and there is nothing to flee from; for the time being, life and pleasure are secure. Many prohibitions and distinctions are waived, and unaccustomed advances are not only permitted but smiled on. For the individual and the atmosphere is one of loosening, not discharge. There is no common identical goal which people have to try and attain together. The feast is the goal and they are there. The density is very great, but equality is in large part an equality simply of indulgence and pleasure. People move to and fro, not in one direction only. The things which are piled up, and of which everyone partakes, are a very important part of the density; they are its core. They were gathered together first, and only when they were all there did people gather round them. It may take years before everything is ready and people may have to endure a long period of want for this brief abundance. But they live for this moment and work steadily towards it. Men who can otherwise rarely see each other are ceremoniously invited with their own groups. The arrival of the various contingents is vigorously acclaimed and each fresh arrival raises the level of universal joy (Canetti 1998:62 emphasis mine). 
Working within this metaphor, we can see feasting publics to be those gathered around shared objects and concerns-or more specifically, and in similar ways to Lippmann's publics, their 'goal' is to be/come together. In other words, Canetti's feast crowds are dense with all sorts of different objects, rituals and people that have similar disruptive potentials to Bakhtin's carnival and Lippmann's phantom public.

If we continue to understand 'public' to comprise situational assemblages of people, places, objects and ideas, then there is probably no area of technological research and development that better explores and exemplifies these complex relations than do recent activities in mobile and context-aware computing. Given the imperatives to locate and connect (see for example Green et al. 2005) that are embedded in otherwise diverse technologies, it should come as no surprise that today's wireless and wearable devices and applications offer unique glimpses into crucial sets of values and expectations surrounding 'the fate of the public.' Here we might also recall the description of urban computing and locative media research trajectories in Chapter 5 , Section 5.4 , and their focus on public interventions.

Increasing calls within social and cultural studies for a spatial or 'mobilities' turn (see for example Bauman 2000; Cresswell 2006; Urry 2000) have been echoed in books like Hoete's (2003) ROAM: Reader on the Aesthetics of Mobilities and Turner and Davenport's (2005) Spaces, spatiality and technology. More to the topic at hand, social and cultural interests in mobile technologies have so far 
concentrated on local and global mobile phone usage, wireless infrastructure and pervasive computing, with exemplary research in anthropology (see Horst and Miller 2006; Ito et al. 2005), cultural studies (see Galloway 2004; Goggin 2006; Mackenzie 2005), sociology (see Castells 2006; Glotz et al. 2005; Katz 2006; Katz and Aakhus 2002; Kopomaa 2000; Ling 2004; Sheller and Urry 2006), social geography (see Graham and Marvin 2001), architecture (see McCullough 2004; Mitchell 2004; Greenfield and Shepard 2007) and computer-supported cooperative work research (see Brown et al. 2001; Hamill and Lassen 2005; Ling and Pedersen 2005), as well as recent multi-disciplinary volumes (see Kavoori and Arceneaux 2006; Seijdel 2006), technology design books (see Greenfield 2006; Sterling 2005) and more popular sociological accounts (see Agar 2005; Levinson 2004; Rheingold 2002).

However, by returning our focus to matters of 'mobile publics' it quickly becomes clear that relatively few of these publications actually tackle the question headon. A recurring theme in mobile technologies discourse is the intrusion of 'private life' into 'public space' through the use of mobile phones, although there is substantially less engagement with any sort of 'reverse' process involving 'public' intrusions into 'private' life with the exception of more recent surveillance studies (see for example Lyon 2006; Lyon 2003). Extending this to the realms of urban computing and locative media practice, we can also see a general and quite prolific focus on technological interventions in 'public space' requiring 'public participation.' However, most discussion and activity surrounding mobile publics as political forces employ notions of social and political networking, such 
as in the Annenberg Center for Communication's Networked Publics

(http://netpublics.annenberg.edu/) research project, and network analyses such as those by Castells (2000) and Larsen et al. (2006). Other wireless commons research (see Schmidt and Townsend 2003) and public projects include the Canadian Mobile Digital Commons Network (http://www.mdcn.ca/) and Montréal's île Sans Fil (http://ilesansfil.org/) community wi-fi project, all of which also rely heavily on network metaphors and networked urban infrastructures.

And so before we can return to the notion of 'public' laid out earlier-one in which different people, objects and ideas converge and dissolve-we may need to distance ourselves a bit from what Sheller (2004) has described as the "mathematically precise" or "hard' imagery" of networks, and focus instead on "more liquid or messy social structures" and "softer visions of porous sociality." Put otherwise, the network model or metaphor is not well equipped to deal with uncertainty, inconsistency and instability-conditions outlined as integral to the sense of 'public' I constructed from the ideas of Lippmann, Marres, Bakhtin and Canetti. However, discussions of mobility, liquidity and flow (see Bauman 2000; Deleuze and Guattari 1983b; Shields 1997; Urry 2000) offer alternative ways of understanding the kind of assemblages and assemblies at stake here.

After all, as White (1992:337-338) points out,

We are creatures living within social goos, shards, and rubbery gels made up by and of ourselves. We, like gels, may dissolve into a different order under some 
heat. Even the frozen shards exhibit only limited orderliness, and even then an orderliness lacking in homogeneity, and an orderliness made more problematic through its dual relation to physical space.

And Sheller (2004:49-50) concludes,

It is the capacity for coupling and decoupling in various ways that enables social action and the emergence of persons ... If 'persons' emerge as identities out of this social gel, it could likewise be argued that collective actors emerge in the same way-that is, as 'more or less rickety ensembles', or sociotechnical assemblages, 'energised in some situation and style' ... Publics are not only collective actors, emerging situationally as action gels around particular issues or debates, but also the slippery quality that allows for persons to slip from one identity to another in the first place ... The mobilisation of publics, then, is not simply predicated on increasing the density or intensity of face-to-face ties (as in a network), but depends instead on the entire context of communication gelling, which enables momentary stabilisations of collective identities as publics ... Mobile publics can perhaps best be envisioned as capacitators for moving in and out of different social gels, including the capacity to take on an identity that is able to speak and to participate in specific contexts.

This kind of temporary coming-together, gelling, or coupling is the kind of public and political agency put forth above, both in the case histories I presented and the subsequent theoretical discussion. For example, the inclusion of 'the public' in research and design activities is one way in which dystopian/industry and utopian/artistic dichotomies are broken down, or blurred. At the same time, envisioning a vital, playful and creative public helps valorise visions of urban computing and locative media-recruiting particular allies and easing translation efforts. In the final section of this chapter I return to the kind of playful and transformative experiences that are expected to accompany urban computing applications and locative media. 


\subsubsection{Playful Cities, Playful Lives}

The social significance of play (see for example Callois 1961; Huizinga 1970;

Sutton-Smith 1997) is too vast to tackle here, but play is most often seen to involve a reversal of what is rational, normal, everyday, practical and expected. In this way, play is a means by which people test boundaries and expand limits, escaping, if only temporarily, our everyday constraints. To clarify, following Lefebvre (1991b), Stevens (2007:29) points out the “dialectical tension underlying escape through play: escape is impossible, illusory, but this illusion in itself constitutes a perceptual and social reality." The playful, or ludic, city then can be seen as fundamentally affective or expressive, "an alternative system of spatial (dis)ordering where transitional identities may be sought, sensual and imaginative experimentation indulged" (Edensor 1998:219).

Recalling Linda Doyle's comments on the Passing Glances project, part of the appeal of technologically augmenting urban spaces is being able to give "people access to interesting content" or to make a place more interesting "because you're giving people access in places they don't expect it.” Similarly, Lalya Gaye said of Sonic City: "Everyday familiar spaces are transformed into resources for musical interaction. In Sonic City we...augment something that users are familiar with, but not in terms of making music with it." In the case of Urban Tapestries, we might also recall the pleasure people derived from experiencing, and imagining, the city in new ways. And the collective potential of such experiences was considered by the researchers to be the primary value of Urban Tapestries as a sharing technology. This desire to defamiliarise the familiar also has a strong 
tradition in theories and critiques of everyday life (see Gardiner 2000; Highmore 2002), and especially within De Certeau's (1984) work and Situationist approaches to the city (see Sadler 1998), from which all three cases presented here clearly take inspiration.

A primary expectation that informs all these research projects is that future technological applications would, and should, facilitate playful or transformative experiences, dense with aesthetical and ethical action. This can be seen as fundamentally tied to what it means to use technology to make everyday life more meaningful-a driving force behind much urban computing and locative media research. However, the potential publics implicated here are best understood not in terms of masses or even network models, but rather as temporary assemblages: those people, places, objects and ideas that are made co-present through the situational use of such context-aware technologies. These are multiple publics that can be/come together through new forms of spatialisation, temporalisation and embodiment that seek to amplify or augment the vital aspects of everyday life. In other words, these applications allow people to play with identities and relations in highly situated ways. However, an alternative reading (see for example Felski 1999/200o) suggests that all the cases likewise mobilise particular race, gender and class-based understandings of the everyday as something that needs to be made 'creative' or 'playful,' or to 'progress' much like technology is believed to do-a point that deserves further examination. 
Nonetheless, while total transformation it is certainly a familiar trope in discourse surrounding new technologies and technological 'progress', I am not convinced that it is actually expected to happen at the global scale predicted by so many of the large stories I discussed in Chapter 5. Looking at the smaller case histories helps temper the totalising visions that are seen to characterise much pervasive and ubiquitous computing. While broadly utopian in their perspective, none of the projects presented here seemed overly naïve to me. They often located the potential to improve people's lives at the most mundane levels, and in the most situated ways. Use scenarios, and system architectures, were kept purposely ambiguous and open-ended, seeking to put control in the hands of (particular) users. In other words, future publics in the ludic city would be free to move and be moved. As Crang and Graham (2007:810) put it, pervasive play "transforms the city space into [a] game board so that the familiar space of the city is transformed into a new and unexpected environment" and these kinds of applications can "work to create and foster new social communities, or sociotechnical communities through locative performances." Recalling Michael's (2006) comments on the density of the technologised city, Crang and Graham further emphasise that

these artistic media are trying to densify the liquid - not solidify places ... [which] may offer the possibility of enriched community formation. Not indeed the embedded and static version of community but community as assemblage in flux, as turbulence and eddies in the data stream (2007:810-811).

In short, the kinds of users or audiences expected to take part in these technological futures are not the public, but many (partial) publics. While 
undoubtedly historically embedded within individualising Western consumer culture, the expectation and promise of urban computing and locative media also points to dissatisfaction with the current status quo. By focussing on creative agency, technosocial innovation or change is tied to playful practices. Without dismissing the real social concerns raised above, in the final chapter of my dissertation I will return to Bakhtin's carnival and Canetti's feasts in order to further explore the implications of such a present, and future.

\subsection{SUMMARY}

This chapter shifted focus to the smaller stories of individual urban computing and locative media research projects in order to question what, exactly, is expected in some of these future scenarios. Contrary to the discursive construction of pervasive computing as 'everywhere,' these projects tended to locate technologies 'somewhere.' Context-aware computing, researchers suggested, enacts particular but dynamic spatialisations, temporalisations and embodiments. In doing so, city spaces and social behaviours are expected to become more affective and expressive, and potentially more meaningful. This extensibility and transmissibility of the city, along with an increased ability to be embedded within in, was a shared expectation amongst all the cases presented here.

Passing Glances was described as an imagined future where images could be embedded in the built environment and triggered by text message, augmenting urban waiting spaces with random and emergent narratives as well as the 
potential for random and emergent social interactions. Sonic City was positioned as both a listening and composing technology that promises the city itself as media co-creator. Although it was not considered an interpersonal technology, it can be seen to expect new relationships between people and places. Urban Tapestries was likewise described as expecting a reinvigorated sense of social and spatial belonging based on the ability to play with boundaries and identities.

Ultimately, I argued that the desire to augment reality is not a desire to use technology to replace people, places or activities, but rather one that seeks to amplify or extend the most vital qualities of our lives in order to multiply possibilities for future connections. Nonetheless, such visions exclude particular people and ways of living; left out of this 'enriched' technological future is anyone who falls outside these assumptions. For example, taking for granted the ideals of consumer capitalism, and firmly situating them in urban rather than rural contexts, the presumed user of these applications both desires, and is able to afford, being 'connected' at all times.

A primary expectation that also informs all these research projects is that future technological applications would, and should, facilitate playful or transformative experiences, dense with aesthetical and ethical action. In this way they position themselves against a totalising vision of ubiquitous computing, and situate their applications as temporary or partial interventions into everyday urban life. 
However, as I have written before, researchers and designers still need to make explicit what, exactly, it is about everyday life that needs to be augmented or improved, especially if these technologies are meant to become part of the everyday (Galloway 2004a:402). 


\subsection{CONCLUSIONS}

As I explained at the beginning, my dissertation actively seeks to raise more questions than provide definitive answers, so this final chapter is dedicated to identifying particular issues and concerns that deserve further consideration. Reconfiguring the structure presented above, I divide my discussion here into two broad categories: ethnographic methods and social studies of technology, space and culture. In each section I summarise what I consider to be the main contributions of my thesis, and end with a set of possible questions for others to pick up.

\subsection{ETHNOGRAPHIC METHODS}

My doctoral project builds on undergraduate and graduate studies in anthropology, and my dissertation's methodological contribution can be found in its examination of data bricolage and research blogging. Seeking to better understand what it might mean to conduct sociological research in the early years of the $21^{\text {st }}$ century, I sought methods that could reflect the way I lived, worked and played. Primarily this involved a methodological bricolage capable of forging a combination of online and offline participant observation. In addition to conducting site visits, questionnaires and interviews, I made a decision to move my research notebook online and pursue writing as a method of inquiry. However, I had no idea at the time how important my weblog would become in shaping both the process and product of my studies. 
When it came time to analyse my findings and begin writing my dissertation, I realised that in addition to the kinds of data regularly collected in ethnographic fieldwork, I had a record of years of observations and conversations contained within my blog. Looking back, I saw evidence of movement much more akin to the inconsistent swaying of a mobile than the stable and linear thought processes usually presented in academic research. Returning to anthropology's longstanding interest in writing culture, I wanted to explore ways of representing my research that better reflected these experiences.

In contrast, perhaps, to many doctoral students I had the distinct pleasure of being part of an intellectual and creative community that spanned the globe, and I wanted their presence to be felt in my dissertation as much as I had felt them during the period of my studies. In feminist epistemological critiques I found prior sociological attempts to textually include the excluded, or make visible the invisible, and I tried to follow their lead.

I took excerpts from academic sources, interviews, blog posts, news stories and personal reflections and presented them in my dissertation alongside more traditional analytical passages. These recombinant strategies were an attempt to encourage listening as much as telling, and often description instead of explanation. The overall result was an infra-reflexive pleated or layered text, where many voices and multiple perspectives come to bear on the issues at hand. 
It was my hope that readers would follow my zig-zagging paths, finding a plethora of entrances and exits that will encourage them to understand things according to their own logic rather than according to a singular logic I have imposed to control them. This is not to say that I saw my dissertation as completely messy or unstructured, but rather that I wanted to encourage readers to become active producers of their own knowledge rather than 'passive' consumers of academic wisdom. At the same time, I also did not wish to position my text as entirely 'open' to interpretation, as a certain amount of 'closedness' helps tie a story together. And ultimately, I wanted to open for debate what advantages and limitations such an approach involves.

What does it mean to do participant observation online and offline? How does it challenge traditional understandings of 'the field' in fieldwork? What kinds of research are possible and impossible given the structure of blogs? Do blog conversations constitute new ways of conducting public and collaborative research? How is the very concept of research reconfigured? Does this kind of writing actually serve to reconfigure long-standing, and largely unequal, relations between expert and lay knowledge? What new relations between authors and audiences are created in infra-reflexive, pleated or layered texts? What degrees of 'openess' and 'closedness' work best? In what ways can such representations be said to be valid or valuable? 


\subsection{SOCIAL STUDIES OF TECHNOLOGY, SPACE AND CULTURE}

My doctoral project also builds on long-standing, and increasingly relevant, social studies of science and technology. Its primary theoretical contribution ties together actor-network theory and the sociology of expectations, and its empirical contribution involves studying an area of cutting-edge design. While actornetwork theory is now well established and widely applied in sociology and anthropology, my dissertation attempted to expand its reach to include emerging, rather than already existing technologies. It struck me that actor-network theory, and related theories of transduction, emphasise associations and connections in ways that are particularly well-suited to understanding how new technologies come to be.

In order to support this focus on emergent technological practices, I turned to a relatively new area of research known as the sociology of expectations. So far limited to future-oriented research in biotechnology, I wanted to see if it could be applied to other future-oriented technologies. While not quite as dramatic as technologies that stand to make the difference between life and death, pervasive computing nonetheless stands to reconfigure current paradigms of humancomputer interaction, and the effects of these transformations could substantially alter people's experiences of spatiality, temporality and embodiment in everyday life.

By combining these methodological approaches and interpretive frameworks, I attempted to draw out the ways in which visions of a proximate technosocial 
future are best understood not as predictions for the future, but rather as ways of shaping relations in the present as a means to orient people, places, objects and ideas in particular ways and not others. Shifting between large and small scale empirical accounts, urban computing and locative media were seen to expect and promise highly situated, and largely utopian, examples of pervasive computing that go a long way in tempering an overarching fear of a dystopian future of total technological surveillance while simultaneously suggesting a less than ideal present.

Again, it was my hope to open up these areas to further research. Can actornetwork theory provide productive ways of engaging emergent technologies? Does a sociology of expectations translate well to other domains of technoscientific research? What are the connections between technological visions, expectations and promises? How do future-oriented visions act in the present and obligate future actions? In terms of technology design, how do market forces and policy decisions affect the outcomes of such exploratory research? How does such collaborative research stand to reconfigure power relations between disciplines or sectors of society? What roles can mass media and public involvement take in shaping future computing technologies? Which people and values are included, and excluded, from present design scenarios and future use?

By identifying a core set of expectations and promises associated with urban computing and locative media, I finally attempted to open up discussion on 
matters related to people's experiences of space and culture. While certainly located within the domain of sociology and anthropology, it is perhaps this area that offers the greatest range of possible research interventions. Cultural geographers, architects and urban planners are just a few of the practitioners that can find shared concerns here. Scholars interested in media and communication ecologies also have many relevant contributions to make to these discussions, as do people working in policy or governance, to name just a few.

My dissertation further suggested that the existing literature on networked urbanism will increasingly need to account for technologies that seek to create hybrid spaces, where data is overlayed on, or embedded in, the physical environment. Not only would this allow information to be attached to particular locations, and accessed from multiple locations, but it stands to increase the current extensibility and transmissibility of urban space. While the seemingly endless disclosability of technologised space has already been noted, my work also suggested that this hybridity and complexity may not find adequate explanation in existing network models.

First of all, I believe that the kind of world envisioned by ubiquitous computing will never have the perfectly seamless or stable infrastructure necessary to make it work at its most global and totalising scale. Computer technologies, including the internet, have always rolled out unevenly and without clear plans-and much of our technological infrastructure is already a mash of disparate parts made to do the best they can until they break, or something better comes along. Rather 
than continuing to focus on the density and intensity evoked by network models, I suggested that this kind of uncertainty, inconsistency and instability is much more amenable to metaphors of fluidity or flow. Furthermore, the kinds of social relations and interactions that are advocated in urban computing and locative media visions are equally uncertain, inconsistent and unstable. This has profound implications for people's understanding and experience of everyday life, and for future social and cultural research. If notions of society have already been replaced by concepts of sociality, then we might also ask-for example-if multiple or mobile publics have replaced that singular public that has been seen to form the public sphere?

In identifying the playful aspects of locative media and urban computing's interaction scenarios, I also conjured my own visions of what such playful and mobile publics might be. Here we can recall Bakhtin's carnival and Canetti's feast crowds as powerful expressions of collective action that temporarily overturn the status quo. Understanding the technological projects presented here as heterodox interventions into everyday life allows for a degree of social and cultural maneuverability that, again, may be best understood in terms of flow. More poetically, we can recall Sartre's descriptions of Alexander Calder's mobile sculptures, and we can ask if social innovation or change is not better understood in such playful terms? At the same time, we can also ask whom such 'creativity' and 'playfulness' serves? 
In closing, I would like to leave readers with a final set of questions: How can utopian locative media and urban computing projects serve as critiques of more dystopian visions of ubiquitous computing and pervasive surveillance? What kinds of social interactions are possible given the kinds of individualising practices they seek to enable? Why are everyday 'creativity' and 'playfulness' so highly valued in these scenarios? How can such temporary interventions reconfigure power relations in the long-term? And what do we stand to gain, or lose, if these expectations and promises come to fruition? 


\section{BIBLIOGRAPHY}

Aarts, E. and Marzano, S. (eds.) (2003) The New Everyday: Views on Ambient Intelligence. Rotterdam: 010 Publishers.

Abowd, G. (2001) "What's in a name? The research agenda beyond the desktop" SIGCHI Bulletin May/June:3 \& 8.

Agar, J. (2005) Constant Touch: A Global History of the Mobile Phone. Cambridge: Icon Books.

Albertsen, N. and B. Diken. (2000) "What is the Social?" Department of Sociology, Lancaster University. Available online at http://www.comp.lancs.ac.uk/sociology/soco33bd.html (Last viewed 21 September, 2007)

Amin, A. and Thrift, N. (2002) Cities: Reimagining the Urban. Cambridge: Polity.

Anderson, B. (2006) "Hope for nanotechnology: anticipatory knowledge and the governance of affect." Area 39(2) 156-165.

Anderson, E., S.N. Brooks, R. Gunn and N. Jones (eds.) (2004) Being Here and Being There: Fieldwork Encounters and Ethnographic Discoveries (The Annals of the American Academy of Political and Social Science). London: Sage.

Augé, M. (1995) Non-places: Introduction to an anthropology of supermodernity. London: Verso.

Azuma, R. (1997) “A survey of augmented reality.” Presence: Teleoperators and Virtual Environments 6(4):355-385.

Bakhtin, M. (1984) Rabelais and His World. Bloomington: Indiana University Press.

Barthes, R. (1997) "Semiology and the Urban" in Rethinking Architecture, edited by N. Leach, pp. 166-171. London: Routledge.

Bauman, Z. (1998) "What Prospects of Morality in Times of Uncertainty" Theory, Culture and Society 15(1): 11-22.

Bauman, Z. (200o) Liquid Modernity. Cambridge:Polity.

Beer, D. (2007) "Tune Out: Music, Soundscapes and the Urban Mise-En-Scène." Information, Communication \& Society 10(6):846-866. 
Bell, G. and Dourish, P. (2007) "Yesterday's tomorrows: notes on ubiquitous computing's dominant vision" Personal and Ubiquitous Computing 11(2):133143 .

Benford, S., Flintham, M., Drodz, A., Tandavanitj, N., Adams, M. and Row Farr, J. (2006) "The Design And Experience Of The Location-Based Performance Uncle Roy All Around You" Leonardo Electronic Almanac 14(3), Available online at: http://leoalmanac.org/journal/Vol 14/lea v14 no3-04/roy.asp (Last viewed: 21 September, 2007)

Benjamin, W. (1999) The Arcades Project. Cambridge: Harvard University Press.

Bochner, A.P. and C. Ellis (eds.) (2002) Ethnographically Speaking:

Autoethnography, Literature and Aesthetics. Walnut Creek: Altamira Press.

Bolter, J.D. (2001) Writing Space: Computers, Hypertext, and the Remediation of Print (2nd ed.) Mahwah:Erlbaum.

Borup, M., Brown, N., Konrad, K. and Van Lente, H. (2006) "The Sociology of Expectations in Science and Technology" Technology Analysis \& Strategic Management 18(3-4):285-298.

Bourdieu, P. (1977) Outline of a Theory of Practice. Cambridge: Cambridge University Press.

Broers, A. (2005) The Triumph of Technology. Cambridge: Cambridge University Press.

Brown, B., R. Harper, N. Green (eds.) (2001) Wireless World: Social and Interactional Aspects of the Mobile Age. London:Springer.

Brown, N. and Michael, M. (2003) "An analysis of changing expectations: or 'retrospecting prospects and prospecting retrospects" Technology Analysis \& Strategic Management 15(1):3-18

Brown, N., Rappert, B. and Webster, A. (Eds.) (2000) Contested Futures: A Sociology of Prospective Techno-Science. Aldershot: Ashgate.

Bull, M. (2000) Sounding Out the City: Personal Stereos and the Management of Everyday Life. Oxford: Berg.

Bull, M. (2002) "The Seduction of Sound in Consumer Culture: Investigating Walkman desires." Journal of Consumer Culture 2(1):81-101.

Bull, M. (2007) Sound Moves: iPod culture and urban experience. London: Routledge. 
Callois, R. (1961) Man, Play and Games. New York: Free Press.

Callon, M, 1986, "Some Elements of a Sociology of Translation: Domestication of the Scallops and the Fishermen of St Brieuc Bay," in Power, Action \& Belief:A New Sociology of Knowledge? Ed. J Law, pp. 196-229. London: Routledge \& Kegan Paul.

Canetti, E. (1998) Crowds and Power. New York: Farrar, Straus \& Giroux.

Castells, M. (2000) The Rise of the Network Society. Oxford: Blackwell.

Castells, M. (2006) Mobile Communication and Society: A Global Perspective. Cambridge: MIT Press.

Chalmers, M. (2003) "Seamful Designs and Ubicomp Infrastructure" Proc. Ubicomp 2003 Workshop At the Crossroads: The Interaction of HCI and Systems Issues in UbiComp. Available online at http://www.dcs.gla.ac.uk/ matthew/papers/ubicomp2003HCISystems.pdf (Last viewed: 21 September, 2007)

Chalmers. M. (2004) "A historical view of context." Computer Supported Cooperative Work 13:223-247.

Chalmers, M. and Galani, A. (2004) "Seamful Interweaving: Heterogeneity in the Theory and Design of Interactive Systems" Proc. ACM DIS 2004: 243-252.

Chandler, D. "Personal Home Pages and the Construction of Identities on the Web" Available online at:

http://www.aber.ac.uk/media/Documents/short/webident.html (Last viewed 21 September, 2007)

Chang, M. and Goodman, E. (2006) "Asphalt Games: Enacting Place Through Locative Media" Leonardo Electronic Almanac 14(3), Available online at: http://leoalmanac.org/journal/Vol 14/lea v14 no3-04/changoodman.asp (Last viewed: 21 September, 2007)

Chase, S.E. (2005) "Narrative Inquiry: Multiple Lenses, Approaches, Voices" in The Sage Handbook of Qualitative Research ( $3^{\text {rd }}$ Edition), edited by N. Denzi and Y. Lincoln, pp. 651-68o. London: Sage.

Clifford, J. (1986) "Introduction: Partial Truths" in Writing Culture, edited by J Clifford and G. E. Marcus, pp. 1-16. Berkeley: University of California Press.

Clifford, J. (1997) "Spatial Practices: Fieldwork, Travel and the Disciplining of Anthropology" in Anthropological Locations: Boundaries and Grounds of a Field Science, edited by A. Gupta and J. Ferguson, pp. 185-221. Berkeley: University of California Press. 
Clifford, J and G.E. Marcus (eds.) (1986) Writing Culture. Berkeley: University of California Press.

Clough, P.T. (2000) AutoAffection: Unconscious Thought in the Age of Technology. Minneapolis: Minnesota University Press.

Cohen, K.R. (2006) "A Welcome for Blogs." Continuum: Journal of Media \& Culture Studies 20(2): 161-173.

Cook, I. et al. (2005) "Positionality / Situated Knowledge" in Cultural Geography: A Critical Dictionary of Key Concepts, edited by D. Sibley, P. Jackson, D. Atkinson and N. Washbourne, pp. 16-26. London: I.B. Tauris.

Coupland, J. (ed.) (2001) Small Talk. London: Pearson Education.

Cousins, M. and A. Hussain (1984) Michel Foucault. Houndmills: Palgrave Macmillan.

Coyle, Fiona (2002) Safe space in "Risk society"? bodies, environments and the complex case of environmental illness. PhD Dissertation, Dept. of Geography, Carleton University.

Crang, M. (2000) "Urban morphology and the shaping of the transmissable city." City 4(3):303-315.

Crang, M. and S. Graham. (2007) "Sentient Cities:Ambient intelligence and the politics of urban space." Information, Communication \& Society 10(6): 789-817.

Cresswell, T. (2006) On the Move: Mobility in the Modern Western World. London: Routledge.

Crow, B., M. Longford and K. Sawchuck (eds.) (in press) Sampling the Spectrum. Toronto: University of Toronto Press.

Cuff, D. (2003) "Immanent Domain: Pervasive Computing and the Public Realm" Journal of Architectural Education 57(1): 43-49.

Debord, G. (2003) The Society of the Spectacle. New York: Zone Books.

De Certeau, M. (1984) The Practice of Everyday Life. Berkeley: University of California Press.

Deleuze, G. (1997) Negotiations: 1972-199o. M. Joughin (trans.) New York: Columbia University Press.

Deleuze, G. and F. Guattari (1983a) On the Line. New York: Semiotext(e). 
Deleuze, G. and F. Guattari (1983b) Anti-Oedipus: Capitalism and Schizophrenia. Minneapolis: University of Minnesota Press.

Deleuze, G. and F. Guattari (1986) Nomadology. New York: Semiotext(e).

Deleuze, G. and F. Guattari (1987) A Thousand Plateaus: Capitalism and Schizophrenia II. Minneapolis: University of Minnesota Press.

Denzin. N. (2003) Performance Ethnography: Critical Pedagogy and the Politics of Culture. London: Sage.

Denzin, N and Y. Lincoln (2005) "Introduction: The Discipline and Practice of Qualitative Research" in Handbook of Qualitative Research, edited by N. Denzin and Y. Lincoln, pp. 1-28. London: Sage.

Dey, A. (2001) "Understanding and Using Context." Personal and Ubiquitous Computing 5(1):4-7.

Dodge, M. \& Kitchin, R. (2005) "Code and the transduction of space." Annals of the Association of American Geographers 95(1):162-180.

Dodge, M. \& Kitchin, R. (2007) “Outlines of a world coming into existence": pervasive computing and the ethics of forgetting." Environment and Planning B: Planning and Design 34( 3):431-445.

Dodgson, M., D. Gann and A. Salter (2005) Think, Play, Do: Innovation, Technology, and Organization. Oxford: Oxford University Press.

Doheny-Farina, S. (1994) "Default = Offline Or Why Ubicomp Scares Me." Computer-Mediated Communication Magazine 1(6):18.

Doruff, S. (2007) “A Pair of Doxa and a Paradox" In (Un)common Ground: Creative Encounters across Sectors and Disciplines, edited by Brickwood, C., Ferran, B., Garcia, D. and Putnam, T., pp. 131-135. Amsterdam: BIS Publishers.

Dourish, P. (2001) Where the Action Is: The Foundations of Embodied Interaction. Cambridge: MIT Press.

Dourish, P. (2004) "What we talk about when we talk about context." Personal and Ubiquitous Computing 8(1):19-30.

Dourish, P. (2006) "Re-Space-ing Place: 'Place' and 'Space' Ten Years On,” Proceedings of CSCW o6, November 4-8, 2006, Banff, Canada, pp. 299-308.

Edensor, T. (1998) "The Culture of the Indian Street" in Images of the Street: Planning, Identity and Control in Public Space, edited by N. Fyfe, pp. 205-223. London: Routledge. 
Ellis, C. (1991) “Emotional Sociology." Studies in Symbolic Interaction 12:123145 .

Ellis, C. (2004) The Ethnographic I: A Methodological Novel About Autoethnography. Walnut Creek: Altamira Press.

Falk, J., Redström, J. \& Björk, S. (1999) 'Amplifying reality', Proceedings of the First International Symposium on Handheld and Ubiquitous Computing (HUC) '99, Springer Verlag, London. Available online at

http://civ.idc.cs.chalmers.se/publications/1999/AmpReality.pdf (Last viewed: 21 September, 2007)

Felski, R. (1999/2000) “The Invention of Everyday Life," New Formations 39: 15-31.

Fine, G. A. (1985) "Rumours and gossiping." In Handbook of discourse analysis, vol. 3, Discourse and dialogue, edited by T. van Dijk, pp. 223-37. London: Academic Press.

Foucault, M. (1977) Discipline and Punish: The Birth of the Prison. New York: Pantheon Books.

Foucault, M. (1980) Power/Knowledge: Selected Interviews and Other Writings, 1972-1977. New York: Pantheon.

Foucault, M. (1997) The Archaeology of Knowledge. London: Routledge.

Fraser, N. (1992) "Rethinking the Public Sphere: A Contribution to the Critique of Actually Existing Democracy" in Habermas and the Public Sphere, edited by C. Calhoun, 109-142. Cambridge: MIT Press.

Gadamer, H-G. (1981) Reason in the Age of Science. Cambridge: MIT Press.

Galloway, A. (2003) "Postcard from the urban frontier." Space and Culture 7(4):446-449.

Galloway, A. (2004) "Intimations of Everyday Life: Ubiquitous Computing and the City" Cultural Studies 18(2-3):384-408.

Galloway, A. and Ward, M. (2006) "Locative Media as Socialising and Spatialising Practice: Learning from Archaeology" Leonardo Electronic Almanac 14(3), Available online at: http://leoalmanac.org/journal/Vol 14/lea v14 no304/gallowayward.asp (Last viewed: 21 September, 2007)

Galloway, A. (2007) "Seams and Scars, Or How to Locate Accountability in Collaborative Work" in (Un)common Ground: Creative Encounters across 
Sectors and Disciplines, edited by C. Brickwood, B. Ferran, D. Garcia and T. Putnam, pp. 152-159. Amsterdam: BIS Publishers.

Galloway, A. (in press) "Mobile Publics and Issues-Based Art and Design" in Sampling the Spectrum, edited by B. Crow, M. Longford and K. Sawchuck, Toronto: University of Toronto Press .

Gannon, S. (2006) "The (Im)Possibilities of Writing the Self-Writing: French Poststructural Theory and Autoethnography." Cultural Studies<->Critical Methodologies 6(4): 474-495.

Gardiner, M. (2000) Critiques of Everyday Life. London: Routledge. Gardiner, M. (2004) "Wild Publics and Grotesque Symposiums: Habermas and Bakhtin on dialogue, everyday life and the public sphere" in After Habermas: New Perspectives on the Public Sphere, edited by J. Roberts and N. Crossley, pp.28-48. Oxford: Blackwell.

Gaver, B., T. Dunne and E. Pacenti (1999) "Design: Cultural Probes.” ACM Interactions January-February 1999: 21-29.

Gaye, L. (2005) "Enabling the Emergence of New Everyday Aesthetic Practices wih Ubiquitous Computing" Summary of thesis proposal for the UbiComp 2005 doctoral colloquium, Tokyo, Japan. Available online at: http://www.viktoria.se/ lalya/texts/Gaye Ubicompo5 doc coll.pdf (Last viewed: 21 September, 2007)

Gaye, L. and Holmquist, L.E. (2006) "Performing Sonic City: Situated Creativity in Mobile Music Making" Leonardo Electronic Almanac 14(3), Available online at: http://leoalmanac.org/journal/Vol 14/lea v14 no3-04/lgaye.asp (Last viewed: 21 September, 2007)

Gaye, L. and Holmquist, L.E. (2004) "In Duet with Everyday Urban Settings: A User Study of Sonic City." NIME 2004, Hamamatsu, Japan. Available online at: http://www.suac.net/NIME/NIMEo4/paper/NIMEO4_3Co2.pdf (Last viewed: 21 September, 2007)

Gaye, L., Mazé, R. and Holmquist, L.E. (2003) "Sonic City: The Urban Environment as a Musical Interface." NIME 20O3, Montréal, Canada. Available online at:

http://www.music.mcgill.ca/musictech/nime/onlineproceedings/Papers/NIMEo 3 Gaye.pdf (Last viewed: 21 September, 2007)

Gibbons, M., C. Limoges, H. Nowotny, S. Schwartzman, P. Scott and M. Trow (1994) The new production of knowledge: the dynamics of science and research in contemporary societies. London: Sage.

Gibson, W. (1984) Neuromancer. New York: Ace Books. 
Glotz, P., S. Bertsch and C. Locke (eds.) (2005) Thumb Culture: The Meaning of Mobile Phones for Society. Bielefeld: Transcript Verlag.

Goffman, I. (1959) The Presentation of Self. Garden City: Doubleday.

Goggin, G. (2006) Cell Phone Culture: Mobile Technology in Everyday Life. New York: Routledge.

Goodman, D. and C. Chant (eds.) (1999) The European Cities and Technology Reader: Industrial to post-industrial city. London: Routledge.

Graham, S. (ed.) (2003) The Cybercities Reader. London: Routledge.

Graham, S. (2003) "Excavating the material geographies of cybercities" in The Cybercities Reader, edited by S. Graham, pp. 138-142. London: Routledge.

Graham, S. (2004) "Beyond the 'dazzling light': from dreams of transcendence to the 'remediation' of urban life: A research manifesto" New Media \& Society $6(1): 16-25$.

Graham, S. and Marvin, S. (2001) Splintering Urbanism: Networked Infrastructures, Technological Mobilities and the Urban Condition. London: Routledge.

Granovetter, M. (1973) "The Strength of Weak Ties" American Journal of Sociology $78(6)$ : $1360-1380$.

Green, S., P. Harvey and H. Knox (2005) "Scales of place and networks: An ethnography of the imperative to connect through information and communications technologies." Current Anthropology 46(5):805-826.

Greenfield, A. (2006) Everyware: The Dawning Age of Ubiquitous Computing. Indianapolis: New Riders.

Greenfield, A. and M. Shepard (2007) Urban Computing and Its Discontents. The Architectural League of New York Situated Technologies Pamphlets 1. New York: The Architectural League of New York.

Gregg, M. (2006) "Feeling Ordinary: Blogging as Conversational Scholarship." Continuum: Journal of Media \& Culture Studies 20(2): 147-160

Gregg, M. (2007) "Banal bohemia: Blogging from the ivory tower hot-desk (Draft)" Available online at: http://homecooked theory.com/wpcontent/uploads/2007/11/Banal-bohemia-Final.doc (Last viewed 14 December, 2007)

Gupta, A. and J. Ferguson (eds.) (1997) Anthropological Locations. 
Berkeley: University of California Press.

Habermas, J. (1989) The Structural Transformation of the Public Sphere: An Inquiry into a Category of Bourgeois Society. Cambridge: MIT Press.

Hackett, E., O. Amsterdamska, M. Lynch and J. Wajcman (Eds.) (2007) The Handbook of Science and Technology Studies (3rd Edition). Cambridge: MIT Press.

Hallnäs, L. \& Redström, J. (2002) "From use to presence: on the expressions and aesthetics of everyday computational things." Available online at http://www.math.chalmers.se/ redstrom/thesis/hi/use2presence.pdf (Last viewed: 21 September, 2007)

Hamill, L. and A. Lasen (ed.) (2005) Mobile World: Past, Present and Future. London: Springer.

Hannerz, U. (2003) "Being there ... and there ... and there! Reflections on multi-site ethnography." Ethnography 4(2): 201-216.

Haraway, D. (1988) "Situated knowledges: The Science Question in Feminism and the Privilege of Partial Perspective" Feminist Studies 14:575-599.

Haraway, D. (1991) Simians, Cyborgs and Women: The Reinvention of Nature. London: Free Association Books.

Haraway, D. (1996) "Situated Knowledges: The Science Question in Feminism and the Privilege of Partial Perspective." in Feminism and Science, edited by Fox Keller, E. and Longino, H., pp.249-263. Oxford University Press: Oxford.

Hayles, K. (2005) “Computing the Human." Theory, Culture \& Society 22(1): $131-151$

Hedgecoe, A. and P. Martin (2003) "The Drugs Don't Work: Expectations and the Shaping of Pharmacogenetics." Social Studies of Science 33(3):327-384.

Heidegger, M. (1996) Being and Time. J. Stambaugh (trans.) Albany: State University of New York Press.

Henderson, K. (1988) "The Role of Material Objects in the Design Process: A Comparison of Two Design Cultures and How They Contend with Automation." Science, Technology \& Human Values 23:139-174.

Hetherington, K. (2001) "Phantasmagoria/ Phantasm Agora: Materialities, Spatialities and Ghosts." Space and Culture 11/12:24-41.

Highmore, B. (2002) Everyday Life and Cultural Theory. London: Routledge. 
Hight, C. and Perry, C. (eds.) (2006) Collective Intelligence in Design. London: Academy Press.

Hine, C. (2000) Virtual Ethnography. London: Sage.

Hoete, A. (ed.) (2003) ROAM: Reader on the Aesthetics of Mobility. London: Black Dog Publishing.

Horst, H. and D. Miller. (2006) The Cell Phone: An Anthropology of Communication. Oxford: Berg.

Hubble, N. (2006) Mass-Observation and Everyday Life: Culture, History, Theory. New York: Palgrave Macmillan.

Huizinga, J. (1970) Homo Ludens: A Study of the Play Element in Culture. London: Temple Smith.

Idhe, D. (1990) Technology and the lifeworld. Bloomington: Indiana University Press.

Idhe, D. (2003) "Auditory Imagination" in The Auditory Culture Reader, edited by M. Bull and L. Back, pp.61-66. Oxford: Berg.

Ingold, T. (1990) "An Anthropologist Looks at Biology." Man 25:208-229.

Ishii, H., Kobayashi, M. and Arita, K. (1994) "Iterative Design of Seamless Collaboration Media." Communications of the ACM 37(8):83-97.

Ishii, H. and Ullmer, B. (1997) "Tangible Bits: Towards Seamless Interfaces between People, Bits and Atoms." Proceedings of the 1997 SIGCHI conference on Human factors in computing systems, pp. 234-241.

Ito, M., D. Okabe and M. Matsuda (eds.) (2005) Personal, Portable, Pedestrian: Mobile Phones in Japanese Life. Cambridge: MIT Press.

James, A., J. Hockey and A. Dawson (1997) After Writing Culture: Epistemology and Practice in Contemporary Anthropology. London: Routledge.

Jameson, F. (1991) Postmodernism, or, The Cultural Logic of Late Capitalism. London: Verso.

Janesick, V. J. (2003) "The Choreography of Qualitative Research Design: Minuets, Improvizations and Crystallization" in Strategies of Qualitative Research (2 ${ }^{\text {nd }}$ Edition), edited by N. Denzin and Y. Lincoln, pp. 46-79. London:Sage. 
Johnson, S. (2002) Emergence: The Connected Lives of Ants, Brains, Cities, and Software. New York: Scribner.

Jungnickel, K. (2004) "Urban Tapestries: sensing the city and other stories." Proboscis Cultural Snapshot. Available online at:

http://proboscis.org.uk/publications/SNAPSHOTS sensingthecity.pdf (Last viewed: 21 September, 2007)

Katz. J. (2006) Magic in the Air: Mobile Communication and the Transformation of Social Life. New Brunswick, NJ: Transaction Publishers.

Katz, J. and M. Aakhus (eds.) (2002) Perpetual Contact: Mobile Communication, Private Talk, Public Performance. Cambridge: Cambridge University Press.

Kavoori, A. and N. Arceneaux (eds.) (2006) The Cell Phone Reader: Essays in Social Transformation. New York: Peter Lang.

Kierkegaard, S. (1978) "Two Ages": The age of revolution and the present age: $A$ literary review. Princeton: Princeton University Press.

Kincheloe, J. (2001) "Describing the bricolage: Conceptualizing a new rigor in qualitative research" Qualitative Inquiry 7(6):679-692.

Kincheloe, J. (2005) "On to the Next Level: Continuing the Conceptualization of the Bricolage" Qualitative Inquiry 11(3): 323-350.

Kindberg, T. and Barton, J. (200o) "Towards a real-world wide web" in Proceedings of the 9th workshop on ACM SIGOPS European workshop: beyond the PC: new challenges for the operating system, pp. 195-200. New York: ACM.

Kindberg, T., Chalmers, M. and Paulos, E. (2007) “Guest Editors' Introduction: Urban Computing” IEEE Pervasive Computing 6(3):18-20.

Kindberg, T., Barton, J., Morgan, J., Becker, G., Caswell, D., Debaty, P., Gopal, G., Frid, M., Krishnan, V., Morris, H., Schettino, J., Serra, B. and Spasojevic, M. (2001) "People, places, things: web presence for the real world ." HP Labs Technical Report 279. Available online at:

http://www.hpl.hp.co.uk/techreports/2001/HPL-2001-279.pdf (Last viewed: 21 September, 2007)

Kinsley, S. (2007) "Researching Ubiquitous Computing as a Geographer." Posted September 12th, 2007. Available online at: http://www.samkinsley.com/?p=10 (Last viewed 23 October, 2007)

Kjeldskov, J. and Paay, J. (2006) "Public Pervasive Computing: Making the Invisible Visible" Computer 39(9):60-65. 
Klapp, O.E. (1986) Overload and boredom: Essays on the quality of life in the information society. New York: Greenwood Press.

Knorr-Cetina, K. (1999) Epistemic Cultures: How the Sciences Make Knowledge. Cambridge: Harvard University Press.

Kopomaa, T. (2000) The City in your Pocket: Birth of the Mobile Information Society. Helsinki: Gaudeamus.

Kondo, D. (1990) Crafting Selves: Power, Gender and Discourses of Identity in a Japanese Workplace. Chicago: University of Chicago Press.

Kostakos, E., O’Neill, E., and Penn, A. (2006) “Designing Urban Pervasive Systems" Computer 39(9):52-59.

Kuhn, T. (1970) The Structure of Scientific Revolutions. Chicago: University of Chicago Press.

Lane, G. (2004) "Social Tapestries: public authoring and civil society." Proboscis Cultural Snapshot. Available online at: http://proboscis.org.uk/publications/SNAPSHOTS socialtapestries.pdf (Last viewed: 21 September, 2007)

Larsen, J., J. Urry and K. Axhausen (eds.) (2006) Mobilities, networks, geographies. Aldershot, UK: Ashgate.

Lather, P. (1993) "Fertile Obsession: Validity after Poststructuralism." Sociological Quarterly 34(4):673-693.

Lather, P. (1995) "The Validity of Angels: Interpretive and Textual Strategies in Researching the Lives of Women With HIV/AIDS." Qualitative Inquiry 1(1): 4168.

Latour, B. (1986) "Visualization and cognition: Thinking with eyes and hands." Knowledge and Society: Studies in the Sociology of Culture Past and Present 6:1-40.

Latour, B. (1987) Science in Action: How to Follow Engineers and Scientists Through Society. Cambridge: Harvard University Press.

Latour, B. (1988) "The politics of explanation," in Steve Woolgar (ed.), Knowledge and Reflexivity: New Frontiers in the Sociology of Knowledge, pp. 155-176, London: Sage.

Latour, B. (1993) We Have Never Been Modern. Cambridge: Harvard University Press. 
Latour, B. (1996) Aramis, or, The love of technology. Cambridge: Harvard University Press.

Latour, B. (1999) Pandora's Hope: Essays on the Reality of Science Studies. Cambridge: Harvard University Press.

Latour, B. (2004) Politics of Nature: How to Bring the Sciences into Democracy. Cambridge: Harvard University Press.

Latour, B. (2005) Reassembling the Social: An Introduction to Actor-Network Theory. Oxford: Oxford University Press.

Latour, B. and Woolgar, S. (1986) Laboratory Life: The Construction of Scientific Facts. Princeton: Princeton University Press.

Law, J. (2004) After Method: Mess in Social Science Research. London: Routledge.

Lefebvre, H. (1991a) The Production of Space. London: Blackwell.

Lefebvre, H. (1991b) The Critique of Everyday Life, Vol 1. London: Verso.

Lefebvre, H. (1996) Writings on Cities. Oxford: Blackwell.

Lévi-Strauss, C. (1966) The Savage Mind. Chicago: University of Chicago Press.

Levinson, P. (2004) Cellphone: The Story of the World's Most Mobile Medium and How It Has Transformed Everything! New York: Palgrave McMillan.

Lightman, A., D. Sarewitz and C. Desser (eds.) (2003) Living with the Genie: Essays on technology and the quest for human mastery. Washington: Island Press.

Lincoln, Y. (2001) "An emerging new bricoleur: Promises and possibilities-a reaction to Joe Kincheloe's 'Describing the bricolage'." Qualitative Inquiry 7(6): 693-696.

Ling, R. (2004) The Mobile Connection: The Cell Phone's Impact on Society. Oxford: Morgan Kauffman.

Ling, R. and P. Pedersen. (2005) Mobile Communications: Re-negotiation of the social sphere. London: Springer.

Lippmann, W. (1925) The Phantom Public. New York: Harcourt Brace. 
Livingstone, S. (2005) "Introduction." Audiences and Publics: When Cultural Engagement Matters for the Public Sphere, edited by S. Livingstone, pp. 9-16. Bristol: Intellect Books.

Lynch, M. (1985) Art and artifact in laboratory science. London: Sage. Lyon, D. (ed.) (2006) Theorizing Surveillance: The Panopticon And Beyond. Cullompton: Willan.

Lyon, D. (2003) Surveillance After September 11. Cambridge: Polity.

MacColl, I., Chalmers, M., Rogers, Y. and Smith, H. (2002) 'Seamful ubiquity: beyond seamless integration', Technical Report Equator-02-020, Equator, September 2002. Available online at http://www.dcs.gla.ac.uk/scripts/global/equator/moin.cgi/SeamfulUbiquity (Last viewed: 21 September, 2007)

Mackenzie, A. (2002) Transductions: Bodies and Machines at Speed. London: Continuum.

Mackenzie, A. (2005) "Untangling the unwired: Wi-Fi and the cultural inversion of infrastructure." Space and Culture 8 (3):269-285.

Maffesoli, M. (1991) "The Ethic of Aesthetics." Theory, Culture \& Society 8:7-20.

Maffesoli, M. (1996) The Time of the Tribes: The Decline of Individualism in Mass Society. London: Sage.

Manovich, L. (2006) "The Poetics of Urban Media Surfaces." First Monday Special Issue \#4. Available online at:

http://firstmonday.org/issues/special11 2/manovich/index.html (Last viewed 21 September, 2007)

Marcus, G. E. (1986) "Contemporary Problems of Ethnography in the Modern World System" in Writing Culture, edited by J Clifford and G. E. Marcus, pp. 165-93. Berkeley: University of California Press.

Marcus, G. E. (1995) 'Ethnography in/of the World System: The Emergence of Multi-Sited Ethnography', Annual Review of Anthropology 24:95-117.

Marcus, G.E. (1998) Ethnography Through Thick and Thin. Princeton: Princeton University Press.

Markham, A. (1998) Life Online: Researching Real Experience in Virtual Space. Walnut Creek: Altamira Press.

Markham, A. (2005a) "The Methods, Politics and Ethics of Representation in Online Ethnography" in The Sage Handbook of Qualitative Research ( $3^{\text {rd }}$ Edition), edited by N. Denzi and Y. Lincoln, pp. 793-820. London: Sage. 
Markam, A. (2005b) "'Go Ugly Early': Fragmented Narrative and Bricolage as Interpretive Method." Qualitative Inquiry 11(6): 813-839.

Marres, N. (2005) "Issues Spark a Public Into Being: A Key but Often Forgotten Point of the Lippmann-Dewey Debate" in Making Things Public: Atmospheres of Democracy, edited by B. Latour and P. Weibel, pp. 208-217. Cambridge: MIT Press.

Marres, N. 2006. "Public (Im)potence." Open 11:78-81. Rotterdam: NAi Publishers.

Massumi, B. (1992) A User's Guide to Capitalism and Schizophrenia. Deviations from Deleuze and Guattari. Cambridge: The MIT Press.

Massumi, B. (2002) "Navigating Movements" in Hope: New Philosophies for Change, edited by Mary Zournazi, pp. 210-243. London: Routledge.

Mazé, R. and Jacobs, M. (2003) "Sonic City: Prototyping a Wearable Experience" ISWC 2003, New York, USA, October 2003. Available online at: http://www.viktoria.se/fal/projects/soniccity/pdf/ISWC03 Maze.pdf (Last viewed: 21 September, 2007)

McCall, M. (2003) "Performance Ethnography: A Brief History and Some Advice" in Strategies of Qualitative Research (2 $2^{\text {nd }}$ Edition), edited by N. Denzin and Y. Lincoln, pp. 112-133. London:Sage.

McCullough, M. (2005) Digital Ground: Architecture, Pervasive Computing, and Environmental Knowing. Cambridge: MIT Press.

McCullough, M. (2006) “On Urban Markup: Frames Of Reference In Location Models For Participatory Urbanism" Leonardo Electronic Almanac 14(3), Available online at: http://leoalmanac.org/journal/Vol 14/lea v14 no304/mmccullough.asp (Last viewed: 21 September, 2007)

McGonigal, J. (2006) This Might Be a Game: Ubiquitous Play and Performance at the Turn of the Twenty-First Century. PhD Dissertation, Dept. of Performance Studies, University of California Berkeley. Available online at: http://www.avantgame.com/dissertation.htm (Last viewed: 21 September, 2007)

Michael, M. (2006) Technoscience and Everyday Life. Maidenhead: Oxford University Press.

Milgram, P. \& Kishino, F. (1994) "A taxonomy of mixed reality visual displays" IEICE (Institute of Electronics, Information and Communication Engineers) Transactions on Information and Systems, Special Issue on Networked Reality, E77D (12):1321-1329. 
Milgram, P., H. Takemura, A. Utsumi and F. Kishino (1994) "Augmented reality: a class of displays on the reality-virtuality continuum" Proceedings of Telemanipulator and Telepresence Technologies SPIE 2351:282-292. Mitchell, W.J. (1995) City of Bits. Cambridge: MIT Press.

Mitchell, W.J. (2003) Me++: The Cyborg Self and the Networked City. Cambridge: MIT Press.

Moran, T. and P. Dourish (2001) "Introduction to This Special Issue on Context Aware Computing" Human Computer Interaction 16:2-8.

Moreira, T. and Palladino, P. (2005) "Between truth and hope: on Parkinson's disease, neurotransplantation and the production of the "self" History of the Human Sciences 18:55-82.

Mortensen, T. and J. Walker (2006) "Blogging thoughts: personal publication as an online research tool" in Researching ICTs in Context, edited by A. Morrison, pp. 249-279. Oslo: University of Oslo.

Nigten, A. (2007) "Art as Boundary Object?" In (Un)common Ground: Creative Encounters across Sectors and Disciplines, pp. 126-129, Brickwood, C., Ferran, B.. Garcia, D. and Putnam, T. (eds.) Amsterdam: BIS Publishers.

Norman, D. (1998) The Invisible Computer. Cambridge: MIT Prèss.

Novak, M. (1996) "Transmitting Architecture: The Transphysical City" CTheory 11/29/1996. Available online at: www.ctheory.net/articles.aspx?id=76. (Last viewed: 21 September, 2007)

Novas, C. (2006) "The Political Economy of Hope: Patients' Organizations, Science and Biovalue.” BioSocieties 1:289-305.

Oldenziel, R. (2004) Making Technology Masculine: Men, Women, and Modern Machines in America, 1870-1945. Amsterdam: Amsterdam University Press.

Orth, M. (2001) Sculpted computational objects with smart and active computing Materials. Doctoral Dissertation, Massachusetts Institute of Technology, Cambridge, MA, Available online at http://web.media.mit.edu/ morth/thesis/thesis.html (Last viewed Aug 25, 2006).

Picard, R. (1997) Affective Computing. Cambridge: MIT Press.

Pickering, A. (1989) The Mangle of Practice: Time, Agency and Science. Chicago: Chicago University Press. 
Porush, D. (1995) "Ubiquitous Computing vs. Radical Privacy: A Reconsideration of the Future." Computer-Mediated Communication Magazine 2(3):46.

Quiggin, J. (2006) “Blogs, wikis and creative innovation." International Journal of Cultural Studies 9(4): 481-496.

Rambo Ronai, C. (1995) "Multiple Reflections of Child Sex Abuse: An Argument for a Layered Account." Journal of Contemporary Ethnography 23(4): 395-426.

Reed Danahay, D. (1997) Auto/ethnography: Rewriting the Self and the Social. Oxford: Berg.

Rescher, N. (1980) Unpopular essays on technological progress. Pittsburgh: University of Pittsburgh Press.

Redström, J. (2001) Designing everyday computational things. $\mathrm{PhD}$ thesis, Dept of Informatics, Göteborg University, Available online at http://www.math.chalmers.se/ redstrom/thesis/ (Last viewed: 21 September, 2007)

Rheingold, H. (1994) "PARC is back" Wired 2.02, Available online at http://www.wired.com/wired/archive/2.02/parc.html (Last viewed: 21 September, 2007)

Rheingold, H. (2002) Smart Mobs: The Next Social Revolution. Toronto: HarperCollins.

Richardson, L. (1993) "Poetics, Dramatics, and Transgressive Validity: The Case of the Skipped Line" The Sociological Quarterly 34(4): 695-710.

Richardson, L. (1997) "Skirting a Pleated Text: De-Disciplining an Academic Life." Qualitative Inquiry 3(3): 295-303.

Richardson, L. (1998) “The Politics of Location: Where Am I Now?" Qualitative Inquiry 4(1): 41-48.

Robbins. B. (ed.) (1993) The Phantom Public Sphere. Minneapolis: University of Minnesota Press.

Roberts, G.K. and P. Steadman (eds.) (1999) The American Cities and Technology Reader: Wilderness to Wired City. London: Routledge, in association with The Open University.

Russell, B. 2004. Locative Media Lab: Transcultural Media Online Reader. Available online at: http://locative.net/tcmreader/index.php?intro;russell (Last viewed 19 September, 2005) 
Russell, Ben. 1999. Headmap. Available online at:

http://headmap.org/book/get/headmap-manifesto.PDF (Last viewed 19

September, 2005)

Russell, B. Headmap 3 Redux. Available online at:

http://www.technoccult.com/library/headmap.pdf (Last viewed: 21 September, 2007)

Sadler, S. (1998) The Situationist City. Cambridge: MIT Press.

Sarma, S., D.L. Brock and K. Ashton (2000) "The Networked Physical World (White Paper)" AutoID Laboratories Proposal for Engineering the Next Generation of Computing, Commerce \& Automatic-Identification. Available online at http://www.autoidlabs.org/single-view/dir/article/6/93/page.html (Last viewed 27 September 2007).

Sartre, J. (1947) "The Mobiles of Calder" Available online at: http://www.calder.org/SETS SUB/life/texts/life texts sartre46 con1.html. (Last viewed 21 September, 2007).

Satyanarayanan, M. (2002) "A Catalyst for Mobile and Ubiquitous Computing" Pervasive Computing 1(1):2-5

Schachtner, C. (2002) "Experience and knowledge: The creative potential of playful action for technological development." Concepts and Transformations $7(2): 193-202$

Schatzki, T.R., K. Knorr Cetina and E. von Savigny (eds.) (2001) The Practice Turn in Contemporary Theory. London: Routledge.

Schivelbusch, W. (1986) The Railway Journey: The Industrialization of Time and Space in the 19th Century. Berkeley: University of California Press.

Schmidt, T. and A. Townsend (2003) "Why wireless networks want to be free." Communications of the ACM 46(5):47-52.

Seijdel, J. (ed.) (2006) Open 11: Hybrid space: How wireless media mobilize public space. Rotterdam: NAi Publishers.

Serres, M. (1982) The Parasite. Baltimore, Johns Hopkins University Press.

Sheller, M. (2004) "Mobile publics: Beyond the network perspective." Environment and Planning D: Society and Space 22: 39-52.

Shields, R. (1997) "Flow as a new paradigm." Space and Culture 1:1-8. 
Shields, R. (2002) "Social Science as a Design Profession: New Visions and Relationships" in Design and the Social Sciences: Making Connections, edited by J. Frascara, pp. 201-206. London: Routledge.

Shields, R. (2003) The Virtual. London: Routledge.

Shields, R. (2004) "Visualicity." Visual Culture in Britain 5(1):23-36.

Shiga, J. (2007) Copy-and-Persist: The Logic of Mash-Up Culture." Critical Studies in Media Communication 24(2):93-114.

Shklovski, I. and Change, M.F. (2006) "Urban Computing: Navigating Space and Context" Computer 39(9):36-37.

Silverstone, R. and Hirsch, E. (eds.) (1994) Consuming Technologies: Media and Information in Domestic Spaces. London: Routledge.

Silverstone, R. and Sujon, Z. (2005) "Urban Tapestries: Experimental Ethnography, Technological Identities and Place." LSE Electronic Working Paper No. 7. Available online at: http://www.lse.ac.uk/collections/media@lse/pdf/EWP7.pdf (Last viewed: 21 September, 2007)

Simmel, G. (1971) "The Stranger" in On Individuality and Social Forms edited by D. N. Levine, pp. 143-49. Chicago: University of Chicago Press.

Simmel. G. (2004) "The Metropolis and Mental Life" in The Blackwell City Reader, edited by Bridge, $\mathrm{G}$ and Watson, S., pp. 11-19. Cambridge: Blackwell.

St. Pierre, E.A. (1997) "Circling the Text: Nomadic Writing Practices." Qualitative Inquiry 3(4): 403-417.

Star, S.L. and J. Griesemer (1989) “"Institutional Ecology, 'Translations,' and Boundary Objects: Amateurs and Professionals in Berkeley's Museum of Vertebrate Zoology, 1907 - 1939." Social Studies of Science 19: 387-420.

Stevens, Q. (2007) The Ludic City: Exploring the Potential of Public Spaces. London: Routledge.

Strathern, A. (1993) Landmarks: Reflections on Anthropology. Kent: Kent State University Press.

Strathern, M. (2004a) Partial Connections (Updated Edition). Walnut Creek: Altamira Press. 
Strathern, M. (2004b) Commons + Borderlands: Working Papers on Interdisciplinarity, Accountability and Flow of Knowledge. Oxon, UK: Sean Kingston Publishing.

Sterling, B. (2005) Shaping Things. Cambridge: MIT Press.

Sterne, J. (2003) The Audible Past: Cultural Origins of Sound Reproduction. Durham: Duke University Press.

Suchman, L. (2006) Human-Machine Reconfigurations: Plans and Situated Actions, $2^{\text {nd }}$ Edition. Cambridge: Cambridge University Press.

Sutton-Smith, B. (1997) The Ambiguity of Play. Cambridge: Harvard University Press.

Tarr, J.A. and G. Dupuy (eds.) (1988) Technology and the Rise of the Networked City in Europe and America. Philadelphia: Temple University Press.

Thackara, J. (2001) "The design challenge of pervasive computing." Interactions $8(3): 46-52$.

Thibaud, J.P. (2003) "The Sonic Composition of the City" in The Auditory Culture Reader, edited by M. Bull and L. Back, pp.329-342. Oxford: Berg.

Thom-Santelli, J. (2007) "Mobile Social Software: Facilitating Serendipity or Encouraging Homogeneity" Pervasive Computing 6(3):46-51.

Thrift, N. (1997) "Cities without modernity: cities with magic" Scottish Geographical Magazine 113:138-149.

Thrift, N. (1999) “The Place of Complexity." Theory, Culture \& Society 16(3):3169.

Toffler, A. (1970) Future Shock. New York: Random House.

Tonkiss, F. (2003) "Aural Postcards: Sound, Memory and the City" in The Auditory Culture Reader, edited by M. Bull and L. Back, pp.303-310. Oxford: Berg.

Traweek, S. (1988) Beamtimes and Lifetimes: The World of High Energy Physicists. Cambridge: Harvard University Press.

Tribble, I. (2005a) "Bloggers Need Not Apply." The Chronicle of Higher Education: Chronicle Careers. Available online at: http://chronicle.com/jobs/2005/07/2005070801c.htm (Last viewed 21 September, 2007) 
Tribble, I. (2005b) “They Shoot Messengers, Don't They?" The Chronicle of Higher Education: Chronicle Careers. Available online at: http://chronicle.com/jobs/2005/09/2005090201c.htm (Last viewed 21 September, 2007)

Turnbull, D. (1993) "The ad hoc collective work of building Gothic cathedrals with templates, string, and geometry." Science, Technology \& Human Values 18:315-40.

Turner, P. and E. Davenport (eds.) (2005) Spaces, spatiality and technology. Dordrecht: Springer.

Tuters, M. 2007. "Beyond Locative." Vague Terrain o6: Locative. Available online at:

http://www.vagueterrain.net/content/archives/journalo6/tuterso1.html (Last viewed: 21 September, 2007)

Tuters, M. and Varnelis, K. (2006) "Beyond Locative Media" Annenberg School of Communication Networked Publics Project Paper. Available online at:

http://networkedpublics.org/locative media/beyond locative media (Last viewed: 21 September, 2007)

Traweek, S. (1988) Beamtimes and Lifetimes: The World of High Energy Physicists. Cambridge: Harvard University Press.

Urry, J. (2000) Sociology Beyond Societies. London: Routledge.

Urry, J. (2003) Global Complexity. Cambridge: Polity.

Urry, J. (2006) "Complexity." Theory, Culture \& Society 23(2-3): 111-115.

Van Loon, J. (2002) 'Social Spatialization and Everyday Life', Space and Culture 5(2): 88-95.

Vaucelle, C., Davenport, G., Wood, A., Anderson, S. Doyle, L. and Falk, J. (2003) "Texting glances: Ambient Interludes from the Dublin Cityscape" Presented at eNARRATIVE 5, Hypertext. Narrative. Art. Tech, May 2003, Boston, Massachusetts. Available online at:

http://medialabeurope.org/research/library/Vaucelle Texting 2003.pdf (Last viewed: 21 September, 2007)

Vaucelle, C., Moriwaki, K., Doyle, L., Anderson, S. and Davenport, G. (2004) "Ambient Urban Interludes: Passing Glances" Late Breaking Results Poster Presented at CHI 2004, April 24-29, 2004, Vienna, Austria. Available online at: http://mf.media.mit.edu/pubs/conference/AmbientUrban.pdf (Last viewed: 21 September, 2007) 
Virilio, P. (1986) Speed \& Politics: An Essay on Dromology. New York: Semiotext(e).

Virilio, P. (1987) “The overexposed city” Zone 1(2):14-31.

Wajcman, J. (1991) Feminism Confronts Technology. University Park: Pennsylvania State University Press.

Walker, J. "Blogging From Inside the Ivory Tower" in Uses of Blogs, edited by A. Bruns and J. Jacobs, pp. 1-11. New York: Peter Lang.

Want, R. (2007) "Carry Small, Live Large" Pervasive Computing 6(3):2-4.

Warner, M. (2002) Publics and Counterpublics. Brooklyn: Zone Books.

Watson, C.W. (ed.) (1999) Being There: Fieldwork in Anthropology. London: Pluto Press.

Weiser, M. (1991) "The computer for the 21st century." Scientific American 265(3): 94-104.

Weiser, M. (1994) “The world is not a desktop," ACM Interactions 1(1):7-8.

Weiser, M. (1995) "The Technologist's Responsibilities and Social Change." Computer-Mediated Communication Magazine 2(4):17.

Weiser, M. \& Brown, J. S. (1997) "The coming age of calm technology" in Beyond calculation: the next fifty years of computing, edited by P.J. Denning, pp. 75-85. New York: Copernicus.

White H. (1992) Identity and Control: A Structural Theory of Social Action. Princeton, NJ: Princeton University Press.

Wiles, R., V. Charles, G. Crow and S. Heath (2006) "Researching Researchers: Lessons for Research Ethics." Qualitative Research 6(3): 283-299.

Williams, A. and Dourish, P. (2006) "Imagining the City: The Cultural Dimensions of Urban Computing" Computer 39(9):38-43.

Zalis, Elayne (2003) "At Home in Cyberspace: Staging Autobiographical Scenes" Biography 26(1):84-119. 


\title{
APPENDIX 1
}

\section{Application to the Research Ethics Committee}

\author{
Anne Galloway \\ Ph.D. Candidate, Dept. of Sociology \& Anthropology \\ 2 February, 2004
} Intimate and Playful Technologies: Ubiquitous Computing, Space and
Culture

\section{Preamble}

This Ph.D. project in Sociology investigates emerging relations between space, culture and new wireless technologies - including social and intellectual milieus of current international technology research and design practice. I have successfully defended my thesis proposal and my research is funded by a doctoral fellowship from the Social Sciences and Humanities Research Council of Canada (SSHRC).

\section{Purpose of the Project}

This project in applied cultural research will contribute to an understanding of the social and cultural contexts of emerging wireless technology design and use. It will shed light on how new technologies "come to be" and provide insights into wireless technology in everyday urban life. Explicitly concerned with creative practice, this project also investigates the roles of play and intimacy in technological innovation and use. Little research has been conducted into design culture, and to the best of my knowledge no research has addressed ubiquitous computing research and design. My project contributes to these fields of inquiry as a starting point for articulating new spaces for social, ethical and political action concerning technology.

\section{Process for Obtaining Informed Consent}

Initial informed consent has been obtained from each of the case study project leads, who have also requested volunteer participants from the project team. Confirmed participants include 2-4 people from each of the following research and design projects:

Mobile Bristol - Hewlett Packard, UK

Sonic City - Future Applications Lab \& PLAY Research, Sweden

Texting Glances - Trinity College Dublin and Media Lab Europe, UK

Urban Tapestries - Proboscis, UK

Each participant will be given an Information Sheet (Appendix A) indicating the purpose of the study, the voluntary nature of participation and strict confidentiality of responses. Respondents are able to withdraw at any time. Following the presentation and explanation of the Information Sheet, agreement to participate in the study will be indicated by a signature on the informed consent form (Appendix B) granting access to the research lab, interviews, follow-up and publication.

\section{Research Instruments}

This project will employ a questionnaire I developed. Questions will be open-ended and collected one-on-one with individual participants and by email. "Cultural probes," a 
method pioneered by Bill Gaver and others ${ }^{1}$, consist of a disposable camera and postcards. Further documentation will be collected in the form of field notes and photographs. My research protocol is outlined in Appendix 3.

\section{Anonymity and Confidentiality}

At the point of contact, each project team volunteered participants, and anonymity was limited within each team. Participants are aware of the other participants from their respective projects only. At the point of publication, all participants are guaranteed complete confidentiality and anonymity.

All data collected in this study will be kept strictly confidential through the assignment of a coded identification number. Interviews will be digitally recorded with participant consent. Interview data and field notes will be anonymised before publication or release. Future publication of photographic documents will be subject to the approval and release of individuals pictured, the person who took the photo, or the project director as necessary.

At the time of in-person interviews and site visits, I will leave behind numbered, selfaddressed and stamped postcards sealed in envelopes, with more postcards mailed from Canada at weekly intervals. Participants will be asked not to sign or identify themselves on the postcards. These will pass through the post, and participants will be asked to answer questions, revealing information as they deem appropriate. The postcards will be mailed to my personal home address in order to improve confidentiality. In addition to the postcards, participants will be given disposable cameras to take photographs of design inspirations. Participants will be informed that photos of people require their permission, unless taken in public situations where there is no expectation of privacy.

\section{Storage of Data}

Numbers will be used as an anonymity tool. Field-notes, digital recordings and photographs will be stored in a secure place, accessible only to me and my Ph.D. committee. Five years after the completion and defense of the Ph.D. Dissertation, these data will be destroyed.

\section{Risks and Benefits to Participants}

The present study poses no risks to participants. The results of this inquiry may lead to a more comprehensive and efficacious public policy approach to the research, development, implementation and use in Canada.

\section{Dissemination of Results to Participants}

Participants have the right to review their interview and "cultural probe" data and withdraw permission to use them at any time prior to the publication of the results of the research. Upon the completion of the study, relevant information will be made available to each participant.

\footnotetext{
${ }^{1}$ Gaver, Bill, Tony Dunne and Elena Pacenti. 1999. Design: Cultural probes. Interactions of the ACM 6(1): $21-29$.
} 


\section{(Appendix A)}

\section{Information Sheet}

\section{Intimate and Playful Technologies: Ubiquitous Computing, Space and Culture}

\section{Principal Researcher}

ANNE GALLOWAY

Ph.D. Candidate

Dept. of Sociology \& Anthropology

$7^{\text {th }}$ Floor, Loeb Building

1125 Colonel By Drive

Ottawa (ON) K1S 5 B6, Canada

Office: (613) 520-2600, ext. 2582 Fax: (613) 520-4062

Email: anne@plsj.org

\section{Purpose of the Project}

I am interested in the relations between wireless technologies, space and culture. How may emerging ubiquitous and pervasive technologies shape our experiences of everyday life in the city? What sorts of playful and intimate relations are created in the research, design and use of these new technologies? My research investigates social and cultural contexts of technology design and use.

Your project has been selected as a case study in the research, design and development of collaborative wireless technologies for urban use. I hope to learn more about these contexts in order to better understand specific social, cultural and intellectual milieus of ubiquitous computing. This research will also help to shed light on users and contexts of use for emerging technologies.

\section{Anonymity and Confidentiality}

All data collected in this study will be kept strictly confidential through the assignment of a coded identification number. Field notes, interview and cultural probe data will be anonymised before publication or release. Future publication of photographic documents will be subject to the approval and release of anyone pictured, the participant who took the photo or the project director, as necessary. Only the researcher and Ph.D. Committee will have access to data collected.

\section{Right to Withdraw or Omit}

Your participation in this research is completely voluntary. You can participate as much or as little as you wish. You do not have to answer any particular question. There is no need to explain your reason for declining to answer a question or deciding not to participate in this study.

If you have any questions please ask me at any time. You can also email me.

\section{(Appendix B)}

\section{Consent to Participate in Research}

"Intimate And Playful Technologies: Ubiquitous Computing, Space And Culture" Ph.D. Dissertation Project 
You are asked to participate in the dissertation project of ANNE GALLOWAY, Ph.D. Candidate, Carleton University. You were selected as a participant in this study because you are someone who is engaged in, or is knowledgeable about, activities in wireless, ubiquitous, augmented or mixed reality technologies for urban and social contexts.

\section{Purpose of the Study}

The dissertation project - Intimate and Playful Technologies: Ubiquitous Computing, Space and Culture - investigates emerging pervasive computing, and the social and intellectual milieu of ubiquitous computing design. As part of the larger project, the investigator is conducting case studies of technology research and design projects currently in-progress in the UK and Sweden to better understand the social and cultural contexts of the research, design and use of wireless technologies.

\section{Procedures}

As a volunteer participant in this research, you are asked to answer a series of questions related to your work in the project. The

investigator will administer both email and in-person interviews/questionnaires. The questions will relate to the nature and objectives of the project, as well as your views on urban and social life, and the interviews/questionnaires will take approximately 2-3 hours of your time, with time allowed for follow-up

For in-person interviews, the investigator will be taking notes and using a digital voice recorder. The interviews will be conducted in your workplace or at a location of your choosing. At the time of site visits, the investigator will also leave behind "cultural probes" consisting of postcards and disposable cameras, with instructions for participation and return shipping to the investigator. All shipping costs will be covered by the investigator. During site visits, I am also interested in taking pictures of the progress of the project, and participating in technology demonstrations.

It is expected that the investigator will conduct follow-up interviews in the spring/summer of 2004 once the preliminary data from interviews and cultural probes has been analysed and the design project has been further developed. She may also contact you by telephone or e-mail after the interview if there were any points arising from the interview that need to be clarified. You may also contact the investigator yourself should you recall any information that may be of use.

\section{Potential Risks and Discomforts}

None. The nature of the questions is not personal or confidential and therefore poses no emotional, psychological or physical risk to you, the participant. You are asked to answer questions only as you deem appropriate, and you may refuse to answer any question without explanation. Participants agree to be interviewed during work hours remunerated by their employer, therefore the research also poses no economic risk to respondents.

\section{Potential Benefits to Subjects}

You will learn more, through the interview, about the issues and considerations involved in social and cultural studies of technology and design. While on-site, I am available for department or team seminars to discuss my research. Electronic copies of the final results of the Intimate and Playful Technologies: Ubiquitous Computing, Space and Culture Ph.D Dissertation Project will also be made available to you. 


\section{Confidentiality}

Information obtained in connection with this study that can be used to personally identify you will remain confidential and will be disclosed only with your permission or as required by law. Confidentiality will be maintained by means of assigning a unique code number to each participant. The key to the code will be maintained by the investigator offline in a separate file and will not be made accessible to anyone outside the Ph.D. Committee. Personally identifiable information will not be released to any party without your permission or as required by law.

You have the right to review your interview data and withdraw permission to use them at any time prior to the publication of the results of the research. The data will be stored in a secured file and will only be made available to the investigator and the Ph.D.

Committee. The participants will remain anonymous to third party researchers as their names will not be published in any documents. The nature of the data resulting from the interview and cultural probes are not personal or confidential, however the photographs, notes, digital recordings and consent forms will be kept in secure storage for the purposes of maintaining confidentiality by the investigator.

\section{Participation and Withdrawal}

Your participation is entirely voluntary. If you decide to participate, you are free to withdraw your consent and discontinue participation at any time and without penalty. You may also refuse to answer any questions you do not want to or cannot answer and remain in the study. You are not waiving any legal claims, rights or remedies because of your participation in this research study. The investigator reserves the right to use any material gathered before the time of your withdrawal, and may withdraw you from this research if circumstances arise which warrant doing so.

\section{Identification of Investigators}

If you have any questions or concerns about the research, please feel free to contact:

\section{ANNE GALLOWAY}

Ph.D. Candidate

Dept. of Sociology \& Anthropology

Carleton University

1125 Colonel By Drive

Ottawa, ON, K1S 5B6 Canada

Mobile: 1.613.262.8405

E-mail: anne@plsj.org

ROB SHIELDS

Professor (Supervisor to the Ph.D. Candidate)

Dept. of Sociology \& Anthropology

Carleton University

1125 Colonel By Drive

Ottawa, ON, K1S 5B6 Canada

Office: 1.613.520.2600 x2602

E-mail: rshields@ccs.carleton.ca

LESLIE MACDONALD HICKS, Ethics Committee Coordinator, Carleton University, 
1125 Colonel By Drive

Ottawa (ON) K1S 5B6, Canada,

Office: 1.613 .520 .2517

Email: LeslieMacDonaldHicks@pigeon.carleton.ca

See also: Tri-Council Policy Statement: Ethical Conduct for Research Involving Humans (http://www.nserc.ca/programs/ethics/english/policy.htm)

\section{Signature of Research Subject}

\section{Date}

\section{Signature of Investigator}

\section{Date}

\section{Permission to Publish and Use for Educational Purposes}

$\mathrm{I}$, grant permission to ANNE

GALLOWAY, Ph.D. Candidate, Carleton University, to publish, present, and use any non-personally identifiable or non-proprietary data collected during the Intimate and Playful Technologies: Ubiquitous Computing, Space and Culture Ph.D. Dissertation Project.

For example, the researcher may use excerpts from interviews conducted, or excerpts of digital audio recordings, photographs or examples of digital objects provided to inform the research and/or papers, reports and etc. for any academic and educational purposes.

This permission extends to any future revisions and editions of any publication, presentation, or report, including the non-exclusive worldwide rights in all languages, and to the prospective publication in academic, research and educational publications, and the Internet, including the Ph.D. Candidate's personal websites and weblogs.

These rights in no way restrict republication of the material by you or by others authorised by you.

\section{Signature of Research Subject}

\section{Date}

\section{Signature of Investigator}

\section{Date}




\section{APPENDIX 2}

\section{Questionnaire \& Interview Protocol}

\section{Questionnaire Questions:}

PLEASE DESCRIBE THE INSPIRATION FOR, AND OBJECTIVES OF THE

PROJECT(S). Things to keep in mind: Were you trying to solve a particular problem? Are you designing for a particular context? What are the main concepts that inform your project? What do you hope to learn, gain or produce in this project?

PLEASE DESCRIBE THE HISTORY AND CURRENT STATUS OF THE PROJECT(S). Things to keep in mind: How is this project supported or funded? What is the project timeline? What is your current status? When do you anticipate completing the project?

PLEASE DESCRIBE THE ANTICIPATED USERS AND CONTEXTS OF USE FOR THIS TECHNOLOGY. Things to keep in mind: How did you select the users and contexts of use? Were personas and/or user scenarios produced? Have these scenarios changed over time? Have you done any user testing?

PLEASE DESCRIBE THE CREATIVE PROCESS OR METHODS YOU USE IN YOUR WORK, AND HOW THAT RELATES TO OTHERS IN THE TEAM. Things to keep in mind: What activities do you do alone? What activities do you do with other members of the team? What products do you produce at each stage of the project? Do you document and archive your process? What do you do when you encounter obstacles? How do you make decisions?

PLEASE DESCRIBE WHAT YOU WOULD CONSIDER A DESIGN SUCCESS AND A DESIGN FAILURE. Things to keep in mind: What are your criteria for "good" design? What do you think contributes to "bad" design? Do these criteria change for the process and the product? How does user feedback influence your work?

PLEASE DESCRIBE WHAT YOU WOULD CONSIDER A TECHNOLOGICAL SUCCESS AND A TECHNOLOGICAL FAILURE. Things to keep in mind: What are your criteria for "good" technology? What do you think contributes to "bad" technology? Do these criteria change for the process and the product? How does user feedback influence your work?

PLEASE DESCRIBE WHAT YOU WOULD CONSIDER SUCCESSFUL USE, AS WELL AS MISUSE OR ABUSE OF THIS TECHNOLOGY BY USERS. Things to keep in mind: What are your criteria for "good" use? What do you think contributes to "bad" use? How do you approach the question or problem of unintended use? How much control of your design or product do you want the user to have?

PLEASE DESCRIBE HOW YOU THINK THIS AND RELATED TECHNOLOGIES MIGHT IMPACT OUR EXPERIENCE OF EVENTS, SPACES AND PLACES. Things to keep in mind: How is location important to this technology? What sorts of locational data does the technology collect? How is it stored? Do users have access to this data? What new relationships between people and spaces become possible? Which become more difficult? 
PLEASE DESCRIBE WHAT YOU THINK THE SOCIAL AND CULTURAL
IMPLICATIONS OF THIS AND RELATED TECHNOLOGIES MIGHT BE, INCLUDING ADVANTAGES AND DISADVANTAGES. Things to keep in mind: How is collective action supported? How might this technology differentiate people? What are some possible risks? How should we address privacy issues? What are the creative potentials of this technology?

\section{PLEASE FEEL FREE TO ADD ANYTHING ELSE YOU THINK IS RELEVANT AT THIS} TIME.

\section{Interview Introduction}

I will use this document to complete some of the context-related questions of the questionnaire. I can then verify how I have completed these questions during the interview. I should note, however, that not all parts of the protocol may be appropriate for each particular case. This also applies to any follow-up questions that I might need to ask, either to solicit a response that answers the questions more closely, or to clarify a response.

I expect one interview to last approximately 1-2 hours, depending upon how detailed the responses are, how many questions the respondent asks of me, and whether I need to complete human subjects assurances. I am responsible for ensuring compliance with applicable human subject regulations before proceeding, and without participant consent I may not proceed.

Italicized text indicates sample dialogue which will be read to the interviewee as needed to facilitate the flow of the interview. Comments in brackets [] are personal notes/reminders for the investigator.

\section{Interview Introduction}

My name is Anne Galloway. I am conducting research in my capacity as a Ph.D. Candidate in Sociology at Carleton University, and today I would like to ask you some questions about <name of project considered $>$ as part of my dissertation research.

Please let me briefly explain to you the aims my project - Intimate and Playful Technologies: Ubiquitous Computing, Space and Culture. I am investigating emerging pervasive computing and its relations with space and culture. In other words, I am interested in how wireless and ubiquitous computing might impact everyday life in the city. As part of the larger project, I am conducting case studies of technology research and design projects in the UK and Sweden to better understand the social and cultural contexts of the research, design and use of emerging technologies.

Are there any questions I can answer for you at this moment about my project before I move on to talk about your involvement?

[Wait for respondent to reply. If there are no questions, move on. If there are questions, try to address them or ask the participant to contact Rob Shields for more information.]

Part of my research effort involves trying to identify what new technology researchers, designers and developers understand to be the social and cultural roles of wireless and 
ubiquitous computing in everyday urban life, and in particular, understandings of users and contexts of use. I am also interested in processes of technological innovation and creative and playful approaches taken by researchers, designers and developers in building new technologies. I have chosen a set of research and design projects to serve as case studies to help me explore these issues.

I have identified <name of project considered $>$ as one of these case studies, and now I am conducting interviews with people who are familiar with <name of project considered $>$ so that I can learn as much as possible about the project.

What I plan to do is to go through a series of questions with you about <name of project considered $>$. I would like you to try to answer me as fully as you can. Please don't worry if I ask you any questions that you do not know how to answer, although it would be helpful if you were able to indicate anyone else who might be able to answer them so that I might also talk to them. Also, I would welcome copies of any appropriate documentation related to the project that you think might assist my understanding.

I will be taking notes as you talk, but I would also like to use a digital recorder to help me with my note-taking and subsequent data analysis. Do you mind if I record our conversation?

[Wait for respondent to reply. If he/she replies that they do not mind being recorded, move on. If she/he has questions about the purpose or subsequent use of the recording, explain that the recording is purely voluntary and that digital files will be kept strictly confidential and only used by me (the investigator). If she/he is not comfortable being recorded, say that is fine and move on. In that case, I will need to take much more detailed notes of the participant's responses.]

Do you have any questions that I can answer for you at this point about how the case study will be conducted or what I will be asking you?

Once I have interviewed you, I will keep the data in a secure place and personally identifiable data will be coded for anonymity. All publications will maintain your confidentiality. Only I and my Ph.D. Committee will have access to these data.

Can I answer any other questions for you at this point?

\section{Human Subject Consent and Publication Permission for Interviews}

Before we progress any further with this interview, I need to go over your rights and what you can expect from me as someone participating in this research study. I would like to reassure you that your participation is completely voluntary and that you have the right to withdraw from the case study at any point. I am now going to give you a human subjects consent form that outlines what I have just gone over with you. I would like you to take a few minutes to read it over, and then, if you don't have any questions, to sign it.

[Give the participant the human subjects consent form and give him/her time to read it over. Ask the participant if she/he has any questions. If no, ask him/her to sign the human subjects consent form, then set it aside in my folder for making a copy to return to the participant, and then file the original with other human subjects' clearances. If yes, 
try to address the questions. If the respondent is reluctant to sign, I will not be able to continue with the case study; thank the respondent for his or her time and conclude the interview.]

\section{Identifying Information}

I would now like to move ahead with the interview questions. I am just going to switch on the digital recorder and make sure it is working.

Today is <date $>$ and we are at <location $>$. Could you please state your name, title and affiliation, as well as your position in the <name of project considered $>$ ?

[Give the respondent time to respond, and ask for clarification if necessary. Thank them and inform them that interview questions will now follow.]

\section{Interview Questions}

1. PLEASE DESCRIBE THE INSPIRATION FOR, AND OBJECTIVES OF, <name of project considered $>$.

[Give the respondent time to respond, and ask for clarification if necessary. Repeat for each question.]

2. PLEASE DESCRIBE THE HISTORY AND CURRENT STATUS OF < name of project considered>.

3. PLEASE DESCRIBE THE ANTICIPATED USERS AND CONTEXTS OF USE FOR THIS TECHNOLOGY.

4. PLEASE DESCRIBE THE CREATIVE PROCESS OR METHODS YOU USE IN YOUR WORK, AND HOW THAT RELATES TO OTHERS IN THE TEAM.

5. PLEASE DESCRIBE WHAT YOU WOULD CONSIDER A DESIGN SUCCESS AND A DESIGN FAILURE.

6. PLEASE DESCRIBE WHAT YOU WOULD CONSIDER A TECHNOLOGICAL SUCCESS AND A TECHNOLOGICAL FAILURE.

7. PLEASE DESCRIBE WHAT YOU WOULD CONSIDER SUCCESSFUL USE, AS WELL AS MISUSE OR ABUSE OF THIS TECHNOLOGY BY USERS.

8. PLEASE DESCRIBE HOW YOU THINK THIS AND RELATED TECHNOLOGIES MIGHT IMPACT OUR EXPERIENCE OF EVENTS, SPACES AND PLACES.

9. PLEASE DESCRIBE WHAT YOU THINK THE SOCIAL AND CULTURAL IMPLICATIONS OF THIS AND RELATED TECHNOLOGIES MIGHT BE, INCLUDING ADVANTAGES AND DISADVANTAGES.]

10. IS THERE ANYTHING ELSE YOU WISH TO DISCUSS?

[Give the respondent time to respond. If yes, discuss. If no, thank them for their participation and proceed.] 


\section{APPENDIX 3}

\section{Cultural Probe Protocol}

As part of my research, I would also like to leave small "cultural probes" with you to complete and return to me. The probes consist of a disposable camera and a set of postcards - and provide different ways for you to express yourself. I will leave the first postcard with you today, and the others will be mailed at weekly intervals.

Please share the camera amongst members of your project to take pictures of those aspects of everyday life you think are relevant to your research and design practice. For example, you could take pictures of things or places that inspire you or frustrate you, as well as contexts where you can imagine your technology in use. If you wish, you can also write down comments on your pictures on the paper provided.

After six weeks have passed, I ask that you please return the used camera to me. I will provide shipping details at a later date.

The second part of the probes is a set of postcards. Each pre-stamped postcard is sealed within an envelope. Please answer the questions on the back of the postcard and place in the post within one week of receipt. Each postcard is numbered and coded for anonymity. Please do not sign or include any identifying information on the postcards, as they will pass through the post.

Do you have any questions about the cameras or the postcards?

[Give the respondent time to respond. If yes, discuss. If no, thank them for their participation and give them the cultural probes.]

\section{Postcard Questions}

Participants will not be shown the postcards in advance. The questions below are included in this document for reference.

1. DESCRIBE THREE PLAYFUL THINGS YOU DID TODAY.

2. WHAT IS YOUR FAVOURITE PLACE IN THE CITY AND WHY?

3. DESCRIBE A DEVICE OR ARTEFACT YOU THINK IS WELL DESIGNED.

4. WHAT WERE THE THREE MOST BORING PARTS OF YOUR DAY?

5. IF YOU COULD DESIGN ANY TECHNOLOGY FOR YOUR NEIGHBOURHOOD, WHAT WOULD IT BE?

\section{Conclusions}

Thank you very much for your participation in the interview today, and your continued participation in the cultural probes. Once I have completed the preliminary analysis of the interviews and cultural probes, I may contact you again with follow-up questions. Before I conclude our meeting, are there any questions or concerns you 
might have about this process and protocol?

[Give the respondent time to respond. If yes, discuss. If no, thank them again and remind them that they may contact you at any time, and that they will be provided electronic copies of the results of the research when complete.] 